INSTITUTO DE PEQUISAS ENERGÉTICAS E NUCLEARES

Autarquia associada à Universidade de São Paulo

AVALIAÇÃO DA TOXICIDADE E DA DEGRADAÇÃO DO FÁRMACO CLORIDRATO DE FLUOXETINA, EM SOLUÇÃO AQUOSA E EM MISTURA COM ESGOTO DOMÉSTICO, EMPREGANDO IRRADIAÇÃO COM FEIXE DE ELÉTRONS

VANESSA HONDA OGIHARA SILVA

Dissertação apresentada como parte dos requisitos para obtenção do Grau de Mestre em Ciências na Área de Tecnologia Nuclear - Aplicações

Orientadora:

Dra. Sueli Ivone Borrely

SÃO PAULO 
Dedico este trabalho a toda minha família, em especial ao meu marido Victor Hugo aos meus pais Sergio e Ivete e aos meus irmãos Camila e Rafael. 
"Temos permitido que as mencionadas substâncias químicas sejam usadas sem que haja investigação alguma, ou apenas uma investigação insuficiente, quanto aos seus efeitos sobre o solo, a água, sobre a vida dos animais silvestres e também sobre o próprio homem. As geraçães futuras não perdoarão, com toda probabilidade, a nossa falta de prudente preocupação a respeito da integridade do mundo natural que sustenta a vida toda." Primavera Silenciosa - Rachel Carson 


\section{Agradecimentos}

Agradeço primeiramente a Deus por todas as oportunidades que me concedeu até este momento da minha vida.

À Dra Sueli pela orientação, ensinamentos e dedicação para a realização deste trabalho. E pela oportunidade da realização deste mestrado.

Ao meu marido, Victor Hugo, pela paciência, compreensão e amor. Muito obrigada por sempre estar ao meu lado me apoiando e incentivando.

Aos meus queridos pais, Sergio e Ivete, pelo enorme apoio e incentivo que a cada dia me motivam a seguir em frente. Sem vocês hoje eu nada seria.

Aos meus irmãos, Camila e Rafael, que sempre estão por perto me ajudando. E que sempre poderão contar comigo para tudo.

Aos meus avós: Akio (in memorian), Leico, Hiroyuki e Rosa.

À minha segunda família: Cláudio, Joana, Marco e Sayuri.

À $\operatorname{Dr}^{\mathrm{a}}$ Ana Paula e ao $\mathrm{Dr}^{\mathrm{o}}$ Antonio Carlos, da Engenharia Química (USP) pela grande ajuda nas análises químicas.

Aos engenheiros responsáveis pelo acelerador de elétrons, Bete e Carlos, pelas irradiações das amostras.

Ao técnico Reginaldo pela ajuda na manutenção do laboratório.

Aos amigos do IPEN, Luana, Rejane, Aline, Daiane e Fernando.

Ao IPEN pelo programa de pós-graduação.

$\mathrm{E}$ ao $\mathrm{CNPq}$ pela bolsa de mestrado.

Muito obrigada a todos! 


\title{
Avaliação da toxicidade e da degradação do fármaco cloridrato de fluoxetina, em solução aquosa e em mistura com esgoto doméstico, empregando irradiação com feixe de elétrons
}

\section{Vanessa Honda Ogihara Silva}

\begin{abstract}
Resumo
A ampla utilização de medicamentos, a falta de gerenciamento na produção e no descarte desses produtos, bem como a dificuldade na remoção de resíduos de fármacos das águas residuais durante as fases do tratamento de efluentes tem causado a liberação destes micropoluentes nos recursos hídricos. O cloridrato de fluoxetina, conhecido comercialmente como Prozac ${ }^{\circledR}$, tem sido muito utilizado em diversos países. Estudos demonstram sua presença no meio ambiente e o potencial de danos que este fármaco pode causar à biota. Desta forma, este trabalho estudou uma tecnologia de tratamento (POA - Processo Oxidativo Avançado) utilizando-se radiação ionizante, proveniente de um acelerador de elétrons, para a degradação do fármaco cloridrato de fluoxetina em solução aquosa e na mistura com esgoto doméstico. Após a irradiação foram feitas análises químicas na solução aquosa do fármaco com Espectrofotometria UV/VIS, Cromatografia Líquida Ultra Rápida (detectores UV/VIS e fluorescência) e quantificação do Carbono Orgânico Total (COT). Também foram empregados ensaios de toxicidade aguda (Daphnia similis e Vibrio fischeri) e crônica (Ceriodaphnia dubia). A eficiência na degradação do fármaco foi superior a 98,00\% na menor dose de radiação $(0,5 \mathrm{kGy})$, porém houve baixa taxa de mineralização para as doses aplicadas neste estudo. Para a Daphnia similis na dose de 0,5 kGy houve eficiência de $83,75 \%$ na redução da toxicidade do cloridrato de fluoxetina e $87,24 \%$ para $5,0 \mathrm{kGy}$, houve eficiência de $100,00 \%$ na redução da toxicidade para o esgoto doméstico e para a mistura (CF + esgoto) 79,32\% na dose de 5,0 kGy. A eficiência para a Vibrio fischeri foi de 17,26\% (melhor eficiência na dose de 5,0 kGy) e após a correção do pH das amostras a melhor eficiência foi para 20,0 kGy (26,78\%), para o esgoto e para a mistura as eficiências ficaram em torno dos 20,00\% para todas as doses de radiação aplicadas. Em relação a toxicidade crônica para Ceriodaphnia dubia a eficiência foi de 97,50\% para 5,0 kGy. Verificou-se que a Ceriodaphnia dubia possui maior sensibilidade ao fármaco, seguido da bactéria Vibrio fischeri e por fim a Daphnia similis.
\end{abstract}

Palavras - chave: degradação do cloridrato de fluoxetina, radiação ionizante, toxicidade de misturas 


\title{
Toxicity and degradation assessment of the drug fluoxetine hydrochloride, in aqueous solution and mixed with domestic sewage, using electron beam irradiation
}

\section{Vanessa Honda Ogihara Silva}

\begin{abstract}
Extensive use of drugs, lack of management in the production and disposal of these products as well as the difficulty in removing residues of pharmaceuticals during wastewater treatment phases imply the release of these micropollutants in water resources. Fluoxetine hydrochloride, known commercially as Prozac ${ }^{\circledR}$, have been often used in many countries. Studies demonstrate their presence in the environment and potential damage that this drug may cause the biota. Therefore, this paper studied a treatment technology (AOP Advanced Oxidative Process) using ionizing radiation from an electron accelerator, for the degradation of the drug fluoxetine hydrochloride in aqueous solution and mixed with domestic sewage. After irradiation at aqueous solution chemical analyzes at the drug were done using spectrophotometry UV/VIS, Ultra Fast Liquid Chromatography (detectors UV/ VIS and fluorescence) and quantification of Total Organic Carbon (TOC). Acute toxicity tests (Daphnia similis and Vibrio fischeri) and chronic (Ceriodaphnia dubia) were employed. The efficiency for the degradation of the drug was greater than $98.00 \%$ at the lowest absorbed dose of radiation $(0.5 \mathrm{kGy})$, however there was low rate of mineralization to the doses applied in this study. The efficiency reduction of toxicity was $83.75 \%$ using Daphnia similis at $0.5 \mathrm{kGy}$ of absorbed dose and $87.24 \%$ at $5.0 \mathrm{kGy}$ to fluoxetine hydrochloride, efficiency was $100.00 \%$ in reducing toxicity to domestic sewage and the mixture (CF + sewage) was $79.32 \%$ at a dose of $5.0 \mathrm{kGy}$. The efficiency to Vibrio fischeri was $17.26 \%$ (better efficiency at the dose of $5.0 \mathrm{kGy}$ ) and after correction of $\mathrm{pH}$ to a better performance was $20.0 \mathrm{kGy}$ (26.78\%), for sewage and mixture efficiencies were about $20,00 \%$ for all doses of radiation applied. In relation to chronic toxicity effects to Ceriodaphnia dubia efficiency was $97.50 \%$ at $5.0 \mathrm{kGy}$. It was verified that Ceriodaphnia dubia is more sensitive to the drug, followed by the bacterium Vibrio fischeri and finally Daphnia similis.
\end{abstract}

Key - words: fluoxetine hydrochloride degradation, ionizing radiation, mixture toxicity 


\section{Sumário}

1. INTRODUÇ̃̃̃

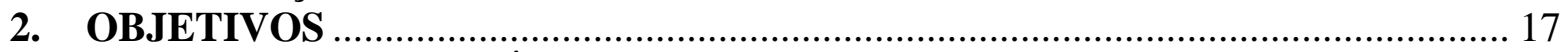

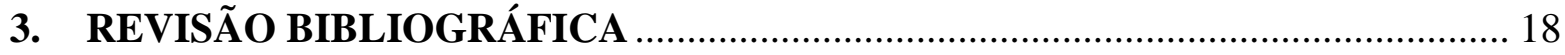

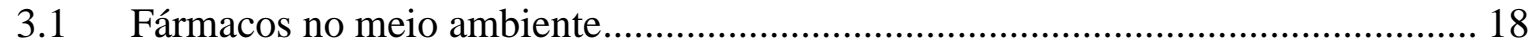

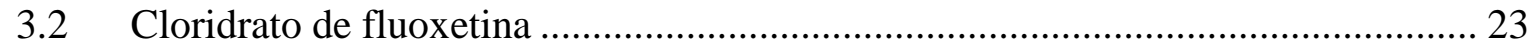

3.2.1 Biodegradabilidade da fluoxetina.................................................................. 23

3.2.2 Presença da fluoxetina no meio ambiente ……………………………………..... 24

3.3 Processos Oxidativos Avançados...................................................................... 26

3.3.1 Radiações Ionizantes ................................................................................. 27

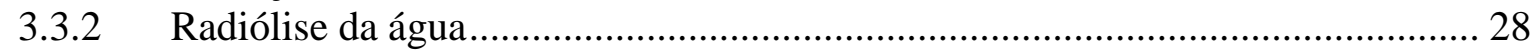

3.3.3 Decomposição de compostos orgânicos pela radiação............................................. 29

3.4 Métodos analíticos para determinação da fluoxetina .................................................. 31

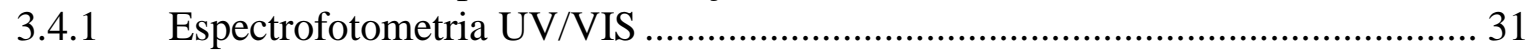

3.4.2 Cromatografia Líquida de Alta Eficiência (CLAE) ……………………………...... 32

3.5 Análise de Carbono Orgânico Total (COT) .............................................................. 32

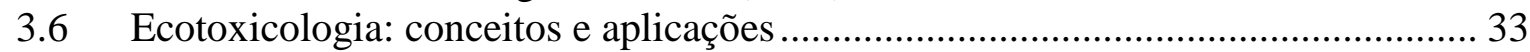

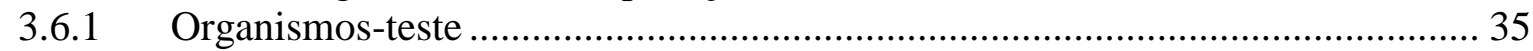

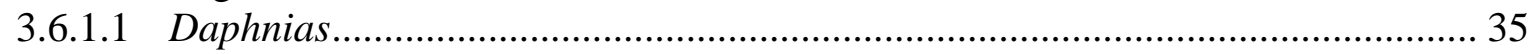

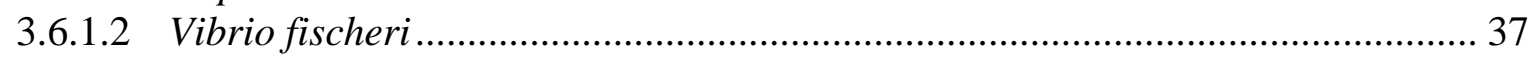

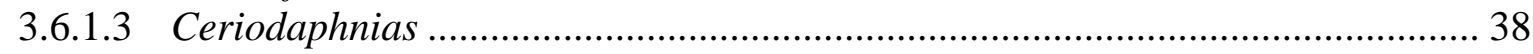

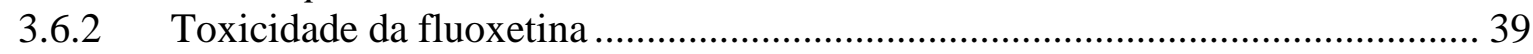

3.6.3 A carta controle e o intervalo de confiança ......................................................... 40

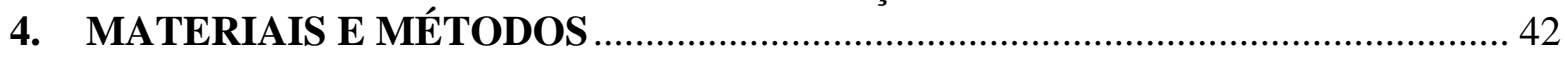

$4.1 \quad$ Substâncias utilizadas no estudo ……………………………………………. 42

4.2 Preparação das soluções-teste e coleta do esgoto bruto …………………………….... 43

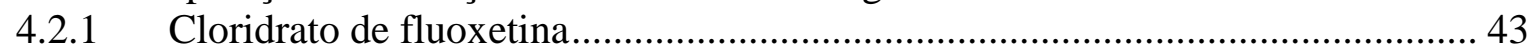

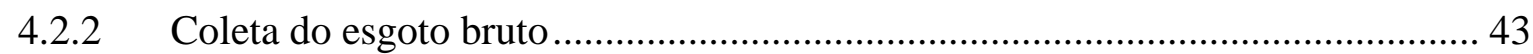

4.2.3 Mistura do cloridrato de fluoxetina e esgoto bruto .............................................. 43

$4.3 \quad$ Irradiações das amostras-testes ........................................................................... 44

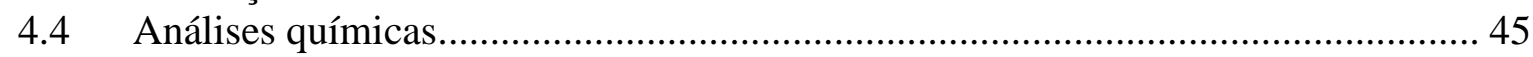

4.4.1 Análise espectrofotométrica UV/VIS …………………………………….... 45

4.4.2 Análises de Cromatografia Líquida Ultra Rápida …………………………….... 45

4.4.2.1 Detector UV/VIS ……………………………….................................. 45

4.4.2.2 Detector de Fluorescência ................................................................................. 46

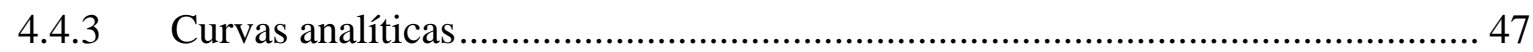

4.4.4 Carbono Orgânico Total (COT) ………………………………………….... 47

4.5 Ensaios de toxicidade .................................................................................... 48

4.5.1 Coleta e preparo da água de cultivo e de diluição .................................................. 48

4.5.2 Preparo do alimento.................................................................................... 49

4.5.3 Manutenção do cultivo de Daphnia similis e Ceriodaphnia dubia ....................... 50

4.5.4 Ensaios de toxicidade aguda com Daphnia similis .............................................. 50

4.5.5 Ensaios de toxicidade aguda com Vibrio fischeri................................................. 51

4.5.6 Ensaios de toxicidade crônica com Ceriodaphnia dubia ………………………......53

4.5.7 Unidades Tóxicas (UT) e Eficiência ………………………………………....5 54

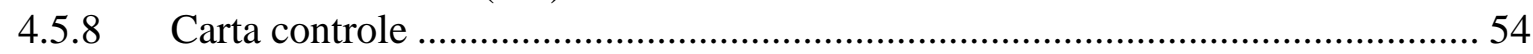

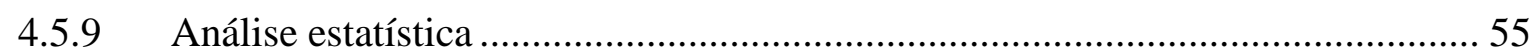

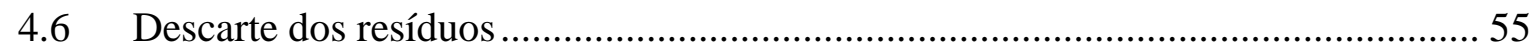




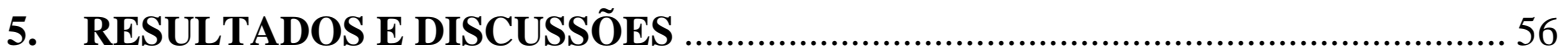

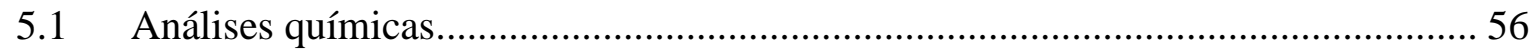

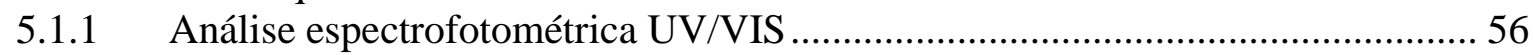

5.1.2 Cromatografia Líquida Ultra Rápida com detecção UV/VIS ............................. 58

5.1.3 Cromatografia Líquida Ultra Rápida com detecção de fluorescência .................. 59

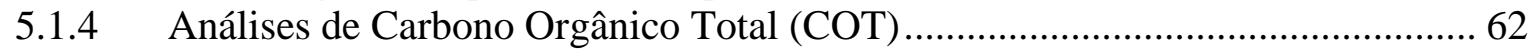

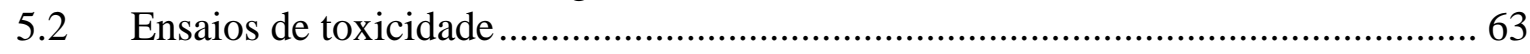

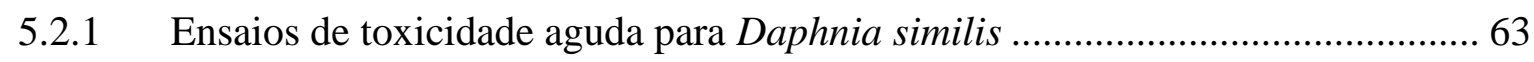

5.2.2 Ensaios de toxicidade aguda com Vibrio fischeri........................................... 73

5.2.3 Ensaios preliminares de toxicidade crônica com Ceriodaphnia dubia ................ 80

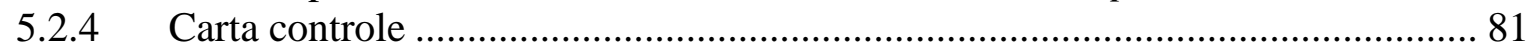

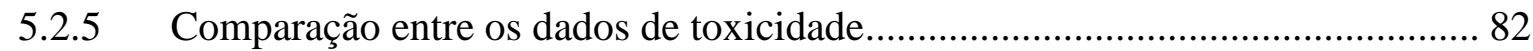

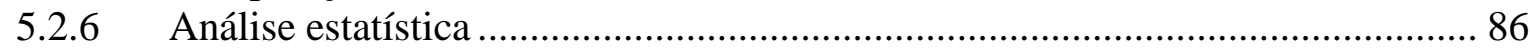

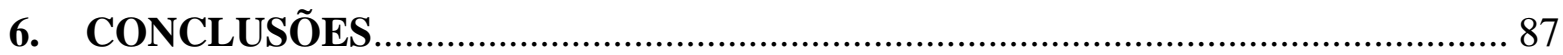

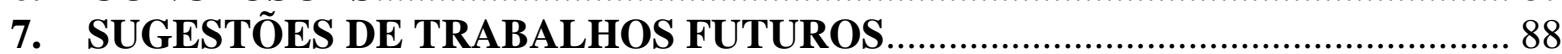

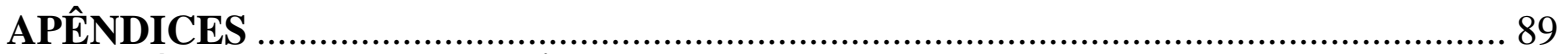

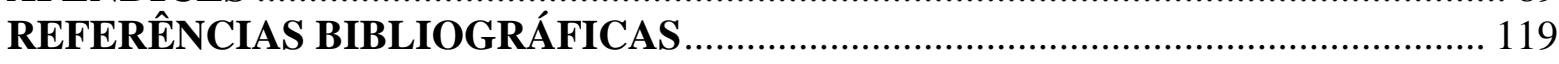




\section{Lista de tabelas}

TABELA 1. Ranking de gastos por classe terapêutica nos EUA em bilhões de dólares.... 22

TABELA 2. Concentrações de fluoxetina detectadas em efluentes e águas........................ 25

TABELA 3. Resumo dos requisitos para o ensaio de toxicidade aguda com Daphnias. ... 36

TABELA 4. Resumo dos requisitos para o ensaio de toxicidade crônica com

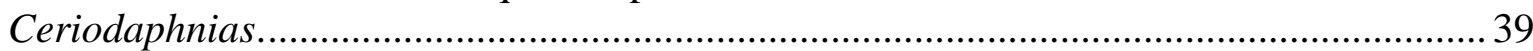

TABELA 5. Valores de toxicidade para diferentes organismos e algas.............................. 40

TABELA 6. Valores da área do pico, concentração $\left(\mathrm{mg} \mathrm{L}^{-1}\right)$ e eficiência na redução do

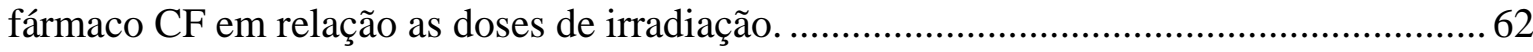

TABELA 7. Valores de pH, oxigênio dissolvido (OD) e condutividade das amostras de cloridrato de fluoxetina utilizadas nos ensaios com Daphnia similis.

TABELA 8. Valores de pH, oxigênio dissolvido (OD) e condutividade das amostras do esgoto bruto utilizadas nos ensaios com Daphnia similis

TABELA 9. Valores de $\mathrm{pH}$, oxigênio dissolvido (OD) e condutividade das amostras de mistura (CF + esgoto) utilizadas nos ensaios com Daphnia similis.

TABELA 10. Valores de $\mathrm{CE}_{50} \mathrm{H}_{4 \mathrm{~h}}\left(\%\right.$ e $\left.\mathrm{mg} \mathrm{L}^{-1}\right)$, UT e eficiência do processo (\%) das amostras de cloridrato de fluoxetina para Daphnia similis

TABELA 11. Valores de CE50 $48 \mathrm{~h}$ (\%), UT e eficiência do processo (\%) das amostras de cloridrato de fluoxetina ( $\mathrm{pH}$ corrigido) para Daphnia similis.

TABELA 12. Valores de CE50 $48 \mathrm{~h}(\%)$, UT e eficiência do processo (\%) das amostras de esgoto bruto para Daphnia similis.

TABELA 13. Valores de CE50 $48 \mathrm{~h}(\%)$, UT e eficiência do processo (\%) das amostras de mistura (CF + esgoto) para Daphnia similis.

TABELA 14. Valores de pH, oxigênio dissolvido (OD) e condutividade das amostras de cloridrato de fluoxetina utilizadas nos ensaios com Vibrio fischeri.

TABELA 15. Valores de pH, oxigênio dissolvido (OD) e condutividade das amostras do esgoto bruto utilizadas nos ensaios com Vibrio fischeri.

TABELA 16. Valores de $\mathrm{pH}$, oxigênio dissolvido (OD) e condutividade das amostras de mistura ( $\mathrm{CF}+$ esgoto) utilizadas nos ensaios com Vibrio fischeri.

TABELA 17. Valores de CE50 15 min $\left(\%\right.$ e mg L $\left.{ }^{-1}\right)$, UT e eficiência do processo (\%) na remoção da toxicidade para amostras do cloridrato de fluoxetina para Vibrio fischeri. ..... 77

TABELA 18. Valores de CE50 15 min $\left(\% \mathrm{e} \mathrm{mg} \mathrm{L}^{-1}\right)$, UT e eficiência do processo (\%) na remoção da toxicidade para amostras do cloridrato de fluoxetina, após correção do $\mathrm{pH}$, para Vibrio fischeri.

TABELA 19. Valores de CE $50_{15 \min }(\%)$, UT e eficiência do processo $(\%)$ na remoção da toxicidade para amostras de esgoto bruto para Vibrio fischeri.

TABELA 20. Valores de CE50 ${ }_{15 \min }(\%)$, UT e eficiência do processo (\%) na remoção da toxicidade para amostras da mistura ( $\mathrm{CF}+$ esgoto) para Vibrio fischeri. 
TABELA 21. Classificação quanto à toxicidade pelo teste " $\mathrm{t}$ " por bioequivalência para a Ceriodaphnia dubia.

TABELA 22. Valores médios de toxicidade para os ensaios realizados. 83

TABELA 23. Classificação da toxicidade aguda de efluentes em relação aos valores de CE50 segundo Bulich (1992 apud Borrely, 2001).

TABELA 24. Classificação das amostras de esgoto e mistura para Daphnia similis..........84 TABELA 25. Dados calculados pelo Teste de Tukey para verificar a variação significativa entre as médias de CE50 .86 


\section{Lista de figuras}

FIGURA 1. Principais rotas de exposição de fármacos em matrizes ambientais (Fonte: Halling-Sorensen et al., 1998).

FIGURA 2. Estrutura molecular do cloridrato de fluoxetina (Soares, 2005)...................... 23

FIGURA 3. Daphnia similis. Fonte: Laboratório de Ensaios Biológicos e Ambientais (LEBA).

FIGURA 4. Bactéria luminescente Vibrio fischeri (Fontes: UW Eye Research Institute, 2013; PNAS, 2013).

FIGURA 5. Ceriodaphnia dubia. Fonte: Laboratório de Ensaios Biológicos e Ambientais (LEBA).

FIGURA 6. Fluxograma das principais etapas experimentais realizadas no estudo.

FIGURA 7. Forma de vidro, recoberta com filme plástico, utilizada para a irradiação das amostras.

FIGURA 8. Equipamento utilizado nas análises cromatográficas..................................... 46

FIGURA 9. Analisador de Carbono Orgânico Total (COT) utilizado no presente estudo... 47

FIGURA 10. Cultivo da microalga Pseudokirchneriella subcapitata.

FIGURA 11. Ensaio de toxicidade aguda com Daphnia similis para a amostra do cloridrato de fluoxetina.

FIGURA 12. Sistema analisador de bioluminescência (Microbics ${ }^{\circledR}-$ M500), empregado para os ensaios de toxicidade aguda com a bactéria Vibrio fischeri.

FIGURA 13. Sistema de manutenção de amostras a serem incubadas durante o ensaio de toxicidade crônica com Ceriodaphnia dubia (dez replicatas).

FIGURA 14. Curva analítica obtida por espectrofotometria UV/VIS no comprimento de onda de $226 \mathrm{~nm}$ para o cloridrato de fluoxetina..

FIGURA 15. Espectros de absorção da solução contendo o cloridrato de fluoxetina em diferentes concentrações.

FIGURA 16. Espectros de absorção da solução de cloridrato de fluoxetina irradiadas e não irradiada.

FIGURA 17. Curva analítica obtida por Cromatografia Líquida Ultra Rápida com detector UV/VIS no intervalo de $11,0-25,0 \mathrm{mg} \mathrm{L}^{-1}$ para o cloridrato de fluoxetina.

FIGURA 18. Curva analítica obtida por Cromatografia Líquida Ultra Rápida com detector fluorescência no intervalo de $0,05-24,0 \mathrm{mg} \mathrm{L}^{-1}$ para o cloridrato de fluoxetina.

FIGURA 19. Curva analítica obtida por Cromatografia Líquida Ultra Rápida com detector fluorescência no intervalo de $0,005-0,08 \mathrm{mg} \mathrm{L}^{-1}$ para o cloridrato de fluoxetina.

FIGURA 20. Cromatogramas dos ensaios 1 e 2 das amostras de cloridrato de fluoxetina irradiadas em diferentes doses obtidos pela Cromatografia Líquida Ultra Rápida com detector de fluorescência.

FIGURA 21. Quantificação do Carbono Orgânico Total em diferentes doses de radiação. . 63 FIGURA 22. Percentual de sobrevivência do organismo Daphnia similis para o cloridrato de fluoxetina não irradiado.

FIGURA 23. Percentual de sobrevivência do organismo Daphnia similis para o cloridrato de fluoxetina irradiado com 5,0 kGy..

FIGURA 24. Percentual de sobrevivência do organismo Daphnia similis para o cloridrato de fluoxetina irradiado com 20,0 kGy.

FIGURA 25. Percentual de sobrevivência do organismo Daphnia similis para o esgoto bruto não irradiado.

FIGURA 26. Percentual de sobrevivência do organismo Daphnia similis para o esgoto bruto irradiado com 5,0 kGy. 
FIGURA 27. Percentual de sobrevivência do organismo Daphnia similis para o esgoto bruto irradiado com 20,0 kGy

FIGURA 28. Percentual de sobrevivência do organismo Daphnia similis para a mistura $(\mathrm{CF}+$ esgoto $)$ não irradiado.

FIGURA 29. Percentual de sobrevivência do organismo Daphnia similis para a mistura

(CF + esgoto) irradiado com 5,0 kGy 72

FIGURA 30. Percentual de sobrevivência do organismo Daphnia similis para a mistura (CF + esgoto) irradiado com 20,0 kGy. 73

FIGURA 31. Média e desvio dos valores de $\mathrm{pH}$ para as amostras de cloridrato de fluoxetina irradiadas e não irradiada utilizadas nos ensaios com Vibrio fischeri.

FIGURA 32. Média e desvio dos valores de condutividade para as amostras de cloridrato de fluoxetina irradiadas e não irradiada utilizadas nos ensaios com Vibrio fischeri.

FIGURA 33. Carta controle dos ensaios de sensibilidade com cloreto de potássio para Daphnia similis

FIGURA 34. Carta controle dos ensaios de sensibilidade com fenol para Vibrio fischeri... 82 


\section{INTRODUÇÃ̃O}

A evolução da população humana resultou na produção de diversos poluentes que afetam direta e indiretamente o meio ambiente. Atualmente um dos problemas ambientais mais importantes são os fármacos, liberados para o meio principalmente através de efluentes tratados e não tratados. Segundo Bound \& Voulvoulis (2004) a rota de entrada mais significativa dos fármacos no ambiente aquático é através das estações de tratamento de esgotos.

Fármacos, produtos para cuidados pessoais, estrogênios (sintéticos e naturais), subprodutos industriais entre outras substâncias são comumente encontrados em águas residuais, assim como em águas superficiais em todo o mundo (Sodré et al., 2010).

Vários estudos demonstraram que diversos fármacos são persistentes no meio ambiente e não são completamente removidos das estações de tratamento de esgotos, desta forma, estas substâncias têm sido encontradas em diversas matrizes ambientais. (Arditsoglou \& Voutsa, 2012; Sodré et al., 2010; Peng et al., 2008; Raimundo, 2007; Ghisele, 2006; Bendz et al., 2005; Carballa et al., 2004; Ternes et al., 1999).

A produção de medicamentos aumentou rapidamente durante as últimas décadas, visando a promoção da saúde de seres humanos e animais. Segundo investigação realizada em 2008 por uma agência americana de notícias, Associated Press (AP), verificou-se que a água potável destinada a cerca de 41 milhões de pessoas os Estados Unidos está contaminada com resíduos de fármacos. Os exames laboratoriais das amostras de água apresentadas pela AP revelaram aproximadamente 63 tipos diferentes de medicamentos (Rodrigues, 2009).

Segundo Deblonde et al. (2011), no levantamento realizado sobre as concentrações de poluentes emergentes em amostras de estações de tratamento de esgotos,

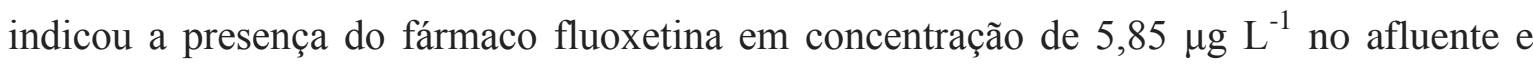
$0,112 \mu \mathrm{g} \mathrm{L}^{-1}$ no efluente. Identificou-se a presença em águas naturais nos Estados Unidos em concentração média de $0,012 \mu \mathrm{g} \mathrm{L}{ }^{-1}$ de fluoxetina (Kolpin et al., 2002).

O fármaco cloridrato de fluoxetina, conhecido popularmente como Prozac ${ }^{\circledR}$, é um medicamento indicado para o tratamento de depressão, associada ou não a ansiedade, da bulimia nervosa, do transtorno obsessivo-compulsivo (TOC) e do transtorno disfórico pré-menstrual (TDPM), incluindo tensão pré-menstrual (TPM), irritabilidade e disforia (Eli Lilly \& Company, 2013; Merck, 2013). 
Segundo Baldessarini (apud Caminada, 2008), este fármaco chegou ao mercado em 1988 e atualmente é um dos mais prescritos no Brasil e no mundo. Desde seu surgimento, são prescritas cerca de 1.000.000 de receitas médicas por mês deste fármaco, tendo sido utilizado por mais de 35 milhões de pessoas no mundo. No Brasil as vendas de antidepressivos aumentaram de US\$ 271,6 milhões em 2006 para US\$ 647,8 milhões em 2010 (Medley, 2013).

Além de serem persistentes, os resíduos de fármacos têm trazido diversos problemas ambientais, como os efeitos causados pelos interferentes endócrinos onde foram reportadas anomalias no sistema reprodutivo de animais (peixes, répteis e pássaros); indução da síntese de vitelogenina (VTG) no plasma de peixes e efeitos na saúde de humanos, tais como, redução na produção de esperma e aumento da incidência de alguns tipos de câncer (Bila \& Dezotti, 2007).

A fluoxetina tem sido reportada como um interferente endócrino, ou seja, possui a capacidade de alterar o funcionamento do sistema endócrino (Gonzalez-Rey \& Bebianno, 2013; Reis Filho et al., 2007).

Segundo Leite et al. (2010) os contaminantes provenientes de fármacos (de uso humano e animal) e produtos de limpeza e de higiene pessoal, presentes nos esgotos sanitários em concentrações da ordem de microgramas por litro $\left(\mu \mathrm{g} \mathrm{L}^{-1}\right)$ ou nanogramas por litro (ng $\left.\mathrm{L}^{-1}\right)$, exercem efeitos tóxicos sobre animais silvestres, tais como a desregulação endócrina, tendo o potencial de afetar adversamente a saúde humana.

Dentre as principais classes de fármacos, destacam-se: antibióticos $(76,6 \%)$, hormônios $(73,6 \%)$ e antidepressivos $(69,4 \%)$, sendo que os respectivos valores correspondem aos percentuais de fármacos de cada classe que possuem inerente risco ambiental (Bound et al., 2006).

Estudos demonstram o potencial de danos que a fluoxetina pode causar aos organismos aquáticos. No trabalho de Brooks et al. (2005), foram determinadas quantidades de fluoxetina em tecidos do músculo, fígado e cérebro de peixes coletados no córrego Pecan Creek (Texas, EUA) a jusante das descargas de efluentes. Em estudo realizado com o peixe Oryzias latipes, foram demonstrados longa persistência e grande potencial de bioacumulação da fluoxetina e norfluoxetina nos tecidos (Paterson \& Metcalfe, 2008). Verificou-se que baixas concentrações de fluoxetina (ng L ${ }^{-1}$ ) foram capazes de alterar o metabolismo de esteroides e reprodução dos mexilhões Dreissena polymorpha (Lazzara et al., 2012). 
Devido a remoção incompleta de diversos fármacos nas estações de tratamento de efluentes por processo de lodo ativado, diversos métodos avançados tem sido estudados dentre eles temos os Processos Oxidativos Avançados (POAs). Uma forma de tratamento de efluentes através de POA é a irradiação com a utilização de Acelerador de Feixe de Elétrons (IAEA, 2008). Através da ação indireta, conhecida como radiólise da água, são produzidas moléculas ionizadas, excitadas e elétrons livres. Essas moléculas ionizadas formam rapidamente os radicais hidroxila, fortemente oxidantes e elétrons aquosos, redutores. (Duarte, 1999). A interação destes radicais livres formados com as moléculas de poluentes induzem reações de oxidação, redução, dissociação ou degradação, responsáveis pelo tratamento (Getoff, 1996).

Os POAs são caracterizados por reações de oxidação química intermediada pelo radical hidroxila $(\mathrm{HO} \bullet)$, esta espécie é extremamente reativa e pouco seletiva (Melo, et al., 2009). Dentre os POAs temos os processos que utilizam radiação $\mathrm{UV}, \mathrm{H}_{2} \mathrm{O}_{2} / \mathrm{UV}$, Fenton, Foto-Fenton, ozônio e a utilização de radiação ionizante (Tambosi, 2008 e Borrely, 2001).

Diversos outros tipos de tratamentos para fármacos têm sido estudados. Para o diclofenaco um estudo que utilizou membranas por processo de osmose reversa carregada negativamente a retenção do medicamento foi de 95\% (Kimura et al., 2003). Rocha et al. (2009) verificou a degradação do diclofenaco por processo via Fenton em reator eletroquímico, onde foi obtida a eficiência de 99,4\% na redução da concentração inicial. Observa-se que em geral o uso de POAs na degradação de fármacos possui elevada eficiência.

O Processo Oxidativo Avançado utilizando radiação ionizante vem sendo estudado como alternativa para o tratamento de diversos tipos de efluentes e substâncias químicas (Higa, 2008; Scapin, 2008; Romanelli, 2006; Casas, 2004; Moraes, 2004; Romanelli, 2004; Borrely, 2001; Duarte, 1999; Borrely, 1995).

Borrely (2001) aplicou a radiação no tratamento de amostras de efluentes industriais e domésticos da ETE Suzano (São Paulo) e avaliou a eficiência do método através de ensaios de toxicidade aguda utilizando Daphnia similis, Vibrio fischeri e Poecilia reticulata. Foi observada a redução gradual da toxicidade, entre $75 \%$ e $95 \%$, com o aumento das doses aplicadas, entre 5,0 kGy e 50,0 kGy, utilizando-se um acelerador de elétrons. 
No estudo de Moraes (2004), o processo da radiação aplicado para a degradação de efluentes que apresentavam surfactantes aniônicos obteve eficiência média de 75,98\% na remoção dos tensoativos, o processo resultou em uma eficiência de 43 a $94,80 \%$ na redução da toxicidade aguda para a Daphnia similis e para a bactéria Vibrio fischeri.

No trabalho de Santos (2012), verificou-se redução da toxicidade de 91,95\%; $82,97 \%$ e 79,21\% para os organismos Hyalella azteca, Daphnia similis e Vibrio fischeri respectivamente, para o fármaco cloridrato de fluoxetina, após o tratamento com radiação ionizante $(5,0 \mathrm{kGy})$, dose esta que se apresentou como mais efetiva para este estudo na redução da toxicidade.

A Cromatografia Líquida de Alta Eficiência está sendo utilizada para análises qualitativas e quantitativas de diversas substâncias como produtos farmacêuticos, produtos de higiene pessoal e interferentes endócrinos. Além, de ser uma ferramenta chave no monitoramento dos processos de degradação de poluentes emergentes, tanto em ambientes naturais quanto artificiais (Silva \& Collins, 2011).

A utilização de POAs para a degradação de produtos orgânicos, nem sempre resulta na mineralização completa dos compostos no tratamento, levando assim à formação de compostos intermediários que podem ser tanto quanto ou até mesmo mais tóxicos do que o composto inicial (Rizzo, 2011). Desta forma é de extrema importância a avaliação da toxicidade após o tratamento com POAs. Visto que somente a avaliação dos parâmetros físico-químicos é insuficiente para se determinar o risco ambiental, pois tais parâmetros não avaliam a interação entre os contaminantes e nem tampouco seus efeitos sobre a biota.

De acordo com Costa et al. (2008) os testes de toxicidade aquática são utilizados para medir os efeitos tóxicos de substâncias particulares em águas contaminadas. Em relação à toxicidade de efluentes industriais, onde há presença de diversas substâncias, podem ocorrer efeitos devido às interações dos mesmos, que podem ser classificados em efeitos aditivos, sinérgicos e antagônicos.

Borrely et al. (2012) demonstrou que testes de toxicidade realizados para o cloridrato de fluoxetina apresentaram elevada toxicidade ao fármaco. Este trabalho também ressalta a baixa biodegradabilidade deste composto e a falta de gerenciamento e legislação no Brasil para o uso e descarte correto de medicamentos. 


\section{OBJETIVOS}

O objetivo desse trabalho é avaliar a toxicidade e a degradação do fármaco cloridrato de fluoxetina, em solução aquosa e na mistura com o esgoto doméstico bruto, após o tratamento por processo oxidativo avançado, utilizando o acelerador de elétrons.

Para se atingir esse objetivo as seguintes etapas foram desenvolvidas:

- Irradiação das amostras em diferentes doses de radiação.

- Análises químicas antes e após a irradiação das soluções aquosas do fármaco cloridrato de fluoxetina. Nesta etapa foram realizadas análises de Espectrofotometria UV/VIS, Cromatografia Líquida Ultra Rápida e determinação de Carbono Orgânico Total.

- Ensaios de toxicidade aguda e crônica, antes e após o tratamento para as soluções aquosas de cloridrato de fluoxetina, para o esgoto doméstico bruto e para a mistura do fármaco $\mathrm{CF}$ com o esgoto, utilizando os organismos Daphnia similis, Vibrio fischeri e Ceriodaphnia dubia. 


\section{REVISÃO BIBLIOGRÁFICA}

Neste item será abordado uma revisão da literatura sobre os principais temas relacionados ao presente trabalho.

\subsection{Fármacos no meio ambiente}

Fármacos são uma classe de contaminantes emergentes que cada vez mais vem sendo utilizada tanto na medicina humana como na veterinária (Fent et al., 2006). Como consequência da ampla utilização, a presença de fármacos residuais no meio ambiente pode causar efeitos adversos aos organismos aquáticos e terrestres (Suchara, 2007). Porém um ponto crítico na avaliação do impacto ambiental destes xenobióticos é saber quantificar qual nível dessas substâncias poderá causar tais efeitos (Machado et al., 2009). Resíduos de fármacos também estão presentes em águas naturais (Ceron, 2011).

Além dos fármacos utilizados pelo homem, há também os medicamentos de uso veterinário que são lançados no ambiente por meio das excretas e do transporte pelas águas pluviais (Almeida \& Weber, 2005).

Os contaminantes emergentes são novos produtos ou substâncias químicas que não possuem regulamentos e cujos efeitos sobre o meio ambiente e na saúde humana são desconhecidos (Deblonde, 2011).

Segundo Reis Filho et al. (2007) os poluentes emergentes tais como produtos farmacêuticos, hormônios naturais e sintéticos, pesticidas, substâncias tensoativas, polímeros de baixa massa molecular, produtos de uso veterinário, solventes, nanopartículas e outros contaminantes orgânicos presentes em efluentes domésticos e industriais, podem atuar como desreguladores endócrinos.

Em virtude de haver poucas informações disponíveis e sabendo-se que alguns desreguladores endócrinos são capazes de produzir efeitos, mesmo em concentrações muito baixas, é aconselhável alocar esforços para determinações destas substâncias em fontes potenciais de exposição humana, como alimentos e nas águas de abastecimento urbano (Reis Filho et al., 2007).

Na FIGURA 1 são apresentadas as principais rotas de entrada de fármacos no meio ambiente, observa-se que grande parte dos compostos farmacêuticos são dispersos para o ambiente aquático o que pode acarretar em efeitos nos organismos presentes neste meio 


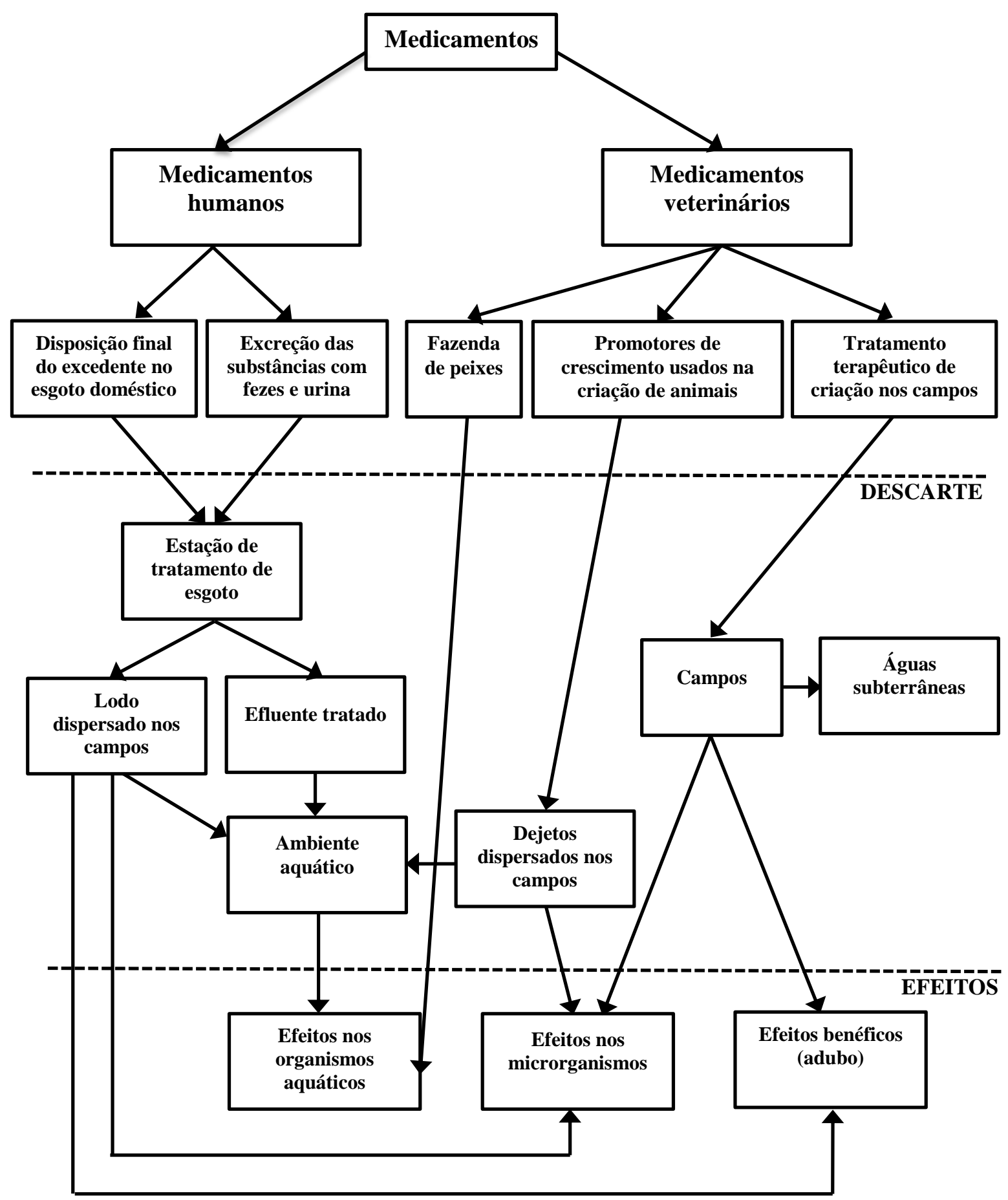

FIGURA 1. Principais rotas de exposição de fármacos em matrizes ambientais (Fonte: Halling-Sorensen et al., 1998). 
Segundo Gil \& Mathias (2005) as possíveis vias de contaminação ambiental por resíduos de fármacos e seus metabólitos na área urbana decorrem principalmente da excreção urinária ou fecal e do descarte de medicamentos vencidos em lixos domésticos. $\mathrm{Na}$ área rural estão associados predominantemente pelo uso de medicamentos veterinários como os antibióticos para a promoção de crescimento, hormônios presentes nas rações e agentes antiparasitários. E de acordo com os mesmos autores, cálculos têm estimado que 70 a $80 \%$ das drogas administradas em fazendas são lançadas no meio aquático.

A avaliação criteriosa dos efeitos desses fármacos no meio aquático é imprescindível. Isto porque, uma vez conhecidos os efeitos, será necessário estabelecer os limites de concentrações para o descarte seguro de efluentes domésticos tratados em corpos receptores. Outro fator de grande importância é o monitoramento da eficiência de remoção desses fármacos pelos processos convencionais de tratamento de efluentes domésticos das Estações de Tratamento de Efluentes (ETEs), pois no futuro serão necessárias adaptações, ou mesmo implantar outros processos de tratamento que complementem a remoção adequada desses medicamentos (Ceron, 2011).

Os efluentes das indústrias farmacêuticas e dos hospitais devem ser considerados assim como a disposição inadequada de fármacos após a expiração do prazo de validade. Para evitar o descarte incorreto se faz necessário um programa para a coleta e destino adequado destas substâncias, além de promover a conscientização da população para tal problemática. Programas que visam o uso racional de medicamentos e o descarte seguro de fármacos devem ser oferecidos durante a formação de profissionais da área de saúde.

Segundo Ceron (2011) em efluentes hospitalares, as concentrações individuais de drogas ocorrem acima de $100 \mu \mathrm{g} \mathrm{L}^{-1}$ e nos sedimentos acima de $100 \mathrm{mg} \mathrm{L}^{-1}$. Para o caso das empresas distribuidoras, farmácias, drogarias e hospitais, diferentemente das indústrias, não possuem estrutura organizacional e não passam por fiscalização, desta forma estes estabelecimentos contam com o apoio da prefeitura para a destinação dos resíduos, e é comum que os municípios não possuam recursos necessários para lidar com este tipo de material. Outro problema citado pelo autor é o descarte pelo consumidor final, pois no Brasil não há legislação e nem sequer orientações para a forma correta de dispor tal resíduo, o mesmo ocorre com farmácias, drogarias e centros de saúde que não são obrigados por lei a recolher esses produtos. 
Em estudo realizado no Reservatório Billings, que fornece águas para a região metropolitana de São Paulo, foram identificadas e quantificadas concentrações de diversos fármacos presentes na água bruta (Almeida \& Weber, 2005).

Na Índia e no Paquistão um estudo demonstrou a redução da população de urubus (Gyps bengalensis) em mais de 95\% devido à morte por insuficiência renal e gota visceral, associada ao consumo do fármaco diclofenaco (Oaks et al., 2004).

Outro problema relacionado aos medicamentos é a utilização abusiva de antibióticos que pode acarretar em dois problemas ambientais: um é a contaminação dos recursos hídricos e o outro é que alguns microrganismos criam resistência a esses fármacos (Bila e Dezotti, 2003).

Nos EUA onde se concentram $60 \%$ do consumo mundial de antidepressivos, em 2011 foram gastos pelos americanos 11,0 bilhões de dólares com este tipo de medicamento, ficando em $7^{\circ}$ lugar (TABELA 1) em vendas prescritas no país (Medley, 2013; IMS Health, 2013).

Segundo o Relatório Mundial das Nações Unidas sobre o desenvolvimento dos recursos hídricos (4) mais de $80 \%$ da água utilizada no mundo não é coletada ou tratada (ONU, 2012). Ou seja, tais efluentes são liberados in natura nos corpos hídricos com certa frequência.

Desta forma, o aumento desenfreado no consumo de diversos tipos de fármacos e a falta de investimentos em saneamento são problemas importantes a serem enfrentados, mesmo nos locais que possuem sistemas de tratamento de efluentes estes muitas vezes não são eficientes na remoção da diversidade de poluentes.

Devido à preocupação em relação aos produtos farmacêuticos para uso humano, a Comissão Europeia publicou a diretiva 2001/83/CE, posteriormente alterada pela diretiva 2004/27/CE, que estabelece a comercialização de novos produtos médicos deva ser acompanhada de uma avaliação de risco ambiental, porém os impactos ambientais que podem ser gerados pelo fármaco não são motivos suficientes para a recusa da entrada do medicamento no mercado. Para produtos farmacêuticos de uso veterinário esta avaliação de risco já era exigida pela diretiva 92/18/CEE.

Com relação à legislação brasileira há necessidade de leis mais específicas com relação aos fármacos e principalmente relacionado ao descarte final deste tipo de resíduo (Rodrigues, 2009). 
Quando um produto químico ou fármaco passa por um tratamento biológico pode ocorrer a biodegradação, ou seja, mineralização a gás carbônico e água; pode sofrer algum processo metabólico e ser parcialmente degradado ou pode passar para o ambiente aquático por não ser biodegradável (Raimundo, 2007).

Como as técnicas de tratamento de efluentes convencionais muitas vezes são insuficientes para remover significativamente os traços dos poluentes de fármacos buscamse técnicas mais avançadas como os Processos Oxidativos Avançados (POAs) ou a filtração com o uso de membranas (Ternes et al., 2003).

$\mathrm{Na}$ TABELA 1 foram organizadas informações sobre gastos com medicamentos da população americana em função do tipo de tratamento necessário entre os anos de 2007 até 2011, conforme a IMS Health. Verifica-se que os antidepressivos se encontram em sétimo lugar no ranking.

TABELA 1. Ranking de gastos por classe terapêutica nos EUA em bilhões de dólares.

\begin{tabular}{c|c|c|c|c|c|c}
\hline Posição & Tipos & 2007 & 2008 & 2009 & 2010 & 2011 \\
\hline 1 & Oncológicos & 18,1 & 19,7 & 21,5 & 22,3 & 23,2 \\
\hline 2 & Agentes respiratórios & 15,1 & 16,0 & 18,1 & 19,3 & 21,0 \\
\hline 3 & Reguladores lipídicos & 19,4 & 18,1 & 18,6 & 18,8 & 20,1 \\
\hline 4 & Antidiabetes & 12,2 & 13,6 & 15,8 & 17,7 & 19,6 \\
\hline 5 & Antipsicóticos & 12,8 & 14,3 & 14,7 & 16,2 & 18,2 \\
\hline 6 & Doenças autoimunes & 7,6 & 8,6 & 9,7 & 10,6 & 12,0 \\
\hline 7 & Antidepressivos & 11,7 & 11,7 & 11,5 & 11,6 & 11,0 \\
\hline 8 & Antivirais HIV & 6,2 & 7,1 & 8,2 & 9,3 & 10,3 \\
\hline 9 & Anti ulcerantes & 14,6 & 14,2 & 14,1 & 11,9 & 10,1 \\
\hline 10 & Analgésicos narcóticos & 6,7 & 7,3 & 8,0 & 8,4 & 8,3 \\
\hline 11 & $\begin{array}{c}\text { Desordem de déficit de } \\
\text { atenção e hiperatividade }\end{array}$ & 4,0 & 4,7 & 5,8 & 6,7 & 7,9 \\
\hline 12 & $\begin{array}{c}\text { Inibidores de agregação de } \\
\text { plaquetas }\end{array}$ & 5,0 & 5,7 & 6,5 & 7,1 & 7,8 \\
\hline 13 & Angiotensina II & 6,5 & 7,6 & 8,6 & 8,7 & 7,6 \\
\hline 14 & Esclerose múltipla & 3,4 & 4,1 & 5,0 & 5,8 & 7,1 \\
\hline 15 & Vacinas (simples, combinadas & 5,9 & 5,0 & 4,7 & 5,7 & 6,3 \\
& e outros) & & & & & \\
\hline 16 & Anti-epilépticos & 10,0 & 11,1 & 6,9 & 5,6 & 5,9 \\
\hline 17 & Contraceptivos hormonais & 4,1 & 4,5 & 4,7 & 4,8 & 5,2 \\
\hline 18 & Eritropoietinas & 8,4 & 6,9 & 6,3 & 6,1 & 5,1 \\
\hline 19 & Agentes imunoestimulantes & 4,1 & 4,1 & 4,1 & 4,2 & 4,5 \\
\hline 20 & Antivirais, excluso Anti - HIV & 3,6 & 3,9 & 4,8 & 3,2 & 3,7 \\
\hline & Total de vendas prescritas & $\mathbf{2 8 0 , 5}$ & $\mathbf{2 8 5 , 7}$ & $\mathbf{3 0 0 , 7}$ & $\mathbf{3 0 8 , 6}$ & $\mathbf{3 1 9 , 9}$ \\
\hline nos EUA & & & & & \\
\hline & & & &
\end{tabular}

Fonte: IMS Health, 2013. 
O cloridrato de fluoxetina é o cloridrato de ( \pm )-N-metil-3-fenil-3-[( $\alpha, \alpha, \alpha-$ trifluoro-p-tolil)-oxi] propilamina, com a fórmula molecular $\mathrm{C}_{17} \mathrm{H}_{18} \mathrm{~F}_{3} \mathrm{NO} \cdot \mathrm{HCl}$ (FIGURA 2). Seu peso é $345,79 \mathrm{~g} \mathrm{~mol}^{-1}$. É um pó cristalino branco ou branco-amarelado, solúvel em água numa concentração de $14 \mathrm{mg} \mathrm{mL}^{-1}$ (Eli Lilly \& Company, 2013; Merck, 2013).

A molécula de fluoxetina foi descrita pela primeira vez na literatura científica como Lilly 110140 (na forma de cloridrato) sendo publicado na revista Life Sciences, em Agosto de 1974 e em 1979 a sua ação antidepressiva foi comprovada. O medicamento foi aprovado para o tratamento da depressão na Bélgica em 1986 e pela FDA dos Estados Unidos em 1987 (Fernandes et al., 2009).

A fluoxetina é um inibidor seletivo da recaptação da serotonina, que é o seu suposto mecanismo de ação. A fluoxetina é extensivamente metabolizada no fígado à norfluoxetina e em outros metabólitos não identificados, que são excretados na urina. A meia-vida de eliminação da fluoxetina é de 4 a 6 dias e a de seu metabólito ativo é de 4 a 16 dias (Eli Lilly \& Company, 2013; Merck, 2013).

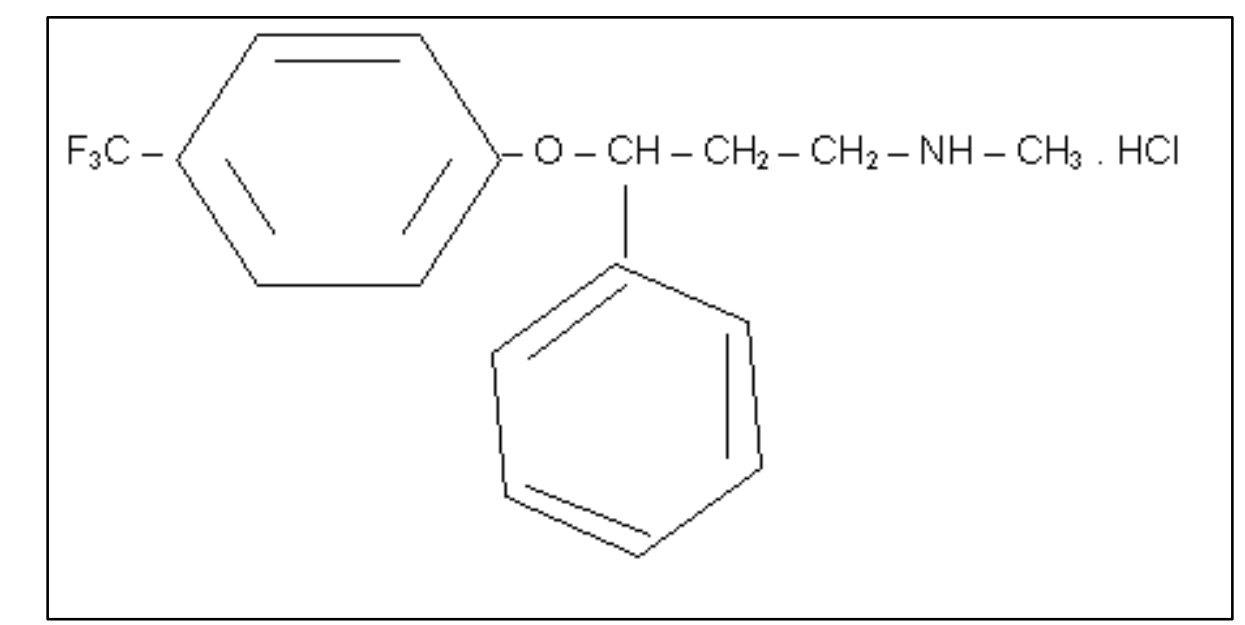

FIGURA 2. Estrutura molecular do cloridrato de fluoxetina (Soares, 2005).

\subsubsection{Biodegradabilidade da fluoxetina}

Em estudo realizado por Caminada (2008), onde foi verificada a biodegradabilidade do hidrocloridrato de fluoxetina através do método de respirometria (Teste de Gledhill-modificado e adaptado), os melhores resultados foram obtidos em concentrações de $200 \mu \mathrm{g} \mathrm{mL} \mathrm{m}^{-1}$ com redução de $27 \%$. 
Outro estudo sobre a biodegradabilidade da fluoxetina em solos que recebiam lodo de ETE e em culturas líquidas verificou-se que não houve degradação estatisticamente significativa (Redshaw et al., 2008).

Estudos com a fluoxetina indicaram que ela e relativamente recalcitrantes à hidrólise, fotólise e a degradação microbiana e que é rapidamente removido das águas superficiais por adsorção nos sedimentos, onde parece ser persistente (Kwon \& Armbrust, 2006).

\subsubsection{Presença da fluoxetina no meio ambiente}

Em levantamento realizado por Deblonde et al. (2011), sobre as concentrações de poluentes emergentes em afluentes e efluentes de estações de tratamento de esgotos, observou-se a presença de fluoxetina em concentração de $5,85 \mu \mathrm{gL}^{-1}$ no afluente e $0,112 \mu \mathrm{g} \mathrm{L}{ }^{-1}$ no efluente.

Em estudo de Metcalfe et al. (2003) em quatro estações de tratamento analisadas no Canadá, em três foram detectadas fluoxetina nos seus efluentes nas concentrações de 0,$038 ; 0,050$ e $0,099 \mu \mathrm{g} \mathrm{L}^{-1}$ e também foi detectada a presença deste fármaco em águas superficiais adjacentes às ETEs nas concentrações de 0,013 e

$0,046 \mu \mathrm{g} \mathrm{L}^{-1}$. Em estudo que analisou a presença de fármacos, hormônios e outros contaminantes orgânicos de efluentes em córregos dos Estados Unidos estimou uma média de $0,012 \mu \mathrm{g} \mathrm{L}^{-1}$ de fluoxetina (Kolpin et al., 2002).

Diversos trabalhos têm demonstrado a presença da fluoxetina em vários tipos de matrizes ambientais, principalmente nos efluentes de ETE e águas superficiais (TABELA 2). É possível verificar números bastante diferentes quanto à presença da fluoxetina em águas nos Estados Unidos, até concentrações acima de $500 \mathrm{ng} \mathrm{L}{ }^{-1} \mathrm{em}$ efluentes de ETEs. Em águas superficiais e de rios as maiores concentrações foram encontradas nos Estados Unidos e na Espanha (100 ng L $\left.{ }^{-1}\right)$. 
TABELA 2. Concentrações de fluoxetina detectadas em efluentes e águas.

\begin{tabular}{|c|c|c|c|}
\hline \multirow{4}{*}{$\begin{array}{l}\text { País } \\
\text { Canadá }\end{array}$} & \multicolumn{2}{|c|}{ Concentração ambiental $\left(\mathrm{ng} \mathrm{L}^{-1}\right)$} & \multirow{3}{*}{$\begin{array}{l}\text { Referência } \\
\text { Metcalfe } \text { et al., } 2003\end{array}$} \\
\hline & 46 & Âguas superficiais & \\
\hline & 99 & Efluentes de ETE & \\
\hline & 509 & Efluentes de ETE & Chen et al.,2006 \\
\hline Croácia & 66 & Águas superficiais & Gros et al., 2006 \\
\hline \multirow[t]{2}{*}{ Coréia do Sul } & $2-7$ & $\begin{array}{l}\text { Águas de rios e } \\
\text { riachos }\end{array}$ & Yoon et al., 2010 \\
\hline & 2 & Efluentes de ETE & $\begin{array}{l}\text { Trenholm et al., 2006; } \\
\text { Kim et al., } 2007\end{array}$ \\
\hline \multirow[t]{5}{*}{ Espanha } & $18-66$ & Águas de rios & Fernández et al., 2010 \\
\hline & 100 & Águas de rios & $\begin{array}{l}\text { Gros \& Ginebreda, } \\
2010\end{array}$ \\
\hline & $8-44$ & Jusante de ETE & Alonso et al., 2010 \\
\hline & $19-299$ & Efluentes de ETE & Martínez et al., 2007 \\
\hline & 70 & Efluentes de ETE & Gros et al., 2006 \\
\hline Suécia & 225 & Efluentes de ETE & Zorita et al., 2007 \\
\hline \multirow{12}{*}{$\begin{array}{l}\text { Estados } \\
\text { Unidos }\end{array}$} & 5 & Água de reúso & Kinney et al., 2006 \\
\hline & $12-20$ & Córrego & $\begin{array}{l}\text { Schultz \& Furlong, } \\
2008\end{array}$ \\
\hline & 2,6 & Águas superficiais & $\begin{array}{l}\text { Vanderford \& Snyder, } \\
2006\end{array}$ \\
\hline & 12 & Águas superficiais & Kolpin et al., 2002 \\
\hline & 111 & Águas superficiais & Bringolf et al., 2010 \\
\hline & 14 & Águas & $\begin{array}{l}\text { Stackelberg et al., } \\
2007\end{array}$ \\
\hline & $17-25$ & Efluentes de ETE & $\begin{array}{l}\text { Vanderford \& Snyder, } \\
2006\end{array}$ \\
\hline & 18 & Efluentes de ETE & $\begin{array}{l}\text { Stackelberg } \text { et al., } \\
2004\end{array}$ \\
\hline & 21 & Efluentes de ETE & $\begin{array}{l}\text { Glassmeyer } \text { et al., } \\
2005\end{array}$ \\
\hline & 58 & Efluentes de ETE & $\begin{array}{l}\text { Schultz \& Furlong, } \\
2008\end{array}$ \\
\hline & 540 & Efluentes de ETE & Weston et al., 2003 \\
\hline & 560 & Efluentes de ETE & $\begin{array}{l}\text { Benotti \& } \\
\text { Brownawell, } 2007\end{array}$ \\
\hline
\end{tabular}

Fonte: Modificado de Gonzalez-Rey \& Bebianno, 2013. 
Apesar do cloridrato de fluoxetina ser encontrado no ambiente em baixas concentrações (ng $\mathrm{L}^{-1}$ ), sua baixa biodegradabilidade e o potencial de bioacumulação podem causar efeitos adversos à biota. Santos et al. (2010) apresenta uma revisão bibliográfica de diversos estudos ecotoxicológicos realizados com uma variedade de fármacos e ressalta a possibilidade de um impacto negativo sobre os diferentes ecossistemas, além da ameaça para a saúde pública.

De acordo com Brooks et al. (2003) existe grande desconhecimento sobre o comportamento da fluoxetina no meio ambiente, em suma a ocorrência de resíduos deste composto em águas e sedimentos e seu potencial efeito sobre os organismos aquáticos, especialmente em invertebrados aquáticos.

\subsection{Processos Oxidativos Avançados}

Os Processos Oxidativos Avançados (POAs) são caracterizados pelas reações de oxidação química intermediada pelo radical hidroxila $\left(\mathrm{HO}^{\circ}\right)$. Estes radicais são espécies extremamente reativas e pouco seletivas, que atacam a maioria das moléculas orgânicas (Andreozzi et al., 1999). Por estes motivos, os POAs têm sido amplamente utilizados no tratamento de águas e águas residuais para a remoção de contaminantes orgânicos e também para melhorar a biodegradabilidade de efluentes industriais (Rizzo, 2011).

Os POAs apresentam diversas vantagens, entre elas podendo-se citar algumas:

- $\quad$ O poluente pode ser mineralizado e não somente transferir de fase;

- $\quad$ Podem mineralizar os contaminantes e não formar subprodutos se forem utilizadas quantidades adequadas de oxidante;

- São amplamente utilizados para a degradação de compostos refratários, onde são transformados em compostos biodegradáveis;

- Podem ser usados em combinação com outros processos de tratamento (pré e pós);

- $\quad$ Possibilitam tratamento in situ (Tambosi, 2008).

Existem vários tipos de POAs dentre eles temos a radiação $\mathrm{UV}, \mathrm{UV} / \mathrm{H}_{2} \mathrm{O}_{2}$, Fenton, foto-Fenton e a ozonização (Tambosi, 2008). Outro tipo de POA que vem sendo estudado é o tratamento através da radiação ionizante que será abordado no item seguinte. 


\subsubsection{Radiações Ionizantes}

As radiações ionizantes têm sido aplicadas em diferentes áreas, como a irradiação: de efluentes líquidos e gasosos, de alimentos para desinfestação e maior durabilidade, de materiais médicos para a radioesterilização, para beneficiamento de pedras preciosas e semipreciosas, para o desenvolvimento de fontes radioativas para radioterapias, para radioesterilização de tecidos e ossos, para modificação estrutural de polímeros, entre outras aplicações.

A radiação ionizante utilizada nestes processos pode ser gerada por fontes de emissão gama como o Cobalto-60 e Césio-137 e os aceleradores de elétrons. Para aplicações ambientais são geralmente preferidos os aceleradores de elétrons (Duarte, 1999). Um tratamento avançado, e em desenvolvimento, é a utilização da radiação ionizante, gerada por Acelerador de Feixe de Elétrons, que também pode ser aplicada ao tratamento de águas e efluentes (IAEA, 2008).

Os aceleradores de elétrons são dispositivos capazes de acelerar partículas subatômicas de valores muito baixos até alguns milhões e vários bilhões de elétrons -Volt (eV) e altas energias cinéticas, pela combinação entre campos elétricos e magnéticos. A unidade elétron-Volt corresponde à variação da energia de um elétron que atravessa uma diferença de potencial de 1 Volt, no vácuo. Um potencial de alta voltagem é estabelecido entre o cátodo e o ânodo, no vácuo, sendo que essa diferença de potencial é responsável pela aceleração das partículas, no caso os elétrons (Romanelli, 2004).

As vantagens do uso do acelerador de elétrons são: taxas de dose altas, rendimento maior de energia, licenciamento similar às máquinas de Raios-X e o sistema liga-desliga que cessa a emissão da radiação ionizante. $\mathrm{E}$ as desvantagens são: baixa penetração dos elétrons e a necessidade de operadores especializados (Duarte, 1999).

A técnica de tratamento de efluentes com utilização da radiação ionizante consiste em submetê-los ao feixe de elétrons, no qual se deve respeitar a espessura da camada de água de acordo com a energia do equipamento que será utilizado (Borrely, 2001).

No processo os elétrons interagem com as moléculas e átomos presentes na amostra irradiada transferindo energia. No caso de átomos estes podem ser ionizados e/ou excitados e as moléculas sofrem rupturas de suas ligações, gerando os radicais livres. Esta interação pode ocorrer de forma direta ou indireta. 
Segundo Duarte (1999) a ação direta da radiação é insignificante, mesmo em altas concentrações dos compostos orgânicos. Na ação indireta, conhecida como radiólise da água, são produzidas moléculas ionizadas e excitadas e elétrons livres, essas espécies químicas formam rapidamente radicais hidroxila, fortemente oxidantes, e os elétrons se tornam hidratados.

\subsubsection{Radiólise da água}

Quando a água ou um sistema aquoso é submetido a uma fonte de radioativa sofre várias modificações induzidas pelas espécies químicas que se formam a partir da interação da água com a radiação e a este processo denomina-se radiólise da água.

A exposição da água a radiação produz moléculas ionizadas, excitadas e elétrons livres e essas espécies químicas levam a formação muito rápida $\left(10^{-14}\right.$ a $\left.10^{-19} \mathrm{~s}\right) \mathrm{de}$ espécies intermediárias reativas redutoras $\left(\mathrm{e}_{\mathrm{aq}}^{-}\right.$e $\left.\mathrm{H} \bullet\right)$ e oxidantes $(\mathrm{OH} \cdot)$ São estes radicais que interagem com os compostos orgânicos e inorgânicos, sendo que os produtos resultantes das reações irão depender dos compostos presentes na solução submetida ao processo de irradiação (Borrely, 2001; Duarte, 1999: Getoff, 1996).

Os principais produtos intermediários e moleculares formados pela interação da radiação com a água estão representados na equação 1, onde são demonstradas as principais espécies formadas e acompanhadas de seus respectivos rendimentos para $100 \mathrm{eV}$ de energia absorvida (valor de $\mathrm{G}$ - apresentados nos colchetes). $\mathrm{O}$ valor $\mathrm{G}$ indica o número de moléculas "produzidas ou reagidas" para uma dada energia da radiação, estes valores são expressos em mol J ${ }^{-1}$ e são dependentes do pH da solução (Moraes, 2004; Romanelli, 2004; Borrely, 2001).

$$
\mathrm{H}_{2} \mathrm{O} \rightarrow[2,6] \mathrm{e}_{\mathrm{aq}}^{-}+[0,6] \mathrm{H}^{\bullet}+[2,7] \mathrm{OH}^{\bullet}+[0,7] \mathrm{H}_{2} \mathrm{O}_{2}+[2,6] \mathrm{H}_{3} \mathrm{O}^{+}+[0,45] \mathrm{H}_{2}
$$

Em meio ácido o $\mathrm{e}_{\mathrm{aq}}^{-}$é convertido em átomo de hidrogênio (equação 2).

$$
\mathrm{e}_{\mathrm{aq}}^{-}+\mathrm{H}_{\mathrm{aq}}^{+} \rightarrow \mathrm{H}^{\bullet}
$$

Em meio básico os átomos de hidrogênio são transformados em $\mathrm{e}_{\mathrm{aq}}^{-}$(equação 3) e os radicais $\mathrm{OH} \cdot$ dissociam-se (equação 4).

$$
\begin{aligned}
& \mathrm{H} \bullet+\mathrm{OH}_{\mathrm{aq}}^{-} \rightarrow \mathrm{e}^{-} \mathrm{aq}^{-} \\
& \mathrm{OH} \bullet \rightarrow \mathrm{O}_{\mathrm{aq}}+\mathrm{H}_{\mathrm{aq}}^{+}
\end{aligned}
$$


E na presença de ar ou nas soluções com oxigênio saturado ocorre a captura do $\mathrm{e}_{\text {aq }}^{-}$e $\mathrm{H}^{\bullet}$ pelo oxigênio gerando os radicais ânion superóxido (equação 5) e perhidroxil (equação 6).

$$
\begin{aligned}
& \mathrm{e}_{\mathrm{aq}}^{-}+\mathrm{O}_{2} \rightarrow \mathrm{O}_{2}^{-} \cdot \\
& \mathrm{H} \cdot+\mathrm{O}_{2} \rightarrow \mathrm{HO}_{2}^{-}
\end{aligned}
$$

A interação destes radicais livres formados com as moléculas de poluentes induzem reações de oxidação, redução, dissociação ou degradação, responsáveis pelo tratamento dos efluentes. A decomposição de compostos orgânicos pela radiação não é seletiva, a dose e sua taxa de radiação, necessária devem ser determinadas experimentalmente (Getoff, 1996).

A quantidade de energia que é transferida da radiação ionizante para a matéria é definida como dose absorvida. E a unidade definida pelo Sistema Internacional de Unidades para dose absorvida é o Joule por quilograma $\left(\mathrm{J} \mathrm{kg}^{-1}\right)$, a qual é dado o nome especial de Gray (Gy), previamente chamado de rad. A relação entre essas unidades é: $1 \mathrm{~Gy}=1 \mathrm{~J} \mathrm{~kg}^{-1}=100 \mathrm{rad}$ (Harvey, 1969).

\subsubsection{Decomposição de compostos orgânicos pela radiação}

Os trabalhos pioneiros das aplicações das radiações ionizantes para o tratamento de águas datam da década de 50, nesta época as fontes gama eram as mais utilizadas. Atualmente para o tratamento de águas e efluentes é dada preferência aos aceleradores de elétrons, baseado no estágio atual da tecnologia existente e sua versatilidade (Getoff, 1996).

Em comparação com outros POAs, a radiação ionizante é a tecnologia mais eficiente na geração de radicais hidroxila, além de dispensar a adição de produtos químicos.

As reações químicas básicas dos compostos orgânicos com as espécies formadas pela radiólise da água são:

- $\mathrm{O} \mathrm{e}_{\mathrm{aq}}^{-}$é um potente redutor e sua forma de atuação é pela transferência de um elétron.

Os compostos alifáticos halogenados sofrem desalogenação quantitativa.

- $\mathrm{O} H \cdot$ reage com os compostos orgânicos pela adição ou pela subtração de hidrogênio. No caso de compostos orgânicos saturados, o $\mathrm{H}^{\bullet}$ geralmente abstrai o hidrogênio 
gerando um radical orgânico e a molécula de $\mathrm{H}_{2}$, enquanto que reações de adição ocorrem com compostos insaturados e aromáticos.

- O principal radical oxidante formado é o $\mathrm{OH}$. Esta espécie pode reagir de várias formas com os compostos orgânicos em solução aquosa e os tipos mais comuns de reação são: adição, subtração de hidrogênio, transferência de elétrons e recombinação radical-radical. As reações de adição ocorrem prontamente com os compostos aromáticos e com os compostos alifáticos insaturados. Reações de subtração ocorrem com compostos orgânicos saturados. As reações de transferência de elétrons ocorrem quando as soluções aquosas são irradiadas com elétrons de alta energia. E a recombinação radical-radical resulta na formação de peróxido de hidrogênio (equação 7), também pode ocorrer à dissociação do peróxido de hidrogênio (equação 8) (Pinheiro, 2011; Duarte, 1999).

$$
\begin{gathered}
\mathrm{OH} \bullet+\mathrm{OH} \bullet \rightarrow \mathrm{H}_{2} \mathrm{O}_{2} \\
\mathrm{e}_{\mathrm{aq}}^{-}+\mathrm{H}_{2} \mathrm{O}_{2} \rightarrow \mathrm{OH}+\mathrm{OH}^{\bullet}
\end{gathered}
$$

No trabalho de Duarte (1999) o processo de irradiação com o feixe de elétrons se mostrou eficiente na degradação de diversos compostos orgânicos (compostos orgânicos aromáticos, trihalometanos, tetracloroetileno, tricloroetileno, metil isobutil cetona $\mathrm{e}$ dicloroetano), presentes em efluentes industriais de natureza diversa e complexa. Porém a irradiação não foi suficiente para melhorar totalmente os parâmetros convencionais dos efluentes industriais, mas serviria como um pré-tratamento para o tratamento biológico. Visto que os principais subprodutos formados da degradação dos compostos orgânicos são os ácidos orgânicos que são facilmente biodegradáveis.

Em relação às doses de radiação, Duarte et al. (2000) sugerem a utilização de 20,0 kGy para o tratamento do efluente industrial antes da entrada na estação de tratamento de efluentes (pré-tratamento) e 5,0 kGy para o tratamento do efluente final, após o tratamento biológico (pós-tratamento), nas condições de mistura de resíduos de vários processos industriais.

No trabalho de Santos (2012) a dose de 5,0 kGy se mostrou como a mais efetiva na redução da toxicidade do fármaco cloridrato de fluoxetina em solução aquosa na concentração de $10 \mathrm{mg} \mathrm{L}^{-1}$.

Outro estudo realizado com o fármaco diclofenaco verificou que doses próximas de 1,0 kGy foi o suficiente para a degradação do medicamento, porém para a 
mineralização dos produtos são requeridas doses mais altas de radiação. Neste caso para a irradiação de efluentes após o tratamento biológico foi sugerida a dose de 1,0 kGy (Homlok et al., 2011).

\subsection{Métodos analíticos para determinação da fluoxetina}

Dentre os métodos descritos na literatura para a determinação da fluoxetina temos a cromatografia líquida de alta eficiência (CLAE), espectrofotometria na região do visível com formação de complexos coloridos da reação de corantes com a fluoxetina, espectrofotometria na região ultravioleta, cromatografia gasosa, espectrofluorimetria, espectrofluorimetria e eletroforese capilar (Fregonezi-Nery et al., 2008; Prado et al., 2006; Gelbhar Bertholdi et al., 2001).

\subsubsection{Espectrofotometria UV/VIS}

A espectrofotometria de absorção molecular no UV/VIS é um método analítico que se baseia na propriedade que tem muitas espécies iônicas ou moleculares de absorver determinados comprimentos de onda da radiação ultravioleta e visível (Leal et al., 2008).

Quando um feixe de radiação monocromática atravessa uma solução contendo uma espécie absorvente, parte da energia radiante é absorvida e a outra parte que resta atravessa o meio. Esta quantidade de energia transportada por segundo através de uma unidade de secção transversal é chamada de potência radiante. A razão entre a potência da radiação transmitida $(\mathrm{P})$ e a potência da radiação incidente $\left(\mathrm{P}_{0}\right)$ é denominada de transmitância (T), dada pela equação 9 (Snyder et al., 2010).

$$
\mathrm{T}=\mathrm{P} / \mathrm{P}_{0}
$$

A lei que rege este processo de absorção de radiação é a Lei de Lambert-Beer (equação 10):

$$
\log \mathrm{P}_{0} / \mathrm{P}=\log (1 / \mathrm{T})=\mathrm{A}=\varepsilon . \mathrm{b} . \mathrm{c}
$$

onde: ( $\varepsilon$ ) é a absortividade molar do analito em um determinado solvente, (b) é o comprimento do percurso ótico e (c) a concentração da substância absorvente (Snyder et al., 2010). 


\subsubsection{Cromatografia Líquida de Alta Eficiência (CLAE)}

De acordo com a International Union of Pure and Applied Chemistry (IUPAC, 1993), “a cromatografia é um método físico de separação, no qual os componentes a serem separados estão distribuídos entre duas fases, uma sendo denominada fase estacionária e a outra fase móvel”.

A cromatografia líquida de alta eficiência (CLAE) ou em inglês High Performance Liquid Chromatography (HPLC) é uma cromatografia onde a fase móvel é líquida e passa pela coluna onde contém a fase estacionária. Uma mistura de compostos é injetada na coluna e são separados, em seguida detectados eletronicamente (Kenkel, 2003).

Outro tipo de cromatografia desenvolvido pela Shimadzu é o Ultra Fast Liquid Chromatography (UFLC) ou em português Cromatografia Líquida Ultra Rápida, este sistema possui como vantagens análises até 10 vezes mais rápidas e 3 vezes melhor separação do que um sistema HPLC convencional (Shimadzu, 2013).

Existem diversos tipos de detectores que são acoplados ao CLAE, dentre eles temos os detectores de absorção espectrofotométrica na faixa do ultravioleta (UV) e o por fluorescência, que são os equipamentos de mais baixo custo quando comparados com os detectores espectrômetro de massas (MS). Porém, os valores de limites de detecção alcançados para detectores de UV são bem mais altos (na faixa de $\mu \mathrm{g} \mathrm{L}^{-1}$ a ng $\mathrm{L}^{-1}$ ) se comparados ao detector MS que pode atingir limites de detecção da ordem de ng $\mathrm{L}^{-1}$ a pg L ${ }^{-1}$ (Silva \& Collins, 2011).

\subsection{Análise de Carbono Orgânico Total (COT)}

O carbono orgânico total de uma determinada solução é a concentração de carbono orgânico oxidado a $\mathrm{CO}_{2}$, em um forno a alta temperatura, e quantificado por meio de analisador infravermelho. Esta análise considera as parcelas biodegradáveis e não biodegradáveis da matéria orgânica, não sofrendo interferência de outros átomos que estejam ligados à estrutura orgânica, quantificando apenas o carbono presente na amostra (CETESB, 2014). 


\section{6}

\section{Ecotoxicologia: conceitos e aplicações}

O termo ecotoxicologia foi sugerido pela primeira vez em junho de 1969 pelo toxicologista francês René Truhaut, durante uma reunião do Committee of the International Council of Scientific Unions (ICSU) em Estocolmo (Truhaut, 1977; Zagatto \& Bertoletti, 2006). E foi definida como um ramo da toxicologia que estuda os efeitos tóxicos de substâncias naturais ou artificiais em organismos vivos, seja animal ou vegetal, terrestre ou aquático, que constitui a biosfera (Rand, 1995).

Esta ciência permite avaliar danos ocorridos em ecossistemas por contaminação e prever impactos futuros, antes da comercialização de produtos químicos e/ou lançamento de despejos no ambiente, sendo assim pode ser utilizada como uma importante ferramenta de prevenção à poluição ambiental (Zagatto \& Bertoletti, 2006). A finalidade das análises ecotoxicológicas é saber em qual grandeza as substâncias químicas, isoladas ou em forma de misturas, são nocivas e de que forma manifestam seus efeitos (Knie \& Lopes, 2004).

Os testes ecotoxicológicos são ensaios onde organismos indicadores são expostos a determinadas substâncias, compostos químicos, amostras de efluentes ou água bruta em diferentes concentrações e por um determinado período de tempo. Devido à característica do organismo em relação a sua tolerância ecológica a determinadas substâncias químicas, estes apresentam alguma alteração fisiológica, morfológica ou comportamental quando expostos a determinados poluentes (Magalhães \& Ferrão Filho, 2008).

Os ensaios de toxicidade aquática são utilizados para detectar e avaliar os potenciais efeitos toxicológicos em organismos que vivem em ambientes aquáticos (Rand, 1995).

Diversos ensaios têm sido desenvolvidos para avaliar os impactos de xenobióticos na biota, isto devido à capacidade destes testes indicarem o impacto global no ambiente que podem ser produzidos por efluentes, sedimentos ou solos de sítios contaminados (Gonzalez et al., 2009). Geralmente estes ensaios permitem uma avaliação bastante segura do potencial tóxico de substâncias ou de meios contaminados, o que permite deduções indiretas do seu risco para o meio ambiente e, com muita cautela, do perigo para o homem (Knie \& Lopes, 2004). 
Para qualquer que seja o ensaio ecotoxicológico é necessário seguir uma série de normas e procedimentos padronizados para que as respostas sejam consideradas válidas (Magalhães \& Ferrão Filho, 2008).

Diversos são os efeitos adversos que podem ser quantificados devido à exposição aos poluentes: número de organismos vivos ou mortos, taxa de reprodução, comprimento e massa corpórea, número de anomalias ou incidência de tumores, alterações fisiológicas, densidade e diversidade de espécies numa determinada comunidade biológica, dentre outros (Zagatto \& Bertoletti, 2006).

Os ensaios de toxicidade com organismos aquáticos desenvolvidos em laboratório têm sido os mais utilizados em estudos para avaliação da toxidez de substâncias químicas, efluentes e águas superficiais, e são divididos em ensaios para efeitos agudos e crônicos (Zagatto \& Bertoletti, 2006).

No caso do ensaio de toxicidade aguda são avaliados os efeitos agudos que ocorrem como resultado de uma exposição de curto período. Uma substância química terá toxicidade aguda, caso $50 \%$ ou mais indivíduos de uma população exposta morrer por ação direta da substância, em um relativo curto período de tempo (Rand, 1995).

Em ensaios de toxicidade crônica são avaliados os efeitos adversos mais sutis, a exposição do organismo ao agente químico, em níveis subletais, podendo não levar o organismo a morte, mas sim causar distúrbios fisiológicos e/ou comportamentais em longo prazo. Deve-se levar em consideração que é comum a mistura de contaminantes no ambiente e cujas interações podem resultar em efeitos sinergéticos, antagônicos, de potenciação e adição (Zagatto \& Bertoletti, 2006).

Os efeitos sinergéticos ocorrem quando um efeito combinado de dois contaminantes é muito maior do que a soma dos efeitos individuais de cada contaminante; antagônicos ocorrem quando dois contaminantes interferem um no efeito do outro; de potenciação ocorrem quando um contaminante tem efeito tóxico somente quando é aplicado em conjunto com outro contaminante e o aditivo quando o efeito combinado de dois contaminantes é igual à soma dos efeitos dos contaminantes individuais (Zagatto \& Bertoletti, 2006).

Os ensaios ecotoxicológicos podem ser realizados de três formas diferentes: como teste estático, semi-estático ou dinâmico. No teste estático a amostra não é trocada e os organismos-teste permanecem expostos à mesma solução-teste durante o período do ensaio. No semi-estático, a solução de teste é substituída, em intervalos definidos. E no 
dinâmico os organismos são expostos a um fluxo contínuo da amostra (Knie \& Lopes, 2004). A escolha na forma da aplicação do ensaio depende de diversos fatores dentre eles, as características da amostra (volatilidade, solubilidade, estabilidade, etc) e do tipo de ensaio (agudo ou crônico).

A utilização dos ensaios de toxicidade como ferramenta de avaliação dos POAs é muito importante, visto que a oxidação parcial de contaminantes orgânicos pode resultar na formação de espécies químicas intermediárias mais tóxicas do que os compostos iniciais (Rizzo, 2011).

\subsubsection{Organismos-teste}

\subsubsection{Daphnias}

As Daphnias (FIGURA 3) também conhecidas como pulgas d'água, possuem comprimento de 0,5 a $5,0 \mathrm{~mm}$ e uma carapaça bivalve transparente que recobre todo o corpo, exceto a cabeça e as antenas. Dafinídeos são organismos filtradores que se alimentam de algas, bactérias e detritos orgânicos presentes na água, suas pernas torácicas agem como peneiras que retêm o alimento, e após ser retido o alimento é transferido para a boca, onde é moído pelas mandíbulas e direcionado para o trato digestivo (Buikema \& Sherberger, 1977 apud Souza, 2008).

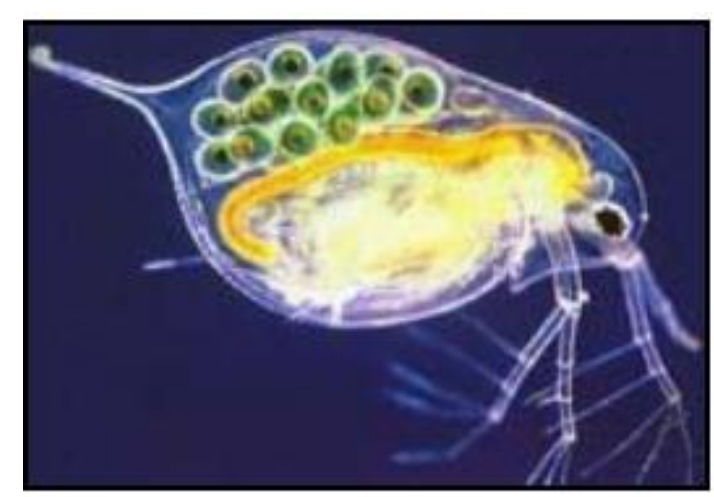

FIGURA 3. Daphnia similis. Fonte: Laboratório de Ensaios Biológicos e Ambientais (LEBA).

A reprodução geralmente é por partenogênese, ou seja, assexuada, onde as fêmeas produzem células diplóides, que dão origem a uma população constituída inteiramente por fêmeas até que ocorra um estresse ambiental, qualquer alteração como 
superpopulação, falta de alimento ou mudança de temperatura podem acarretar no surgimento de machos e também fêmeas com dois ovos haplóides que são fecundados pelos machos (Zagatto \& Bertoletti, 2006).

A Daphnia torna-se reprodutiva de cinco a dez dias após seu nascimento (Buikema \& Sherberger, 1977 apud Souza, 2008). Em condições favoráveis as crias possuem de 4 a 65 jovens, que depende ainda da idade dos organismos (Zagatto \& Bertoletti, 2006).

O fornecimento de alimento adequado é primordial para a boa reprodução da Daphnia, o excesso de alimento pode causar a obstrução do aparelho filtrador e a diminuição do oxigênio dissolvido na água. Pode ser utilizada como alimento uma cultura de algas (Pseudokirchneriella subcapitata) em fase axênica de crescimento e alimento composto de ração de peixe digerida e levedura dissolvida (conhecida como RL). Sendo que devem ser fornecidas $3,2 \times 10^{6}$ células por Daphnia por dia e 0,02 ml de RL, com

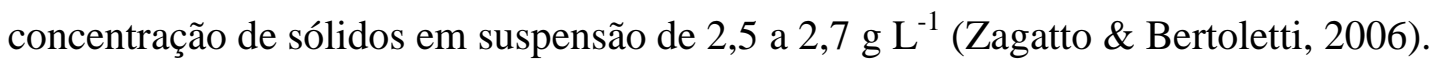

$\mathrm{Na}$ TABELA 3 constam os principais requisitos e condições para os ensaios com Daphnia similis.

TABELA 3. Resumo dos requisitos para o ensaio de toxicidade aguda com Daphnias.

\begin{tabular}{c|c}
\hline Requisitos & Condições (Daphnia similis) \\
\hline Tipo de ensaio & Estático: $48 \mathrm{~h}$ \\
\hline Idade do organismo-teste & 6h a $24 \mathrm{~h}$ \\
\hline Água de diluição & Água reconstituída \\
\hline $\begin{array}{c}\text { Volume mínimo da solução-teste por } \\
\text { organismo }\end{array}$ & $2 \mathrm{ml}$ \\
\hline Número mínimo de diluições (quantitativo) & Cinco, mais controle \\
\hline Número mínimo de replicatas por diluição & Duas \\
\hline Número mínimo de organismos por diluição & 20 \\
\hline Alimentação & Nenhuma \\
\hline Temperatura & $18^{\circ} \mathrm{C}$ a $22^{\circ} \mathrm{C}$ \\
\hline Fotoperíodo & Escuro ou $16 \mathrm{~h}$ de luz \\
\hline Efeito observado & Imobilidade \\
\hline Expressão dos resultados & $\mathrm{CE}(\mathrm{I}) 50$, FT ou tóxico e não tóxico \\
\hline
\end{tabular}

Fonte: ABNT NBR 12713/2009.

Estes crustáceos de água doce são bastante utilizados em testes de toxicidade porque são amplamente distribuídos nos corpos d'água doce, são importantes em muitas cadeias alimentares e são fontes significativas de alimento para peixes, possuem um ciclo de vida relativamente curto, são facilmente cultivados em laboratório, são sensíveis a 
vários contaminantes do ambiente aquático e devido ao seu pequeno tamanho, necessitam de volumes menores de amostras-teste e água de diluição se comparados com peixes (Rand, 1995).

\subsubsection{Vibrio fischeri}

A Vibrio fischeri é uma bactéria de origem marinha e luminescente (FIGURA 4) utilizada como microrganismo-teste no ensaio de toxicidade aguda, usualmente esta bactéria é utilizada na forma liofilizada (CETESB, 2001; Knie \& Lopes, 2004). É uma bactéria gram negativa e anaeróbia facultativa que emite luz naturalmente, sob condições ambientais favoráveis e concentrações de oxigênio superiores a $0,5 \mathrm{mg} \mathrm{L}^{-1}$ (Knie \& Lopes, 2004; Soares, 2012).
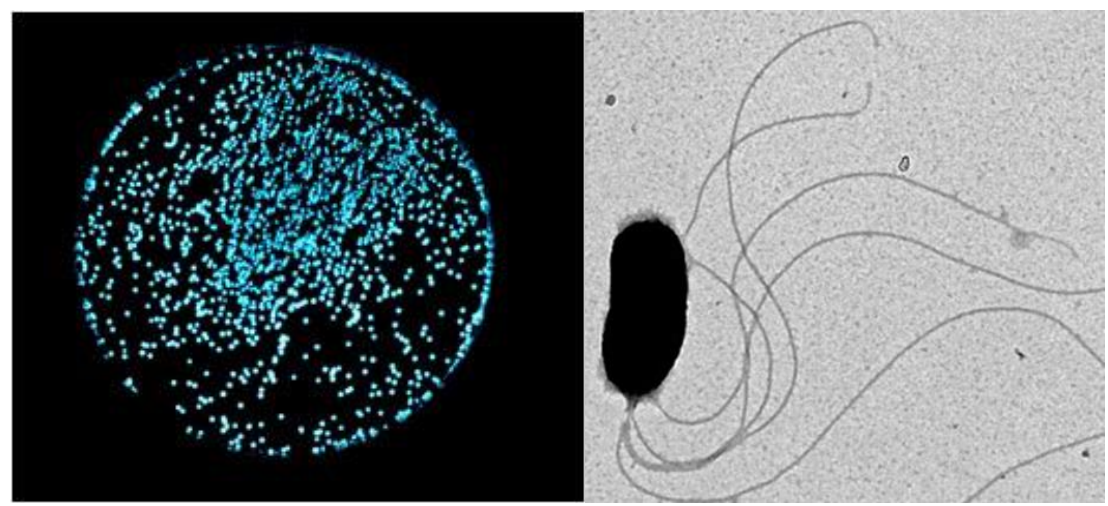

FIGURA 4. Bactéria luminescente Vibrio fischeri (Fontes: UW Eye Research Institute, 2013; PNAS, 2013).

Segundo Soares (2012) dentre os diversos testes ecotoxicológicos existentes, o de toxicidade aguda utilizando Vibrio fischeri vem sendo muito utilizado para a determinação de toxicidade de amostras ambientais em diferentes partes do mundo.

O teste se baseia na medição da luminescência emitida pela bactéria Vibrio fischeri após exposição à amostra por 15 ou 30 minutos. E a intensidade da luz é comparada a de um controle, onde não é colocada a amostra, somente solução diluente. No caso da amostra possuir substâncias tóxicas a bioluminescência diminui, sendo que a quantidade de perda de luz é proporcional à toxicidade da amostra (Knie \& Lopes, 2004).

Apesar de controvérsias na utilização deste organismo por ser de ambiente marinho, este apresenta resultados similares a outros ensaios de toxicidade de águas doces. Suas vantagens são a sensibilidade, simplicidade e rapidez do teste bem como a necessidade de pequenas quantidades de amostra. Por outro lado uma desvantagem deste 
teste é a necessidade do ajuste da salinidade, isto porque a adição de cloreto de sódio ou sacarose pode causar variações na toxicidade de alguns compostos e dificultar as comparações dos resultados obtidos em outros organismos de água doce (Soares, 2012).

Segundo Knie \& Lopes, 2004 este ensaio permite a avaliação tanto de amostras de água doce quanto salina.

No Brasil, o teste com esta bactéria vem sendo cada vez mais utilizado pelos setores industriais e órgãos ambientais, sendo contemplado pelas legislações de Santa Catarina e Paraná para lançamento de efluentes em corpos d'água e possui padronização pela Associação Brasileira de Normas Técnicas (ABNT NBR 15411- (1,2 e 3) /2012) e pela Companhia Ambiental do Estado de São Paulo (CETESB - Norma Técnica L5.227/2001) (Soares, 2012).

\subsubsection{Ceriodaphnias}

As Ceriodaphnias (Figura 5) possuem cultivo e biologia bastante semelhantes aos das Daphnias (Zagatto \& Bertoletti, 2006). Porém são menores e possui ciclo reprodutivo mais curto, produzem de 3-4 crias por semana em condições ótimas (USEPA, 1986).

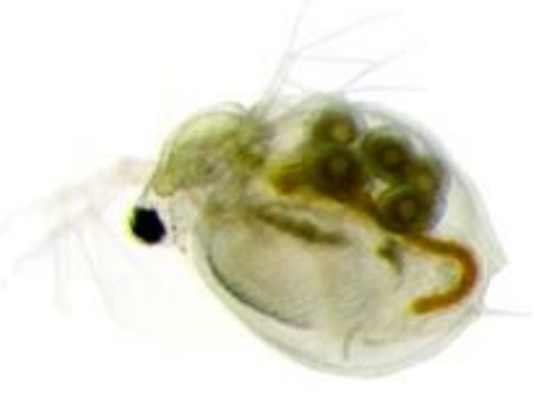

FIGURA 5. Ceriodaphnia dubia. Fonte: Laboratório de Ensaios Biológicos e Ambientais (LEBA).

Geralmente no ambiente aquático os organismos são expostos a níveis subletais de poluentes, e tais exposições pode não causar a morte do organismo e sim causar distúrbios fisiológicos e/ou comportamentais a longo prazo. Como esses efeitos não são detectados no teste de toxicidade aguda, sendo necessários testes de toxicidade crônica que permitem avaliar os efeitos adversos mais sutis aos organismos expostos (Zagatto \& Bertoletti, 2006).

Os ensaios de toxicidade crônica mais difundidos no mundo são os testes com Daphnia e Ceriodaphnia com duração de 21 e 7 dias respectivamente. Sendo o teste com a 
Ceriodaphnia o mais utilizado para avaliação de toxicidade crônica de amostras ambientais como águas e efluentes líquidos (Zagatto \& Bertoletti, 2006).

$\mathrm{Na}$ TABELA 4 seguem os principais requisitos para o ensaio de toxicidade crônica com Ceriodaphnias.

TABELA 4. Resumo dos requisitos para o ensaio de toxicidade crônica com Ceriodaphnias.

\begin{tabular}{c|c}
\hline Requisitos & Condições \\
\hline Tipo de ensaio & Semi - estático \\
\hline Idade do organismo-teste & $6 \mathrm{~h}$ a $24 \mathrm{~h}$ \\
\hline Água de diluição & Água reconstituída \\
\hline $\begin{array}{c}\text { Volume mínimo da solução-teste } \\
\text { Número mínimo de diluições (teste } \\
\text { quantitativo) }\end{array}$ & Cinco, mais controle \\
\hline Número mínimo de replicatas por diluição & 10 \\
\hline Número de organismos por replicata & Um \\
\hline Alimentação & Sim \\
\hline Temperatura & $23^{\circ} \mathrm{C} \mathrm{a} 27^{\circ} \mathrm{C}$ \\
\hline Fotoperíodo & $16 \mathrm{~h} \mathrm{de} \mathrm{luz}$ \\
\hline Efeito observado & Sobrevivência e reprodução \\
\hline Expressão dos resultados & CENO (I), CEO (I), VC (I), Clp (I), \\
tóxico e não-tóxico e efeito agudo
\end{tabular}

Fonte: ABNT NBR 13373/2010.

\subsubsection{Toxicidade da fluoxetina}

Diversos estudos demonstraram o potencial toxicológico da fluoxetina para diferentes organismos (TABELA 5). Apesar dos valores de toxicidade serem mais altos do que os valores encontrados no meio ambiente, estudos atuais têm buscado analisar outros efeitos que são desencadeados por concentrações que podem ser quantificadas em águas superficiais.

No estudo de Lazzara et al., 2012 verificou-se que baixas concentrações de fluoxetina $\left(\eta g \mathrm{~L}^{-1}\right)$ foi capaz de alterar o metabolismo de esteroides e reprodução de mexilhões (Dreissena polymorpha).

Baixas concentrações de fluoxetina $\left(10 \eta g \mathrm{~L}^{-1}-100 \eta \mathrm{g} \mathrm{L}^{-1}\right)$ resultaram em diminuição significativa na atividade dos organismos e diminuição do crescimento populacional nos invertebrados bentônicos Gammarus pulex (De-Lange et al., 2006).

Outro estudo demonstrou que concentrações ambientais da fluoxetina causaram impactos no comportamento de peixes Pimephales promelas, principalmente os machos se 
tornaram antissociais e agressivos. Em pequenas concentrações da fluoxetina os peixes machos ignoravam as fêmeas e, na hora da caça, levavam mais tempo para capturar a presa, com o aumento da concentração (de forma compatível com os níveis encontrados em algumas das águas residuais coletadas), os machos tornaram-se ainda mais agressivos, e em alguns casos mataram as fêmeas (Weinberger II \& Klaper, 2013).

TABELA 5. Valores de toxicidade para diferentes organismos e algas.

\begin{tabular}{|c|c|c|c|c|}
\hline Organismo-teste & CE50 & CENO & $\mathrm{CEO}$ & Autor \\
\hline $\begin{array}{l}\text { Pseudokirchneriella } \\
\text { subcapitata (alga) }\end{array}$ & $0,024 \mathrm{mg} \mathrm{L}^{-1}$ & ND & $0,0136 \mathrm{mg} \mathrm{L}^{-1}$ & $\begin{array}{c}\text { Brooks et al., } \\
2003\end{array}$ \\
\hline $\begin{array}{l}\text { Ceriodaphnia dubia } \\
\text { (microcrustáceo) }\end{array}$ & $0,234 \mathrm{mg} \mathrm{L}^{-1}$ & $0,056 \mathrm{mg} \mathrm{L}^{-1}$ & $0,112 \mathrm{mg} \mathrm{L}^{-1}$ & $\begin{array}{c}\text { Brooks et al., } \\
2003\end{array}$ \\
\hline $\begin{array}{l}\text { Daphnia magna } \\
\text { (microcrustáceo) }\end{array}$ & $0,82 \mathrm{mg} \mathrm{L}^{-1}$ & NA & NA & $\begin{array}{c}\text { Brooks et al., } \\
2003\end{array}$ \\
\hline $\begin{array}{c}\text { Pimephales } \\
\text { promelas (peixe) }\end{array}$ & $0,705 \mathrm{mg} \mathrm{L}^{-1}$ & NA & NA & $\begin{array}{c}\text { Brooks et al., } \\
2003\end{array}$ \\
\hline $\begin{array}{c}\text { Hyalella } \\
\text { azteca (anfípoda) }\end{array}$ & $>43 \mathrm{mg} \mathrm{kg}^{-1}$ & ND & $5,4 \mathrm{mg} \mathrm{kg}^{-1}$ & $\begin{array}{c}\text { Brooks et al., } \\
2003\end{array}$ \\
\hline $\begin{array}{l}\text { Chironomus tentans } \\
\text { (larva de mosquito) }\end{array}$ & $15,2 \mathrm{mg} \mathrm{kg}^{-1}$ & ND & $1,3 \mathrm{mg} \mathrm{kg}^{-1}$ & $\begin{array}{c}\text { Brooks et al., } \\
2003\end{array}$ \\
\hline $\begin{array}{l}\text { Daphnia similis } \\
\text { (microcrustáceo) }\end{array}$ & $1,44 \mathrm{mg} \mathrm{L}^{-1}$ & $\mathrm{NA}$ & NA & Santos, 2012 \\
\hline $\begin{array}{c}\text { Vibrio fischeri } \\
\text { (bact. luminescente) }\end{array}$ & $0,69 \mathrm{mg} \mathrm{L}^{-1}$ & $\mathrm{NA}$ & $\mathrm{NA}$ & Santos, 2012 \\
\hline $\begin{array}{c}\text { Hyalella } \\
\text { azteca (anfípoda) }\end{array}$ & $0,563 \mathrm{mg} \mathrm{L}^{-1}$ & ND & ND & Santos, 2012 \\
\hline $\begin{array}{c}\text { Ceriodaphnia dubia } \\
\text { (microcrustáceo) }\end{array}$ & $0,51 \mathrm{mg} \mathrm{L}^{-1}$ & $0,089 \mathrm{mg} \mathrm{L}^{-1}$ & ND & $\begin{array}{l}\text { Henry et al., } \\
2004\end{array}$ \\
\hline
\end{tabular}

ND: Não determinado, NA: Não avaliável

\subsubsection{A carta controle e o intervalo de confiança}

Para a garantia da qualidade analítica de estudos que utilizam ensaios de toxicidade aguda e crônica é o uso de substâncias de referência. Tais substâncias são utilizadas para avaliar as condições de "saúde" ou sensibilidade dos organismos-teste e também em pesquisas básicas com organismos aquáticos e terrestres para definir condições essenciais de ensaio para cada espécie (Zagatto \& Bertoletti, 2006).

No estudo de Buratini (2002), onde foi testado o uso do cloreto de potássio como alternativa de substância de referência em testes de toxicidade aguda para Daphnia similis, demonstrou que esta substância seria mais adequada do que o dicromato de 
potássio, pois não sofre interferência da qualidade da água na sua toxicidade, além de ser mais seguro em relação à sua disposição no ambiente.

Com os resultados de CL50, CE50, VC ou CI50 ou 25, da substância de referência, deve-se elaborar um gráfico controle. Calcula-se a média e os valores correspondentes a dois desvios-padrão superior e inferior à média. Desta forma estabelecese um limite de aceitabilidade de dados de $\pm 2 S$ da média (Zagatto \& Bertoletti, 2006).

Nos ensaios de toxicidade aguda, normalmente, estima-se a concentração da substância teste que causa efeito a 50\% da população exposta em um determinado período de tempo. Tal concentração pode corresponder à CE ou CL50 (concentração efetiva ou concentração letal mediana) (Zagatto \& Bertoletti, 2006).

Como a CE ou CL50 constitui estimativa pontual, estabelecida a partir de dados obtidos com uma única amostra, para determinada espécie, provavelmente não deve coincidir com a verdadeira CE ou CL50. Assim, é possível calcular um intervalo em torno desse valor obtido, que se denomina intervalo de confiança, que deve conter o valor verdadeiro com probabilidade conhecida e, quanto menor sua extensão, maior a precisão (Zagatto \& Bertoletti, 2006).

Quanto maior a inclinação da reta da curva concentração/resposta indica que os dados de origem têm maior variabilidade e, consequentemente, um intervalo de confiança mais amplo. A inclinação da reta também indica o modo de ação da substância, uma reta com menor inclinação pode representar uma substância cujos efeitos tóxicos se manifestam algum tempo após a exposição, ou uma substância que tem absorção deficiente ou ainda, com rápida excreção ou destoxificação, já uma reta com maior inclinação pode indicar rápida absorção, com rápida manifestação dos efeitos tóxicos (Zagatto \& Bertoletti, 2006). 


\section{MATERIAIS E MÉTODOS}

A metodologia do trabalho consistiu na irradiação de amostras de cloridrato de fluoxetina, esgoto doméstico bruto e mistura do fármaco cloridrato de fluoxetina com o esgoto doméstico. As irradiações foram realizadas no acelerador de feixe de elétrons. Para a avaliação da degradação do cloridrato de fluoxetina em solução aquosa foram utilizadas análises químicas de espectrofotometria UV/VIS, Cromatografia Líquida Ultra Rápida e quantificação do Carbono Orgânico Total (COT). Para avaliar efeitos biológicos dos efluentes envolvidos neste estudo foram empregados ensaios de toxicidade aguda e crônica. Um breve fluxograma da sequência experimental adotada foi apresentado na FIGURA 6.

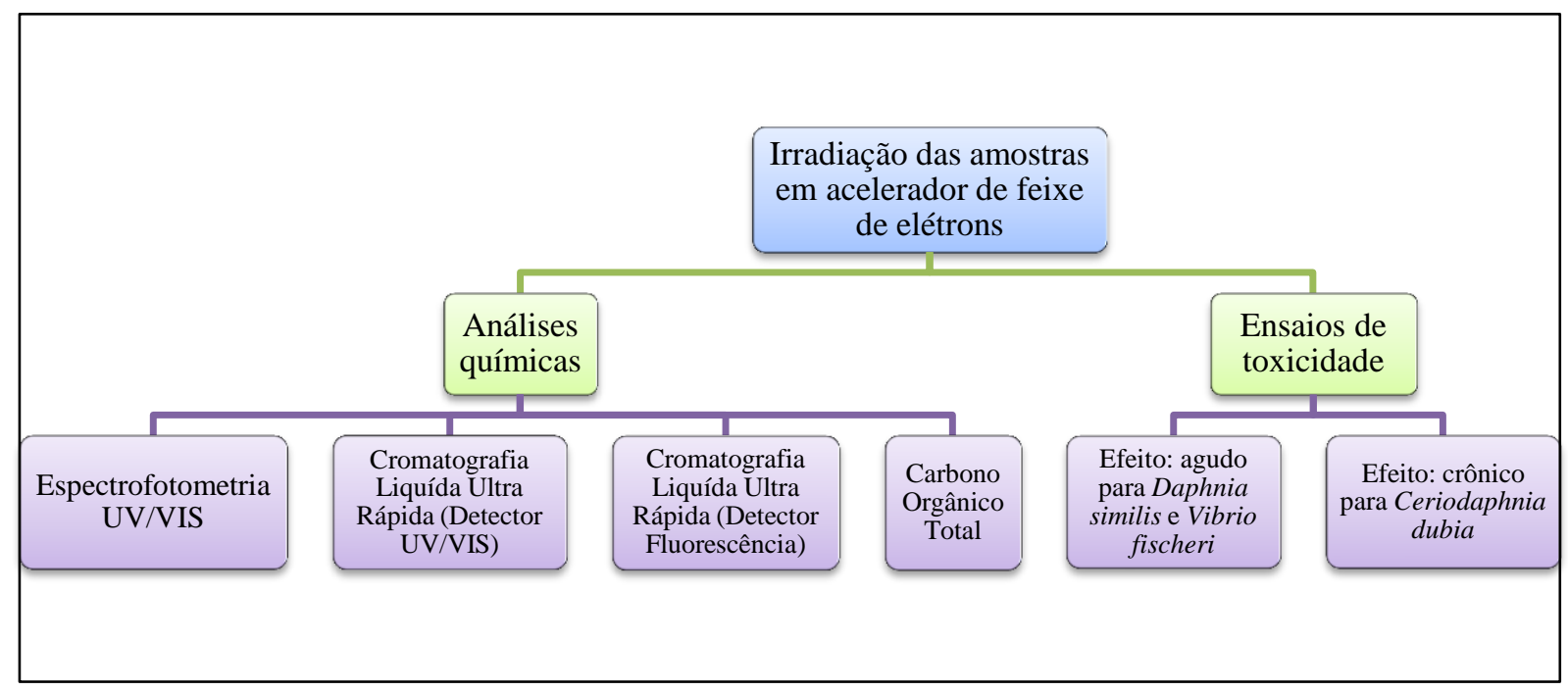

FIGURA 6. Fluxograma das principais etapas experimentais realizadas no estudo.

\subsection{Substâncias utilizadas no estudo}

Utilizou-se o fármaco cloridrato de fluoxetina da empresa Divis Pharmaceuticals Pvt. Ltda com grau de pureza de 98,78\%.

Para a validação dos ensaios de toxicidade utilizou-se como substância de referência o cloreto de potássio $(\mathrm{KCl})$ para a Daphnia similis e o fenol para a Vibrio fischeri, ambas grau P.A (mín. 99\%) da marca Anidrol Produtos Químicos.

Todas as soluções utilizadas neste estudo foram diluídas em água destilada. Para as soluções utilizadas nas análises espectrofotométricas e cromatográficas foi utilizada água Mili- $Q^{\circledR}$. 


\subsection{Preparação das soluções-teste e coleta do esgoto bruto}

\subsubsection{Cloridrato de fluoxetina}

A solução estoque do fármaco foi preparada com a diluição de uma cápsula (150 mg de cloridrato de fluoxetina) em 3 litro de água destilada. Foi utilizado o agitador magnético por um período de 24 horas para a diluição da solução.

\subsubsection{Coleta do esgoto bruto}

O esgoto bruto utilizado nos ensaios de toxicidade foi fornecido pelo Centro Tecnológico de Hidráulica da Escola Politécnica da USP e fora proveniente do Conjunto Residencial da USP (CRUSP) juntamente com a contribuição do esgoto proveniente da cozinha do Restaurante Central da USP, possuindo características similares ao esgoto doméstico. $\mathrm{O}$ esgoto bruto passou apenas pelo processo de gradeamento para a remoção dos sólidos grosseiros.

As coletas foram realizadas sempre um dia antes do processamento das amostras por radiação e foram armazenadas em refrigerador até o seu uso.

\subsubsection{Mistura do cloridrato de fluoxetina e esgoto bruto}

Visto que é preciso levar em consideração que no meio ambiente como há uma mistura de contaminantes, isto pode trazer interações toxicológicas resultando em efeitos que podem ser sinergéticos, antagônicos, de potenciação e adição. Uma das finalidades de se misturar o fármaco cloridrato de fluoxetina com o esgoto bruto foi avaliar se poderia ocorrer alguma interação toxicológica entre as substâncias da mistura. Outra questão foi a de simular o tratamento do fármaco em condições mais próximas de um afluente real.

Em balão volumétrico de $1 \mathrm{~L}$ misturou-se $200 \mathrm{~mL}$ para ensaios com Daphnia similis e $100 \mathrm{~mL}$ para os ensaios com Vibrio fischeri da solução estoque do cloridrato de fluoxetina com concentração de $50,0 \mathrm{mg} \mathrm{L}^{-1}$ e completou-se o balão com o esgoto bruto.

Com base em estudos preliminares as concentrações selecionadas para os ensaios de toxicidade foram distintas, devido a maior sensibilidade da bactéria Vibrio fischeri ao fármaco. Ensaios com Vibrio fischeri partiram de uma concentração final de cloridrato de fluoxetina de $5,0 \mathrm{mg} \mathrm{L}^{-1}$ e para Daphnia similis de $10,0 \mathrm{mg} \mathrm{L}^{-1}$, tanto para a mistura como para a solução aquosa do fármaco. 


\subsection{Irradiações das amostras-testes}

As amostras de cloridrato de fluoxetina, esgoto bruto e mistura (esgoto + cloridrato de fluoxetina) foram irradiadas no Acelerador Industrial de Elétrons Dynamitron $^{\circledR}$. As características do acelerador são potência de $37,5 \mathrm{~kW}$, energia do feixe de elétrons de 0,5 a 1,5 MeV e corrente elétrica de 0,3 até 25,0 mA. Durante este trabalho a energia do acelerador foi fixada em 1,4 MeV, variando-se apenas a corrente elétrica para que as irradiações atingissem as doses de radiação previamente definidas para o estudo.

As amostras foram irradiadas em forma de vidro, com volume de $246 \mathrm{ml} \mathrm{de}$ modo a assegurar o máximo de $4 \mathrm{~mm}$ de lâmina de espessura na forma (FIGURA 7). Para fins de proteção física e evitar possíveis contaminações os recipientes foram recobertos com plástico filme. Durante o processamento por irradiação, a amostra (forma de vidro) é transportada por esteira automática com velocidade de $6,72 \mathrm{~m} \mathrm{~min}^{-1}$, a amostra passa sob o feixe de elétrons duas vezes recebendo a metade da dose de radiação requerida em cada passada.

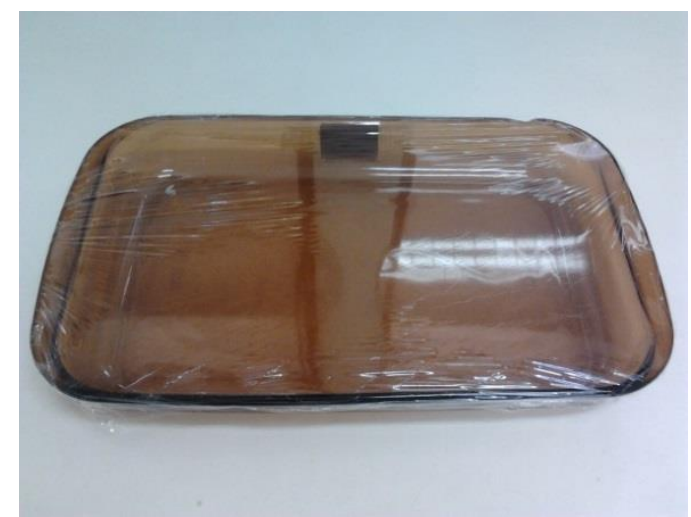

FIGURA 7. Forma de vidro, recoberta com filme plástico, utilizada para a irradiação das amostras.

Com base na literatura foram selecionadas doses entre 0,5 e 20,0 kGy, sendo 0,5 a menor dose aplicável pelo acelerador de elétrons utilizado no estudo. No trabalho de Santos (2012), a dose de 5,0 kGy foi a dose mais eficiente na remoção da toxicidade para o cloridrato de fluoxetina na concentração de $10 \mathrm{mgL}^{-1}$, assim esta dose foi inserida em todos os ensaios de toxicidade. O limite máximo de dose adotado neste estudo foi de 20,0 kGy, uma vez que doses muito elevadas inviabilizam economicamente o uso deste tipo de tratamento devido ao aumento do custo de sua operação. 
Quanto à preservação das amostras, no caso dos ensaios de toxicidade com Vibrio fischeri e nas análises químicas a irradiação das amostras envolvidas foi realizada no mesmo dia das análises. Para os ensaios de toxicidade com Daphnia similis e Ceriodaphnia dubia, as amostras foram congeladas e mantidas a temperatura de $-10^{\circ} \mathrm{C} \pm 2^{\circ} \mathrm{C}$ e utilizadas no máximo em 60 dias.

\subsection{Análises químicas}

As análises químicas foram realizadas no Departamento de Engenharia Química da Escola Politécnica da USP.

\subsubsection{Análise espectrofotométrica UV/VIS}

Para a análise espectrofotométrica utilizou-se um espectrofotômetro UV/VIS da Varian, modelo Cary 50, obtendo-se as absorbâncias nos comprimentos de onda de 200 a $800 \mathrm{~nm}$. Foram utilizadas cubetas de quartzo de caminho óptico de $1 \mathrm{~cm}$.

\subsubsection{Análises de Cromatografia Líquida Ultra Rápida}

\subsubsection{Detector UV/VIS}

Para as análises de Cromatografia Líquida Ultra Rápida utilizou-se o equipamento da marca Shimadzu, modelo LC 20AD (FIGURA 8) equipado com detector UV/VIS (SPD 20A). Coluna $\mathrm{C}_{18}$ (Kinetex $5 \mu \mathrm{m}$ Phenomenex ${ }^{\circledR}, 150$ x 4,6 mm) em temperatura de $40^{\circ} \mathrm{C}$. 


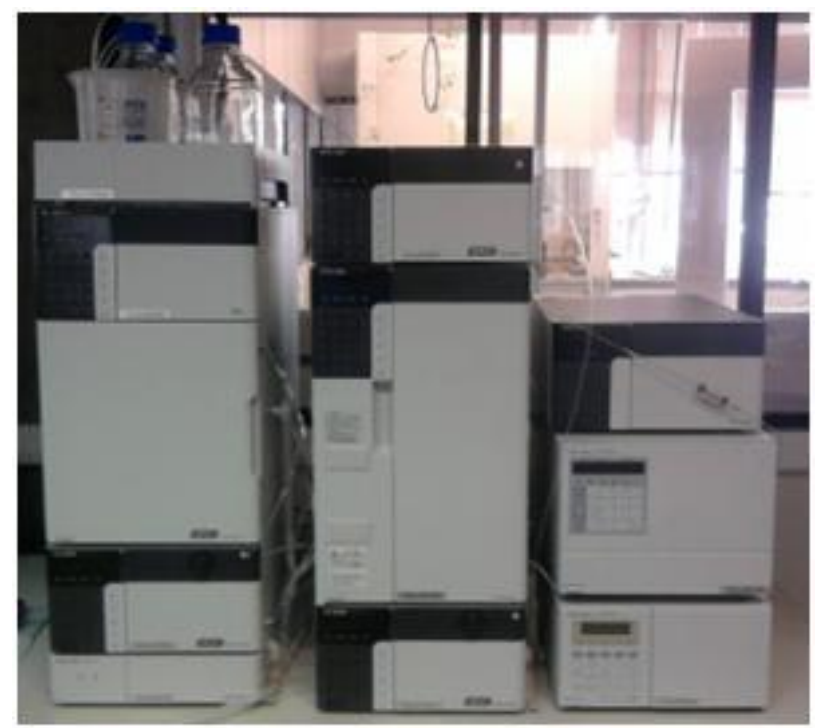

FIGURA 8. Equipamento utilizado nas análises cromatográficas.

O comprimento de onda para a leitura das amostras foi de $226 \mathrm{~nm}$, este valor foi selecionado a partir das análises com o espectrofotômetro, onde a máxima absorção se deu neste comprimento de onda.

O volume de injeção da amostra foi de $50 \mu \mathrm{L}$. A fase móvel foi (a) $1 \%$ de ácido acético + água e (b) acetonitrila na razão de 70:30 (v/v) e vazão de 1,0 $\mathrm{ml} \mathrm{min}^{-1}$.

\subsubsection{Detector de Fluorescência}

Utilizou-se o mesmo equipamento das análises com UV/VIS (LC 20AD), porém equipado com detector fluorescência (RF-10Axl). Coluna $\mathrm{C}_{18}$ (Kinetex $5 \mu \mathrm{m}$ Phenomenex ${ }^{\circledR}, 150 \times 4,6 \mathrm{~mm}$ ) em temperatura de $40^{\circ} \mathrm{C}$ (FIGURA 9).

O volume de injeção da amostra foi de $7 \mu \mathrm{L}$ para a amostra não irradiada e $50 \mu \mathrm{L}$ para as irradiadas, houve a necessidade de volumes maiores de injeção das amostras irradiadas para aumentar a sensibilidade do método. E a fase móvel foi (A) 0,2\% de ácido acético + água e (B) acetonitrila na razão de 70:30 (v/v) e vazão de 1,5 $\mathrm{ml} \mathrm{min}^{-1}$. A leitura foi feita nos comprimentos de onda de excitação e emissão de $290 \mathrm{~nm}$ e $230 \mathrm{~nm}$, respectivamente. 


\subsubsection{Curvas analíticas}

Para a construção das curvas analíticas obtidas pelas análises cromatográficas, preparou-se uma solução estoque concentrada de $1000 \mathrm{mg} \mathrm{L}^{-1}$ de CF diluída em metanol. A partir desta solução estoque foram feitas as diluições necessárias, em água Mili- $Q^{\circledR}$.

Os valores do Limite de Detecção (LD) e do Limite de Quantificação (LQ) podem ser expressos pelas fórmulas:

$$
\begin{aligned}
& \mathrm{LD}=3,3 \times s / \mathrm{S} \\
& \mathrm{LQ}=10 \times s / \mathrm{S}
\end{aligned}
$$

Onde $s$ é o coeficiente linear e o S é o coeficiente angular da curva analítica (Ribani et al., 2004).

\subsubsection{Carbono Orgânico Total (COT)}

Para a quantificação do COT utilizou-se o analisador Shimadzu, modelo TOC5000A (FIGURA 9). As frações de Carbono Total (CT) e Carbono Inorgânico (CI), contidas nas amostras, são quantificadas e pela diferença entre essas medidas obtêm-se o COT.

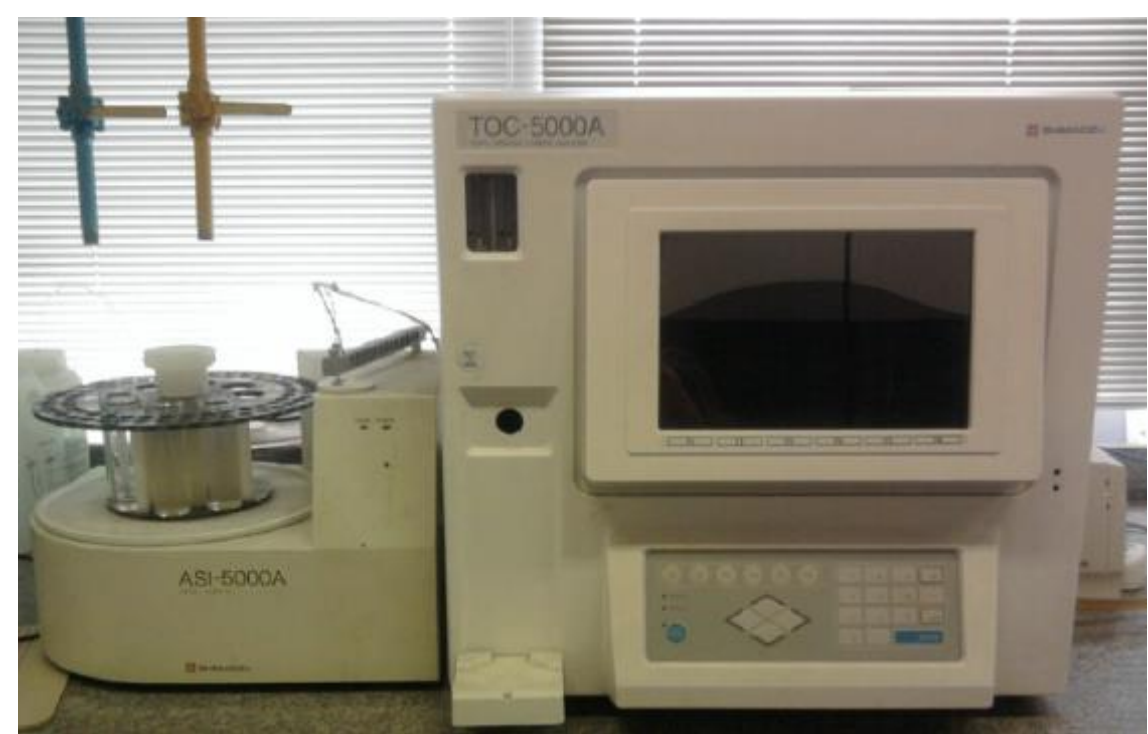

FIGURA 9. Analisador de Carbono Orgânico Total (COT) utilizado no presente estudo. 
Para todos os ensaios de toxicidade e para o cultivo dos organismos-teste em laboratório seguiram-se as normas recomendadas pela Associação Brasileira de Normas Técnicas (ABNT).

No caso da Daphnia similis utilizou-se a norma ABNT NBR 12713/09, para Vibrio fischeri a norma ABNT NBR 15411-3/12 e para a Ceriodaphnia dubia a norma ABNT NBR 13373/10.

\subsubsection{Coleta e preparo da água de cultivo e de diluição}

A água utilizada para a diluição das amostras e para o cultivo em laboratório dos organismos-teste (Daphnia similis e Ceriodaphnia dubia) foi coletada trimestralmente no reservatório de Ribeirão do Piraí, Bacia do Rio Jundiaí, localizado no município de Salto/SP, Brasil.

A água foi coletada e armazenada em bombonas de polietileno de 20 litros e estocadas no Laboratório de Ensaios Biológicos Ambientais (LEBA), localizado no Centro de Tecnologia das Radiações (CTR), Instituto de Pesquisas Energéticas e Nucleares (IPEN).

Após cada coleta de água natural, a mesma passou por uma triagem para verificar a viabilidade da água para seu uso no cultivo dos organismos. Foram determinados o pH, oxigênio dissolvido na água (OD), condutividade elétrica, dureza e o ensaio de viabilidade. Este último consiste em expor no mínimo 20 organismos-teste em pelo menos duas replicatas da água recém-coletada (com correção apenas da dureza) por 48 horas, e sem adição de alimento. Os lotes de água foram aceitos, pois em todos não foram excedidos $10 \%$ de imobilidade do total de organismos expostos.

As determinações de $\mathrm{pH}$ foram feitas no pHmetro de bancada da marca Micronal e modelo B474, os valores de OD e condutividade foram obtidos pelo multi medidor da marca HACH e modelo HQ40d e a dureza foi medida pelo método titulométrico do EDTA (CETESB, 1992).

A dureza da água natural e coletada em Salto foi sempre corrigida para

$45 \pm 2 \mathrm{mg} \mathrm{CaCO}_{3} \mathrm{~L}^{-1}$, tal correção foi feita de acordo com as especificações descritas nas normas ABNT NBR 12713/09 e ABNT NBR 13373/10. Com relação ao oxigênio 
dissolvido na água, esta foi mantida sob aeração constante por no mínimo 24 horas, para garantir a saturação dos níveis de oxigênio dissolvido e a completa solubilização dos sais.

Antes da utilização da água nos cultivos e nos ensaios de toxicidade, foi realizada a filtração desta água em rede de malha de $68 \mu \mathrm{m}$, para remoção de possíveis materiais em suspensão.

\subsubsection{Preparo do alimento}

Alimentação dos organismos Daphnia similis e Ceriodaphnia dubia foi provida de microalga Pseudokirchneriella subcapitata e do complemento alimentar que é a ração de peixe líquida com adição de leveduras (RL).

A microalga foi cultivada no LEBA em meio de cultura L.C. Oligo preparada de acordo com as normas ABNT NBR 12713/09 e ABNT NBR 13373/10, sob aeração e iluminação constantes (FIGURA 10).

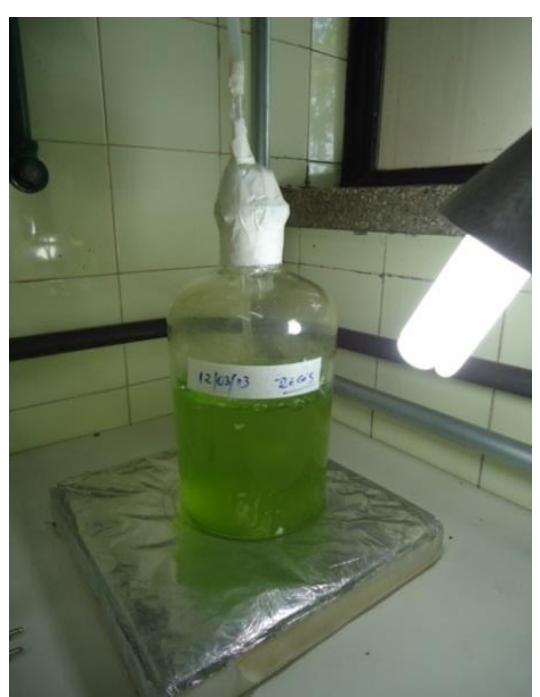

FIGURA 10. Cultivo da microalga Pseudokirchneriella subcapitata.

Para a concentração da microalga, o meio de cultura foi centrifugado por

5 minutos em centrífuga de tubos da marca Quimis modelo Q222T, o sobrenadante foi descartado e a microalga concentrada foi ressuspensa em cerca de $1 \mathrm{ml}$ de água de cultivo no agitador de tubos tipo vortex da marca Phoenix modelo AP56.

A ração líquida foi preparada com ração de peixe em flocos da marca Alcon Basic $^{\circledR}$ MEP 200 Complex fermentada. Para a fermentação foram adicionados 5,0 g de ração em 1 litro de água destilada e mantida sob aeração constante por uma semana. Foram utilizados no preparo da RL $50 \mathrm{ml}$ da ração fermentada, $0,5 \mathrm{~g}$ de fermento biológico (levedura) e $75 \mathrm{ml}$ de água destilada. 


\subsubsection{Manutenção do cultivo de Daphnia similis e Ceriodaphnia dubia}

Os cultivos de Daphnia similis e Ceriodaphnia dubia foram mantidos em câmara de germinação a temperatura de $20^{\circ} \mathrm{C} \pm 1^{\circ} \mathrm{C}$ e $25^{\circ} \mathrm{C} \pm 1^{\circ} \mathrm{C}$, respectivamente, e fotoperíodo de 16 horas de claro. Foram mantidos 40 organismos em cristalizadores de vidro com aproximadamente $2 \mathrm{~L}$ de água de cultivo para a Daphnia e 20 organismos em 1L de água de cultivo para a Ceriodaphnia.

Diariamente transferiram-se os neonatos dos cristalizadores para um béquer contendo água de cultivo. Também foram removidas as carapaças que se originam do processo de "muda" e por fim foi realizada a alimentação com o concentrado de microalga e RL.

A troca total de água foi realizada semanalmente, e somente aos sábados, domingos e feriados não foram realizados os procedimentos de manutenção. Tomou-se o cuidado de não ultrapassar mais de três dias sem os procedimentos de manutenção.

Os organismos adultos com mais de 28 dias (Daphnia), 21 dias (Ceriodaphnia) e os neonatos não utilizados em ensaios ou renovação de cultivo foram acondicionados em um béquer para o devido descarte.

\subsubsection{Ensaios de toxicidade aguda com Daphnia similis}

Para os ensaios de toxicidade aguda com Daphnia similis seguiu-se a norma ABNT NBR 12713/09.

Os organismos jovens utilizados no ensaio apresentavam faixa etária de 6 a 24 horas e foram obtidos de fêmeas com idade entre 7 a 28 dias. Para assegurar o período de vida dos organismos jovens estes foram transferidos da cuba de cultivo, no mínimo 6 horas antes do início do teste, para um béquer com água de diluição, diariamente.

Os neonatos foram expostos nas seguintes diluições 6,$25 ; 12,50 ; 25,00 ; 50,00$; 75,00 e 100,00\% da solução estoque de cloridrato de fluoxetina e mais o controle contendo apenas água de cultivo. A solução estoque foi preparada com água destilada e as diluições subsequentes com água de cultivo. As mesmas porcentagens de diluição foram realizadas para o esgoto e para a mistura (CF + esgoto) com água de cultivo.

A concentração da solução inicial nos primeiros ensaios foi de $10,0 \mathrm{mg} \mathrm{L}^{-1}$,

porém em alguns ensaios a concentração foi aumentada para $20,0 \mathrm{mg} \mathrm{L}^{-1}$ devido a necessidade de uma concentração maior para as análises cromatográficas. 
Os valores de $\mathrm{pH}$, oxigênio dissolvido (OD) e condutividade da água foram determinados em todas as diluições e no controle, antes e após a exposição das amostras aos organismos-teste.

Foram feitas 4 réplicas contendo 5 organismos em cada, totalizando

20 organismos para cada diluição, em cada réplica colocou-se $10 \mathrm{ml}$ de amostra. Os recipientes-testes consistiam em tubos de vidro, dispostos em grade metálica e cobertos com filme plástico, mantidos cobertos com plástico preto em temperatura de $20^{\circ} \mathrm{C} \pm 1^{\circ} \mathrm{C}$ (FIGURA 11).

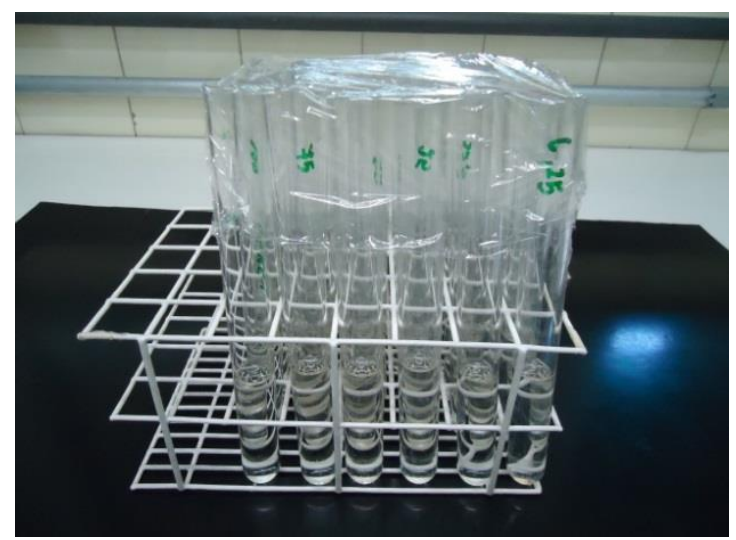

FIGURA 11. Ensaio de toxicidade aguda com Daphnia similis para a amostra do cloridrato de fluoxetina.

Os ensaios realizados foram mantidos dentro de câmara de germinação com fotoperíodo (16h claro) controlados, sob as mesmas condições de cultivo por um período de 48 horas.

Após 48 horas, anotou-se o número de organismos imóveis e calculou-se o valor de CE50 da amostra através do método Trimmed Spearman-Karber com o auxílio de programa computacional (Hamilton et al., 1977).

\subsubsection{Ensaios de toxicidade aguda com Vibrio fischeri}

As bactérias Vibrio fischeri foram adquiridas na forma liofilizada da marca Biolux ${ }^{\circledR}$ e mantidas à $-20^{\circ} \mathrm{C} \pm 2^{\circ} \mathrm{C}$ até a sua utilização. Seguiu-se a Norma ABNT NBR 15411-3/12, para ensaios de toxicidade aguda com Vibrio fischeri na forma liofilizada.

O ensaio foi precedido da hidratação da bactéria Vibrio fischeri (Biolux ${ }^{\circledR}$ ), utilizando $1000 \mu 1$ de solução tampão de reativação. Após a hidratação das bactérias este material ficou armazenado no aparelho de leitura Microbics ${ }^{\circledR}$ (M500 Toxicity Analyzer) a 
uma temperatura de $4^{\circ} \mathrm{C}$ (FIGURA 12). Para se utilizar estas bactérias no ensaio, a mesma foi diluída na proporção $1000 \mu$ l de solução diluente para $100 \mu 1$ de bactéria hidratada, permanecendo armazenada em outro compartimento a $15^{\circ} \mathrm{C}$.

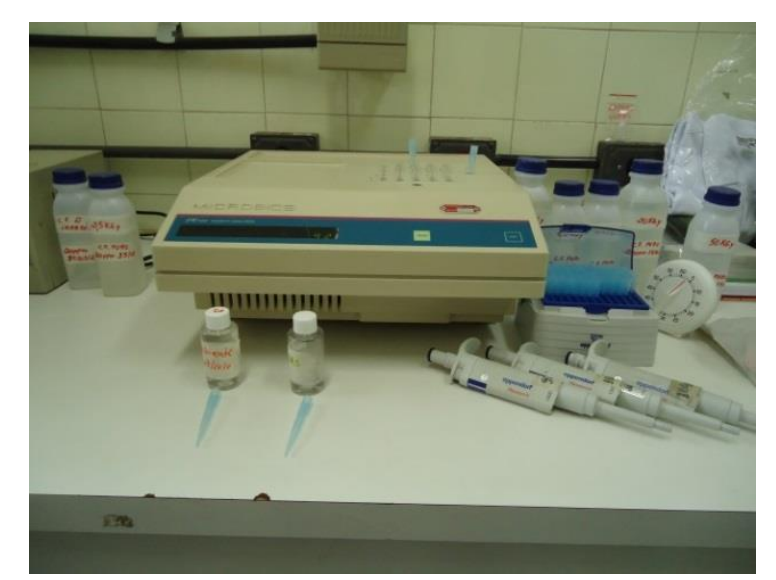

FIGURA 12. Sistema analisador de bioluminescência (Microbics ${ }^{\circledR}-$ M500), empregado para os ensaios de toxicidade aguda com a bactéria Vibrio fischeri.

Foi realizada a diluição serial das amostras, sendo que na maior concentração foi adicionada a solução salina $22 \%$ para o ajuste osmótico.

Para cada amostra existem duas séries de cubetas dispostas no equipamento, sendo uma para a diluição em série e a segunda para as leituras. Foram analisadas quatro diluições e mais o controle.

Nas cubetas de leitura foram adicionadas $100 \mu 1$ da solução contendo as bactérias hidratadas e já diluídas na proporção 1:10 e feitas as leituras de bioluminescência inicial $\left(\mathrm{I}_{0}\right)$. Após este procedimento adicionou-se $900 \mu \mathrm{l}$ das amostras da diluição serial e após 15 minutos (exposição do organismo-teste ao contaminante de interesse) para a leitura da bioluminescência final $\left(\mathrm{I}_{15}\right)$. Todo o ensaio foi feito com as amostras a temperatura de $15^{\circ} \mathrm{C}$.

Os dados de $\mathrm{I}_{0}$ e $\mathrm{I}_{15}$ foram inseridos em uma planilha Excel que realiza o cálculo de regressão linear e ao realizar o ajuste dos pontos calcula o CE50 e o intervalo de confiança, com base na perda de luminescência em função da presença de compostos tóxicos nas amostras analisadas. 


\subsubsection{Ensaios de toxicidade crônica com Ceriodaphnia dubia}

Os organismos jovens utilizados no ensaio possuíam faixa etária entre 6 a 24 horas e foram obtidos por partenogênese, a partir de fêmeas com idade de 7 a 21 dias, em condições de laboratório (Norma ABNT NBR 13373/10).

No ensaio 1 a solução-padrão (utilizada para os ensaios com a amostra não irradiada e nas irradiadas) foi preparada com concentração de $5,0 \mathrm{mg} \mathrm{L}^{-1}$ e no ensaio 2 com $20,0 \mathrm{mg} \mathrm{L}^{-1}$.

Para cada diluição foram preparadas 10 replicatas, colocando-se $20 \mathrm{ml}$ de solução-teste em cada recipiente-teste com alimento. Em cada recipiente foi colocado 1 organismo jovem (FIGURA 13).

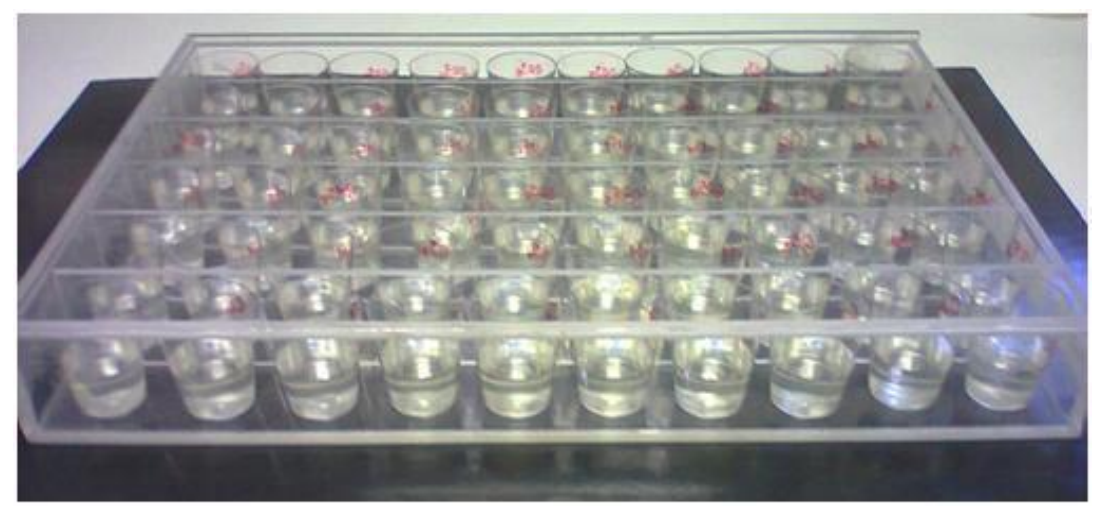

FIGURA 13. Sistema de manutenção de amostras a serem incubadas durante o ensaio de toxicidade crônica com Ceriodaphnia dubia (dez replicatas).

$\mathrm{O}$ ensaio foi mantido a temperatura de $25^{\circ} \mathrm{C} \pm 1^{\circ} \mathrm{C}$ por aproximadamente 7 dias (não ultrapassando o oitavo dia) e com fotoperíodo de $16 \mathrm{~h}$ de luz difusa. As soluções-teste foram renovadas por duas vezes durante o ensaio e com intervalo de dois a três dias.

$\mathrm{O}$ alimento foi fornecido diariamente e nas sextas-feira adicionou-se o dobro de alimento, garantindo a alimentação durante o final de semana. A microalga Pseudokirchneriella subcapitata é a base principal de alimentação para esses crustáceos, sendo oferecidos para cada organismo $100 \mu \mathrm{L} /$ dia de solução concentrada dessas algas e $100 \mu \mathrm{L}$ de RL (ração + leveduras) apenas no início do ensaio do ensaio e nas renovações das soluções-teste.

Nas renovações das soluções-teste foram registrados os números de organismos adultos sobreviventes e os números de neonatos vivos em cada recipiente-teste. 
Os ensaios só terminavam quando $60 \%$ ou mais das fêmeas adultas sobreviventes no controle tiverem produzido no mínimo 15 organismos jovens, não ultrapassando o oitavo dia.

Os valores de $\mathrm{pH}$, oxigênio dissolvido e condutividade foram medidos na maior e na menor concentração e no controle.

As análises estatísticas para o ensaio com Ceriodaphnia foram realizadas com o programa TOXSTAT Versão 3.5, sendo utilizado o teste "t" por bioequivalência. A constante de bioequivalência (B) calculada por Bertoletti et al. (2007) para Ceriodaphnia dubia $(\mathrm{B}=0,79)$ foi utilizada nos cálculos. A partir dos dados da análise estatística, as amostras foram classificadas como "tóxicas" ou "não tóxicas” em relação ao controle.

\subsubsection{Unidades Tóxicas (UT) e Eficiência}

A Unidade Tóxica (UT) é uma transformação da CE50, visto que a relação entre a CE50 e a toxicidade são grandezas inversamente proporcionais, ou seja, quanto maior o valor de CE50 menor a toxicidade de uma determinada amostra, o valor de UT é obtida pela relação 100/CE50. Desta forma a grandeza UT é diretamente proporcional à toxicidade.

A partir dos valores de UT foi possível calcular a eficiência do tratamento na remoção da toxicidade de uma amostra através da equação 11:

$$
\text { Eficiência }=\left(\left(\mathrm{UT}_{\text {bruto }}-\mathrm{UT}_{\text {amostra irradiada }}\right) \times 100 / \mathrm{UT}_{\text {bruto }}\right)
$$

Sendo:

$\mathrm{UT}_{\text {bruto }}=$ Unidade Tóxica da amostra antes do tratamento.

$\mathrm{UT}_{\text {amostra irradiada }}=$ Unidade Tóxica da amostra irradiada em determinada dose de radiação.

\subsubsection{Carta controle}

Para a elaboração da carta controle foram feitos ensaios de toxicidade com uma substância de referência (cloreto de potássio para Daphnia e fenol para Vibrio) nas mesmas condições dos ensaios definitivos.

Calculou-se a média dos valores de CE50 e os valores correspondentes a dois desvios-padrão superior e inferior a esta média (intervalo de confiança). Para a garantia da qualidade analítica do estudo seja aprovada os valores de CE50 obtidos para a substância de referência precisam estar dentro deste intervalo de confiança. Outra análise a ser 
considerada é a variabilidade dos resultados que pode ser analisada através do coeficiente de variação $(\mathrm{CV})$, dada pela fórmula 12 :

$$
\mathrm{CV}=(\mathrm{S} / \mathrm{X}) \times 100
$$

onde: $\mathrm{S}=$ desvio padrão e $\mathrm{X}=$ média dos resultados

No geral, um método ecotoxicológico é considerado bom quando a variação dos resultados, expressa pelo valor de CV seja inferior ou igual a 30\%. Caso a sensibilidade dos organismos-teste esteja fora da faixa definida por alguma norma, para uma determinada substância de referência, é sinal que ocorreu alteração em algum fator no ambiente do sistema do teste, razão pela qual este deve ser submetido a uma nova avaliação completa (Zagatto \& Bertoletti, 2006).

\subsubsection{Análise estatística}

Para os dados coletados mais de uma vez, foram calculados os valores de média e desvio padrão.

Para a avaliação estatística de significância entre os dados coletados utilizou-se o método estatístico Análise de Variância (ANOVA) com o Teste de Tukey. A Análise de Variância é um procedimento utilizado para comparar três ou mais condições impostas ou objetos que se deseja medir ou avaliar em um experimento (UFPR, 2009).

Após verificar que há variação significativa pela ANOVA, o procedimento seguinte é o de comparar as médias das condições utilizando algum teste de comparação de médias ou contrastes para identificar quais condições são diferentes. Um deles é o Teste de Tukey, este teste permite testar qualquer contraste, sempre, entre duas médias de condições (UFPR, 2009).

O teste de normalidade utilizado para verificar se a distribuição é normal foi o de Shapiro-Wilk. Utilizou-se o software Action versão 2.6 para as análises estatísticas.

\subsection{Descarte dos resíduos}

As soluções utilizadas nos ensaios foram armazenadas em bombonas de $20 \mathrm{~L}$ corretamente identificadas e entregues ao setor responsável pela coleta e destinação final do IPEN. Evitando desta forma possíveis contaminações ambientais pelas substâncias utilizadas no estudo. 


\section{RESULTADOS E DISCUSSÕES}

Neste capítulo serão apresentados os resultados de degradação e avaliação de toxicidade obtidos pelas análises químicas realizadas e dos ensaios de toxicidade das amostras do cloridrato de fluoxetina, do esgoto doméstico e da mistura do cloridrato de fluoxetina com o esgoto. Tanto as análises químicas como as de toxicidade foram realizadas antes e após o tratamento das amostras (em solução aquosa) por radiação ionizante proveniente de um acelerador de elétrons.

\subsection{Análises químicas}

\subsubsection{Análise espectrofotométrica UV/VIS}

Pela análise de espectrofotometria na região do UV/VIS verificou-se que o pico de absorção do cloridrato de fluoxetina ocorreu no comprimento de onda de $226 \mathrm{~nm}$ (FIGURA 15), sendo este comprimento de onda o mesmo utilizado por Prado et al. (2006) em seu estudo para validação de método analítico para determinação da fluoxetina com CLAE acoplado a detector UV/VIS.

Através dos valores de absorbância no comprimento de onda de $226 \mathrm{~nm}$ foi possível plotar a curva analítica (FIGURA 14), obtendo-se assim o coeficiente de absortividade molar, que é a capacidade de $1 \mathrm{~mol}$ do composto absorver certa quantidade de luz em um dado comprimento de onda, este valor foi obtido através do coeficiente angular da curva analítica $\left(\varepsilon=12443 \mathrm{~L} \mathrm{~mol}^{-1} \mathrm{~cm}^{-1}\right)$. O valor do coeficiente de absortividade molar teve a mesma ordem de grandeza do valor reportado $\left(\varepsilon=15900 \mathrm{~L} \mathrm{~mol}^{-1} \mathrm{~cm}^{-1}\right)$ para a solução de fluoxetina em água-metanol (1:1, v/v) em $226 \mathrm{~nm}$ (Raggi et al., 1998). 


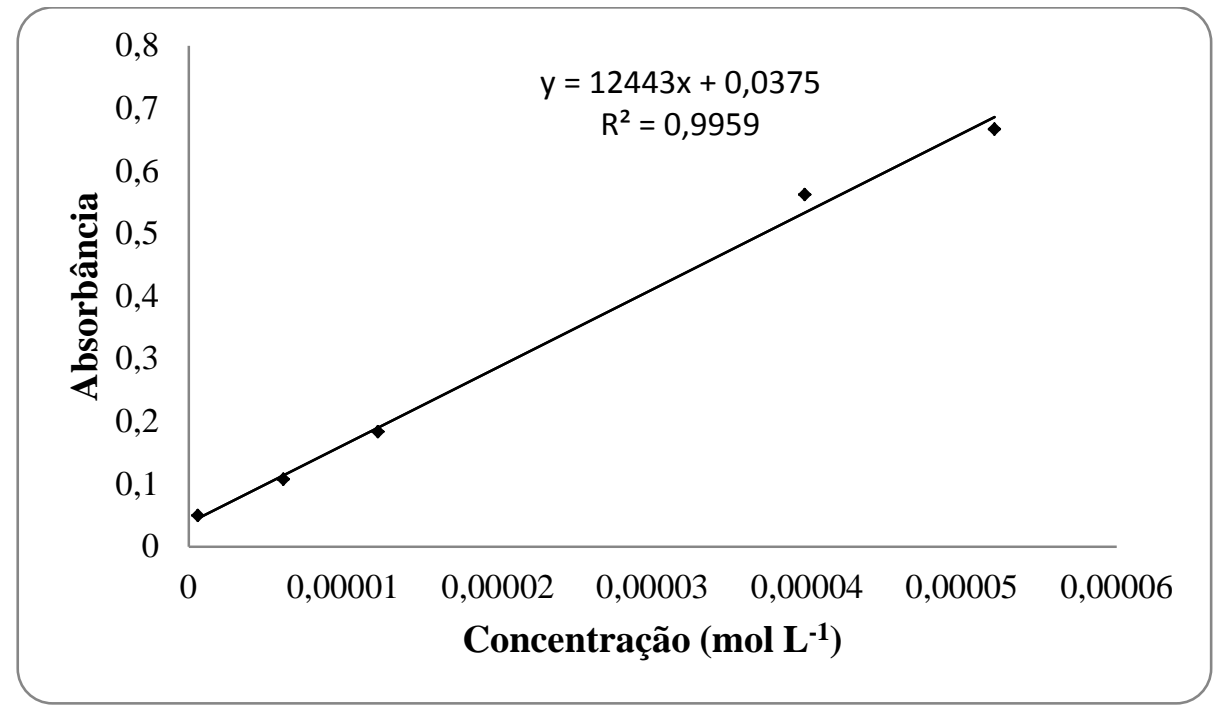

FIGURA 14. Curva analítica obtida por espectrofotometria UV/VIS no comprimento de onda de $226 \mathrm{~nm}$ para o cloridrato de fluoxetina.

Visto que as bandas de absorbância de uma substância na faixa de comprimento de onda de 190 a $300 \mathrm{~nm}$ representam as ligações duplas e triplas conjugadas de uma molécula, isto explica a banda de absorção do cloridrato de fluoxetina que possui ligações duplas nos dois anéis aromáticos em sua estrutura química (Holler et al., 2009).

Foi possível observar que não houve nenhum composto capaz de absorver nos comprimentos de onda entre 300 e $800 \mathrm{~nm}$, tanto para a amostra não irradiada como após a irradiação, ou seja, após o tratamento por irradiação não houve a formação de espécies químicas capazes de absorver neste intervalo de comprimentos de onda.

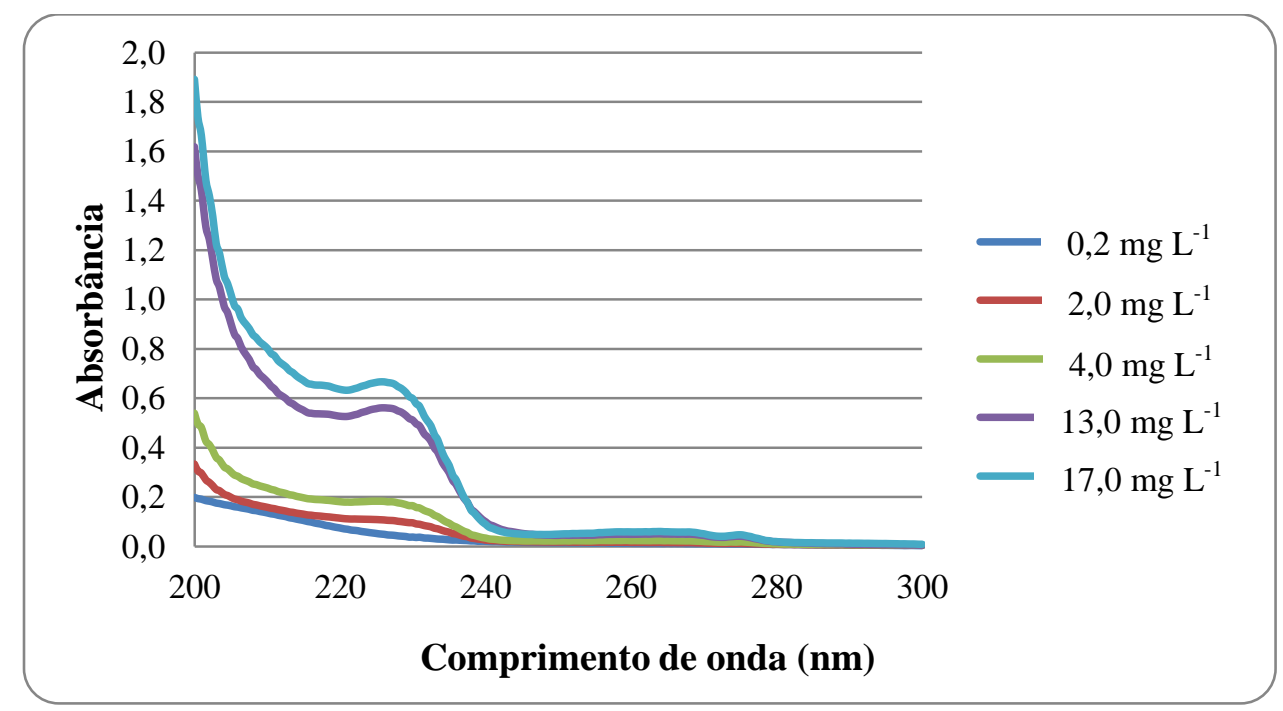

FIGURA 15. Espectros de absorção da solução contendo o cloridrato de fluoxetina em diferentes concentrações. 


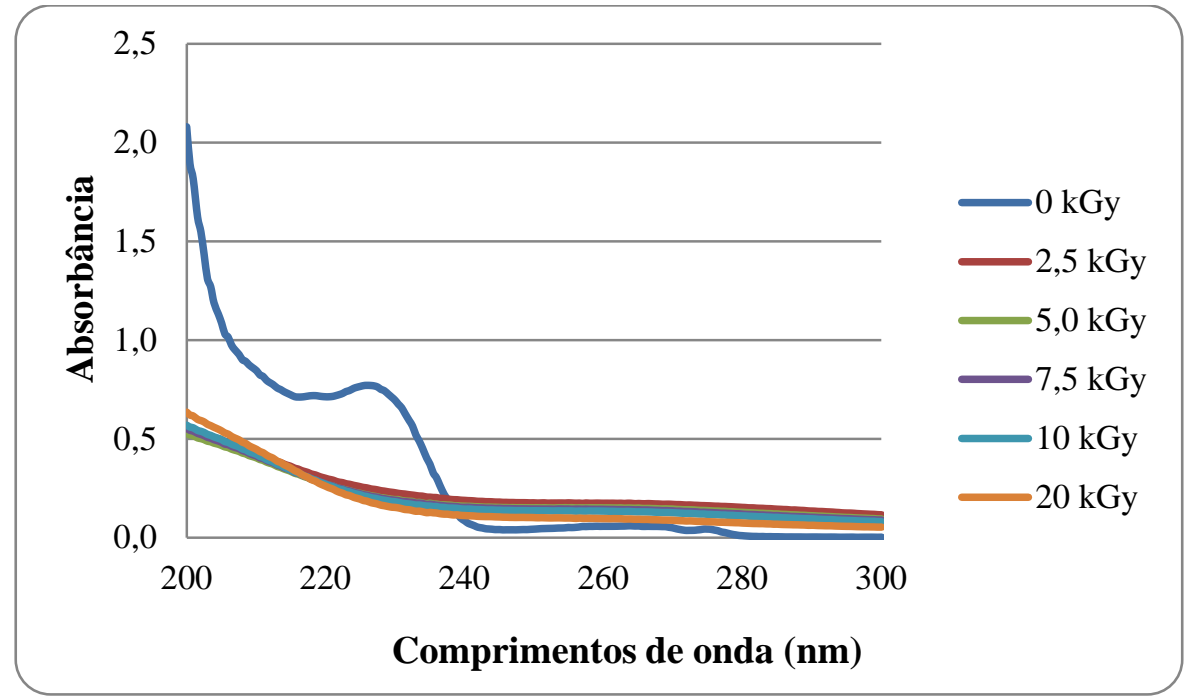

FIGURA 16. Espectros de absorção da solução de cloridrato de fluoxetina irradiadas e não irradiada.

Após a irradiação das amostras do fármaco observou-se que quanto maior a dose de radiação menor a absorbância na faixa de $226 \mathrm{~nm}$ (FIGURA 16). O mesmo fato ocorreu no trabalho de Santos (2012), onde o autor discute que tal fato pode estar associado à quebra das ligações duplas presentes na molécula do fármaco, indicando que o processo de irradiação pode agir sobre essas ligações duplas e modificar a molécula precursora.

No trabalho de Homlok et al. (2011) verificou-se uma modificação na faixa de absorbância para o fármaco diclofenaco, após a irradiação em solução aquosa, associada a esta possível modificação estrutural da molécula precursora.

A abertura do anel aromático e a formação de compostos de baixo peso molecular são modificações comuns na degradação de moléculas aromáticas (Guo et al., 2012; Karci et al., 2012).

\subsubsection{Cromatografia Líquida Ultra Rápida com detecção UV/VIS}

A análise de Cromatografia Líquida Ultra Rápida com detector UV/VIS não foi o método mais adequado para este estudo. A baixa absortividade molar do fármaco $\left(\varepsilon=12443 \mathrm{~L} \mathrm{~mol}^{-1} \mathrm{~cm}^{-1}\right)$ para a faixa do UV/VIS implicou em limites de detecção e quantificação muito elevados o que acarretou na não detecção do fármaco após o processamento por irradiação $\left(\mathrm{LD}=21,0 \mathrm{mg} \mathrm{L}^{-1} \mathrm{e} \mathrm{LQ}=63,8 \mathrm{mg} \mathrm{L}^{-1}\right)$. 
Para a Cromatografia Líquida Ultra Rápida com detector UV/VIS foram realizadas análises em triplicatas, obtendo-se os valores médios e os desvios padrões apresentados na curva analítica da FIGURA 17.

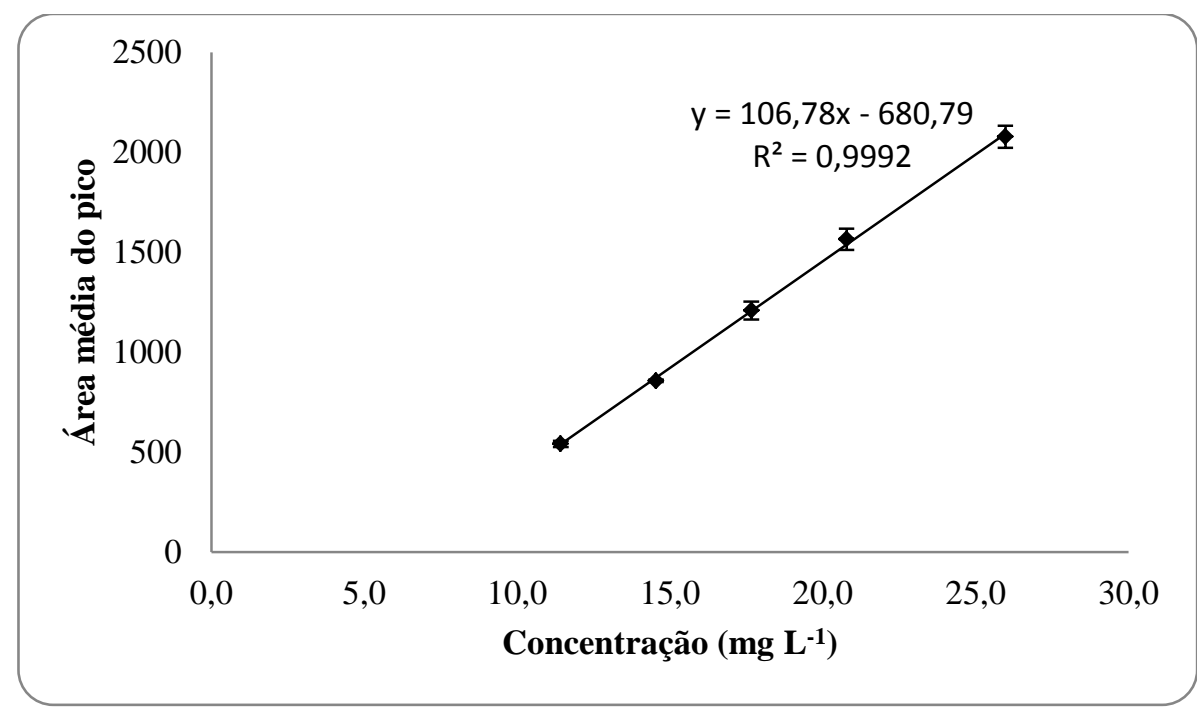

FIGURA 17. Curva analítica obtida por Cromatografia Líquida Ultra Rápida com detector UV/VIS no intervalo de 11,0 - 25,0 $\mathrm{mg} \mathrm{L}^{-1}$ para o cloridrato de fluoxetina.

\subsubsection{Cromatografia Líquida Ultra Rápida com detecção de fluorescência}

A utilização do detector de fluorescência aumentou a sensibilidade em 1000 vezes, diminuindo assim os valores dos limites de detecção (LD) e quantificação (LQ).

Foram feitas duas curvas analíticas, com análises em triplicatas, uma com concentrações entre 0,05 - 24,0 $\mathrm{mg} \mathrm{L}^{-1}$, (FIGURA 18) com volume de injeção de amostra de $7 \mu \mathrm{L},\left(\mathrm{LD}=0,53 \mathrm{mg} \mathrm{L}^{-1}\right.$ e $\left.\mathrm{LQ}=1,61 \mathrm{mg} \mathrm{L}^{-1}\right)$ e outra para concentrações menores de

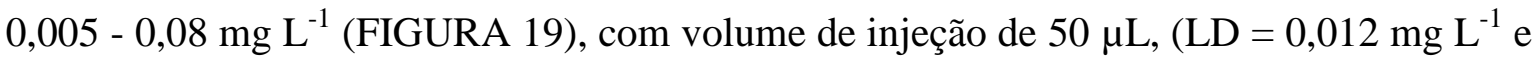
$\mathrm{LQ}=0,035 \mathrm{mg} \mathrm{L}^{-1}$ ). Foi necessária a construção da segunda curva analítica, pois com o volume de injeção de $7 \mu \mathrm{L}$ da amostra irradiada não foi possível detectar o cloridrato de fluoxetina residual. 


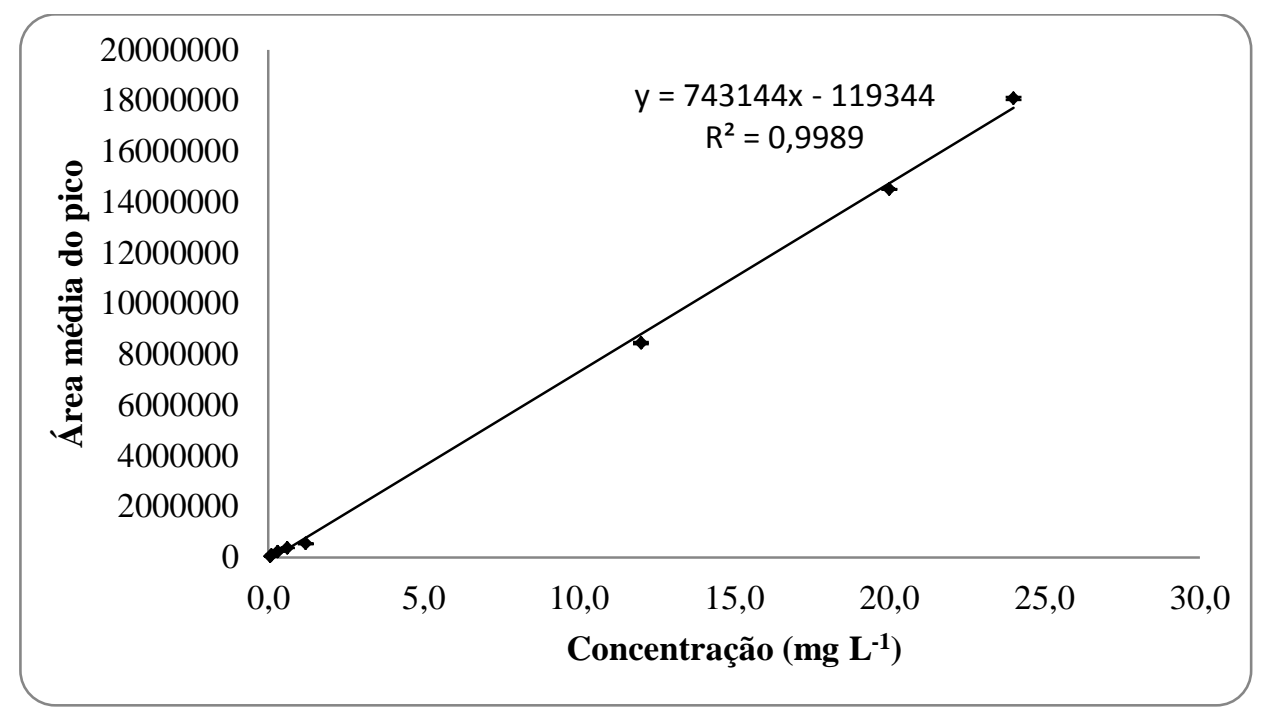

FIGURA 18. Curva analítica obtida por Cromatografia Líquida Ultra Rápida com detector fluorescência no intervalo de $0,05-24,0 \mathrm{mg} \mathrm{L}^{-1}$ para o cloridrato de fluoxetina.

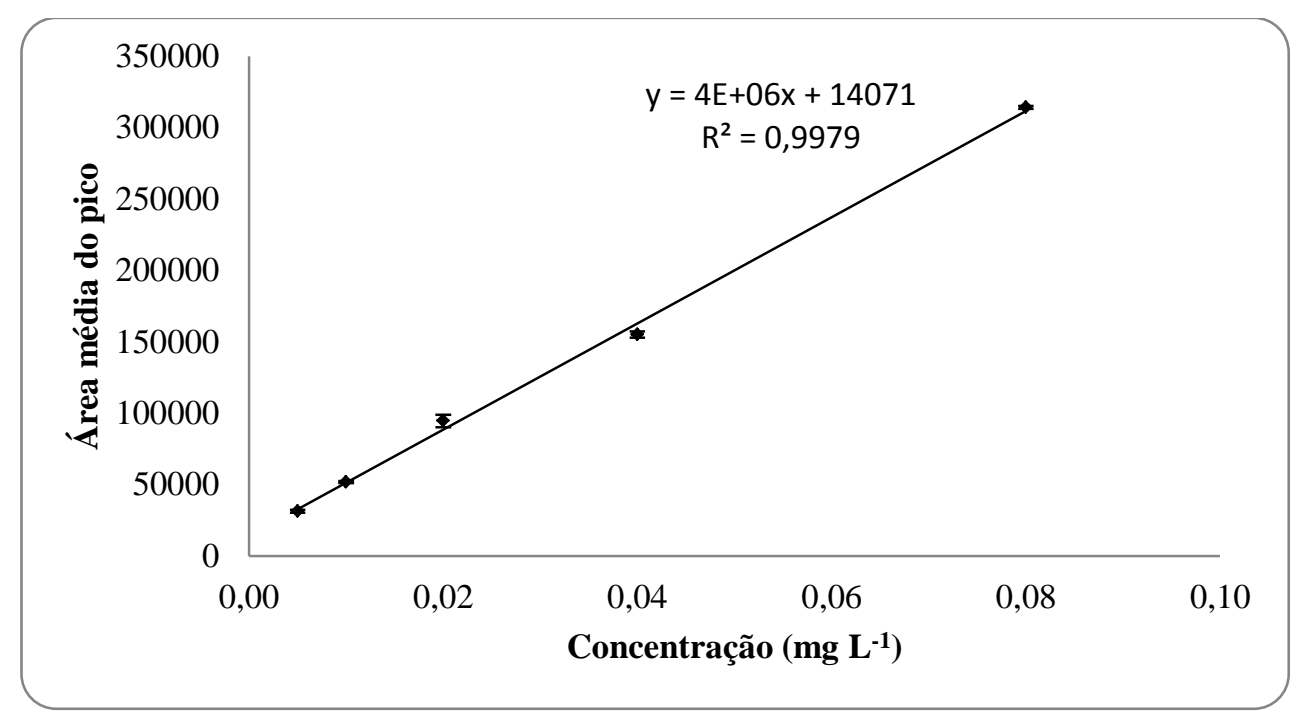

FIGURA 19. Curva analítica obtida por Cromatografia Líquida Ultra Rápida com detector fluorescência no intervalo de $0,005-0,08 \mathrm{mg} \mathrm{L}^{-1}$ para o cloridrato de fluoxetina.

Observou-se que nas doses de 0,5; 1,0 e 2,0 houve a formação de substâncias intermediárias capazes de serem detectados pelo detector de fluorescência (todos os picos nos cromatogramas que não correspondem ao do cloridrato de fluoxetina). Nas amostras que receberam doses mais elevadas, apesar de não apresentar picos de detecção de substâncias intermediárias pode haver substâncias não fluorescentes ou com baixa sensibilidade ao detector por fluorescência (FIGURA 20). 

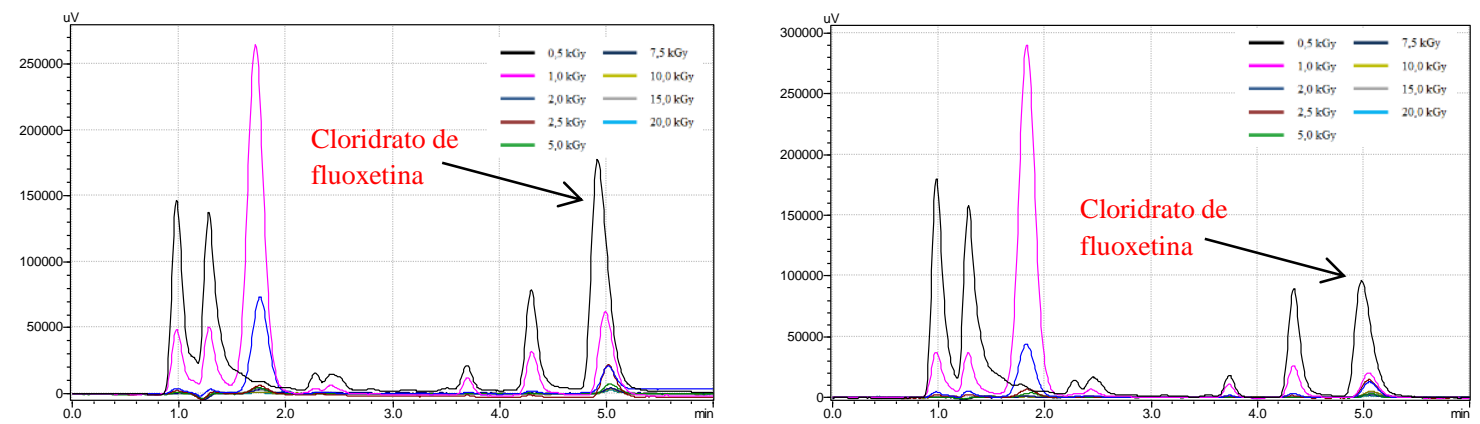

FIGURA 20. Cromatogramas dos ensaios 1 e 2 das amostras de cloridrato de fluoxetina irradiadas em diferentes doses obtidos pela Cromatografia Líquida Ultra Rápida com detector de fluorescência.

Diversos trabalhos utilizaram o detector UV/VIS para a determinação do fármaco fluoxetina, no estudo de El-Dawy et al. (2002) o limite de detecção (LD) foi de $5 \mu \mathrm{g} \mathrm{L}{ }^{-1}$. Outros estudos apresentaram faixa de linearidade em concentrações de $\mu \mathrm{g} \mathrm{mL}^{-1}$ (Gelbhar Bertholdi et al., 2001; Fregonezi-Nery et al., 2008).

Utilizando a espectroscopia de fluorescência para o cloridrato de fluoxetina com as propriedades de emissão da fluorescência (excitação de $230 \mathrm{~nm}$ e emissão de $290 \mathrm{~nm}$ ) foi possível construir uma curva analítica no intervalo de concentração de 50 a $500 \mathrm{ng} \mathrm{mL}^{-1}$ com valores de limites de detecção e quantificação (LD e LQ) de $15 \mathrm{ng} \mathrm{mL}^{-1} \mathrm{e}$ $48 \mathrm{ng} \mathrm{mL} \mathrm{mL}^{-1}$, respectivamente. Ou seja, o método por fluorescência apresentou alta sensibilidade ao cloridrato de fluoxetina (Ricachenevsky et al., 2007).

$\mathrm{Na}$ TABELA 6 foram apresentadas as concentrações de CF residual para as diversas doses aplicadas, verificou-se que na menor dose $(0,5 \mathrm{kGy})$ a eficiência média foi de $98,02 \%$ e a partir de 5,0 kGy a concentração residual do fármaco ficou abaixo do Limite de Detecção apresentando eficiências acima de 99,94\%, notou-se que mesmo em baixas doses de radiação já se verificou a degradação do fármaco.

No trabalho de Santoke et al. (2012), onde foram avaliadas a degradação dos antidepressivos duloxetina, venlafaxina e bupropiona atráves de radiação gama obteve-se as respectivas eficiências da degradação 73,7\%; 46,3 \% e 18,4 \% (água pura) e 71,8\%; $43,6 \%$ e $18,1 \%$ (água natural). 
TABELA 6. Valores da área do pico, concentração $\left(\mathrm{mg} \mathrm{L}^{-1}\right)$ e eficiência na redução do fármaco CF em relação as doses de irradiação.

\begin{tabular}{|c|c|c|c|c|c|c|c|c|}
\hline & \multicolumn{3}{|c|}{ Ensaio 1 } & \multicolumn{3}{|c|}{ Ensaio 2} & \multicolumn{2}{|c|}{ Valores médios } \\
\hline $\begin{array}{l}\text { Dose } \\
\text { (kGy) }\end{array}$ & $\begin{array}{c}\text { Área do } \\
\text { pico }\end{array}$ & $\begin{array}{c}\text { Conc. } \\
\left(\mathrm{mg} \mathrm{L}^{-1}\right)\end{array}$ & $\begin{array}{c}\text { Eficiência } \\
(\%)\end{array}$ & $\begin{array}{c}\text { Área do } \\
\text { pico }\end{array}$ & $\begin{array}{c}\text { Conc. } \\
\left(\mathrm{mg} \mathrm{L}^{-1}\right)\end{array}$ & $\begin{array}{c}\text { Eficiência } \\
(\%)\end{array}$ & $\begin{array}{c}\text { Concentração } \\
X \pm S\end{array}$ & $\begin{array}{c}\text { Eficiência } \\
X \pm S\end{array}$ \\
\hline 0,0 & 14184237 & 19,250 & - & 14368473 & 19,500 & - & $19,37 \pm 0,18$ & - \\
\hline 0,5 & 1979225 & 0,491 & 97,45 & 1114710 & 0,275 & 98,59 & $0,38 \pm 0,15$ & $98,02 \pm 0,81$ \\
\hline 1,0 & 637983 & 0,156 & 99,19 & 231929 & 0,054 & 99,72 & $0,10 \pm 0,07$ & $99,46 \pm 0,38$ \\
\hline 2,0 & 258080 & 0,061 & 99,68 & 151711 & 0,034 & 99,82 & $0,05 \pm 0,02$ & $99,75 \pm 0,01$ \\
\hline 2,5 & 235285 & 0,055 & 99,71 & 137073 & 0,031 & 99,84 & $0,04 \pm 0,02$ & $99,78 \pm 0,09$ \\
\hline 5,0 & 82261 & 0,017 & 99,91 & 39435 & $<\mathrm{LD}^{*}$ & $>99,94$ & $<\mathbf{L D} *$ & $>99,94$ \\
\hline 7,5 & 41585 & $<\mathrm{LD}^{*}$ & $>99,94$ & 38945 & $<\mathrm{LD}^{*}$ & $>99,94$ & $<\mathbf{L D} *$ & $>99,94$ \\
\hline 10,0 & 38358 & $<\mathrm{LD}^{*}$ & $>99,94$ & 38321 & $<\mathrm{LD}^{*}$ & $>99,94$ & $<\mathbf{L D}^{*}$ & $>99,94$ \\
\hline 15,0 & 37201 & $<\mathrm{LD}^{*}$ & $>99,94$ & 37761 & $<\mathrm{LD}^{*}$ & $>99,94$ & $<\mathbf{L D} *$ & $>99,94$ \\
\hline 20,0 & 22873 & $<\mathrm{LD}^{*}$ & $>99,94$ & 15484 & $<\mathrm{LD}^{*}$ & $>99,94$ & $<\mathbf{L D} *$ & $>99,94$ \\
\hline
\end{tabular}

* < LD: As amostras apresentaram concentração menor que o Limite de Detecção $\left(0,012 \mathrm{mg} \mathrm{L}^{-1}\right)$.

\subsubsection{Análises de Carbono Orgânico Total (COT)}

Através da análise de Carbono Orgânico Total observou-se que houve baixa mineralização do cloridrato de fluoxetina. Na concentração inicial de $20,0 \mathrm{mg} \mathrm{L}^{-1}$ de $\mathrm{CF}$, há aproximadamente $13,0 \mathrm{mg} \mathrm{L}^{-1}$ de carbono orgânico total em solução aquosa. Nestas condições, 22\% do COT foi mineralizado após a irradiação com 20,0 kGy (FIGURA 21).

A remoção incompleta de COT durante o processo de degradação utilizando a irradiação por feixe de elétrons também foi relatado anteriormente para corantes em solução aquosa (Abdou et al., 2011; Paul et al., 2011; Pinheiro, 2011). 


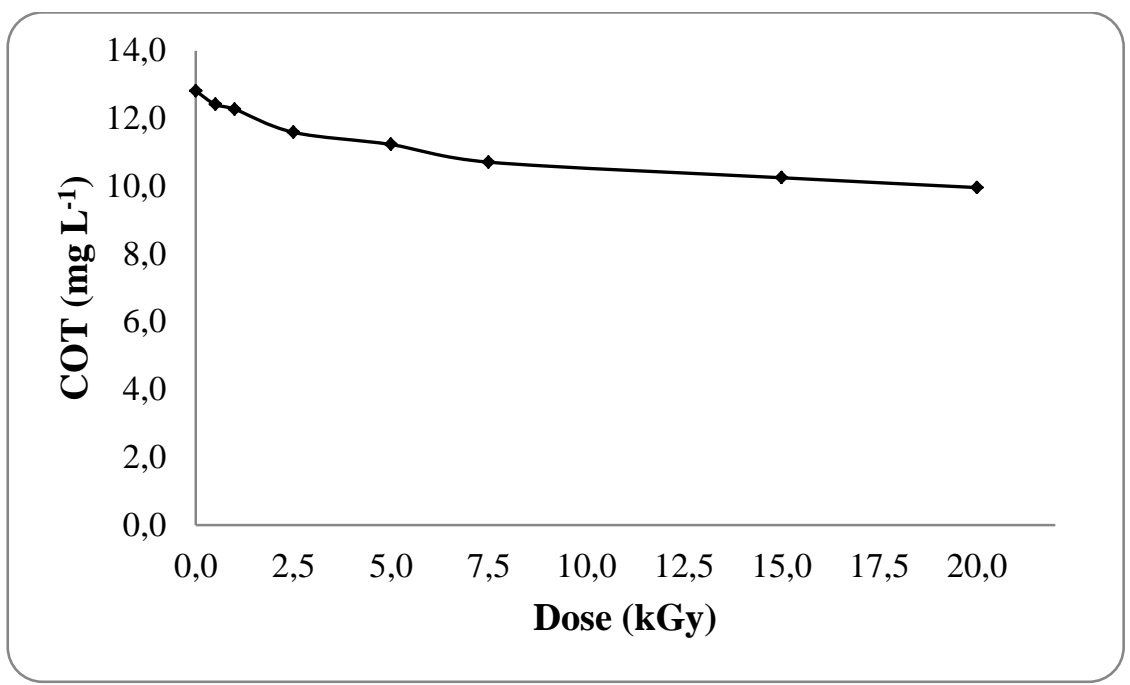

FIGURA 21. Quantificação do Carbono Orgânico Total em diferentes doses de radiação.

O tratamento com radiação ionizante por acelerador de elétrons demonstrou alta eficiência na degradação da molécula, porém baixa capacidade de mineralização dos compostos orgânicos, este efeito também foi verificado no trabalho de Homlok et al. (2011) para o fármaco diclofenaco. Para a mineralização dos produtos há necessidade de altas doses de irradiação, ou a combinação com outros tipos de tratamento.

\subsection{Ensaios de toxicidade}

\subsubsection{Ensaios de toxicidade aguda para Daphnia similis}

Para os ensaios de toxicidade aguda com Daphnia similis, estes foram realizados com amostras do cloridrato de fluoxetina, esgoto doméstico (bruto) e mistura (CF + esgoto), não irradiada e irradiadas nas doses de 5,0 kGy e 20,0 kGy. Os ensaios 1, 2 e 3 foram realizados com solução de $10,0 \mathrm{mg} \mathrm{L}^{-1}$ de $\mathrm{CF}$, os ensaios 4 e 5 foram realizados com solução de 10,0 mg L ${ }^{-1}$ de CF com correção de pH e os ensaios 6 e 7 com solução de $20,0 \mathrm{mg} \mathrm{L}^{-1}$, houve aumento da concentração pela necessidade de concentração mais alta para as análises químicas. 
TABELA 7. Valores de pH, oxigênio dissolvido (OD) e condutividade das amostras de cloridrato de fluoxetina utilizadas nos ensaios com Daphnia similis.

\begin{tabular}{|c|c|c|c|c|}
\hline $\begin{array}{l}\text { Doses } \\
(\mathrm{kGy})\end{array}$ & Ensaio & $\mathrm{pH}$ & $\begin{array}{c}\text { Oxigênio dissolvido } \\
\left(\mathrm{mg} \mathrm{L}^{-1}\right)\end{array}$ & $\begin{array}{c}\text { Condutividade } \\
\left(\mu \mathrm{S} \mathrm{cm}^{-1}\right)\end{array}$ \\
\hline \multirow[t]{7}{*}{0,0} & 1 & 6,68 & 8,02 & 14,7 \\
\hline & 2 & 7,00 & 9,01 & 7,8 \\
\hline & 3 & 6,66 & 6,55 & 5,2 \\
\hline & $X \pm S$ & $6,78 \pm 0,19$ & $7,86 \pm 1,24$ & $9,2 \pm 4,9$ \\
\hline & 6 & 6,42 & 7,72 & 8,9 \\
\hline & 7 & 7,14 & 8,63 & 11,0 \\
\hline & $X \pm S$ & $6,78 \pm 0,51$ & $8,17 \pm 0,64$ & $9,9 \pm 1,5$ \\
\hline \multirow[t]{3}{*}{0,5} & 6 & 4,20 & 8,49 & 40,2 \\
\hline & 7 & 4,25 & 8,47 & 39,2 \\
\hline & $X \pm S$ & $4,22 \pm 0,04$ & $8,48 \pm 0,01$ & $39,7 \pm 0,71$ \\
\hline \multirow[t]{7}{*}{5,0} & 1 & 4,21 & 8,29 & 40,4 \\
\hline & 2 & 4,19 & 7,80 & 40,5 \\
\hline & 3 & 4,01 & 7,00 & 39,6 \\
\hline & $\mathrm{X} \pm \mathrm{S}$ & $4,14 \pm 0,11$ & $7,70 \pm 0,65$ & $40,2 \pm 0,5$ \\
\hline & 6 & 4,00 & 7,99 & 56,2 \\
\hline & 7 & 3,94 & 7,84 & 55,3 \\
\hline & $X \pm S$ & $3,97 \pm 0,04$ & $7,91 \pm 0,11$ & $55,7 \pm 0,6$ \\
\hline \multirow[t]{7}{*}{20,0} & 1 & 4,04 & 8,03 & 52,6 \\
\hline & 2 & 4,19 & 7,80 & 40,5 \\
\hline & 3 & 3,77 & 7,05 & 52,5 \\
\hline & $X \pm S$ & $4,00 \pm 0,21$ & $7,63 \pm 0,51$ & $48,5 \pm 7,0$ \\
\hline & 6 & 3,80 & 7,84 & 83,8 \\
\hline & 7 & 3,74 & 7,94 & 91,7 \\
\hline & $X \pm S$ & $3,77 \pm 0,04$ & $7,89 \pm 0,07$ & $87,7 \pm 5,6$ \\
\hline
\end{tabular}

TABELA 8. Valores de pH, oxigênio dissolvido (OD) e condutividade das amostras do esgoto bruto utilizadas nos ensaios com Daphnia similis.

\begin{tabular}{c|c|c|c|c}
\hline $\begin{array}{c}\text { Doses } \\
(\mathrm{kGy})\end{array}$ & Ensaio & $\mathrm{pH}$ & $\begin{array}{c}\text { Oxigênio dissolvido } \\
\left(\mathrm{mg} \mathrm{L}^{-1}\right)\end{array}$ & $\begin{array}{c}\text { Condutividade } \\
\left(\mu \mathrm{Sm}^{-1}\right)\end{array}$ \\
\hline \multirow{4}{*}{0,0} & 1 & 7,91 & 7,46 & 694,0 \\
\cline { 2 - 5 } & 2 & 8,09 & 6,61 & 667,0 \\
\cline { 2 - 5 } & 3 & 7,84 & 6,26 & 683,0 \\
\cline { 2 - 5 } & $\mathbf{X} \pm \mathbf{S}$ & $\mathbf{7 , 9 5} \pm \mathbf{0 , 1 3}$ & $\mathbf{6 , 7 7} \pm \mathbf{0 , 6 2}$ & $\mathbf{6 8 1 , 3} \pm \mathbf{1 3 , 6}$ \\
\hline \multirow{4}{*}{5,0} & 1 & 8,02 & 7,78 & 684,0 \\
\cline { 2 - 5 } & 2 & 7,85 & 8,04 & 686,0 \\
\cline { 2 - 5 } & 3 & 8,08 & 6,63 & 63,0 \\
\cline { 2 - 5 } & $\mathbf{X} \pm \mathbf{S}$ & $\mathbf{7 , 9 8} \pm \mathbf{0 , 1 2}$ & $\mathbf{7 , 4 8} \pm \mathbf{0 , 7 5}$ & 668,0 \\
\hline \multirow{5}{*}{20,0} & 1 & 8,08 & 7,77 & 695,0 \\
\cline { 2 - 5 } & 2 & 7,86 & 7,24 & 682,0 \\
\cline { 2 - 5 } & 3 & 8,05 & 6,96 & $\mathbf{6 8 1 , 7} \pm \mathbf{1 3 , 5}$ \\
\cline { 2 - 5 } & $\mathbf{X} \pm \mathbf{S}$ & $\mathbf{8 , 0 0} \pm \mathbf{0 , 1 2}$ & $\mathbf{7 , 3 2} \pm \mathbf{0 , 4 1}$ & $\mathbf{6 9 2 , 7}$ \\
\hline
\end{tabular}


TABELA 9. Valores de pH, oxigênio dissolvido (OD) e condutividade das amostras de mistura (CF + esgoto) utilizadas nos ensaios com Daphnia similis.

\begin{tabular}{c|c|c|c|c}
\hline $\begin{array}{c}\text { Doses } \\
(\mathrm{kGy})\end{array}$ & Ensaio & $\mathrm{pH}$ & $\begin{array}{c}\text { Oxigênio dissolvido } \\
\left(\mathrm{mg} \mathrm{L}^{-1}\right)\end{array}$ & $\begin{array}{c}\text { Condutividade } \\
\left(\mu \mathrm{Sm}^{-1}\right)\end{array}$ \\
\hline \multirow{4}{*}{0,0} & 1 & 7,77 & 7,90 & 585,0 \\
\cline { 2 - 5 } & 2 & 7,83 & 6,63 & 581,0 \\
\cline { 2 - 5 } & 3 & 7,87 & 6,48 & 580,0 \\
\cline { 2 - 5 } & $\mathbf{X} \pm \mathbf{S}$ & $\mathbf{7 , 8 2} \pm \mathbf{0 , 0 5}$ & $\mathbf{7 , 0 0} \pm \mathbf{0 , 7 8}$ & $\mathbf{5 8 2 , 0} \pm \mathbf{2 , 6}$ \\
\hline \multirow{5}{*}{5,0} & 1 & 7,92 & 7,63 & 575,0 \\
\cline { 2 - 5 } & 2 & 7,97 & 7,87 & 573,0 \\
\cline { 2 - 5 } & 3 & 7,98 & 6,16 & 571,0 \\
\cline { 2 - 5 } & $\mathbf{X} \pm \mathbf{S}$ & $\mathbf{7 , 9 6} \pm \mathbf{0 , 0 3}$ & $\mathbf{7 , 2 2} \pm \mathbf{0 , 9 2}$ & $573, \mathbf{0} \pm \mathbf{2 , 0}$ \\
\hline \multirow{5}{*}{20,0} & 1 & 7,83 & 8,18 & 537,0 \\
\cline { 2 - 5 } & 2 & 7,83 & 6,70 & 546,0 \\
\cline { 2 - 5 } & 3 & 7,79 & 6,28 & $\mathbf{5 4 7 , 0} \pm \mathbf{1 0 , 5}$ \\
\cline { 2 - 5 } & $\mathbf{X} \pm \mathbf{S}$ & $\mathbf{7 , 8 2} \pm \mathbf{0 , 0 2}$ & $\mathbf{7 , 0 5} \pm \mathbf{1 , 0 0}$ & \\
\hline
\end{tabular}

Nas TABELAS 7, 8 e 9 foram apresentados os valores de $\mathrm{pH}$, oxigênio dissolvido e condutividade das soluções iniciais de $\mathrm{CF}$, esgoto bruto e mistura, respectivamente, utilizadas nos ensaios com Daphnia similis. Os valores dos parâmetros físico-químico das diluições iniciais e finais (submetidas ao ensaio de 48 horas) e das amostras que tiveram o $\mathrm{pH}$ corrigido, foram apresentados no APÊNDICE A.

Verificou-se diminuição dos valores de pH e um aumento nos valores de condutividade com o aumento da dose para as amostras de CF (TABELA 7), estes dados serão discutidos adiante

Para as amostras de esgoto bruto e mistura não houve variações significativas entre os parâmetros físico-químicos analisados (TABELAS 8 e 9). 
TABELA 10. Valores de CE $50_{48 \mathrm{~h}}\left(\%\right.$ e mg L $\left.\mathrm{L}^{-1}\right)$, UT e eficiência do processo (\%) das amostras de cloridrato de fluoxetina para Daphnia similis.

\begin{tabular}{|c|c|c|c|c|c|}
\hline $\begin{array}{l}\text { Doses } \\
(\mathrm{kGy})\end{array}$ & Ensaio & $\mathrm{CE} 0_{48 \mathrm{~h}}(\%)$ & $\overline{\mathrm{UT}}$ & $\mathrm{CE} 50_{48 \mathrm{~h}}\left(\mathrm{mg} \mathrm{L}^{-1}\right)$ & $\begin{array}{c}\text { Eficiência } \\
(\%)\end{array}$ \\
\hline \multirow[t]{7}{*}{0,0} & 1 & $11,46(9,47-13,88)$ & 8,73 & 1,15 & - \\
\hline & 2 & $15,93(13,01-19,51)$ & 6,28 & 1,59 & - \\
\hline & 3 & $11,00(9,53-12,71)$ & 9,09 & 1,10 & - \\
\hline & $\mathrm{X} \pm \mathrm{S}$ & $12,80 \pm 2,72$ & $8,03 \pm 1,53$ & $1,28 \pm 0,30$ & - \\
\hline & 6 & $6,82(4,86-9,57)$ & 14,66 & 1,36 & - \\
\hline & 7 & $6,75(4,97-9,16)$ & 14,81 & 1,35 & - \\
\hline & $X \pm S$ & $6,78 \pm 0,05$ & $14,73 \pm 0,11$ & $1,35 \pm 0,01$ & - \\
\hline \multirow[t]{3}{*}{0,5} & 6 & $43,73(38,03-50,28)$ & 2,29 & - & 84,37 \\
\hline & 7 & $39,98(34,43-46,43)$ & 2,50 & - & 83,12 \\
\hline & $X \pm S$ & $41,86 \pm 2,65$ & $2,40 \pm 0,15$ & - & $83,75 \pm 0,88$ \\
\hline \multirow[t]{7}{*}{5,0} & 1 & $74,00(68,32-80,14)$ & 1,35 & - & 84,51 \\
\hline & 2 & $76,71(71,24-82,60)$ & 1,30 & - & 79,23 \\
\hline & 3 & $70,11(63,76-77,08)$ & 1,43 & - & 84,27 \\
\hline & $X \pm S$ & $73,61 \pm 3,32$ & $\mathbf{1 , 3 6} \pm \mathbf{0 , 0 7}$ & - & $82,67 \pm 2,98$ \\
\hline & 6 & $49,16(43,58-55,44)$ & 2,03 & - & 86,13 \\
\hline & 7 & $57,96(53,85-62,40)$ & 1,73 & - & 88,35 \\
\hline & $X \pm S$ & $53,56 \pm 6,22$ & $1,88 \pm 0,21$ & - & $87,24 \pm 1,57$ \\
\hline \multirow[t]{7}{*}{20,0} & 1 & $71,57(66,26-77,31)$ & 1,40 & - & 83,99 \\
\hline & 2 & $72,82(67,39-78,69)$ & 1,37 & - & 78,12 \\
\hline & 3 & $68,09(63,40-73,13)$ & 1,47 & - & 83,83 \\
\hline & $\mathbf{X} \pm \mathrm{S}$ & $70,83 \pm 2,45$ & $1,41 \pm 0,05$ & - & $81,98 \pm 3,34$ \\
\hline & 6 & $58,77(53,71-64,30)$ & 1,70 & - & 88,40 \\
\hline & 7 & $59,58(56,47-62,85)$ & 1,68 & - & 88,67 \\
\hline & $\mathbf{X} \pm S$ & $59,17 \pm 0,57$ & $1,69 \pm 0,02$ & - & $88,53 \pm 0,19$ \\
\hline
\end{tabular}

Os valores obtidos de $\mathrm{CE}_{50} 0_{48 \mathrm{~h}}\left(\%\right.$ e mg L $\left.\mathrm{L}^{-1}\right)$, Unidade Tóxica (UT) e Eficiência do processo (\%), nos ensaios de 48 horas de exposição para Daphnia similis foram apresentados nas TABELAS 10 - 13 com os respectivos valores de médias e desvios

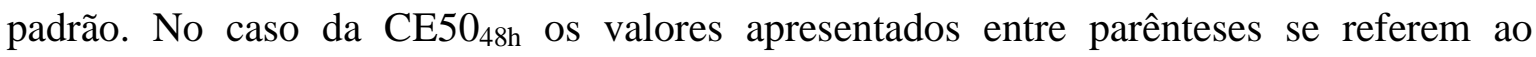
intervalo de confiança.

Na TABELA 10 foram apresentados os valores médios de UT para os ensaios realizados com o fármaco cloridrato de fluoxetina, foi possível verificar a redução da toxicidade entre a amostra não irradiada e as amostras irradiadas. Em relação a eficiência do processo, observou-se que não houve diferenças significativas entre as eficiências de redução em relação às doses aplicadas.

Determinou-se o valor médio de $\mathrm{CE}_{40} 0_{48 \mathrm{~h}}$ para os 5 ensaios com Daphnia similis onde obteve-se o valor de $1,31 \mathrm{mg} \mathrm{L}^{-1}$, este valor corrobora com os valores 
determinados por Santos (2012) onde a média dos valores de CE50 ${ }_{48 \mathrm{~h}}$ foi de 1,44 $\mathrm{mg} \mathrm{L}^{-1}$ (fármaco manipulado).

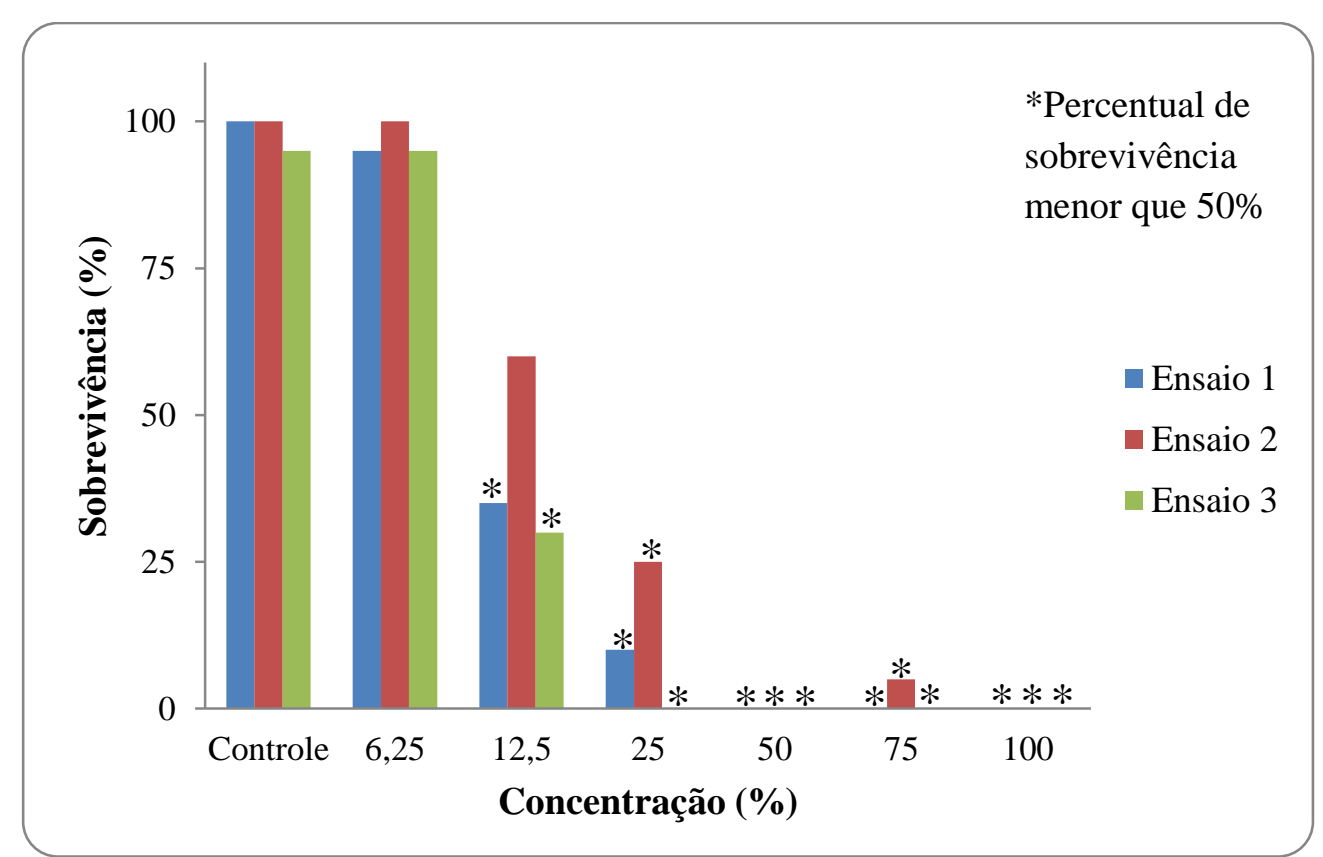

FIGURA 22. Percentual de sobrevivência do organismo Daphnia similis para o cloridrato de fluoxetina não irradiado.

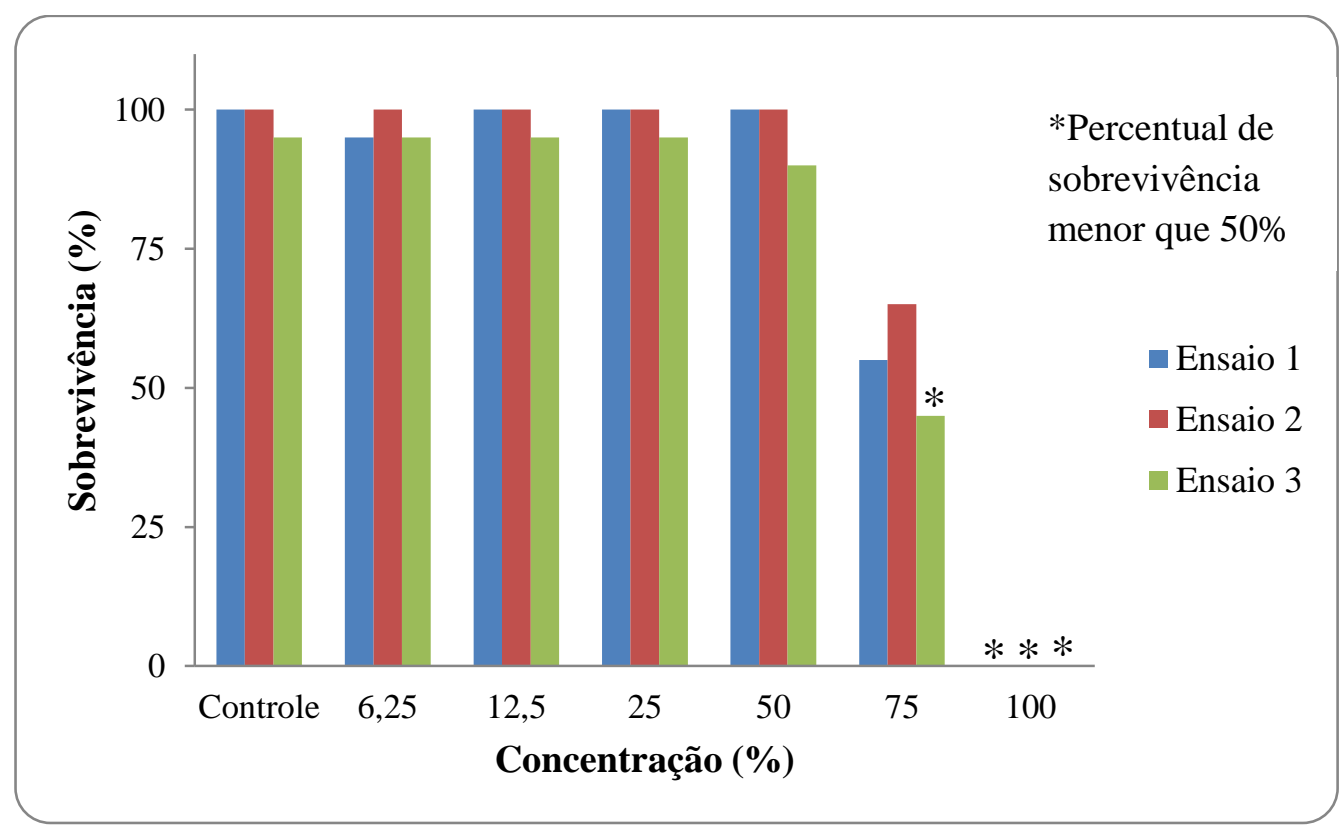

FIGURA 23. Percentual de sobrevivência do organismo Daphnia similis para o cloridrato de fluoxetina irradiado com 5,0 kGy. 


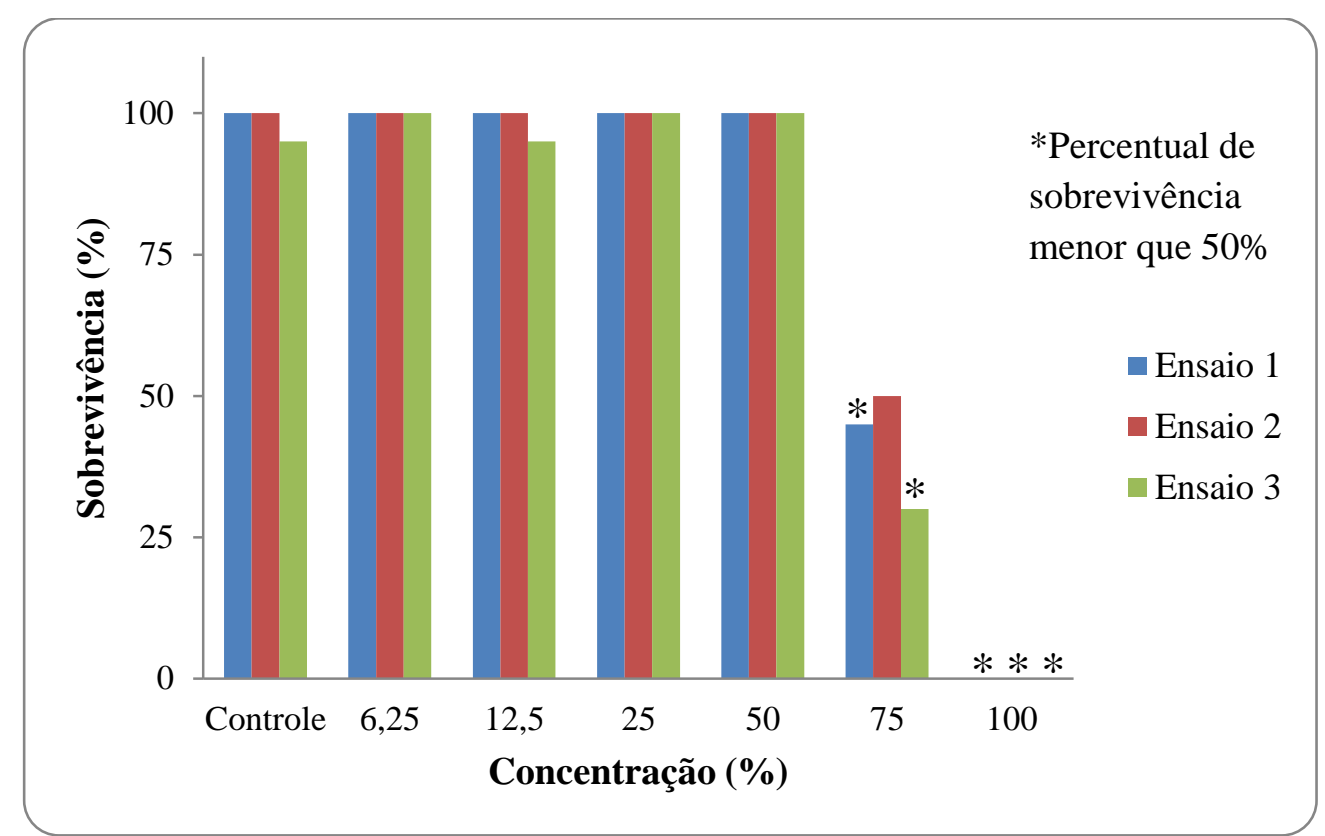

FIGURA 24. Percentual de sobrevivência do organismo Daphnia similis para o cloridrato de fluoxetina irradiado com 20,0 kGy.

$\mathrm{Na}$ FIGURA 22 foram apresentados os valores de porcentagem de sobrevivência versus as concentrações do CF utilizadas no estudo antes da irradiação e nas FIGURAS 23 e 24 estão apresentados os valores após as irradiações, foi possível verificar o aumento do nível de sobrevivência após a irradiação das amostras de cloridrato de fluoxetina.

TABELA 11. Valores de CE50 $48 \mathrm{~h}\left(\%\right.$ e $\left.\mathrm{mg} \mathrm{L}^{-1}\right)$, UT e eficiência do processo (\%) das amostras de cloridrato de fluoxetina ( $\mathrm{pH}$ corrigido) para Daphnia similis.

\begin{tabular}{c|c|c|c|c|c}
\hline $\begin{array}{c}\text { Doses } \\
(\mathrm{kGy})\end{array}$ & Ensaio & CE50 $48 \mathrm{~h}(\%)$ & UT & $\begin{array}{c}\text { CE50 } \\
\left(\mathrm{mg} \mathrm{L}^{-1}\right)\end{array}$ & Eficiência (\%) \\
\hline \multirow{2}{*}{0,0} & 4 & $13,87(11,96-16,08)$ & 7,21 & 1,39 & - \\
\cline { 2 - 6 } & 5 & $12,50(10,71-14,60)$ & 8,00 & 1,25 & - \\
\cline { 2 - 6 } & $\mathbf{X} \pm \mathbf{S}$ & $\mathbf{1 3 , 1 8} \pm \mathbf{0 , 9 7}$ & $\mathbf{7 , 6 0} \pm \mathbf{0 , 5 6}$ & $\mathbf{1 , 3 2} \pm \mathbf{0 , 1 0}$ & - \\
\hline \multirow{2}{*}{5,0} & 4 & $100,00\left(\mathrm{NT}^{*}\right)$ & $<1,00$ & - & 100,00 \\
\cline { 2 - 6 } & 5 & $100,00\left(\mathrm{NT}^{*}\right)$ & $<1,00$ & - & 100,00 \\
\cline { 2 - 6 } & $\mathbf{X} \pm \mathbf{S}$ & $\mathbf{1 0 0 , 0 0} \pm \mathbf{0 , 0 0}$ & $\mathbf{1 , 0 0} \pm \mathbf{0 , 0 0}$ & - & $\mathbf{1 0 0 , 0 0} \pm \mathbf{0 , 0 0}$ \\
\hline \multirow{2}{*}{20,0} & 4 & $100,00\left(\mathrm{NT}^{*}\right)$ & $<1,00$ & - & 100,00 \\
\cline { 2 - 6 } & 5 & $100,00\left(\mathrm{NT}^{*}\right)$ & $<1,00$ & - & 100,00 \\
\cline { 2 - 6 } & $\mathbf{X} \pm \mathbf{S}$ & $\mathbf{1 0 0 , 0 0} \pm \mathbf{0 , 0 0}$ & $\mathbf{1 , 0 0} \pm \mathbf{0 , 0 0}$ & - & $\mathbf{1 0 0 , 0 0} \pm \mathbf{0 , 0 0}$ \\
\hline
\end{tabular}

*NT= Não Tóxica

Na TABELA 11 foram apresentados os valores de CE50 $48 \mathrm{~h}\left(\%\right.$ e mg L $\left.{ }^{-1}\right)$, Unidade Tóxica (UT) e Eficiência do processo (\%) para a amostra com o valor de $\mathrm{pH}$ corrigido e concentração inicial de $10 \mathrm{mg} \mathrm{L}^{-1}$, foi possível verificar que tanto para a dose 
de 5,0 kGy quanto para a dose de 20,0 kGy as amostras não apresentaram toxicidade, o que indica que após o tratamento com irradiação devido a formação dos ácidos orgânicos há necessidade da correção do pH para melhorar a eficiência na remoção da toxicidade, uma vez que os organismos são sensíveis a valores de pH ácidos (Zhao et al., 1998).

TABELA 12. Valores de CE50 ${ }_{48 \mathrm{~h}}(\%)$, UT e eficiência do processo (\%) das amostras de esgoto bruto para Daphnia similis.

\begin{tabular}{c|c|c|c|c}
\hline $\begin{array}{c}\text { Doses } \\
(\mathrm{kGy})\end{array}$ & Ensaio & CE50 $_{48 \mathrm{~h}}(\%)$ & UT & $\begin{array}{c}\text { Eficiência } \\
(\%)\end{array}$ \\
\hline \multirow{2}{*}{0,0} & 1 & $44,57(37,09-53,54)$ & 2,24 & - \\
\cline { 2 - 5 } & 2 & $42,79(34,67-52,82)$ & 2,34 & - \\
\cline { 2 - 5 } & 3 & $40,10(32,55-49,39)$ & 2,49 & - \\
\cline { 2 - 5 } & $\mathbf{X} \pm \mathbf{S}$ & $\mathbf{4 2 , 4 9} \pm \mathbf{2 , 2 5}$ & $\mathbf{2 , 3 6} \pm \mathbf{0 , 1 2}$ & - \\
\hline \multirow{5}{*}{5,0} & 1 & $100,00\left(\mathrm{NT}^{*}\right)$ & $<1,00$ & 100,00 \\
\cline { 2 - 5 } & 2 & $100,00\left(\mathrm{NT}^{*}\right)$ & $<1,00$ & 100,00 \\
\cline { 2 - 5 } & 3 & $100,00\left(\mathrm{NT}^{*}\right)$ & $<1,00$ & 100,00 \\
\cline { 2 - 5 } & $\mathbf{X} \pm \mathbf{S}$ & $\mathbf{1 0 0 , 0 0} \pm \mathbf{0 , 0 0}$ & $\mathbf{1 , 0 0} \pm \mathbf{0 , 0 0}$ & $\mathbf{1 0 0 , 0 0} \pm \mathbf{0 , 0 0}$ \\
\hline \multirow{2}{*}{20,0} & 1 & $84,17(79,39-89,23)$ & 1,19 & 47,05 \\
\cline { 2 - 5 } & 2 & $76,59(60,63-96,74)$ & 1,30 & 44,44 \\
\cline { 2 - 5 } & 3 & $86,60(\mathrm{NC} * *)$ & 1,15 & 53,81 \\
\cline { 2 - 5 } & $\mathbf{X} \pm \mathbf{S}$ & $\mathbf{8 2 , 4 5} \pm \mathbf{5 , 2 2}$ & $\mathbf{1 , 2 1} \pm \mathbf{0 , 0 8}$ & $\mathbf{4 8 , 4 3} \pm \mathbf{4 , 8 3}$ \\
\hline
\end{tabular}

*NT= Não Tóxica e $* *$ NC= Não Calculável

Na TABELA 12 foram apresentados os dados referentes ao esgoto doméstico, apesar da diferença entre os valores de eficiência para as doses de 5,0 e 20,0 kGy os valores de $\mathrm{CE} 5_{48 \mathrm{~h}}$ foram considerados como Não Tóxicos. Com os valores médios e desvio padrão de UT e eficiência obtidos para as amostras de esgoto bruto também foi possível verificar a redução da toxicidade para as amostras do esgoto irradiadas. 


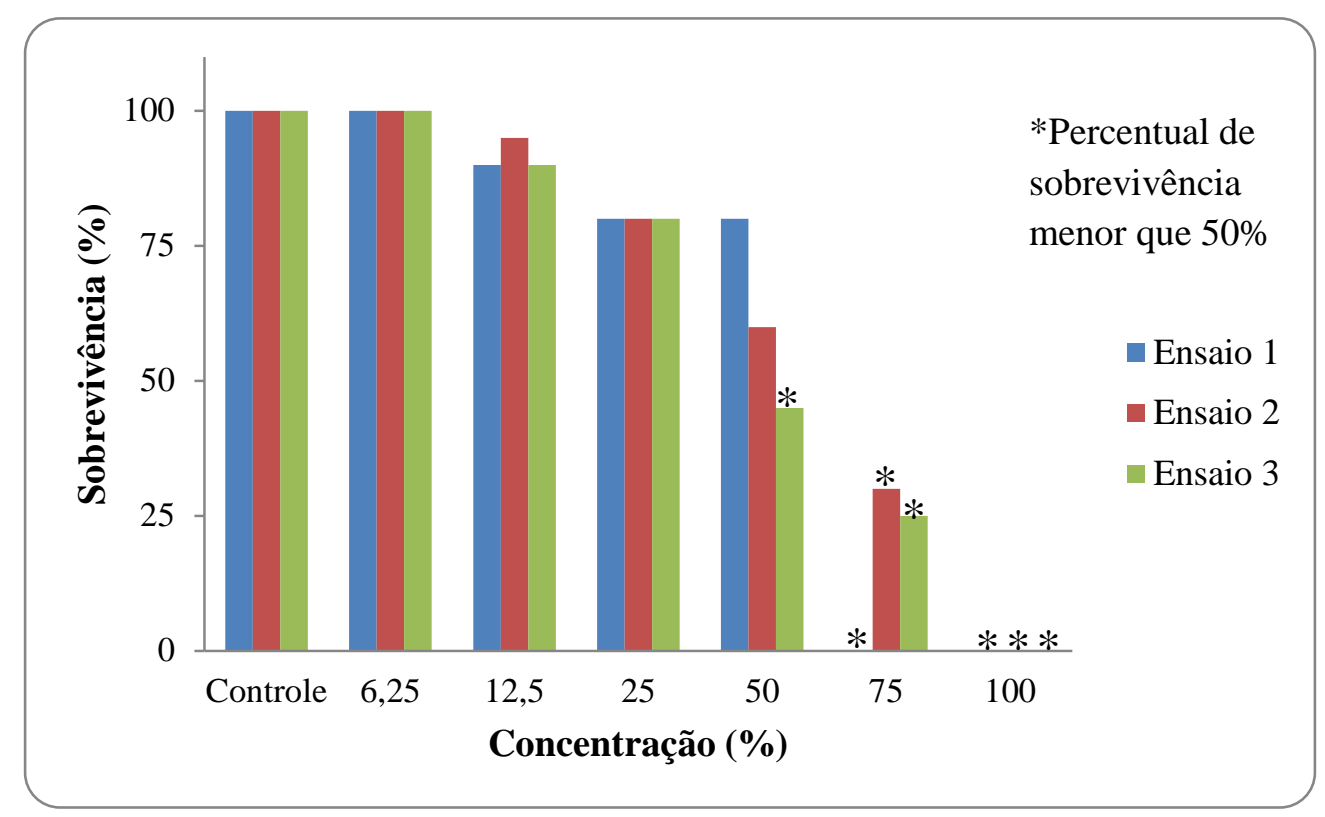

FIGURA 25. Percentual de sobrevivência do organismo Daphnia similis para o esgoto bruto não irradiado.

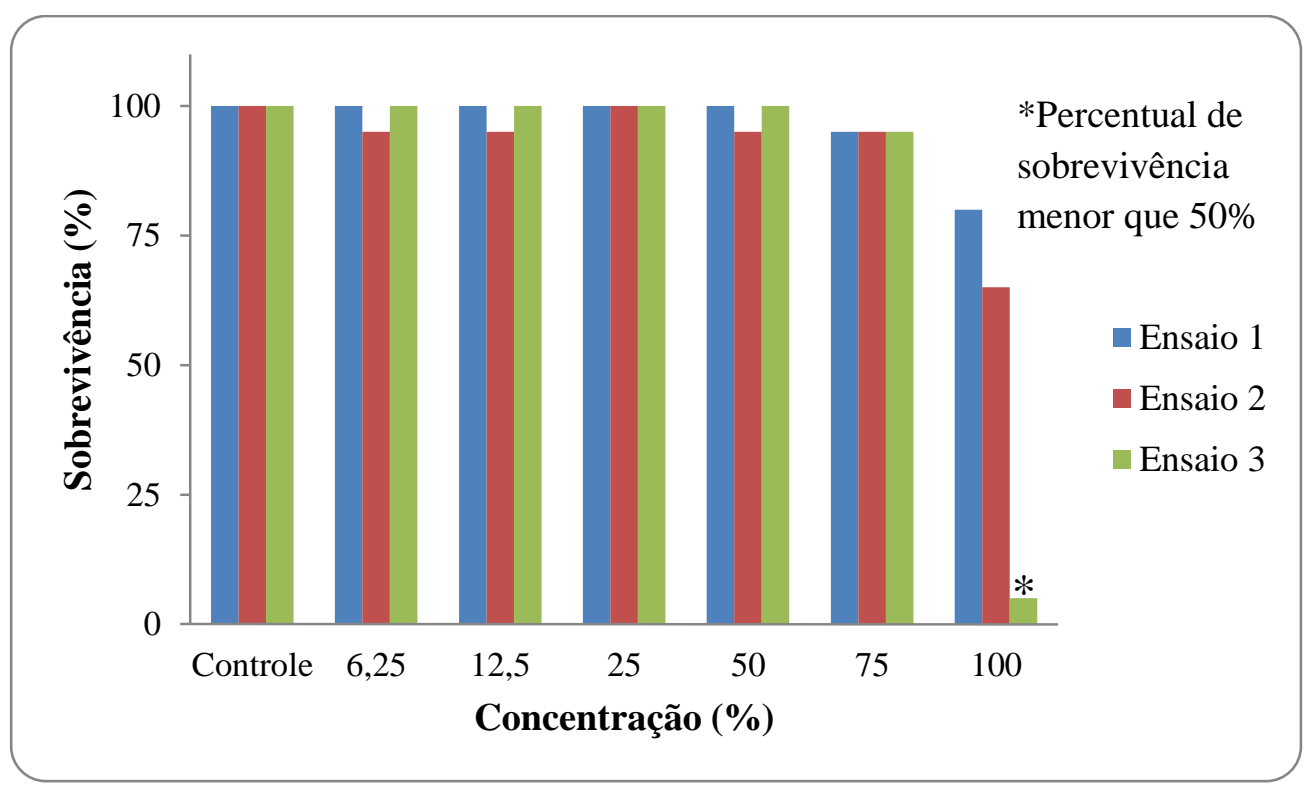

FIGURA 26. Percentual de sobrevivência do organismo Daphnia similis para o esgoto bruto irradiado com 5,0 kGy. 


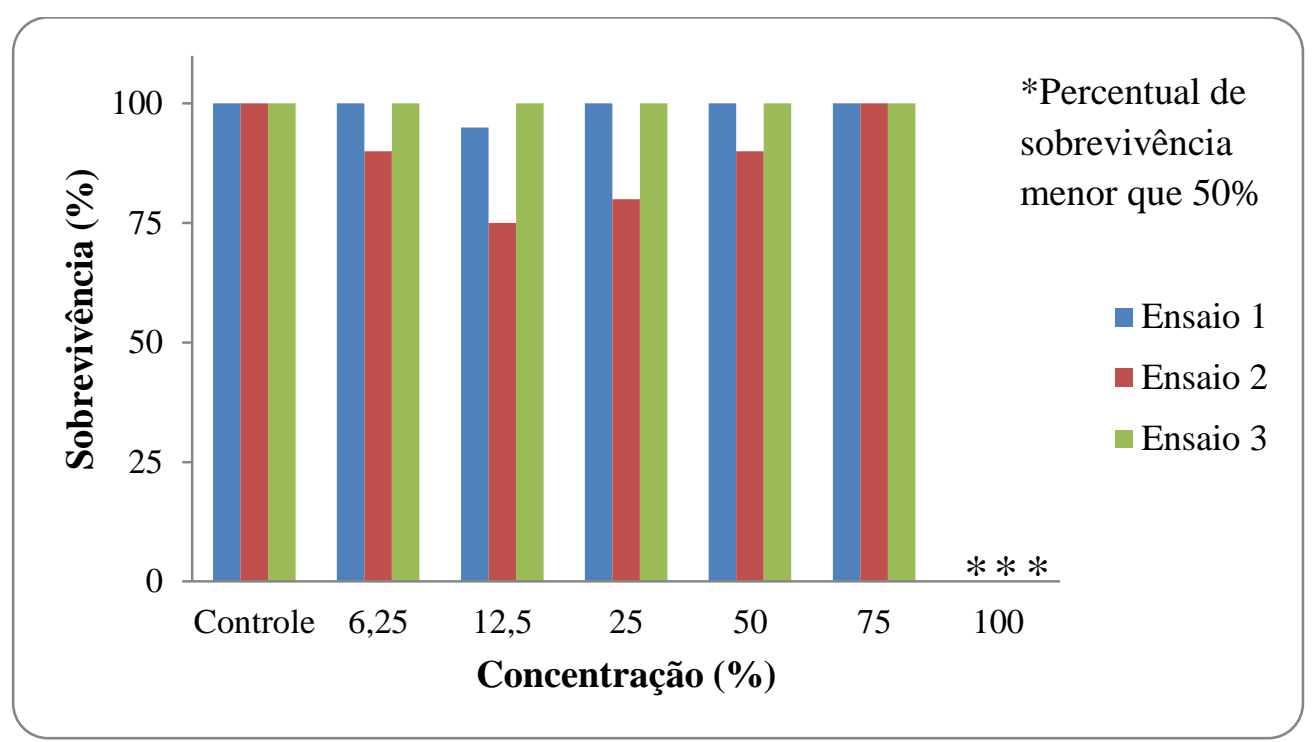

FIGURA 27. Percentual de sobrevivência do organismo Daphnia similis para o esgoto bruto irradiado com 20,0 kGy.

Nas FIGURAS 25, 26 e 27 foram apresentados os valores de porcentagem de sobrevivência versus as concentrações do esgoto bruto, também verificou-se o aumento do nível de sobrevivência após a irradiação das amostras.

TABELA 13. Valores de CE50 $48 \mathrm{~h}(\%)$, UT e eficiência do processo (\%) em amostras de mistura (CF + esgoto) para Daphnia similis.

\begin{tabular}{c|c|c|c|c}
\hline $\begin{array}{c}\text { Doses } \\
(\mathrm{kGy})\end{array}$ & Ensaio & $\mathrm{CE}_{40}(\%)$ & $\mathrm{UT}$ & $\begin{array}{c}\text { Eficiência } \\
(\%)\end{array}$ \\
\hline \multirow{2}{*}{0,0} & 1 & $18,79(15,21-23,21)$ & 5,32 & - \\
\cline { 2 - 5 } & 2 & $21,19(16,24-27,65)$ & 4,72 & - \\
\cline { 2 - 5 } & 3 & $15,15(11,88-19,33)$ & 6,60 & - \\
\cline { 2 - 5 } & $\mathbf{X} \pm \mathbf{S}$ & $\mathbf{1 8 , 3 8} \pm \mathbf{3 , 0 4}$ & $\mathbf{5 , 5 5} \pm \mathbf{0 , 9 6}$ & - \\
\hline \multirow{5}{*}{5,0} & 1 & $94,90(86,37-104,28)$ & 1,05 & 80,26 \\
\cline { 2 - 5 } & 2 & $79,61(73,13-86,66)$ & 1,26 & 73,30 \\
\cline { 2 - 5 } & 3 & $96,85(85,32-109,95)$ & 1,03 & 84,39 \\
\cline { 2 - 5 } & $\mathbf{X} \pm \mathbf{S}$ & $\mathbf{9 0 , 4 5} \pm \mathbf{9 , 4 4}$ & $\mathbf{1 , 1 1} \pm \mathbf{0 , 1 3}$ & $\mathbf{7 9 , 3 2} \pm \mathbf{5 , 6 0}$ \\
\hline \multirow{3}{*}{20,0} & 1 & $66,78(62,44-71,42)$ & 1,50 & 71,80 \\
\cline { 2 - 5 } & 2 & $51,19(44,64-58,71)$ & 1,95 & 58,69 \\
\cline { 2 - 5 } & 3 & $74,10(68,60-80,04)$ & 1,35 & 79,54 \\
\cline { 2 - 5 } & $\mathbf{X} \pm \mathbf{S}$ & $\mathbf{6 4 , 0 2} \pm \mathbf{1 1 , 7 0}$ & $\mathbf{1 , 6 0} \pm \mathbf{0 , 3 1}$ & $\mathbf{7 0 , 0 0} \pm \mathbf{1 0 , 5 4}$ \\
\hline
\end{tabular}

Na TABELA 13 foram apresentados os dados referentes à mistura $(\mathrm{CF}+$ esgoto). Há uma melhor redução de toxicidade para a dose de 5,0 kGy se comparada com a dose de 20,0 kGy, o mesmo efeito foi verificado para o esgoto bruto. No trabalho de Romanelli et al. (2004) também verificou-se menor eficiência na redução da toxicidade 
para Daphnia similis em doses mais altas de radiação para o surfactante dodecil sulfato de sódio.

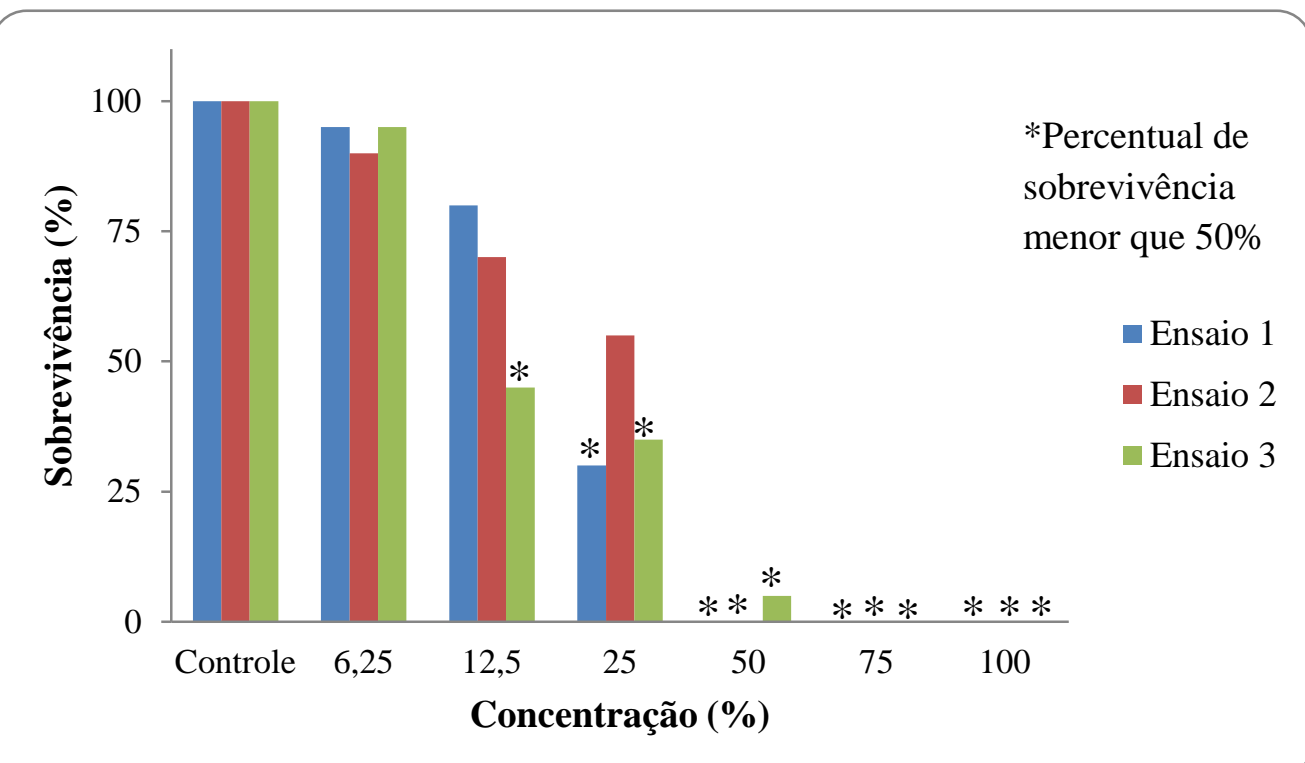

FIGURA 28. Percentual de sobrevivência do organismo Daphnia similis para a mistura $(\mathrm{CF}+$ esgoto $)$ não irradiado.

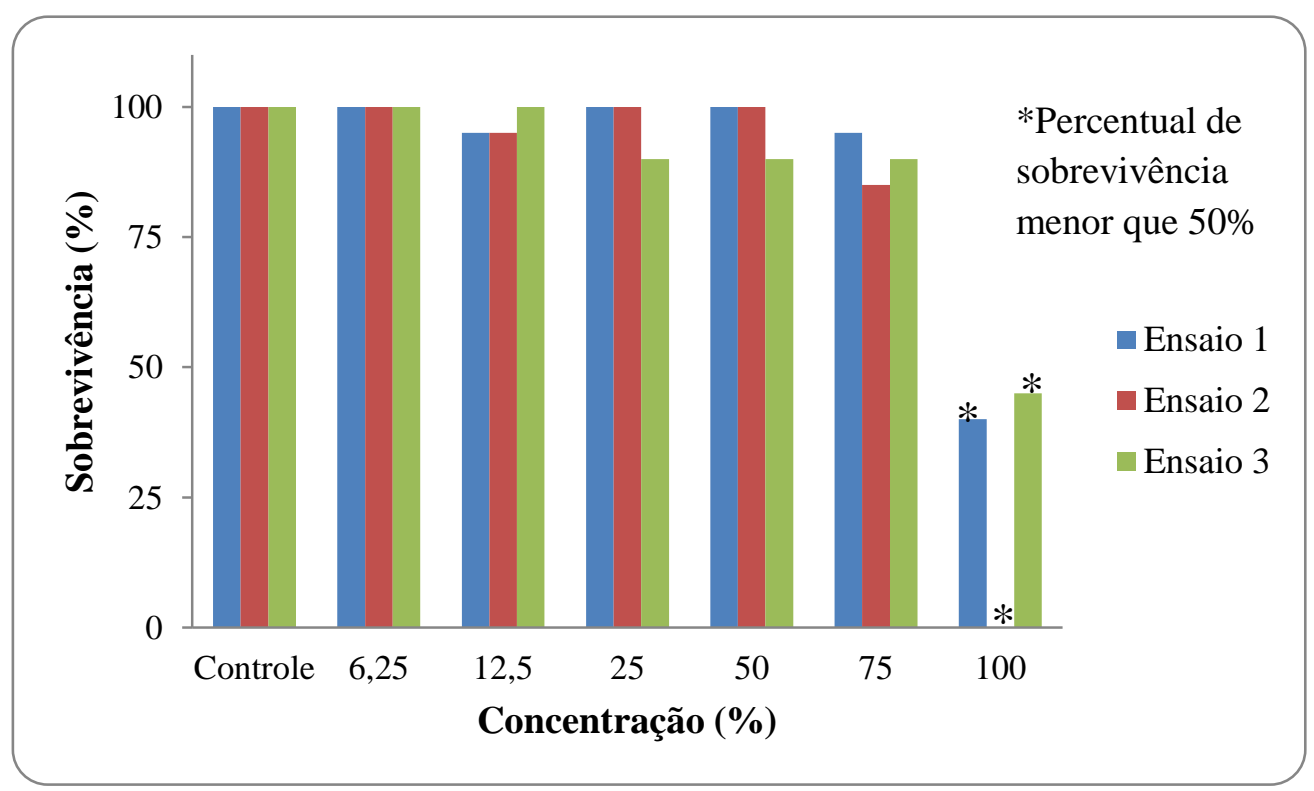

FIGURA 29. Percentual de sobrevivência do organismo Daphnia similis para a mistura (CF + esgoto) irradiado com 5,0 kGy. 


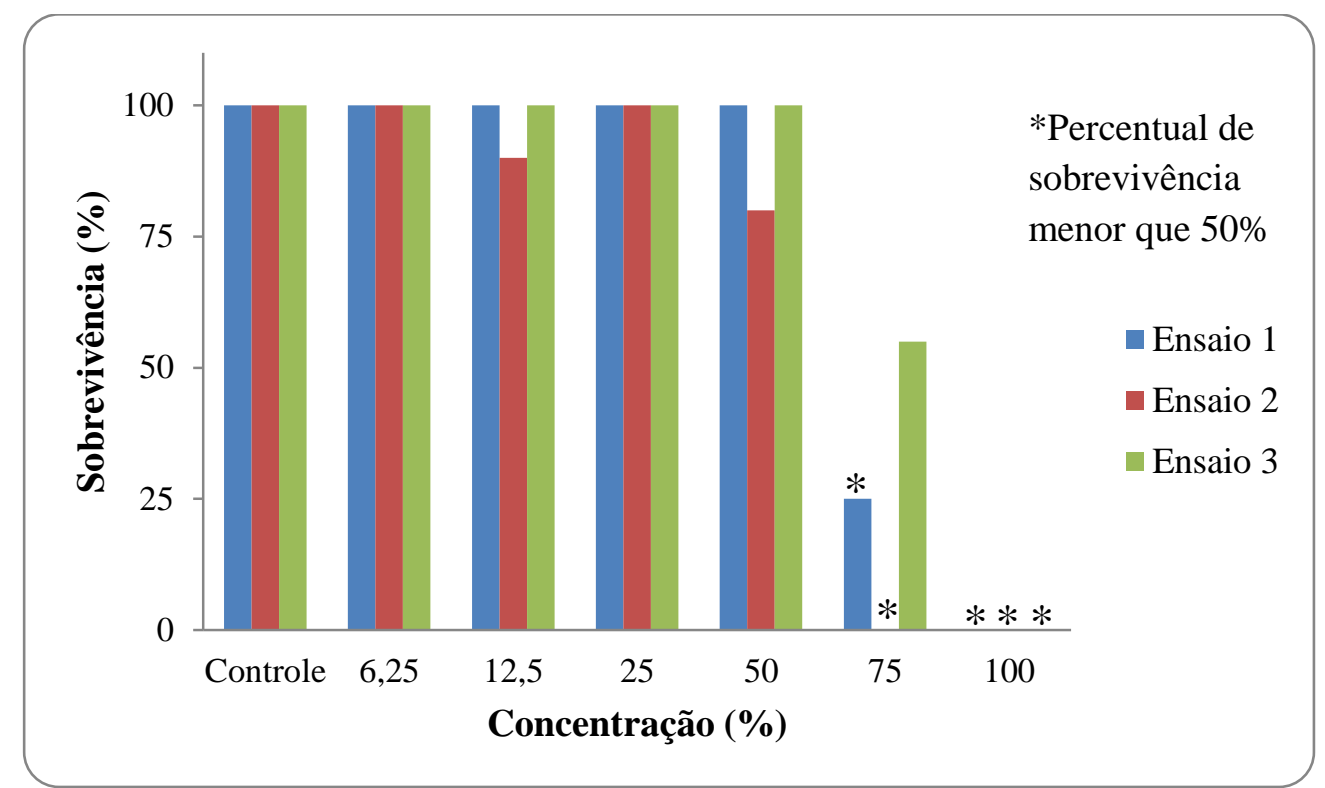

FIGURA 30. Percentual de sobrevivência do organismo Daphnia similis para a mistura (CF + esgoto) irradiado com 20,0 kGy.

Nas FIGURAS 28, 29 e 30 foram apresentados os valores de porcentagem de sobrevivência versus as concentrações da mistura ( $\mathrm{CF}+$ esgoto), também verificou-se o aumento do nível de sobrevivência após a irradiação das amostras.

\subsubsection{Ensaios de toxicidade aguda com Vibrio fischeri}

Foram realizados ensaios de toxicidade aguda com a bactéria Vibrio fischeri com amostras do cloridrato de fluoxetina, esgoto doméstico (bruto) e mistura (CF + esgoto), irradiadas e não irradiada. A concentração de CF tanto para a solução aquosa como para a mistura foi de $5 \mathrm{mg} \mathrm{L}^{-1}$. 
TABELA 14. Valores de $\mathrm{pH}$, oxigênio dissolvido (OD) e condutividade das amostras de cloridrato de fluoxetina utilizadas nos ensaios com Vibrio fischeri.

\begin{tabular}{|c|c|c|c|c|}
\hline $\begin{array}{l}\text { Doses } \\
(\mathrm{kGy})\end{array}$ & Ensaio & $\overline{\mathrm{pH}}$ & $\begin{array}{c}\text { Oxigênio dissolvido } \\
\left(\mathrm{mg} \mathrm{L}^{-1}\right)\end{array}$ & $\begin{array}{c}\text { Condutividade } \\
\left(\mu \mathrm{S} \mathrm{cm}^{-1}\right)\end{array}$ \\
\hline \multirow[t]{5}{*}{0,0} & 1 & 5,52 & 7,45 & 12,9 \\
\hline & 2 & 6,06 & 7,55 & 6,1 \\
\hline & 3 & 5,96 & 7,75 & 4,9 \\
\hline & 4 & 6,04 & 7,95 & 11,4 \\
\hline & $X \pm S$ & $5,89 \pm 0,25$ & $7,67 \pm 0,22$ & $8,8 \pm 3,9$ \\
\hline \multirow[t]{5}{*}{5,0} & 1 & 4,43 & 7,43 & 23,7 \\
\hline & 2 & 4,34 & 7,44 & 24,2 \\
\hline & 3 & 4,36 & 7,37 & 27,9 \\
\hline & 4 & 4,57 & 7,51 & 20,1 \\
\hline & $X \pm S$ & $4,42 \pm 0,10$ & $7,44 \pm 0,06$ & $24,0 \pm 3,2$ \\
\hline \multirow[t]{5}{*}{7,5} & 1 & 4,31 & 7,35 & 27,5 \\
\hline & 2 & 4,23 & 7,46 & 25,4 \\
\hline & 3 & 4,23 & 7,37 & 27,5 \\
\hline & 4 & 4,20 & 7,45 & 24,2 \\
\hline & $X \pm S$ & $4,24 \pm 0,05$ & $7,41 \pm 0,06$ & $26,1 \pm 1,6$ \\
\hline \multirow[t]{4}{*}{15} & 2 & 4,11 & 7,43 & 25,6 \\
\hline & 3 & 3,95 & 7,32 & 28,0 \\
\hline & 4 & 4,06 & 7,43 & 27,0 \\
\hline & $X \pm S$ & $4,04 \pm 0,08$ & $7,39 \pm 0,06$ & $26,9 \pm 1,2$ \\
\hline \multirow[t]{4}{*}{20} & 2 & 3,78 & 7,43 & 27,0 \\
\hline & 3 & 3,75 & 7,46 & 32,9 \\
\hline & 4 & 3,72 & 7,35 & 27,6 \\
\hline & $X \pm S$ & $3,75 \pm 0,03$ & $7,41 \pm 0,06$ & $29,2 \pm 3,2$ \\
\hline
\end{tabular}

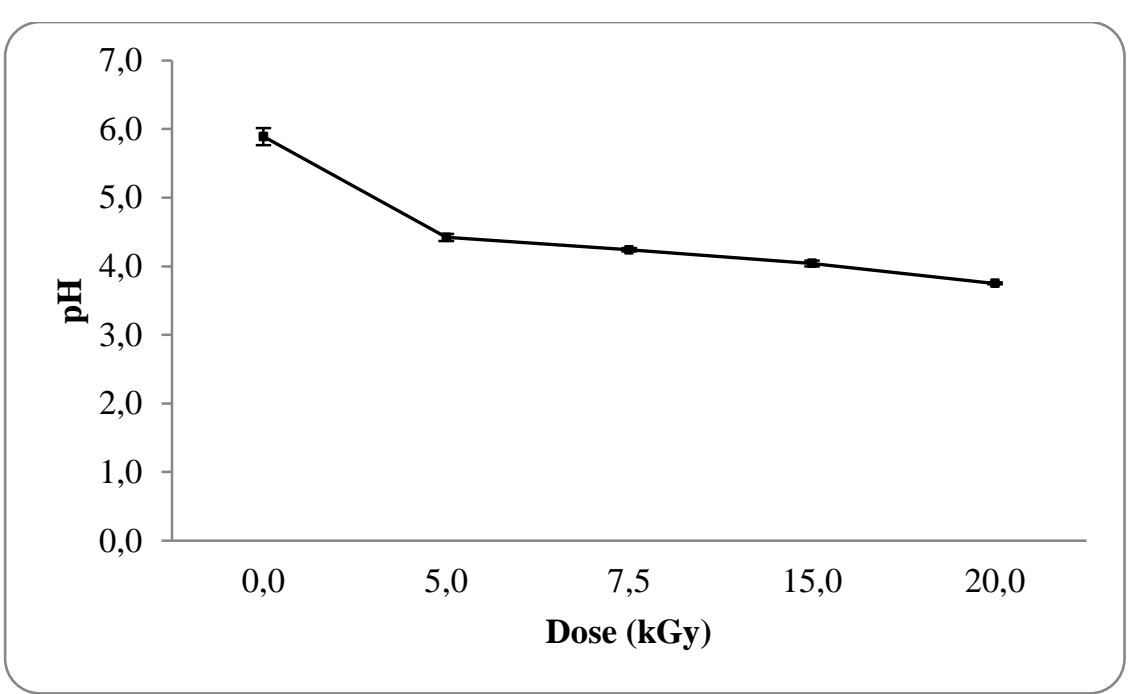

FIGURA 31. Média e desvio dos valores de pH para as amostras de cloridrato de fluoxetina irradiadas e não irradiada utilizadas nos ensaios com Vibrio fischeri. 


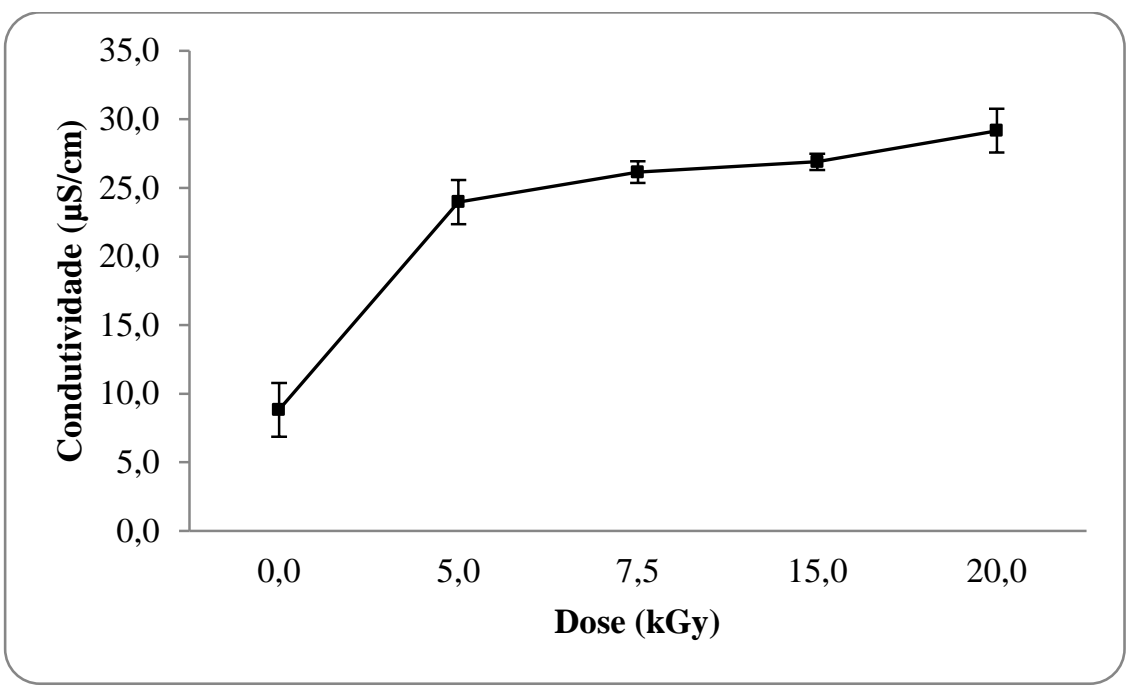

FIGURA 32. Média e desvio dos valores de condutividade para as amostras de cloridrato de fluoxetina irradiadas e não irradiada utilizadas nos ensaios com Vibrio fischeri.

Observa-se pela FIGURA 31 a diminuição do valor de pH com o aumento da dose de radiação que pode ter ocorrido pela formação de ácidos orgânicos na degradação do fármaco. A diminuição do $\mathrm{pH}$ devido a formação de ácidos orgânicos provenientes da degradação dos compostos orgânicos decorrente do tratamento com irradiação já fora verificada por outros autores (Duarte, 1999; Borrely, 2001; Romanelli, 2004; Higa, 2008; Santos, 2012).

Em relação ao CF também houve o aumento da condutividade em função do aumento da dose de radiação ionizante aplicada (FIGURA 32). Visto que quanto maior a dose de radiação maior será o número de moléculas ionizadas, como consequência tem-se uma maior condutividade de uma solução (Romanelli, 2004; Santos, 2012). 
TABELA 15. Valores de $\mathrm{pH}$, oxigênio dissolvido (OD) e condutividade das amostras do esgoto bruto utilizadas nos ensaios com Vibrio fischeri.

\begin{tabular}{|c|c|c|c|c|}
\hline Doses (kGy) & Ensaio & $\overline{\mathrm{pH}}$ & $\begin{array}{c}\text { Oxigênio dissolvido } \\
\left(\mathrm{mg} \mathrm{L}^{-1}\right)\end{array}$ & $\begin{array}{c}\text { Condutividade } \\
\left(\mu \mathrm{S} \mathrm{cm}^{-1}\right)\end{array}$ \\
\hline \multirow[t]{4}{*}{0,0} & 1 & 7,60 & 0,43 & 663,0 \\
\hline & 2 & 7,55 & 1,33 & 537,0 \\
\hline & 3 & 7,63 & 1,54 & 707,0 \\
\hline & $X \pm S$ & $7,59 \pm 0,04$ & $1,10 \pm 0,59$ & $635,7 \pm 88,2$ \\
\hline \multirow[t]{4}{*}{5,0} & 1 & 7,73 & 4,16 & 660,0 \\
\hline & 2 & 7,66 & 5,36 & 550,0 \\
\hline & 3 & 7,73 & 4,08 & 727,0 \\
\hline & $\mathrm{X} \pm \mathrm{S}$ & $7,71 \pm 0,04$ & $4,53 \pm 0,72$ & $645,7 \pm 89,4$ \\
\hline \multirow[t]{4}{*}{7,5} & 1 & 7,71 & 3,98 & 663,0 \\
\hline & 2 & 7,62 & 5,84 & 550,0 \\
\hline & 3 & 7,82 & 4,96 & 726,0 \\
\hline & $\mathrm{X} \pm \mathrm{S}$ & $7,72 \pm 0,10$ & $4,93 \pm 0,93$ & $646,3 \pm 89,2$ \\
\hline \multirow[t]{3}{*}{15} & 2 & 7,64 & 6,53 & 549,0 \\
\hline & 3 & 7,81 & 4,96 & 722,0 \\
\hline & $X \pm S$ & $7,73 \pm 0,12$ & $5,75 \pm 1,11$ & $635,5 \pm 122,3$ \\
\hline \multirow[t]{3}{*}{20} & 2 & 7,56 & 6,76 & 553 \\
\hline & 3 & 7,74 & 5,72 & 723 \\
\hline & $X \pm S$ & $7,65 \pm 0,13$ & $6,24 \pm 0,74$ & $638,0 \pm 120,2$ \\
\hline
\end{tabular}

TABELA 16. Valores de $\mathrm{pH}$, oxigênio dissolvido (OD) e condutividade das amostras da mistura ( $\mathrm{CF}+$ esgoto) utilizadas nos ensaios com Vibrio fischeri.

\begin{tabular}{|c|c|c|c|c|}
\hline $\begin{array}{l}\text { Doses } \\
\text { (kGy) }\end{array}$ & Ensaio & $\mathrm{pH}$ & $\begin{array}{l}\text { Oxigênio dissolvido } \\
\left(\mathrm{mg} \mathrm{L}^{-1}\right)\end{array}$ & $\begin{array}{l}\text { Condutividade } \\
\left(\mu \mathrm{S} \mathrm{cm}^{-1}\right)\end{array}$ \\
\hline \multirow[t]{4}{*}{0,0} & 1 & 7,66 & 0,28 & 497,0 \\
\hline & 2 & 7,74 & 0,25 & 487,0 \\
\hline & 3 & 7,56 & 0,96 & 648,0 \\
\hline & $X \pm S$ & $7,65 \pm 0,09$ & $0,50 \pm 0,40$ & $544,0 \pm 90,2$ \\
\hline \multirow[t]{4}{*}{5,0} & 1 & 7,57 & 4,83 & 514,0 \\
\hline & 2 & 7,65 & 5,26 & 498,0 \\
\hline & 3 & 7,75 & 4,08 & 661,0 \\
\hline & $X \pm S$ & $7,66 \pm 0,09$ & $4,72 \pm 0,60$ & $557,7 \pm 89,8$ \\
\hline \multirow[t]{4}{*}{7,5} & 1 & 7,55 & 4,71 & 515,0 \\
\hline & 2 & 7,56 & 5,38 & 498,0 \\
\hline & 3 & 7,77 & 4,76 & 660,0 \\
\hline & $\mathbf{X} \pm \mathrm{S}$ & $7,63 \pm 0,12$ & $4,95 \pm 0,37$ & $557,7 \pm 89,0$ \\
\hline \multirow[t]{3}{*}{15} & 2 & 7,53 & 5,89 & 498,0 \\
\hline & 3 & 7,81 & 5,23 & 655,0 \\
\hline & $X \pm S$ & $7,67 \pm 0,20$ & $5,56 \pm 0,47$ & $576,5 \pm 111,0$ \\
\hline \multirow[t]{3}{*}{20} & 2 & 7,56 & 6,67 & 502,0 \\
\hline & 3 & 7,68 & 5,77 & 645,0 \\
\hline & $X \pm S$ & $7,62 \pm 0,08$ & $6,22 \pm 0,64$ & $573,5 \pm 101,1$ \\
\hline
\end{tabular}


Nas TABELAS 14, 15 e 16 foram apresentados os valores de pH, oxigênio dissolvido e condutividade das soluções iniciais de CF, esgoto bruto e mistura, respectivamente, utilizadas nos ensaios com Vibrio fischeri.

Em relação ao esgoto bruto e a mistura foi possível verificar que não houve alterações significativas nos valores de pH e condutividade após a irradiação das amostras, apresentando apenas aumento no valor do oxigênio dissolvido (TABELAS 15 e 16).

TABELA 17. Valores de CE50 15 min $\left(\%\right.$ e $\left.\mathrm{mg} \mathrm{L}^{-1}\right)$, UT e eficiência do processo (\%) na remoção da toxicidade para amostras do cloridrato de fluoxetina para Vibrio fischeri.

\begin{tabular}{|c|c|c|c|c|c|}
\hline $\begin{array}{l}\text { Doses } \\
(k G y)\end{array}$ & Ensaio & $\operatorname{CE} 50_{15 \min }(\%)$ & UT & $\begin{array}{l}\mathrm{CE}_{50}{ }_{15 \min } \\
\left(\mathrm{mg} \mathrm{L}^{-1}\right)\end{array}$ & $\begin{array}{c}\text { Eficiência } \\
(\%)\end{array}$ \\
\hline \multirow[t]{5}{*}{0,0} & 1 & $21,30(5,28-84,92)$ & 4,69 & 1,07 & \\
\hline & 2 & $23,96(6,53-87,88)$ & 4,17 & 1,20 & - \\
\hline & 3 & $22,71(9,21-55,99)$ & 4,40 & 1,14 & - \\
\hline & 4 & $24,08(4,79-121,16)$ & 4,15 & 1,20 & - \\
\hline & $\mathrm{X} \pm \mathrm{S}$ & $23,01 \pm 1,30$ & $4,35 \pm 0,25$ & $1,15 \pm 0,06$ & - \\
\hline \multirow[t]{5}{*}{5,0} & 1 & $27,35(8,33-89,72)$ & 3,66 & - & 21,96 \\
\hline & 2 & $28,60(10,52-77,76)$ & 3,50 & - & 16,22 \\
\hline & 3 & $25,80(11,57-57,51)$ & 3,88 & - & 11,98 \\
\hline & 4 & $29,63(4,87-180,36)$ & 3,37 & - & 18,73 \\
\hline & $X \pm S$ & $27,84 \pm 1,65$ & $3,60 \pm 0,22$ & & $17,26 \pm 4,27$ \\
\hline \multirow[t]{5}{*}{7,5} & 1 & $26,29(14,11-48,99)$ & 3,80 & - & 18,98 \\
\hline & 2 & $26,00(9,79-69,06)$ & 3,85 & - & 7,85 \\
\hline & 3 & $25,78(8,26-80,45)$ & 3,87 & - & 11,91 \\
\hline & 4 & $26,71(4,05-176,13)$ & 3,74 & - & 9,85 \\
\hline & $\mathrm{X} \pm \mathrm{S}$ & $26,16 \pm 0,49$ & $\mathbf{3 , 8 2} \pm \mathbf{0 , 0 7}$ & & $9,87 \pm 2,03$ \\
\hline \multirow[t]{4}{*}{15,0} & 2 & $26,35(9,81-70,79)$ & 3,80 & - & 9,07 \\
\hline & 3 & $23,98(9,59-59,99)$ & 4,17 & - & 5,30 \\
\hline & 4 & $26,65(3,90-182,09)$ & 3,75 & - & 9,64 \\
\hline & $X \pm S$ & $25,66 \pm 1,46$ & $3,91 \pm 0,23$ & & $8,00 \pm 2,36$ \\
\hline \multirow[t]{4}{*}{20,0} & 2 & $26,57(11,70-60,32)$ & 3,76 & - & 9,82 \\
\hline & 3 & $23,29(7,90-68,64)$ & 4,29 & - & 2,49 \\
\hline & 4 & $24,58(3,80-158,93)$ & 4,07 & - & 2,03 \\
\hline & $X \pm S$ & $24,81 \pm 1,65$ & $4,04 \pm 0,27$ & & $4,78 \pm 4,37$ \\
\hline
\end{tabular}

Os valores obtidos de $\mathrm{CE}_{50} 0_{15 \mathrm{~min}}\left(\%\right.$ e $\left.\mathrm{mg} \mathrm{L}^{-1}\right)$, Unidade Tóxica (UT) e Eficiência do processo (\%), nos ensaios com Vibrio fischeri (15 minutos de exposição) para o CF foram apresentados na TABELA 17 com os respectivos valores de médias e desvios padrão. 
Para a Vibrio fischeri, Santos (2012) obteve o valor de CE50 15 min de $0,69 \mathrm{mg} \mathrm{L}^{-1}$ (CF manipulado), valor menor que o encontrado para as amostras deste estudo $\left(1,15 \mathrm{mg} \mathrm{L}^{-1}\right)$ para o fármaco cloridrato de fluoxetina puro. Caminada (2008) verificou que a toxicidade do fármaco fluoxetina possui forte interferência em relação a formulação do composto devido a toxicidade apresentada pelo excipiente utilizado, isto pode explicar a maior toxicidade do fármaco manipulado se comparado com o fármaco puro.

$\mathrm{Na}$ TABELA 17 verificou-se um ligeiro aumento na toxicidade em função do aumento da dose, isto pode ter ocorrido devido a diminuição do $\mathrm{pH}$ decorrente da formação de maiores quantidades de ácidos orgânicos e/ou a formação de alguma espécie química intermediária. Este aumento na toxicidade com o aumento da dose acarretou na perda da eficiência nas doses mais elevadas.

TABELA 18. Valores de CE50 15 min $\left(\%\right.$ e $\left.\mathrm{mg} \mathrm{L}^{-1}\right)$, UT e eficiência do processo (\%) na remoção da toxicidade para amostras do cloridrato de fluoxetina, após correção do pH, para Vibrio fischeri.

\begin{tabular}{c|c|c|c|c|c}
\hline $\begin{array}{c}\text { Doses } \\
(\mathrm{kGy})\end{array}$ & Ensaio & $\mathrm{CE} 50_{15 \min }(\%)$ & $\mathrm{UT}$ & $\begin{array}{c}\mathrm{CE} 0_{15 \min } \\
\left(\mathrm{mg} \mathrm{L}^{-1}\right)\end{array}$ & $\begin{array}{c}\text { Eficiência } \\
(\%)\end{array}$ \\
\hline 0,0 & 5 & $24,55(4,40-136,96)$ & 4,07 & 1,23 & - \\
\hline 0,5 & 5 & $27,22(4,47-165,83)$ & 3,67 & - & 9,83 \\
\hline 5,0 & 5 & $27,19(3,53-209,31)$ & 3,68 & - & 9,58 \\
\hline 7,5 & 5 & $28,54(4,41-184,77)$ & 3,50 & - & 14,00 \\
\hline 15,0 & 5 & $31,27(6,60-148,17)$ & 3,20 & - & 21,37 \\
\hline 20,0 & 5 & $33,58(8,39-134,34)$ & 2,98 & - & 26,78 \\
\hline
\end{tabular}

Na TABELA 18 seguem os valores obtidos de CE50 15 min $\left(\%\right.$ e mg L $\left.{ }^{-1}\right)$, Unidade Tóxica (UT) e Eficiência do processo (\%), para o ensaio realizado para as amostras com os valores de $\mathrm{pH}$ corrigidos para valores próximos de 7,3 (a correção do $\mathrm{pH}$ foi realizada na amostra após o tratamento por irradiação com solução de hidróxido de sódio $0,05 \mathrm{M}$ ). Verificou-se que após a alteração do $\mathrm{pH}$, ao contrário dos valores sem a correção do mesmo, houve uma relação diretamente proporcional entre a dose de radiação e a eficiência do tratamento. Apesar de ter ocorrido a redução da toxicidade após a irradiação, a eficiência mesmo com a correção de pH continuou abaixo de 30\%, o que indica que não foi apenas o $\mathrm{pH}$ que influenciou na toxicidade da amostra, mas também a formação de algum subproduto que conferiu toxicidade a Vibrio fischeri. 
TABELA 19. Valores de CE $50_{15 \min }(\%)$, UT e eficiência do processo (\%) na remoção da toxicidade para amostras de esgoto bruto para Vibrio fischeri.

\begin{tabular}{c|c|c|c|c}
\hline Doses $(\mathrm{kGy})$ & Ensaio & CE50 $15 \min (\%)$ & UT & Eficiência (\%) \\
\hline \multirow{5}{*}{0,0} & 1 & $16,36(6,36-42,05)$ & 6,23 & - \\
\cline { 2 - 5 } & 2 & $18,15(8,79-37,47)$ & 5,40 & - \\
\cline { 2 - 5 } & 3 & $15,64(6,35-38,47)$ & 6,39 & - \\
\cline { 2 - 5 } & $\mathbf{X} \pm \mathbf{S}$ & $\mathbf{1 6 , 7 2} \pm \mathbf{1 , 2 9}$ & $\mathbf{6 , 0 1} \pm \mathbf{0 , 5 3}$ & - \\
\hline \multirow{5}{*}{5,0} & 1 & $20,58(5,97-70,93)$ & 4,60 & 20,51 \\
\cline { 2 - 5 } & 2 & $21,43(6,32-72,62)$ & 4,70 & 15,31 \\
\cline { 2 - 5 } & 3 & $20,14(6,60-61,47)$ & 4,97 & 22,34 \\
\cline { 2 - 5 } & $\mathbf{X} \pm \mathbf{S}$ & $\mathbf{2 0 , 7 2} \pm \mathbf{0 , 6 6}$ & $\mathbf{4 , 7 6} \pm \mathbf{0 , 1 9}$ & $\mathbf{1 9 , 3 9} \pm \mathbf{3 , 6 5}$ \\
\cline { 2 - 5 } & 1 & $20,88(6,39-68,22)$ & 5,05 & 21,65 \\
\cline { 2 - 5 } & 2 & $20,07(6,05-66,53)$ & 4,18 & 9,57 \\
\cline { 2 - 5 } & $\mathbf{X} \pm \mathbf{S}$ & $19,60(6,63-57,92)$ & 5,10 & $\mathbf{1 7 , 1 4} \pm \mathbf{6 , 6 0}$ \\
\hline \multirow{5}{*}{15,0} & 2 & $22,35(7,73-64,58)$ & 4,60 & 18,79 \\
\cline { 2 - 5 } & 3 & $20,48(7,19-58,32)$ & 4,88 & 23,63 \\
\cline { 2 - 5 } & $\mathbf{X} \pm \mathbf{S}$ & $\mathbf{2 1 , 4 2} \pm \mathbf{1 , 3 2}$ & $\mathbf{4 , 7 4} \pm \mathbf{0 , 2 0}$ & $\mathbf{2 1 , 2 1} \pm \mathbf{3 , 4 2}$ \\
\hline \multirow{5}{*}{20,0} & 2 & $21,78(7,19-65,93)$ & 4,69 & 16,67 \\
\cline { 2 - 5 } & 3 & $20,21(6,38-63,93)$ & 4,95 & 22,61 \\
\cline { 2 - 5 } & $\mathbf{X} \pm \mathbf{S}$ & $\mathbf{2 0 , 9 9} \pm \mathbf{1 , 1 1}$ & $\mathbf{4 , 8 2} \pm \mathbf{0 , 1 8}$ & $\mathbf{1 9 , 6 4} \pm \mathbf{4 , 2 0}$ \\
\hline
\end{tabular}

Os valores obtidos de $\mathrm{CE}_{50}{ }_{15 \min }\left(\%\right.$ e $\left.\mathrm{mg} \mathrm{L}^{-1}\right)$, Unidade Tóxica (UT) e Eficiência do processo (\%), nos ensaios de 15 minutos de exposição para o esgoto bruto foram apresentados na TABELA 19 com os respectivos valores de médias e desvios padrão. Foi possível verificar que houve redução da toxicidade após o tratamento, porém entre as doses aplicadas não houve variações significativas entre as doses aplicadas, apresentando assim valores próximos de eficiências. 
TABELA 20. Valores de CE $50_{15 \min }(\%)$, UT e eficiência do processo (\%) na remoção da toxicidade para amostras da mistura (CF + esgoto) para Vibrio fischeri.

\begin{tabular}{c|c|c|c|c}
\hline Doses $(\mathrm{kGy})$ & Ensaio & CE50 $15 \min (\%)$ & UT & Eficiência (\%) \\
\hline \multirow{5}{*}{0,0} & 1 & $16,05(6,92-37,22)$ & 6,23 & - \\
\cline { 2 - 5 } & 2 & $18,53(8,67-39,59)$ & 5,40 & - \\
\cline { 2 - 5 } & 3 & $14,85(6,90-31,94)$ & 6,73 & - \\
\cline { 2 - 5 } & $\mathbf{X} \pm \mathbf{S}$ & $\mathbf{1 6 , 4 8} \pm \mathbf{1 , 8 8}$ & $\mathbf{6 , 1 2} \pm \mathbf{0 , 6 7}$ & - \\
\hline \multirow{5}{*}{5,0} & 1 & $21,75(9,10-50,03)$ & 4,60 & 26,21 \\
\cline { 2 - 5 } & 2 & $21,29(7,30-62,09)$ & 4,70 & 12,96 \\
\cline { 2 - 5 } & 3 & $20,14(7,83-51,82)$ & 4,97 & 26,27 \\
\cline { 2 - 5 } & $\mathbf{X} \pm \mathbf{S}$ & $\mathbf{2 1 , 0 6} \pm \mathbf{0 , 8 3}$ & $\mathbf{4 , 7 6} \pm \mathbf{0 , 1 9}$ & $\mathbf{2 1 , 8 1} \pm \mathbf{7 , 6 7}$ \\
\cline { 2 - 5 } & 1 & $19,82(5,58-70,36)$ & 5,05 & 19,02 \\
\cline { 2 - 5 } & 2 & $23,90(7,78-73,42)$ & 4,18 & 22,47 \\
\cline { 2 - 5 } & $\mathbf{X} \pm \mathbf{S}$ & $19,40(5,53-68,08)$ & 5,15 & 23,45 \\
\hline \multirow{5}{*}{15,0} & 2 & $21,72(6,76-69,74)$ & 4,60 & 14,69 \\
\cline { 2 - 5 } & 3 & $18,74(5,69-61,69)$ & 5,34 & 20,76 \\
\cline { 2 - 5 } & $\mathbf{X} \pm \mathbf{S}$ & $\mathbf{2 0 , 2 3} \pm \mathbf{2 , 1 1}$ & $\mathbf{4 , 9 7} \pm \mathbf{0 , 5 2}$ & $\mathbf{1 7 , 7 2} \pm \mathbf{4 , 2 9}$ \\
\hline \multirow{5}{*}{20,0} & 2 & $21,32(6,61-68,68)$ & 4,69 & 13,09 \\
\cline { 2 - 5 } & 3 & $20,50(6,78-61,96)$ & 4,88 & 27,56 \\
\cline { 2 - 5 } & $\mathbf{X} \pm \mathbf{S}$ & $\mathbf{2 0 , 9 1} \pm \mathbf{0 , 5 8}$ & $\mathbf{4 , 7 9} \pm \mathbf{0 , 1 3}$ & $\mathbf{2 0 , 3 2} \pm \mathbf{1 0 , 2 3}$ \\
\hline
\end{tabular}

$\mathrm{Na}$ TABELA 20 foram apresentados os valores obtidos de CE50 $15 \mathrm{~min}(\% \mathrm{e}$ $\mathrm{mg} \mathrm{L}^{-1}$ ), Unidade Tóxica (UT) e Eficiência do processo (\%), nos ensaios de 15 minutos de exposição para a mistura ( $\mathrm{CF}$ + esgoto) com os respectivos valores de médias e desvios padrão. Verificou-se o mesmo comportamento do esgoto bruto, houve redução da toxicidade após o tratamento, porém entre as doses aplicadas não houve variações significativas entre as doses aplicadas, apresentando assim valores próximos de eficiência.

Em relação a mistura ( $\mathrm{CF}$ + esgoto) observou-se que não ocorreu efeitos na toxicidade decorrente da mistura dos poluentes em questão.

\subsubsection{Ensaios preliminares de toxicidade crônica com Ceriodaphnia dubia}

No ensaio 1 foi preparada uma amostra de CF com concentração de $5 \mathrm{mg} \mathrm{L}^{-1}$ e esta mesma amostra foi irradiada com 5,0 kGy. As soluções irradiadas e não irradiada foram diluídas em água de cultivo nas porcentagens indicadas na TABELA 21.

No ensaio 2 a amostra inicial foi preparada com $20 \mathrm{mg} \mathrm{L}^{-1}$ e também irradiada com 5,0 kGy. O ensaio 2 com a amostra irradiada foi realizada a partir da concentração de $100 \%$ da amostra e apenas nesta concentração apresentou toxicidade crônica, em relação ao ensaio 1 a concentração inicial foi de $20 \%$ da amostra irradiada e não apresentou 
toxicidade crônica. Para as amostras não irradiadas em ambos os ensaios a solução com $0,5 \mathrm{mg} \mathrm{L}^{-1}\left(2,5 \%\right.$ da amostra inicial de $20 \mathrm{mg} \mathrm{L}^{-1}$ e $10 \%$ da amostra inicial de $\left.5 \mathrm{mg} \mathrm{L}^{-1}\right)$ e no ensaio 1 a solução de $0,25 \mathrm{mg} \mathrm{L}^{-1}$ apresentaram toxicidade crônica.

Foi possível verificar que em baixas concentrações de cloridrato de fluoxetina houve um aumento na reprodução da Ceriodaphnia dubia em relação ao controle, este fato também foi observado por Brooks et al. (2003).

TABELA 21. Classificação quanto à toxicidade pelo teste " $t$ " por bioequivalência para a Ceriodaphnia dubia.

\begin{tabular}{|c|c|c|c|c|}
\hline \multicolumn{3}{|c|}{ Ensaio crônico 1} & \multicolumn{2}{|c|}{ Ensaio crônico 2} \\
\hline & $\begin{array}{l}\text { Concentrações } \\
(\% \text { em relação a solução } \\
\left.\text { de } 5 \mathrm{mg} \mathrm{L}^{-1}\right)\end{array}$ & Classe & $\begin{array}{l}\text { Concentrações } \\
(\% \text { em relação a solução de } \\
\left.20 \mathrm{mg} \mathrm{L}^{-1}\right)\end{array}$ & Classe \\
\hline \multirow{5}{*}{$\begin{array}{l}\text { Amostra } \\
\text { não } \\
\text { irradiada }\end{array}$} & $\begin{array}{c}0,63 \%(0,03125 \\
\left.\mathrm{mg} \mathrm{L}^{-1}\right)\end{array}$ & Não tóxico & $\begin{array}{c}0,16 \%(0,03125 \\
\left.\mathrm{mg} \mathrm{L}^{-1}\right)\end{array}$ & Não tóxico \\
\hline & $\begin{array}{c}1,25 \%(0,065 \\
\left.\mathrm{mg} \mathrm{L}^{-1}\right)\end{array}$ & Não tóxico & $\begin{array}{c}0,31 \%(0,065 \\
\left.\mathrm{mg} \mathrm{L}^{-1}\right)\end{array}$ & Não tóxico \\
\hline & $\begin{array}{c}2,5 \%(0,125 \\
\left.\mathrm{mg} \mathrm{L}^{-1}\right)\end{array}$ & Não tóxico & $\begin{array}{c}0,63 \%(0,125 \\
\left.\mathrm{mg} \mathrm{L}^{-1}\right)\end{array}$ & Não tóxico \\
\hline & $5 \%\left(0,25 \mathrm{mg} \mathrm{L}^{-1}\right)$ & Tóxico & $1,25 \%\left(0,25 \mathrm{mg} \mathrm{L}^{-1}\right)$ & Não tóxico \\
\hline & $10 \%\left(0,50 \mathrm{mg} \mathrm{L}^{-1}\right)$ & Tóxico & $2,50 \%\left(0,50 \mathrm{mg} \mathrm{L}^{-1}\right)$ & Tóxico \\
\hline \multirow{5}{*}{$\begin{array}{l}\text { Amostra } \\
\text { irradiada } \\
5,0 \mathrm{kGy}\end{array}$} & $1,25 \%$ & Não tóxico & $6,25 \%$ & Não tóxico \\
\hline & $2,50 \%$ & Não tóxico & $12,50 \%$ & Não tóxico \\
\hline & $5,00 \%$ & Não tóxico & $25,00 \%$ & Não tóxico \\
\hline & $10,00 \%$ & Não tóxico & $50,00 \%$ & Não tóxico \\
\hline & $20,00 \%$ & Não tóxico & $100,00 \%$ & Tóxico \\
\hline
\end{tabular}

\subsubsection{Carta controle}

Nas FIGURAS 33 e 34 foram apresentados os resultados da carta controle para a Daphnia similis e Vibrio fischeri, respectivamente.

Para a Daphnia o valor referente ao coeficiente de variação (CV) foi de $4,5 \%$ e para a bactéria Vibrio foi de 7,9\%, desta forma como os valores foram inferiores a $30 \%$ os dados foram considerados válidos. Observa-se também que todos os resultados se encontram dentro da faixa de sensibilidade. 


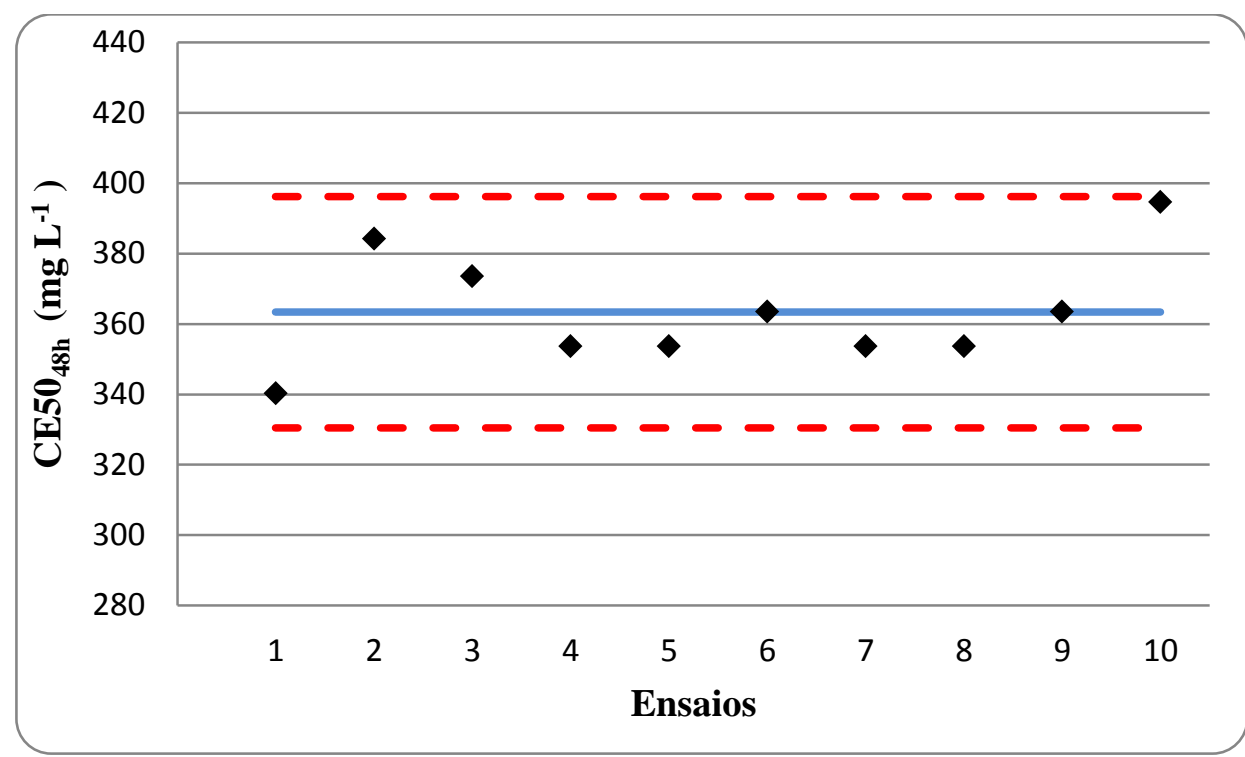

FIGURA 33. Carta controle dos ensaios de sensibilidade com cloreto de potássio para Daphnia similis.

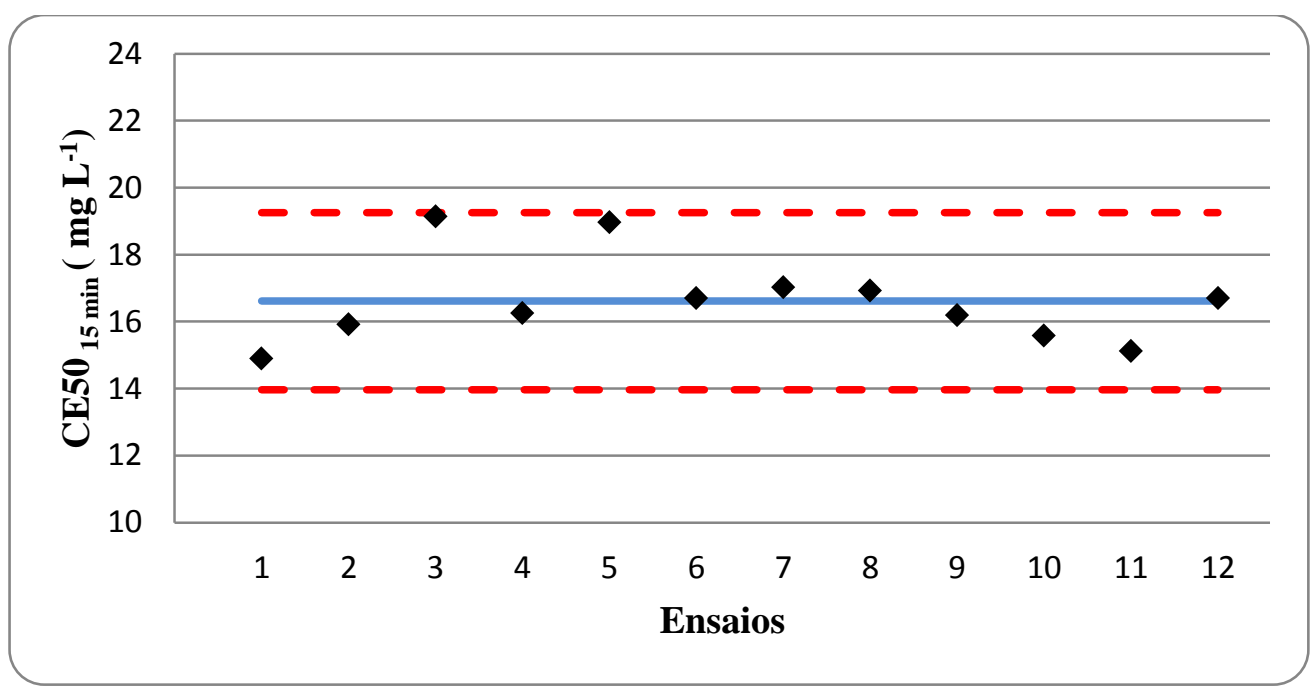

FIGURA 34. Carta controle dos ensaios de sensibilidade com fenol para Vibrio fischeri.

\subsubsection{Comparação entre os dados de toxicidade}

Os valores médios de toxicidade foram destacados na TABELA 22. Verificouse que a Ceriodaphnia dubia possui maior sensibilidade ao fármaco, seguido da bactéria Vibrio fischeri e por fim a Daphnia similis. 
TABELA 22. Valores médios de toxicidade para os ensaios realizados.

\begin{tabular}{c|c|c|c|c}
\hline \multirow{2}{*}{ Organismo } & \multicolumn{2}{|c|}{ Daphnia similis } & Vibrio fischeri & Ceriodaphnia dubia \\
\cline { 2 - 3 } & $10 \mathrm{mg} \mathrm{L}^{-1^{* *}}$ & $20 \mathrm{mg} \mathrm{L}^{-1^{* *}}$ & & \\
\hline $\mathrm{CE} 50\left(\mathrm{mg} \mathrm{L}^{-1}\right)$ & 1,28 & 1,35 & 1,15 & $0,5^{*}$ \\
\hline
\end{tabular}

*Para Ceriodaphnia este valor não se refere a CE50, mas sim a concentração que apresentou toxicidade crônica nos dois ensaios realizados, no primeiro ensaio a concentração de $0,25 \mathrm{mg} \mathrm{L}^{-1}$ também apresentou toxicidade.

**Concentração inicial do fármaco CF puro.

De acordo com as categorias de toxicidade baseadas nos valores de CE50, estabelecidos pela legislação europeia são considerados como: "muito tóxico" para organismos aquáticos $\left(\right.$ CE50 $\left.\leq 1 \mathrm{mg} \mathrm{L}^{-1}\right)$, "tóxico" (CE50 no intervalo de 1 a $\left.10 \mathrm{mg} \mathrm{L}^{-1}\right)$ e "perigosas" (CE50 no intervalo de 10 a $100 \mathrm{mg} \mathrm{L}^{-1}$ ) (Commission of the European Communities, 1996). Conforme esse sistema os resultados obtidos durante este trabalho classificam o cloridrato de fluoxetina como substância tóxica tanto para a Vibrio fischeri quanto para a Daphnia similis.

No trabalho de Brooks et al. (2003) os valores de CE50 da fluoxetina encontrados para Ceriodaphnia dubia e Daphnia magna foram de $0,234 \mathrm{mg} \mathrm{L}^{-1} \mathrm{e}$ $0,82 \mathrm{mg} \mathrm{L}^{-1}$ respectivamente. E de toxicidade crônica para a Ceriodaphnia dubia, a CENO (Concentração de efeito não observado) de $0,056 \mathrm{mg} \mathrm{L}^{-1}$ e a CEO (Concentração de efeito observado) de $0,112 \mathrm{mg} \mathrm{L}^{-1}$.

Outro estudo realizado por Henry et al. (2004) para Ceriodaphnia dubia o valor de CL50 encontrado foi de $0,51 \mathrm{mg} \mathrm{L}^{-1}$ e os valores de CENO e CEO foram $0,089 \mathrm{mg} \mathrm{L}^{-1}$ e $0,447 \mathrm{mg} \mathrm{L}^{-1}$. Os valores aqui obtidos foram similares aos encontrados na literatura.

Apesar dos valores de CE50 determinados durante este estudo $\left(\mathrm{mg} \mathrm{L}^{-1}\right)$ estarem acima das concentrações ambientais (ng $\left.\mathrm{L}^{-1}\right)$ não significa que o ambiente está protegido. Um estudo realizado com mexilhões Dreissena polymorpha com baixas concentrações de fluoxetina trouxe evidências que concentrações de $200 \mathrm{ng} \mathrm{L}^{-1}$ foram capazes de alterar o metabolismo de esteroides e a reprodução destes mexilhões (Lazzara et al., 2012). Ou seja, ainda há necessidade de estudos que avaliem outros organismos e "endpoints", além da avaliação de misturas, uma vez que no ambiente temos uma vasta gama de contaminantes presentes nas águas que entram em contato com os organismos, além de aspectos de sinergias entre compostos e formação de subprodutos. 
Na TABELA 23 há uma classificação para a toxicidade aguda de efluentes em relação aos valores de CE50 em porcentagem.

TABELA 23. Classificação da toxicidade aguda de efluentes em relação aos valores de CE50 segundo Bulich (1992 apud Borrely, 2001).

\begin{tabular}{c|c}
\hline CE 50 (\%, v/v) & Classificação \\
\hline$<25$ & Muito tóxica \\
\hline $25-50$ & Moderadamente tóxica \\
\hline $51-75$ & Tóxica \\
\hline$>75$ & Levemente tóxica \\
\hline
\end{tabular}

A seguir temos a classificação das amostras de esgoto bruto e da mistura para a Daphnia similis (TABELA 24).

TABELA 24. Classificação das amostras de esgoto e mistura para Daphnia similis.

\begin{tabular}{c|c|c|c}
\hline Amostra & $\mathbf{0 , 0} \mathbf{~ k G y}$ & $\mathbf{5 , 0} \mathbf{~ k G y}$ & $\mathbf{2 0 , 0} \mathbf{k G y}$ \\
\hline Esgoto bruto & $\begin{array}{c}\text { Moderadamente } \\
\text { tóxica }\end{array}$ & $\begin{array}{c}\text { Levemente } \\
\text { tóxica }\end{array}$ & $\begin{array}{c}\text { Levemente } \\
\text { tóxica }\end{array}$ \\
\hline Mistura & Muito tóxica & $\begin{array}{c}\text { Levemente } \\
\text { tóxica }\end{array}$ & Tóxica \\
\hline
\end{tabular}

O aumento de toxicidade para a dose de 20,0 kGy (Daphnia similis) pode ter ocorrido devido a formação de espécies químicas intermediárias com toxicidade mais elevada do que as substâncias formadas em doses mais baixas.

Segundo os dados das TABELAS 19 e 20 observou-se que tanto para as amostras irradiadas como para as não irradiadas, as amostras de esgoto bruto e mistura foram classificadas como muito tóxicas para a Vibrio fischeri.

A Vibrio fischeri apresentou maior sensibilidade às amostras do que a Daphnia, resultados semelhantes foram encontrados para ácidos benzoicos a bactéria Vibrio fischeri também apresentou maior sensibilidade que os outros organismos testados (Daphnia magna e a carpa Cyprinus carpiol) (Zhao et al., 1998).

Em relação à Daphnia magna o aumento do pH das soluções de ácidos benzoicos implicou no decréscimo da toxicidade, o que também foi verificado no presente estudo (Zhao et al., 1998).

No trabalho de Borrely (2001), onde foram realizados ensaios de toxicidade aguda (Daphnia similis e Vibrio fischeri) para a avaliação do tratamento de efluente da ETE Suzano após a irradiação com feixe de elétrons, apresentou eficiência acima de $85 \%$ na remoção da toxicidade para os dois organismos-teste. Em relação às doses, para o efluente coletado na primeira elevatória de esgotos (predominância de efluentes 
industriais) foi necessária dose de 50,0 kGy para reduzir a toxicidade com eficiência acima de $85 \%$, para o efluente coletado na grade média da estação (diluição com efluentes domésticos) 20,0 kGy e para o efluente final da estação dose de 5,0 kGy.

No caso de efluentes coloridos e da indústria química (que fabrica corantes) apenas doses superiores a 40,0 kGy apresentaram eficiência na remoção da toxicidade aguda (Daphnia similis e Vibrio fischeri) e cor. Para efluentes da indústria têxtil doses de 0,5 e 3,0 kGy tiveram eficiências significativas (Higa, 2008).

Duarte et al. (2000) sugerem a utilização de 20,0 kGy para o tratamento de efluente industrial antes da entrada na ETE e no caso para o tratamento do efluente final (após o tratamento biológico) uma dose de 5,0 kGy para a amostra utilizada neste caso.

Em seu trabalho Duarte (1999) salienta que o processo de tratamento por radiação ionizante não se apresenta como a solução definitiva no tratamento de efluentes industriais, devendo ser combinado com outras técnicas, principalmente o tratamento biológico convencional. Uma vez que os principais subprodutos formados da degradação dos compostos orgânicos por este método são ácidos orgânicos de estrutura simples que são facilmente biodegradáveis.

No presente estudo foi possível verificar que 0,5 kGy aplicado ao cloridrato de fluoxetina resultou alta eficiência na degradação (> 98\%) e na remoção da toxicidade aguda para Daphnia similis (> 80\%).

Para o esgoto e para a mistura a dose que se mostrou mais eficiente foi a de 5,0 kGy apresentando valores médios de CE50 $48 \mathrm{~h}$ acima dos $90 \%$, não foram aplicadas doses mais baixas para estas amostras pois como há presença de maior quantidade e variedade de compostos orgânicos doses mais altas são requeridas.

Apesar da alta eficiência na degradação do fármaco após o tratamento, a baixa taxa de mineralização inviabiliza o processo como solução definitiva como discutido anteriormente. Visto que o processo reduz a toxicidade das amostras e que os principais subprodutos formados após o tratamento por irradiação são ácidos orgânicos de estrutura simples o efluente gerado neste tratamento poderia seguir para um tratamento biológico convencional.

Desta forma este tipo de tratamento visa a degradação de substâncias que possuem baixa biodegradabilidade e que, devido a este fato, não são removidos com eficiência nas estações de tratamento de esgotos convencionais. 


\subsubsection{Análise estatística}

Pelo Teste Shapiro-Wilk verificou-se que os conjuntos de dados seguem uma distribuição normal, desta forma utilizou-se o método ANOVA.

Em relação às análises estatísticas para Daphnia similis foi possível verificar pelo método ANOVA que houve variação significativa entre as médias das amostras do cloridrato de fluoxetina, esgoto doméstico e mistura (CF + esgoto). Para a Vibrio fischeri, não houve variação significativa para a mistura pelo método ANOVA, por isso não foi realizado o Teste de Tukey, uma vez que este teste é utilizado no caso da ocorrência de variação significativa, buscar em quais níveis está ocorrendo variação significativa entre as médias.

TABELA 25. Dados calculados pelo Teste de Tukey para verificar a variação significativa entre as médias de CE50.

\begin{tabular}{|c|c|c|c|c|c|}
\hline Organismo & Amostra & Níveis & Estat. F & P-valor & $\begin{array}{c}\text { Variação } \\
\text { significativa }\end{array}$ \\
\hline \multirow{2}{*}{$\begin{array}{c}\text { Daphnia similis } \\
\left(10 \mathrm{mg} \mathrm{L}^{-1} *\right)\end{array}$} & \multirow{2}{*}{$\begin{array}{l}\text { Cloridrato de } \\
\text { fluoxetina }\end{array}$} & $0,0-5,0 \mathrm{kGy}$ & \multirow{2}{*}{434,28} & $7,15 \times 10^{-7}$ & Sim \\
\hline & & $0,0-20,0 \mathrm{kGy}$ & & $8,67 \times 10^{-7}$ & Sim \\
\hline \multirow{3}{*}{$\begin{array}{c}\text { Daphnia similis } \\
\left(20 \mathrm{mg} \mathrm{L}^{-1} *\right)\end{array}$} & \multirow{3}{*}{$\begin{array}{l}\text { Cloridrato de } \\
\text { fluoxetina }\end{array}$} & $0,0-0,5 \mathrm{kGy}$ & \multirow{3}{*}{95,93} & 0,001729 & Sim \\
\hline & & $0,0-5,0 \mathrm{kGy}$ & & 0,000560 & Sim \\
\hline & & $0,0-20,0 \mathrm{kGy}$ & & 0,000359 & Sim \\
\hline \multirow[t]{2}{*}{ Daphnia similis } & \multirow{2}{*}{$\begin{array}{c}\text { Esgoto } \\
\text { doméstico }\end{array}$} & $0,0-5,0 \mathrm{kGy}$ & \multirow{2}{*}{241,91} & $1,63 \times 10^{-6}$ & Sim \\
\hline & & $0,0-20,0 \mathrm{kGy}$ & & $1,38 \times 10^{-5}$ & Sim \\
\hline \multirow{2}{*}{$\begin{array}{l}\text { Daphnia similis } \\
\left(10 \mathrm{mg} \mathrm{L}^{-1} *\right)\end{array}$} & \multirow{2}{*}{$\begin{array}{l}\text { Mistura (CF } \\
\text { + esgoto) }\end{array}$} & $0,0-5,0 \mathrm{kGy}$ & \multirow{2}{*}{50,85} & 0,000145 & Sim \\
\hline & & $0,0-20,0 \mathrm{kGy}$ & & 0,001792 & Sim \\
\hline \multirow{4}{*}{$\begin{array}{l}\text { Vibrio fischeri } \\
\left(5 \mathrm{mg} \mathrm{L}^{-1} *\right)\end{array}$} & \multirow{4}{*}{$\begin{array}{l}\text { Cloridrato de } \\
\text { fluoxetina }\end{array}$} & $0,0-5,0 \mathrm{kGy}$ & \multirow{4}{*}{6,94} & 0,001617 & Sim \\
\hline & & $0,0-7,5 \mathrm{kGy}$ & & 0,035023 & Sim \\
\hline & & $0,0-15,0 \mathrm{kGy}$ & & 0,131999 & Não \\
\hline & & $0,0-20,0 \mathrm{kGy}$ & & 0,437201 & Não \\
\hline \multirow[t]{4}{*}{ Vibrio fischeri } & \multirow{4}{*}{$\begin{array}{c}\text { Esgoto } \\
\text { doméstico }\end{array}$} & $0,0-5,0 \mathrm{kGy}$ & \multirow{4}{*}{9,86} & 0,007736 & Sim \\
\hline & & $0,0-7,5 \mathrm{kGy}$ & & 0,017574 & Sim \\
\hline & & $0,0-15,0 \mathrm{kGy}$ & & 0,005741 & Sim \\
\hline & & $0,0-20,0 \mathrm{kGy}$ & & 0,010046 & Sim \\
\hline
\end{tabular}

* Concentração de cloridrato de fluoxetina na amostra.

$\mathrm{Na}$ TABELA 25, foram apresentados os valores de p-valor calculados pelo Teste de Tukey, valores menores que 0,05 indicam que há variação significativa entre as médias.

Observou-se que houve variação significativa entre as médias das amostras tratadas e não tratadas para todos os ensaios com Daphnia similis. Para a Vibrio fischeri não houve variação para as amostras de CF nas doses de 15,0 e 20,0 kGy e para as amostras de mistura ( $\mathrm{CF}+$ esgoto) em todas as doses de radiação. 


\section{CONCLUSÕES}

* O detector de fluorescência foi o mais adequado para o estudo em análises de cromatografia líquida para a detecção do cloridrato de fluoxetina, obtendo-se sensibilidade de detecção de 1000 vezes, se comparado ao detector UV/VIS.

* Quanto à toxicidade do cloridrato de fluoxetina aos organismos-teste empregados verificou-se maior sensibilidade na seguinte ordem Ceriodaphnia dubia, Vibrio fischeri e Daphnia similis.

* O tratamento da solução aquosa do fármaco cloridrato de fluoxetina por radiação com acelerador de elétrons foi eficiente, sendo obtida eficiência média de 98,02\% de remoção do composto com $0,5 \mathrm{kGy}$, partindo de $20 \mathrm{mg} \mathrm{L}^{-1}$. Foi obtido $22 \%$ de mineralização do cloridrato de fluoxetina com 20,0 kGy.

* Eficiência da irradiação na redução da toxicidade: relativamente baixa para o ensaios com Vibrio fischeri $(<22 \%)$ tanto para as soluções com o fármaco como para a mistura (solução de fármaco + esgoto doméstico). Acima de $80 \%$ de remoção da toxicidade para Daphnia similis mesmo com 0,5 kGy. Para o esgoto doméstico e para a mistura (CF + esgoto) a melhor dose foi de 5,0 kGy, apresentando eficiência de $100 \%$ e $79,32 \%$, respectivamente. Houve influência do $\mathrm{pH}$ na toxicidade das amostras de cloridrato de fluoxetina após a irradiação.

* Com relação ao efeito crônico, eficiência de 97,50\% foi obtida para amostras tratadas com 5,0 kGy e expostas à Ceriodaphnia dubia.

* Visto que a irradiação possui baixa capacidade de mineralização de compostos orgânicos e elevado potencial de degradação e remoção de toxicidade, este processo pode ser utilizado como pré-tratamento de efluentes, facilitando a remoção de substâncias recalcitrantes. Desta forma doses baixas (entre 0,5 e 5,0 kGy) se apresentam como as mais adequadas, representando, ainda, benefícios em termos de custo do processo. 


\section{SUGESTÕES DE TRABALHOS FUTUROS}

* Sugere-se para trabalhos futuros a combinação de outros tipos de tratamentos, como por exemplo o tratamento biológico convencional, após o pré-tratamento utilizando a radiação ionizante. Visto que este Processo Oxidativo Avançado possui alta taxa de degradação, porém baixa mineralização dos compostos orgânicos.

* Verifica-se a necessidade de estudos ecotoxicológicos que analisem outros "endpoints", ou seja, outros efeitos que possam surgir devido as características tóxicas de substâncias e que causem danos menos perceptíveis mas que possam causar problemas graves sem causar a mortalidade dos organismos.

* O monitoramento de fármacos no ambiente, principalmente nos reservatórios de águas para o abastecimento.

* Finalmente é muito importante propor trabalhos que enfatizem o uso e descarte racionais para os medicamentos, bem como o adequado gerenciamento industrial deste tipo de resíduo de modo a evitar a contaminação dos ambientes aquáticos. 


\section{APÊNDICES \\ APÊNDICE A: Fichas - controle dos ensaios de toxicidade aguda com Daphnia similis}

Ensaios com cloridrato de fluoxetina em concentrações de $10,0 \mathrm{mg} \mathrm{L}^{-1}(0,0 \mathrm{kGy})$

Ensaio 1

\begin{tabular}{|c|c|c|c|c|c|c|c|c|c|c|c|}
\hline \multicolumn{9}{|c|}{ ENSAIO DE TOXICIDADE AGUDA - Daphnia similis } & \multirow{2}{*}{\multicolumn{3}{|c|}{$\begin{array}{l}\text { Dose de radiação: } 0,0 \text { kGy } \\
\text { Água de diluição } \\
\end{array}$}} \\
\hline \multicolumn{5}{|l|}{ Início } & \multicolumn{4}{|l|}{ Término } & & & \\
\hline $\begin{array}{l}\text { Data: } \\
07 / 05 / 2013\end{array}$ & \multicolumn{4}{|c|}{$\begin{array}{l}\text { Hora: } \\
16: 15\end{array}$} & \multicolumn{2}{|c|}{$\begin{array}{l}\text { Data: } \\
09 / 05 / 2013\end{array}$} & \multicolumn{2}{|c|}{$\begin{array}{l}\text { Hora: } \\
16: 15\end{array}$} & \multicolumn{2}{|c|}{ Dureza: 45,0} & $\begin{array}{l}\text { Manancial } \\
\text { Salto-SP }\end{array}$ \\
\hline \multicolumn{5}{|c|}{ Organismo - teste: Daphnia similis } & \multicolumn{4}{|c|}{ Amostra: Cloridrato de fluoxetina } & \multicolumn{3}{|c|}{ Operador: Vanessa } \\
\hline \multirow[t]{2}{*}{$\begin{array}{l}\text { Concentração } \\
\text { nominal (\%) }\end{array}$} & \multicolumn{4}{|c|}{$\begin{array}{l}\text { Organismos } \\
\text { imóveis por réplica }\end{array}$} & \multirow[t]{2}{*}{$\begin{array}{l}\% \text { de } \\
\text { imóveis }\end{array}$} & \multirow[t]{2}{*}{$\mathrm{pH}_{\mathrm{i}}$} & \multirow[t]{2}{*}{$\mathrm{pH}_{\mathrm{f}}$} & \multirow[t]{2}{*}{$\begin{array}{l}\mathrm{OD}_{\mathrm{i}} \\
\left(\mathrm{mg} \mathrm{L}^{-1}\right)\end{array}$} & \multirow[t]{2}{*}{$\begin{array}{l}\mathrm{OD}_{\mathrm{f}} \\
\left(\mathrm{mg} \mathrm{L}^{-1}\right)\end{array}$} & \multirow[t]{2}{*}{$\begin{array}{l}\text { Cond }_{\cdot \mathrm{i}} \\
\left(\mu \mathrm{cm}^{-1}\right)\end{array}$} & \multirow[t]{2}{*}{$\begin{array}{l}\text { Cond }_{\cdot f} \\
\left(\mu \mathrm{S} \mathrm{cm}^{-1}\right)\end{array}$} \\
\hline & 1 & 2 & 3 & 4 & & & & & & & \\
\hline Controle & 0 & 0 & 0 & 0 & 0 & 8,02 & 7,66 & 7,93 & 7,89 & 172,3 & 177,2 \\
\hline 6,25 & 0 & 0 & 0 & 1 & 5 & 7,89 & 7,90 & 7,75 & 7,83 & 168,6 & 164,6 \\
\hline 12,50 & 3 & 3 & 2 & 5 & 65 & 7,96 & 7,95 & 7,78 & 7,82 & 155,3 & 153,3 \\
\hline 25,00 & 4 & 5 & 5 & 4 & 90 & 7,98 & 7,90 & 7,84 & 7,79 & 135,4 & 135,3 \\
\hline 50,00 & 5 & 5 & 5 & 5 & 100 & 7,89 & 7,79 & 7,88 & 7,74 & 94,1 & 97,5 \\
\hline 75,00 & 5 & 5 & 5 & 5 & 100 & 7,57 & 7,60 & 7,97 & 7,74 & 52,5 & 56,9 \\
\hline 100,00 & 5 & 5 & 5 & 5 & 100 & 6,68 & 7,06 & 8,02 & 7,77 & 6,8 & 14,7 \\
\hline \multicolumn{12}{|c|}{ Observações: CE50 $_{48 \mathrm{~h}}: 11,46(9,47-13,88)$} \\
\hline
\end{tabular}

Ensaio 2

\begin{tabular}{|c|c|c|c|c|c|c|c|c|c|c|c|}
\hline \multicolumn{9}{|c|}{ ENSAIO DE TOXICIDADE AGUDA - Daphnia similis } & \multirow{2}{*}{\multicolumn{3}{|c|}{$\begin{array}{l}\text { Dose de radiação: } 0,0 \mathrm{kGy} \\
\text { Água de diluição }\end{array}$}} \\
\hline \multicolumn{5}{|l|}{ Início } & \multicolumn{4}{|l|}{ Término } & & & \\
\hline $\begin{array}{l}\text { Data: } \\
11 / 06 / 2013\end{array}$ & $\begin{array}{l}\mathrm{Ho} \\
16:\end{array}$ & & & & $\begin{array}{l}\text { Data: } \\
13 / 06 / 201\end{array}$ & & ora: & & \multicolumn{2}{|c|}{ Dureza: 45,0} & $\begin{array}{l}\text { Manancial: } \\
\text { Salto - SP }\end{array}$ \\
\hline \multicolumn{5}{|c|}{ Organismo - teste: Daphnia similis } & \multicolumn{4}{|c|}{ Amostra: Cloridrato de fluoxetina } & \multicolumn{3}{|c|}{ Operador: Vanessa } \\
\hline \multirow[t]{2}{*}{$\begin{array}{l}\text { Concentração } \\
\text { nominal (\%) }\end{array}$} & \multicolumn{4}{|c|}{$\begin{array}{l}\text { Organismos imóveis } \\
\text { por réplica }\end{array}$} & \multirow[t]{2}{*}{$\begin{array}{l}\text { \% de } \\
\text { imóveis }\end{array}$} & \multirow[t]{2}{*}{$\mathrm{pH}_{\mathrm{i}}$} & \multirow[t]{2}{*}{$\mathrm{pH}_{\mathrm{f}}$} & \multirow[t]{2}{*}{$\begin{array}{l}\mathrm{OD}_{\mathrm{i}} \\
\left(\mathrm{mg} \mathrm{L}^{-1}\right)\end{array}$} & \multirow[t]{2}{*}{$\begin{array}{l}\mathrm{OD}_{\mathrm{f}} \\
\left(\mathrm{mg} \mathrm{L}^{-1}\right)\end{array}$} & \multirow[t]{2}{*}{$\begin{array}{l}\text { Cond }_{\cdot \mathrm{i}} \\
\left(\mu \mathrm{cm}^{-1}\right)\end{array}$} & \multirow[t]{2}{*}{$\begin{array}{l}\text { Cond }_{. f} \\
\left(\mu \mathrm{cm}^{-1}\right)\end{array}$} \\
\hline & 1 & 2 & 3 & 4 & & & & & & & \\
\hline Controle & 0 & 0 & 0 & 0 & 0 & 7,90 & 7,68 & 7,90 & 7,91 & 173,0 & 176,9 \\
\hline 6,25 & 0 & 0 & 0 & 0 & 0 & 7,80 & 7,77 & 7,86 & 7,89 & 158,3 & 156,3 \\
\hline 12,50 & 2 & 1 & 4 & 1 & 40 & 7,82 & 7,74 & 7,85 & 7,87 & 153,9 & 153,1 \\
\hline 25,00 & 4 & 4 & 3 & 4 & 75 & 7,84 & 7,73 & 7,83 & 7,85 & 134,8 & 139,1 \\
\hline 50,00 & 5 & 5 & 5 & 5 & 100 & 7,77 & 7,75 & 7,78 & 7,82 & 95,4 & 98,0 \\
\hline 75,00 & 5 & 4 & 5 & 5 & 95 & 7,60 & 7,79 & 7,72 & 7,81 & 53,2 & 58,7 \\
\hline 100,00 & 5 & 5 & 5 & 5 & 100 & 7,00 & 7,92 & 7,00 & 7,83 & 9,0 & 11,9 \\
\hline
\end{tabular}

Ensaio 3

\begin{tabular}{|c|c|c|c|c|c|c|c|c|c|c|c|}
\hline \multicolumn{9}{|c|}{ ENSAIO DE TOXICIDADE AGUDA - Daphnia similis } & \multirow{2}{*}{\multicolumn{3}{|c|}{$\begin{array}{l}\text { Dose de radiação: } 0,0 \mathrm{kGy} \\
\text { Água de diluição }\end{array}$}} \\
\hline \multicolumn{5}{|l|}{ Início } & \multicolumn{4}{|l|}{ Término } & & & \\
\hline $\begin{array}{l}\text { Data: } \\
29 / 10 / 2013\end{array}$ & $\begin{array}{l}\mathrm{Hol} \\
16:\end{array}$ & & & & $\begin{array}{l}\text { Data: } \\
31 / 10 / 201\end{array}$ & & $\begin{array}{l}\text { Hora: } \\
\text { 16:00 }\end{array}$ & & \multicolumn{2}{|c|}{ Dureza: 45,0} & $\begin{array}{l}\text { Manancial: } \\
\text { Salto-SP }\end{array}$ \\
\hline \multicolumn{5}{|c|}{ Organismo - teste: Daphnia similis } & \multicolumn{4}{|c|}{ Amostra: Cloridrato de fluoxetina } & \multicolumn{3}{|c|}{ Operador: Vanessa } \\
\hline \multirow[t]{2}{*}{$\begin{array}{l}\text { Concentração } \\
\text { nominal (\%) }\end{array}$} & \multicolumn{4}{|c|}{$\begin{array}{l}\text { Organismos imóveis } \\
\text { por réplica }\end{array}$} & \multirow[t]{2}{*}{$\begin{array}{l}\text { \% de } \\
\text { imóveis }\end{array}$} & \multirow[t]{2}{*}{$\mathrm{pH}_{\mathrm{i}}$} & \multirow[t]{2}{*}{$\mathrm{pH}_{\mathrm{f}}$} & \multirow[t]{2}{*}{$\begin{array}{l}\mathrm{OD}_{\mathrm{i}} \\
\left(\mathrm{mg} \mathrm{L}^{-1}\right)\end{array}$} & \multirow[t]{2}{*}{$\begin{array}{l}\mathrm{OD}_{\mathrm{f}} \\
\left(\mathrm{mg} \mathrm{L}^{-1}\right)\end{array}$} & \multirow[t]{2}{*}{$\begin{array}{l}\text { Cond. }_{\cdot \mathrm{i}} \\
\left(\mu \mathrm{S} \mathrm{cm}^{-1}\right)\end{array}$} & \multirow[t]{2}{*}{$\begin{array}{l}\text { Cond }_{\cdot f} \\
\left(\mu \mathrm{S} \mathrm{cm}^{-1}\right)\end{array}$} \\
\hline & 1 & 2 & 3 & 4 & & & & & & & \\
\hline Controle & 0 & 1 & 0 & 0 & 5 & 7,97 & 7,97 & 7,14 & 7,61 & 190,7 & 183,7 \\
\hline 6,25 & 0 & 0 & 1 & 0 & 5 & 7,89 & 8,01 & 6,92 & 7,73 & 177,5 & 174,1 \\
\hline 12,50 & 3 & 4 & 4 & 3 & 70 & 7,80 & 7,98 & 6,92 & 7,71 & 168,2 & 165,1 \\
\hline 25,00 & 5 & 5 & 5 & 5 & 100 & 7,64 & 7,91 & 6,93 & 7,70 & 145,5 & 146,6 \\
\hline 50,00 & 5 & 5 & 5 & 5 & 100 & 7,32 & 7,73 & 6,88 & 7,69 & 99,2 & 105,1 \\
\hline 75,00 & 5 & 5 & 5 & 5 & 100 & 7,14 & 7,44 & 6,77 & 7,68 & 53,0 & 59,1 \\
\hline 100,00 & 5 & 5 & 5 & 5 & 100 & 6,66 & 6,66 & 6,55 & 7,69 & 5,2 & 16,8 \\
\hline
\end{tabular}




\section{Ensaios com cloridrato de fluoxetina em concentrações de $10,0 \mathrm{mg} \mathrm{L}^{-1} \mathrm{com}$ pH corrigido $(0,0 \mathrm{kGy})$}

Ensaio 4

\begin{tabular}{|c|c|c|c|c|c|c|c|c|c|c|c|}
\hline \multicolumn{9}{|c|}{ ENSAIO DE TOXICIDADE AGUDA - Daphnia similis } & \multirow{2}{*}{\multicolumn{3}{|c|}{$\begin{array}{l}\text { Dose de radiação: } 0,0 \mathrm{kGy} \\
\text { Água de diluição }\end{array}$}} \\
\hline \multicolumn{5}{|c|}{ 2010 } & \multicolumn{4}{|l|}{ Término } & & & \\
\hline $\begin{array}{l}\text { Data: } \\
05 / 12 / 2013\end{array}$ & $\begin{array}{l}\mathrm{Ho} \\
16:\end{array}$ & & & & $\begin{array}{l}\text { Data: } \\
07 / 12 / 201\end{array}$ & & $\begin{array}{l}\text { Hora: } \\
16: 00\end{array}$ & & \multicolumn{2}{|c|}{$\begin{array}{l}\text { Dureza: } 45,0 \\
\mathrm{mg} \mathrm{CaCO}_{3} \mathrm{~L}^{-1}\end{array}$} & $\begin{array}{l}\text { Manancial: } \\
\text { Salto - SP }\end{array}$ \\
\hline \multicolumn{5}{|c|}{ Organismo - teste: Daphnia similis } & \multicolumn{4}{|c|}{ Amostra: Cloridrato de fluoxetina } & \multicolumn{3}{|c|}{ Operador: Vanessa } \\
\hline \multirow[t]{2}{*}{$\begin{array}{l}\text { Concentração } \\
\text { nominal }(\%)\end{array}$} & \multicolumn{4}{|c|}{$\begin{array}{l}\text { Organismos imóveis } \\
\text { por réplica }\end{array}$} & \multirow[t]{2}{*}{$\begin{array}{l}\text { \% de } \\
\text { imóveis }\end{array}$} & \multirow[t]{2}{*}{$\mathrm{pH}_{\mathrm{i}}$} & \multirow[t]{2}{*}{$\mathrm{pH}_{\mathrm{f}}$} & \multirow[t]{2}{*}{$\begin{array}{l}\mathrm{OD}_{\mathrm{i}} \\
\left(\mathrm{mg} \mathrm{L}^{-1}\right)\end{array}$} & \multirow[t]{2}{*}{$\begin{array}{l}\mathrm{OD}_{\mathrm{f}} \\
\left(\mathrm{mg} \mathrm{L}^{-1}\right)\end{array}$} & \multirow[t]{2}{*}{$\begin{array}{l}\text { Cond }_{\cdot \mathrm{i}} \\
\left(\mu \mathrm{cm}^{-1}\right)\end{array}$} & \multirow[t]{2}{*}{$\begin{array}{l}\text { Cond }_{. f} \\
\left(\mu \mathrm{cm}^{-1}\right)\end{array}$} \\
\hline & 1 & 2 & 3 & 4 & & & & & & & \\
\hline Controle & 0 & 0 & 0 & 0 & 0 & 8,07 & 8,02 & 7,18 & 7,43 & 198,0 & 197,1 \\
\hline 6,25 & 0 & 0 & 0 & 0 & 0 & 8,02 & 7,98 & 7,12 & 7,67 & 183,8 & 194,6 \\
\hline 12,50 & 1 & 2 & 2 & 2 & 35 & 8,04 & 7,96 & 7,11 & 7,68 & 174,6 & 176,1 \\
\hline 25,00 & 5 & 5 & 5 & 5 & 100 & 8,05 & 7,96 & 7,10 & 7,61 & 152,2 & 153,6 \\
\hline 50,00 & 5 & 5 & 5 & 5 & 100 & 7,84 & 7,85 & 7,08 & 7,61 & 107,5 & 108,2 \\
\hline 75,00 & 5 & 5 & 5 & 5 & 100 & 7,80 & 7,82 & 7,08 & 7,65 & 58,3 & 62,0 \\
\hline 100,00 & 5 & 5 & 5 & 5 & 100 & 7,03 & 7,01 & 7,10 & 7,68 & 9,8 & 15,9 \\
\hline
\end{tabular}

Ensaio 5

\begin{tabular}{|c|c|c|c|c|c|c|c|c|c|c|c|}
\hline \multicolumn{9}{|c|}{ ENSAIO DE TOXICIDADE AGUDA - Daphnia similis } & \multirow{2}{*}{\multicolumn{3}{|c|}{$\begin{array}{l}\text { Dose de radiação: } 0,0 \mathrm{kGy} \\
\text { Água de diluição }\end{array}$}} \\
\hline \multicolumn{5}{|l|}{ Início } & \multicolumn{4}{|l|}{ Término } & & & \\
\hline $\begin{array}{l}\text { Data: } \\
12 / 02 / 2014\end{array}$ & \multicolumn{4}{|c|}{$\begin{array}{l}\text { Hora: } \\
15: 30\end{array}$} & $\begin{array}{l}\text { Data: } \\
\text { 14/02/201 }\end{array}$ & \multicolumn{3}{|c|}{ Data: } & \multicolumn{2}{|c|}{$\begin{array}{l}\text { Dureza: } 45,0 \\
\mathrm{mg} \mathrm{CaCO}_{3} \mathrm{~L}^{-1}\end{array}$} & $\begin{array}{l}\text { Manancial: } \\
\text { Salto - SP }\end{array}$ \\
\hline \multicolumn{5}{|c|}{ Organismo - teste: Daphnia similis } & \multicolumn{4}{|c|}{ Amostra: Cloridrato de fluoxetina } & \multicolumn{3}{|c|}{ Operador: Vanessa } \\
\hline \multirow[t]{2}{*}{$\begin{array}{l}\text { Concentração } \\
\text { nominal }(\%)\end{array}$} & \multicolumn{4}{|c|}{$\begin{array}{l}\text { Organismos imóveis } \\
\text { por réplica }\end{array}$} & \multirow[t]{2}{*}{$\begin{array}{l}\text { \% de } \\
\text { imóveis }\end{array}$} & \multirow[t]{2}{*}{$\mathrm{pH}_{\mathrm{i}}$} & \multirow[t]{2}{*}{$\mathrm{pH}_{\mathrm{f}}$} & \multirow[t]{2}{*}{$\begin{array}{l}\mathrm{OD}_{\mathrm{i}} \\
\left(\mathrm{mg} \mathrm{L}^{-1}\right)\end{array}$} & \multirow[t]{2}{*}{$\begin{array}{l}\mathrm{OD}_{\mathrm{f}} \\
\left(\mathrm{mg} \mathrm{L}^{-1}\right)\end{array}$} & \multirow[t]{2}{*}{$\begin{array}{l}\text { Cond }_{\cdot \mathrm{i}} \\
\left(\mu \mathrm{S} \mathrm{cm}^{-1}\right)\end{array}$} & \multirow[t]{2}{*}{$\begin{array}{l}\text { Cond }_{f} \\
\left(\mu \mathrm{S} \mathrm{cm}^{-1}\right)\end{array}$} \\
\hline & 1 & 2 & 3 & 4 & & & & & & & \\
\hline Controle & 0 & 0 & 0 & 0 & 0 & 7,91 & 7,86 & 6,68 & 7,10 & 193,8 & 204,1 \\
\hline 6,25 & 0 & 0 & 0 & 0 & 0 & 7,80 & 7,81 & 6,70 & 6,89 & 187,2 & 192,3 \\
\hline 12,50 & 3 & 2 & 3 & 3 & 50 & 7,79 & 7,80 & 6,75 & 6,90 & 172,3 & 173,2 \\
\hline 25,00 & 5 & 5 & 5 & 5 & 100 & 7,77 & 7,78 & 6,72 & 6,95 & 157,8 & 157,0 \\
\hline 50,00 & 5 & 5 & 5 & 5 & 100 & 7,70 & 7,70 & 6,73 & 7,01 & 111,7 & 113,4 \\
\hline 75,00 & 5 & 5 & 5 & 5 & 100 & 7,63 & 7,64 & 6,74 & 7,05 & 69,0 & 70,9 \\
\hline 100,00 & 5 & 5 & 5 & 5 & 100 & 7,50 & 7,56 & 6,74 & 7,13 & 25,1 & 31,1 \\
\hline
\end{tabular}


Ensaios com cloridrato de fluoxetina em concentrações de $20,0 \mathrm{mg} \mathrm{L}^{-1}(0,0 \mathrm{kGy})$

Ensaio 6

\begin{tabular}{|c|c|c|c|c|c|c|c|c|c|c|c|}
\hline \multicolumn{9}{|c|}{ ENSAIO DE TOXICIDADE AGUDA - Daphnia similis } & \multirow{2}{*}{\multicolumn{3}{|c|}{$\begin{array}{l}\text { Dose de radiação: } 0,0 \mathrm{kGy} \\
\text { Água de diluição }\end{array}$}} \\
\hline \multicolumn{5}{|l|}{ Início } & \multicolumn{4}{|l|}{ Término } & & & \\
\hline $\begin{array}{l}\text { Data: } \\
03 / 04 / 2013\end{array}$ & \multicolumn{4}{|c|}{$\begin{array}{l}\text { Hora: } \\
16: 00\end{array}$} & \multicolumn{2}{|c|}{$\begin{array}{l}\text { Data: } \\
05 / 04 / 2013\end{array}$} & \multicolumn{2}{|l|}{$\begin{array}{l}\text { Hora: } \\
16: 00\end{array}$} & \multicolumn{2}{|c|}{$\begin{array}{l}\text { Dureza: } 45,0 \\
\text { mg CaCO}_{3} \mathrm{~L}^{-1}\end{array}$} & $\begin{array}{l}\text { Manancial: } \\
\text { Salto - SP }\end{array}$ \\
\hline \multicolumn{5}{|c|}{ Organismo - teste: Daphnia similis } & \multicolumn{4}{|c|}{ Amostra: Cloridrato de fluoxetina } & \multicolumn{3}{|c|}{ Operador: Vanessa } \\
\hline \multirow[t]{2}{*}{$\begin{array}{l}\text { Concentração } \\
\text { nominal }(\%)\end{array}$} & \multicolumn{4}{|c|}{$\begin{array}{l}\text { Organismos imóveis } \\
\text { por réplica }\end{array}$} & \multirow[t]{2}{*}{$\begin{array}{l}\text { \% de } \\
\text { imóveis }\end{array}$} & \multirow[t]{2}{*}{$\mathrm{pH}_{\mathrm{i}}$} & \multirow[t]{2}{*}{$\mathrm{pH}_{\mathrm{f}}$} & \multirow[t]{2}{*}{$\begin{array}{l}\mathrm{OD}_{\mathrm{i}} \\
\left(\mathrm{mg} \mathrm{L}^{-1}\right)\end{array}$} & \multirow[t]{2}{*}{$\begin{array}{l}\mathrm{OD}_{\mathrm{f}} \\
\left(\mathrm{mg} \mathrm{L}^{-1}\right)\end{array}$} & \multirow[t]{2}{*}{$\begin{array}{l}\text { Cond }_{\cdot \mathrm{i}} \\
\left(\mu \mathrm{cm}^{-1}\right)\end{array}$} & \multirow[t]{2}{*}{$\begin{array}{l}\text { Cond }_{. f} \\
\left(\mu S \mathrm{~cm}^{-1}\right)\end{array}$} \\
\hline & 1 & 2 & 3 & 4 & & & & & & & \\
\hline Controle & 0 & 0 & 0 & 0 & 0 & 7,84 & 7,97 & 7,50 & 7,43 & 176,3 & 233,0 \\
\hline 6,25 & 3 & 1 & 2 & 3 & 45 & 7,97 & 8,00 & 7,43 & 7,44 & 164,5 & 164,2 \\
\hline 12,50 & 4 & 3 & 5 & 5 & 85 & 7,99 & 8,04 & 7,38 & 7,45 & 154,2 & 155,7 \\
\hline 25,00 & 5 & 5 & 5 & 5 & 100 & 7,88 & 8,02 & 7,38 & 7,45 & 136,0 & 138,4 \\
\hline 50,00 & 5 & 5 & 5 & 5 & 100 & 7,80 & 7,94 & 7,37 & 7,52 & 95,7 & 98,1 \\
\hline 75,00 & 5 & 5 & 5 & 5 & 100 & 7,49 & 7,60 & 7,37 & 7,50 & 53,8 & 58,1 \\
\hline 100,00 & 5 & 5 & 5 & 5 & 100 & 6,42 & 7,14 & 7,72 & 7,53 & 8,9 & 16,9 \\
\hline
\end{tabular}

Ensaio 7

\begin{tabular}{|c|c|c|c|c|c|c|c|c|c|c|c|}
\hline \multicolumn{9}{|c|}{ ENSAIO DE TOXICIDADE AGUDA - Daphnia similis } & \multirow{2}{*}{\multicolumn{3}{|c|}{$\begin{array}{l}\text { Dose de radiação: } 0,0 \text { kGy } \\
\text { Água de diluição }\end{array}$}} \\
\hline \multicolumn{5}{|l|}{ Início } & \multicolumn{4}{|c|}{ Término } & & & \\
\hline $\begin{array}{l}\text { Data: } \\
16 / 07 / 2013\end{array}$ & \multicolumn{4}{|c|}{$\begin{array}{l}\text { Hora: } \\
16: 15\end{array}$} & \multicolumn{2}{|c|}{$\begin{array}{l}\text { Data: } \\
18 / 07 / 2013\end{array}$} & \multicolumn{2}{|l|}{$\begin{array}{l}\text { Hora: } \\
16: 15\end{array}$} & \multicolumn{2}{|c|}{$\begin{array}{l}\text { Dureza: } 45,0 \\
\mathrm{mg} \mathrm{CaCO}_{3} \mathrm{~L}^{-1}\end{array}$} & $\begin{array}{l}\text { Manancial: } \\
\text { Salto - SP }\end{array}$ \\
\hline \multicolumn{5}{|c|}{ Organismo - teste: Daphnia similis } & \multicolumn{4}{|c|}{ Amostra: Cloridrato de fluoxetina } & \multicolumn{3}{|c|}{ Operador: Vanessa } \\
\hline \multirow[t]{2}{*}{$\begin{array}{l}\text { Concentração } \\
\text { nominal (\%) }\end{array}$} & \multicolumn{4}{|c|}{$\begin{array}{l}\text { Organismos imóveis } \\
\text { por réplica }\end{array}$} & \multirow[t]{2}{*}{$\begin{array}{l}\% \text { de } \\
\text { imóveis }\end{array}$} & \multirow[t]{2}{*}{$\mathrm{pH}_{\mathrm{i}}$} & \multirow[t]{2}{*}{$\mathrm{pH}_{\mathrm{f}}$} & \multirow[t]{2}{*}{$\begin{array}{l}\mathrm{OD}_{\mathrm{i}} \\
\left(\mathrm{mg} \mathrm{L}^{-1}\right)\end{array}$} & \multirow[t]{2}{*}{$\begin{array}{l}\mathrm{OD}_{\mathrm{f}} \\
\left(\mathrm{mg} \mathrm{L}^{-1}\right)\end{array}$} & \multirow[t]{2}{*}{$\begin{array}{l}\text { Cond }_{\cdot \mathrm{i}} \\
\left(\mu \mathrm{cm}^{-1}\right)\end{array}$} & \multirow[t]{2}{*}{$\begin{array}{l}\text { Cond.f }_{. f} \\
\left(\mu \mathrm{S} \mathrm{cm}^{-1}\right)\end{array}$} \\
\hline & 1 & 2 & 3 & 4 & & & & & & & \\
\hline Controle & 0 & 0 & 0 & 0 & 0 & 7,66 & 7,65 & 8,05 & 7,82 & 175,5 & 175,5 \\
\hline 6,25 & 1 & 3 & 2 & 3 & 45 & 7,67 & 7,77 & 8,15 & 7,72 & 156,8 & 158,8 \\
\hline 12,50 & 4 & 4 & 5 & 5 & 90 & 7,76 & 7,83 & 8,06 & 7,67 & 154,6 & 155,2 \\
\hline 25,00 & 5 & 5 & 5 & 5 & 100 & 7,81 & 7,82 & 8,05 & 7,64 & 135,5 & 137,8 \\
\hline 50,00 & 5 & 5 & 5 & 5 & 100 & 7,81 & 7,80 & 8,16 & 7,64 & 96,4 & 99,5 \\
\hline 75,00 & 5 & 5 & 5 & 5 & 100 & 7,71 & 7,60 & 8,29 & 7,68 & 54,6 & 59,0 \\
\hline 100,00 & 5 & 5 & 5 & 5 & 100 & 7,14 & 7,12 & 8,63 & 7,73 & 11,0 & 17,8 \\
\hline
\end{tabular}


Ensaios com cloridrato de fluoxetina em concentrações de $20,0 \mathrm{mg} \mathrm{L}^{-1}(0,5 \mathrm{kGy})$

Ensaio 6

\begin{tabular}{|c|c|c|c|c|c|c|c|c|c|c|c|}
\hline \multicolumn{9}{|c|}{ ENSAIO DE TOXICIDADE AGUDA - Daphnia similis } & \multirow{2}{*}{\multicolumn{3}{|c|}{$\begin{array}{l}\text { Dose de radiação: } 0,5 \mathrm{kGy} \\
\text { Água de diluição }\end{array}$}} \\
\hline \multicolumn{5}{|l|}{ Início } & \multicolumn{4}{|l|}{ Término } & & & \\
\hline $\begin{array}{l}\text { Data: } \\
16 / 07 / 2013\end{array}$ & $\begin{array}{l}\text { Ho } \\
16:\end{array}$ & & & & $\begin{array}{l}\text { Data: } \\
18 / 07 / 201\end{array}$ & & $\begin{array}{l}\text { Hora: } \\
16: 45\end{array}$ & & \multicolumn{2}{|c|}{$\begin{array}{l}\text { Dureza: } 45,0 \\
\mathrm{mg} \mathrm{CaCO}_{3} \mathrm{~L}^{-1}\end{array}$} & $\begin{array}{l}\text { Manancial: } \\
\text { Salto - SP }\end{array}$ \\
\hline \multicolumn{5}{|c|}{ Organismo - teste: Daphnia similis } & \multicolumn{4}{|c|}{ Amostra: Cloridrato de fluoxetina } & \multicolumn{3}{|c|}{ Operador: Vanessa } \\
\hline \multirow[t]{2}{*}{$\begin{array}{l}\text { Concentração } \\
\text { nominal (\%) }\end{array}$} & \multicolumn{4}{|c|}{$\begin{array}{l}\text { Organismos imóveis } \\
\text { por réplica }\end{array}$} & \multirow[t]{2}{*}{$\begin{array}{l}\text { \% de } \\
\text { imóveis }\end{array}$} & \multirow[t]{2}{*}{$\mathrm{pH}_{\mathrm{i}}$} & \multirow[t]{2}{*}{$\mathrm{pH}_{\mathrm{f}}$} & \multirow[t]{2}{*}{$\begin{array}{l}\mathrm{OD}_{\mathrm{i}} \\
\left(\mathrm{mg} \mathrm{L}^{-1}\right)\end{array}$} & \multirow[t]{2}{*}{$\begin{array}{l}\mathrm{OD}_{\mathrm{f}} \\
\left(\mathrm{mg} \mathrm{L}^{-1}\right)\end{array}$} & \multirow[t]{2}{*}{$\begin{array}{l}\text { Cond }_{\cdot \mathrm{i}} \\
\left(\mu \mathrm{sm}^{-1}\right)\end{array}$} & \multirow[t]{2}{*}{$\begin{array}{l}\text { Cond }_{f_{\mathrm{f}}} \\
\left(\mu \mathrm{S} \mathrm{cm}^{-1}\right)\end{array}$} \\
\hline & 1 & 2 & 3 & 4 & & & & & & & \\
\hline Controle & 0 & 0 & 0 & 0 & 0 & 7,81 & 7,72 & 7,96 & 8,08 & 185,8 & 185,1 \\
\hline 6,25 & 0 & 0 & 0 & 0 & 0 & 7,78 & 7,77 & 8,30 & 8,06 & 164,1 & 167,1 \\
\hline 12,50 & 0 & 0 & 0 & 0 & 0 & 7,73 & 7,75 & 8,31 & 8,05 & 161,6 & 162,3 \\
\hline 25,00 & 0 & 1 & 0 & 0 & 5 & 7,68 & 7,71 & 8,31 & 8,04 & 140,6 & 141,7 \\
\hline 50,00 & 3 & 2 & 3 & 3 & 55 & 7,40 & 7,42 & 8,32 & 8,03 & 98,9 & 99,8 \\
\hline 75,00 & 5 & 5 & 5 & 5 & 100 & 6,62 & 6,66 & 8,40 & 8,05 & 55,0 & 58,0 \\
\hline 100,00 & 5 & 5 & 5 & 5 & 100 & 4,20 & 4,21 & 8,49 & 8,07 & 40,2 & 41,7 \\
\hline
\end{tabular}

Ensaio 7

\begin{tabular}{|c|c|c|c|c|c|c|c|c|c|c|c|}
\hline \multicolumn{9}{|c|}{ ENSAIO DE TOXICIDADE AGUDA - Daphnia similis } & \multirow{2}{*}{\multicolumn{3}{|c|}{$\begin{array}{l}\text { Dose de radiação: } 0,5 \text { kGy } \\
\text { Água de diluição }\end{array}$}} \\
\hline \multicolumn{5}{|c|}{ 2010 } & \multicolumn{4}{|c|}{ Término } & & & \\
\hline $\begin{array}{l}\text { Data: } \\
14 / 08 / 2013\end{array}$ & \multicolumn{4}{|c|}{$\begin{array}{l}\text { Hora: } \\
16: 00\end{array}$} & \multicolumn{2}{|l|}{ Data: } & \multicolumn{2}{|l|}{$\begin{array}{l}\text { Hora: } \\
16: 00\end{array}$} & $\begin{array}{l}\text { Dureza: } 4 \\
\mathrm{mg} \mathrm{CaCC}\end{array}$ & ${ }_{3}^{5} \mathrm{~L}^{-1}$ & $\begin{array}{l}\text { Manancial: } \\
\text { Salto - SP }\end{array}$ \\
\hline \multicolumn{5}{|c|}{ Organismo - teste: Daphnia similis } & \multicolumn{4}{|c|}{ Amostra: Cloridrato de fluoxetina } & \multicolumn{3}{|c|}{ Operador: Vanessa } \\
\hline \multirow[t]{2}{*}{$\begin{array}{l}\text { Concentração } \\
\text { nominal }(\%)\end{array}$} & \multicolumn{4}{|c|}{$\begin{array}{l}\text { Organismos imóveis } \\
\text { por réplica }\end{array}$} & \multirow[t]{2}{*}{$\begin{array}{l}\% \text { de } \\
\text { imóveis }\end{array}$} & \multirow[t]{2}{*}{$\mathrm{pH}_{\mathrm{i}}$} & \multirow[t]{2}{*}{$\mathrm{pH}_{\mathrm{f}}$} & \multirow[t]{2}{*}{$\begin{array}{l}\mathrm{OD}_{\mathrm{i}} \\
\left(\mathrm{mg} \mathrm{L}^{-1}\right)\end{array}$} & \multirow[t]{2}{*}{$\begin{array}{l}\mathrm{OD}_{\mathrm{f}} \\
\left(\mathrm{mg} \mathrm{L}^{-1}\right)\end{array}$} & \multirow[t]{2}{*}{$\begin{array}{l}\text { Cond }_{\cdot \mathrm{i}} \\
\left(\mu \mathrm{cm}^{-1}\right)\end{array}$} & \multirow[t]{2}{*}{$\begin{array}{l}\text { Cond.f }_{. f} \\
\left(\mu \mathrm{S} \mathrm{cm}^{-1}\right)\end{array}$} \\
\hline & 1 & 2 & 3 & 4 & & & & & & & \\
\hline Controle & 0 & 0 & 0 & 0 & 0 & 7,66 & 7,65 & 8,05 & 7,82 & 175,5 & 175,5 \\
\hline 6,25 & 0 & 0 & 0 & 0 & 0 & 7,76 & 7,90 & 8,00 & 7,79 & 161,1 & 162,1 \\
\hline 12,50 & 0 & 0 & 0 & 0 & 0 & 7,75 & 7,86 & 8,02 & 7,79 & 153,6 & 155,3 \\
\hline 25,00 & 0 & 2 & 0 & 0 & 10 & 7,57 & 7,65 & 8,11 & 7,77 & 134,1 & 136,5 \\
\hline 50,00 & 2 & 3 & 5 & 3 & 75 & 7,23 & 7,25 & 8,13 & 7,66 & 94,2 & 97,8 \\
\hline 75,00 & 5 & 5 & 5 & 5 & 100 & 6,59 & 6,55 & 8,15 & 7,53 & 54,3 & 55,9 \\
\hline 100,00 & 5 & 5 & 5 & 5 & 100 & 4,25 & 4,22 & 8,47 & 7,65 & 39,2 & 40,2 \\
\hline
\end{tabular}




\section{Ensaios com cloridrato de fluoxetina em concentrações de $10,0 \mathrm{mg} \mathrm{L}^{-1}(5,0 \mathrm{kGy})$}

Ensaio 1

\begin{tabular}{|c|c|c|c|c|c|c|c|c|c|c|c|}
\hline \multicolumn{9}{|c|}{ ENSAIO DE TOXICIDADE AGUDA - Daphnia similis } & \multirow{2}{*}{\multicolumn{3}{|c|}{$\begin{array}{l}\text { Dose de radiação: } 5,0 \text { kGy } \\
\text { Água de diluição }\end{array}$}} \\
\hline \multicolumn{5}{|l|}{ Início } & \multicolumn{4}{|l|}{ Término } & & & \\
\hline $\begin{array}{l}\text { Data: } \\
07 / 05 / 2013\end{array}$ & $\begin{array}{l}\text { Ho } \\
16:\end{array}$ & & & & $\begin{array}{l}\text { Data: } \\
09 / 05 / 201\end{array}$ & & $\begin{array}{l}\text { Hora: } \\
16: 30\end{array}$ & & \multicolumn{2}{|c|}{$\begin{array}{l}\text { Dureza: } 45,0 \\
\text { mg CaCO}_{3} \mathrm{~L}^{-1}\end{array}$} & $\begin{array}{l}\text { Manancial: } \\
\text { Salto - SP }\end{array}$ \\
\hline \multicolumn{5}{|c|}{ Organismo - teste: Daphnia similis } & \multicolumn{4}{|c|}{ Amostra: Cloridrato de fluoxetina } & \multicolumn{3}{|c|}{ Operador: Vanessa } \\
\hline \multirow[t]{2}{*}{$\begin{array}{l}\text { Concentração } \\
\text { nominal (\%) }\end{array}$} & \multicolumn{4}{|c|}{$\begin{array}{l}\text { Organismos imóveis } \\
\text { por réplica }\end{array}$} & \multirow[t]{2}{*}{$\begin{array}{l}\text { \% de } \\
\text { imóveis }\end{array}$} & \multirow[t]{2}{*}{$\mathrm{pH}_{\mathrm{i}}$} & \multirow[t]{2}{*}{$\mathrm{pH}_{\mathrm{f}}$} & \multirow[t]{2}{*}{$\begin{array}{l}\mathrm{OD}_{\mathrm{i}} \\
\left(\mathrm{mg} \mathrm{L}^{-1}\right)\end{array}$} & \multirow[t]{2}{*}{$\begin{array}{l}\mathrm{OD}_{\mathrm{f}} \\
\left(\mathrm{mg} \mathrm{L}^{-1}\right)\end{array}$} & \multirow[t]{2}{*}{$\begin{array}{l}\text { Cond }_{\cdot \mathrm{i}} \\
\left(\mu \mathrm{sm}^{-1}\right)\end{array}$} & \multirow[t]{2}{*}{$\begin{array}{l}\text { Cond }_{\cdot f} \\
\left(\mu \mathrm{Sm}^{-1}\right)\end{array}$} \\
\hline & 1 & 2 & 3 & 4 & & & & & & & \\
\hline Controle & 0 & 0 & 0 & 0 & 0 & 8,02 & 7,66 & 7,93 & 7,89 & 172,3 & 177,2 \\
\hline 6,25 & 0 & 0 & 0 & 1 & 5 & 7,81 & 7,84 & 7,83 & 7,83 & 159,1 & 158,0 \\
\hline 12,50 & 0 & 0 & 0 & 0 & 0 & 7,88 & 7,90 & 7,82 & 7,84 & 154,1 & 154,2 \\
\hline 25,00 & 0 & 0 & 0 & 0 & 0 & 7,87 & 7,90 & 7,84 & 7,84 & 135,6 & 135,9 \\
\hline 50,00 & 0 & 0 & 0 & 0 & 0 & 7,56 & 7,74 & 7,88 & 7,81 & 95,1 & 95,9 \\
\hline 75,00 & 3 & 3 & 1 & 2 & 45 & 6,94 & 7,19 & 7,98 & 7,66 & 52,4 & 55,9 \\
\hline 100,00 & 5 & 5 & 5 & 5 & 100 & 4,21 & 4,42 & 8,29 & 7,80 & 40,4 & 36,7 \\
\hline
\end{tabular}

Ensaio 2

\begin{tabular}{|c|c|c|c|c|c|c|c|c|c|c|c|}
\hline \multicolumn{9}{|c|}{ ENSAIO DE TOXICIDADE AGUDA - Daphnia similis } & \multirow{2}{*}{\multicolumn{3}{|c|}{$\begin{array}{l}\text { Dose de radiação: } 5,0 \mathrm{kGy} \\
\text { Água de diluição }\end{array}$}} \\
\hline \multicolumn{5}{|l|}{ Início } & \multicolumn{4}{|l|}{ Término } & & & \\
\hline $\begin{array}{l}\text { Data: } \\
11 / 06 / 2013\end{array}$ & $\begin{array}{l}\mathrm{Ho} \\
16:\end{array}$ & & & & $\begin{array}{l}\text { Data: } \\
13 / 06 / 201\end{array}$ & & $\begin{array}{l}\text { Hora: } \\
16: 15\end{array}$ & & \multicolumn{2}{|c|}{ Dureza: 45,0} & $\begin{array}{l}\text { Manancial: } \\
\text { Salto - SP }\end{array}$ \\
\hline \multicolumn{5}{|c|}{ Organismo - teste: Daphnia similis } & \multicolumn{4}{|c|}{ Amostra: Cloridrato de fluoxetina } & \multicolumn{3}{|c|}{ Operador: Vanessa } \\
\hline \multirow[t]{2}{*}{$\begin{array}{l}\text { Concentração } \\
\text { nominal (\%) }\end{array}$} & \multicolumn{4}{|c|}{$\begin{array}{l}\text { Organismos imóveis } \\
\text { por réplica }\end{array}$} & \multirow[t]{2}{*}{$\begin{array}{l}\text { \% de } \\
\text { imóveis }\end{array}$} & \multirow[t]{2}{*}{$\mathrm{pH}_{\mathrm{i}}$} & \multirow[t]{2}{*}{$\mathrm{pH}_{\mathrm{f}}$} & \multirow[t]{2}{*}{$\begin{array}{l}\mathrm{OD}_{\mathrm{i}} \\
\left(\mathrm{mg} \mathrm{L}^{-1}\right)\end{array}$} & \multirow[t]{2}{*}{$\begin{array}{l}\mathrm{OD}_{\mathrm{f}} \\
\left(\mathrm{mg} \mathrm{L}^{-1}\right)\end{array}$} & \multirow[t]{2}{*}{$\begin{array}{l}\text { Cond }_{\cdot \mathrm{i}} \\
\left(\mu \mathrm{cm}^{-1}\right)\end{array}$} & \multirow[t]{2}{*}{$\begin{array}{l}\text { Cond }_{\cdot f} \\
\left(\mu \mathrm{cm}^{-1}\right)\end{array}$} \\
\hline & 1 & 2 & 3 & 4 & & & & & & & \\
\hline Controle & 0 & 0 & 0 & 0 & 0 & 7,90 & 7,90 & 7,68 & 7,91 & 173,0 & 176,9 \\
\hline 6,25 & 0 & 0 & 0 & 0 & 0 & 7,82 & 7,87 & 7,78 & 7,86 & 162,9 & 163,4 \\
\hline 12,50 & 0 & 0 & 0 & 0 & 0 & 7,83 & 7,88 & 7,72 & 7,83 & 153,4 & 153,7 \\
\hline 25,00 & 0 & 0 & 0 & 0 & 0 & 7,81 & 7,89 & 7,71 & 7,89 & 134,8 & 138,4 \\
\hline 50,00 & 0 & 0 & 0 & 0 & 0 & 7,51 & 7,62 & 7,72 & 7,89 & 95,0 & 97,2 \\
\hline 75,00 & 1 & 2 & 3 & 1 & 35 & 6,72 & 7,21 & 7,76 & 7,74 & 54,0 & 58,6 \\
\hline 100,00 & 5 & 5 & 5 & 5 & 100 & 4,19 & 4,65 & 7,80 & 7,86 & 40,5 & 33,0 \\
\hline
\end{tabular}

Ensaio 3

\begin{tabular}{|c|c|c|c|c|c|c|c|c|c|c|c|}
\hline \multicolumn{9}{|c|}{ ENSAIO DE TOXICIDADE AGUDA - Daphnia similis } & \multirow{2}{*}{\multicolumn{3}{|c|}{$\begin{array}{l}\text { Dose de radiação: } 5,0 \text { kGy } \\
\text { Água de diluição }\end{array}$}} \\
\hline \multicolumn{5}{|l|}{ Início } & \multicolumn{4}{|l|}{ Término } & & & \\
\hline $\begin{array}{l}\text { Data: } \\
29 / 10 / 2013\end{array}$ & \multicolumn{4}{|c|}{$\begin{array}{l}\text { Hora: } \\
16: 15\end{array}$} & \multicolumn{2}{|c|}{$\begin{array}{l}\text { Data: } \\
31 / 10 / 2013\end{array}$} & \multicolumn{2}{|l|}{$\begin{array}{l}\text { Hora: } \\
16: 15\end{array}$} & \multicolumn{2}{|c|}{$\begin{array}{l}\text { Dureza: } 45,0 \\
\text { mg CaCO} 3 \mathrm{~L}^{-1}\end{array}$} & $\begin{array}{l}\text { Manancial: } \\
\text { Salto - SP }\end{array}$ \\
\hline \multicolumn{5}{|c|}{ Organismo - teste: Daphnia similis } & \multicolumn{4}{|c|}{ Amostra: Cloridrato de fluoxetina } & \multicolumn{3}{|c|}{ Operador: Vanessa } \\
\hline \multirow[t]{2}{*}{$\begin{array}{l}\text { Concentração } \\
\text { nominal }(\%)\end{array}$} & \multicolumn{4}{|c|}{$\begin{array}{l}\text { Organismos imóveis } \\
\text { por réplica }\end{array}$} & \multirow[t]{2}{*}{$\begin{array}{l}\% \text { de } \\
\text { imóveis }\end{array}$} & \multirow[t]{2}{*}{$\mathrm{pH}_{\mathrm{i}}$} & \multirow[t]{2}{*}{$\mathrm{pH}_{\mathrm{f}}$} & \multirow[t]{2}{*}{$\begin{array}{l}\mathrm{OD}_{\mathrm{i}} \\
\left(\mathrm{mg} \mathrm{L}^{-1}\right)\end{array}$} & \multirow[t]{2}{*}{$\begin{array}{l}\mathrm{OD}_{\mathrm{f}} \\
\left(\mathrm{mg} \mathrm{L}^{-1}\right)\end{array}$} & \multirow[t]{2}{*}{$\begin{array}{l}\text { Cond. }_{\cdot \mathrm{i}} \\
\left(\mu \mathrm{S} \mathrm{cm}^{-1}\right)\end{array}$} & \multirow[t]{2}{*}{$\begin{array}{l}\text { Cond }_{. f} \\
\left(\mu \mathrm{cm}^{-1}\right)\end{array}$} \\
\hline & 1 & 2 & 3 & 4 & & & & & & & \\
\hline Controle & 0 & 1 & 0 & 0 & 5 & $7,9^{7}$ & 7,97 & 7,14 & 7,61 & 190,7 & 183,7 \\
\hline 6,25 & 1 & 0 & 0 & 0 & 5 & 7,8 & 8,03 & 7,13 & 7,52 & 177,4 & 173,7 \\
\hline 12,50 & 0 & 1 & 0 & 0 & 5 & 7,8 & 8,01 & 7,13 & 7,47 & 167,9 & 166,7 \\
\hline 25,00 & 0 & 1 & 0 & 0 & 5 & 7,72 & 7,92 & 7,09 & 7,46 & 145,7 & 146,8 \\
\hline 50,00 & 0 & 1 & 1 & 0 & 10 & 7,1 & 7,75 & 7,08 & 7,43 & 99,1 & 104,2 \\
\hline 75,00 & 3 & 3 & 2 & 3 & 55 & 6,5 & 7,13 & 7,02 & 7,39 & 54,6 & 58,9 \\
\hline 100,00 & 5 & 5 & 5 & 5 & 100 & 4,0 & 4,23 & 7,00 & 7,49 & 39,6 & 39,3 \\
\hline
\end{tabular}




\section{Ensaios com cloridrato de fluoxetina em concentrações de $10,0 \mathrm{mg} \mathrm{L}^{-1} \mathrm{com} \mathrm{pH}$ corrigido $(5,0 \mathrm{kGy})$}

Ensaio 4

\begin{tabular}{|c|c|c|c|c|c|c|c|c|c|c|c|}
\hline \multicolumn{9}{|c|}{ ENSAIO DE TOXICIDADE AGUDA - Daphnia similis } & \multirow{2}{*}{\multicolumn{3}{|c|}{$\begin{array}{l}\text { Dose de radiação: } 5,0 \mathrm{kGy} \\
\text { Água de diluição }\end{array}$}} \\
\hline \multicolumn{5}{|l|}{ Início } & \multicolumn{4}{|l|}{ Término } & & & \\
\hline $\begin{array}{l}\text { Data: } \\
05 / 12 / 2013\end{array}$ & $\begin{array}{l}\mathrm{Ho} \\
16:\end{array}$ & & & & $\begin{array}{l}\text { Data: } \\
07 / 12 / 201\end{array}$ & & $\begin{array}{l}\text { Hora: } \\
16: 15\end{array}$ & & \multicolumn{2}{|c|}{$\begin{array}{l}\text { Dureza: } 45,0 \\
\mathrm{mg} \mathrm{CaCO}_{3} \mathrm{~L}^{-1}\end{array}$} & $\begin{array}{l}\text { Manancial: } \\
\text { Salto - SP }\end{array}$ \\
\hline \multicolumn{5}{|c|}{ Organismo - teste: Daphnia similis } & \multicolumn{4}{|c|}{ Amostra: Cloridrato de fluoxetina } & \multicolumn{3}{|c|}{ Operador: Vanessa } \\
\hline \multirow[t]{2}{*}{$\begin{array}{l}\text { Concentração } \\
\text { nominal }(\%)\end{array}$} & \multicolumn{4}{|c|}{$\begin{array}{l}\text { Organismos imóveis } \\
\text { por réplica }\end{array}$} & \multirow[t]{2}{*}{$\begin{array}{l}\text { \% de } \\
\text { imóveis }\end{array}$} & \multirow[t]{2}{*}{$\mathrm{pH}_{\mathrm{i}}$} & \multirow[t]{2}{*}{$\mathrm{pH}_{\mathrm{f}}$} & \multirow[t]{2}{*}{$\begin{array}{l}\mathrm{OD}_{\mathrm{i}} \\
\left(\mathrm{mg} \mathrm{L}^{-1}\right)\end{array}$} & \multirow[t]{2}{*}{$\begin{array}{l}\mathrm{OD}_{\mathrm{f}} \\
\left(\mathrm{mg} \mathrm{L}^{-1}\right)\end{array}$} & \multirow[t]{2}{*}{$\begin{array}{l}\text { Cond }_{\cdot \mathrm{i}} \\
\left(\mu \mathrm{cm}^{-1}\right)\end{array}$} & \multirow[t]{2}{*}{$\begin{array}{l}\text { Cond }_{. f} \\
\left(\mu \mathrm{cm}^{-1}\right)\end{array}$} \\
\hline & 1 & 2 & 3 & 4 & & & & & & & \\
\hline Controle & 0 & 0 & 0 & 0 & 0 & 8,07 & 8,02 & 7,18 & 7,43 & 198,0 & 197,1 \\
\hline 6,25 & 0 & 0 & 0 & 0 & 0 & 8,20 & 8,17 & 7,06 & 7,62 & 220,0 & 217,5 \\
\hline 12,50 & 0 & 0 & 0 & 0 & 0 & 8,20 & 8,19 & 7,04 & 7,57 & 247,0 & 242,0 \\
\hline 25,00 & 0 & 0 & 0 & 0 & 0 & 8,19 & 8,19 & 7,04 & 7,55 & 296,0 & 288,0 \\
\hline 50,00 & 0 & 0 & 0 & 0 & 0 & 8,19 & 8,27 & 7,03 & 7,55 & 392,0 & 379,0 \\
\hline 75,00 & 0 & 0 & 0 & 0 & 0 & 8,18 & 8,30 & 7,02 & 7,53 & 489,0 & 473,0 \\
\hline 100,00 & 1 & 0 & 1 & 1 & 15 & 8,01 & 8,33 & 7,05 & 7,54 & 593,0 & 566,0 \\
\hline
\end{tabular}

\section{Ensaio 5}

\begin{tabular}{|c|c|c|c|c|c|c|c|c|c|c|c|}
\hline \multicolumn{9}{|c|}{ ENSAIO DE TOXICIDADE AGUDA - Daphnia similis } & \multirow{2}{*}{\multicolumn{3}{|c|}{$\begin{array}{l}\text { Dose de radiação: } 5,0 \mathrm{kGy} \\
\text { Água de diluição }\end{array}$}} \\
\hline \multicolumn{5}{|l|}{ Início } & \multicolumn{4}{|l|}{ Término } & & & \\
\hline $\begin{array}{l}\text { Data: } \\
12 / 02 / 2014\end{array}$ & \multicolumn{4}{|c|}{$\begin{array}{l}\text { Hora: } \\
16: 00\end{array}$} & \multicolumn{2}{|l|}{ Data: } & \multicolumn{2}{|l|}{$\begin{array}{l}\text { Hora: } \\
16: 00\end{array}$} & \multicolumn{2}{|c|}{$\begin{array}{l}\text { Dureza: } 45,0 \\
\mathrm{mg} \mathrm{CaCO}_{3} \mathrm{~L}^{-1}\end{array}$} & $\begin{array}{l}\text { Manancial: } \\
\text { Salto - SP }\end{array}$ \\
\hline \multicolumn{5}{|c|}{ Organismo - teste: Daphnia similis } & \multicolumn{4}{|c|}{ Amostra: Cloridrato de fluoxetina } & \multicolumn{3}{|c|}{ Operador: Vanessa } \\
\hline \multirow[t]{2}{*}{$\begin{array}{l}\text { Concentração } \\
\text { nominal }(\%)\end{array}$} & \multicolumn{4}{|c|}{$\begin{array}{l}\text { Organismos imóveis } \\
\text { por réplica }\end{array}$} & \multirow[t]{2}{*}{$\begin{array}{l}\text { \% de } \\
\text { imóveis }\end{array}$} & \multirow[t]{2}{*}{$\mathrm{pH}_{\mathrm{i}}$} & \multirow[t]{2}{*}{$\mathrm{pH}_{\mathrm{f}}$} & \multirow[t]{2}{*}{$\begin{array}{l}\mathrm{OD}_{\mathrm{i}} \\
\left(\mathrm{mg} \mathrm{L}^{-1}\right)\end{array}$} & \multirow[t]{2}{*}{$\begin{array}{l}\mathrm{OD}_{\mathrm{f}} \\
\left(\mathrm{mg} \mathrm{L}^{-1}\right)\end{array}$} & \multirow[t]{2}{*}{$\begin{array}{l}\text { Cond }_{\cdot \mathrm{i}} \\
\left(\mu \mathrm{S} \mathrm{cm}^{-1}\right)\end{array}$} & \multirow[t]{2}{*}{$\begin{array}{l}\text { Cond.f }_{. f} \\
\left(\mu \mathrm{cm}^{-1}\right)\end{array}$} \\
\hline & 1 & 2 & 3 & 4 & & & & & & & \\
\hline Controle & 0 & 0 & 0 & 0 & 0 & 7,9 & 7,86 & 6,68 & 7,10 & 193,8 & 204,1 \\
\hline 6,25 & 0 & 0 & 0 & 0 & 0 & 7,8 & 7,86 & 6,70 & 7,11 & 187,5 & 187,9 \\
\hline 12,50 & 0 & 0 & 0 & 0 & 0 & 7,8 & 7,85 & 6,74 & 7,15 & 171,5 & 173,9 \\
\hline 25,00 & 0 & 0 & 0 & 0 & 0 & 7,7 & 7,78 & 6,74 & 7,15 & 160,1 & 160,0 \\
\hline 50,00 & 0 & 0 & 0 & 0 & 0 & 7,6 & 7,72 & 6,76 & 7,14 & 127,2 & 127,9 \\
\hline 75,00 & 0 & 1 & 1 & 0 & 10 & 7,5 & 7,74 & 6,81 & 7,14 & 94,6 & 95,7 \\
\hline 100,00 & 2 & 1 & 2 & 2 & 35 & 7,5 & 7,70 & 7,10 & 7,16 & 58,8 & 67,4 \\
\hline
\end{tabular}

Observações: CE50 ${ }_{48 \mathrm{~h}}$ : NT (Não tóxico) 
Ensaios com cloridrato de fluoxetina em concentrações de $20,0 \mathrm{mg} \mathrm{L}^{-1}(5,0 \mathrm{kGy})$

Ensaio 6

\begin{tabular}{|c|c|c|c|c|c|c|c|c|c|c|c|}
\hline \multicolumn{9}{|c|}{ ENSAIO DE TOXICIDADE AGUDA - Daphnia similis } & \multirow{2}{*}{\multicolumn{3}{|c|}{$\begin{array}{l}\text { Dose de radiação: } 5,0 \text { kGy } \\
\text { Água de diluição }\end{array}$}} \\
\hline \multicolumn{5}{|l|}{ Início } & \multicolumn{4}{|l|}{ Término } & & & \\
\hline $\begin{array}{l}\text { Data: } \\
19 / 03 / 2013\end{array}$ & $\begin{array}{l}\text { Ho } \\
16:\end{array}$ & & & & $\begin{array}{l}\text { Data: } \\
21 / 03 / 201\end{array}$ & & $\begin{array}{l}\text { Hora: } \\
16: 00\end{array}$ & & \multicolumn{2}{|c|}{$\begin{array}{l}\text { Dureza: } 45,0 \\
\text { mg CaCO}_{3} \mathrm{~L}^{-1}\end{array}$} & $\begin{array}{l}\text { Manancial: } \\
\text { Salto - SP }\end{array}$ \\
\hline \multicolumn{5}{|c|}{ Organismo - teste: Daphnia similis } & \multicolumn{4}{|c|}{ Amostra: Cloridrato de fluoxetina } & \multicolumn{3}{|c|}{ Operador: Vanessa } \\
\hline \multirow[t]{2}{*}{$\begin{array}{l}\text { Concentração } \\
\text { nominal (\%) }\end{array}$} & \multicolumn{4}{|c|}{$\begin{array}{l}\text { Organismos imóveis } \\
\text { por réplica }\end{array}$} & \multirow[t]{2}{*}{$\begin{array}{l}\text { \% de } \\
\text { imóveis }\end{array}$} & \multirow[t]{2}{*}{$\mathrm{pH}_{\mathrm{i}}$} & \multirow[t]{2}{*}{$\mathrm{pH}_{\mathrm{f}}$} & \multirow[t]{2}{*}{$\begin{array}{l}\mathrm{OD}_{\mathrm{i}} \\
\left(\mathrm{mg} \mathrm{L}^{-1}\right)\end{array}$} & \multirow[t]{2}{*}{$\begin{array}{l}\mathrm{OD}_{\mathrm{f}} \\
\left(\mathrm{mg} \mathrm{L}^{-1}\right)\end{array}$} & \multirow[t]{2}{*}{$\begin{array}{l}\text { Cond }_{\cdot \mathrm{i}} \\
\left(\mu \mathrm{sm}^{-1}\right)\end{array}$} & \multirow[t]{2}{*}{$\begin{array}{l}\text { Cond }_{\cdot f} \\
\left(\mu S \mathrm{~cm}^{-1}\right)\end{array}$} \\
\hline & 1 & 2 & 3 & 4 & & & & & & & \\
\hline Controle & 0 & 0 & 0 & 0 & 0 & 7,78 & 7,88 & 7,74 & 7,62 & 173,8 & 167,2 \\
\hline 6,25 & 0 & 0 & 0 & 0 & 0 & 7,8 & 7,91 & 7,67 & 7,63 & 161,3 & 162,0 \\
\hline 12,50 & 0 & 0 & 0 & 0 & 0 & 7,5 & 7,90 & 7,64 & 7,62 & 151,8 & 154,1 \\
\hline 25,00 & 0 & 0 & 0 & 0 & 0 & $7,6^{\prime}$ & 7,85 & 7,66 & 7,63 & 132,8 & 134,3 \\
\hline 50,00 & 2 & 2 & 2 & 2 & 40 & 7,3 & 7,66 & 7,68 & 7,52 & 92,4 & 96,4 \\
\hline 75,00 & 5 & 5 & 5 & 5 & 100 & 6,3 & 6,90 & 7,72 & 7,44 & 51,9 & 57,0 \\
\hline 100,00 & 5 & 5 & 5 & 5 & 100 & 4,0 & 4,06 & 7,99 & 7,64 & 56,2 & 51,7 \\
\hline
\end{tabular}

Ensaio 7

\begin{tabular}{|c|c|c|c|c|c|c|c|c|c|c|c|}
\hline \multicolumn{9}{|c|}{ ENSAIO DE TOXICIDADE AGUDA - Daphnia similis } & \multirow{2}{*}{\multicolumn{3}{|c|}{$\begin{array}{l}\text { Dose de radiação: 5,0 kGy } \\
\text { Água de diluição }\end{array}$}} \\
\hline \multicolumn{5}{|l|}{ Início } & \multicolumn{4}{|l|}{ Término } & & & \\
\hline $\begin{array}{l}\text { Data: } \\
17 / 07 / 2013\end{array}$ & $\begin{array}{l}\mathrm{Ho} \\
16:\end{array}$ & & & & $\begin{array}{l}\text { Data: } \\
19 / 07 / 201\end{array}$ & & $\begin{array}{l}\text { Hora: } \\
\text { 16:00 }\end{array}$ & & \multicolumn{2}{|c|}{ Dureza: 45,0} & $\begin{array}{l}\text { Manancial: } \\
\text { Salto - SP }\end{array}$ \\
\hline \multicolumn{5}{|c|}{ Organismo - teste: Daphnia similis } & \multicolumn{4}{|c|}{ Amostra: Cloridrato de fluoxetina } & \multicolumn{3}{|c|}{ Operador: Vanessa } \\
\hline \multirow[t]{2}{*}{$\begin{array}{l}\text { Concentração } \\
\text { nominal (\%) }\end{array}$} & \multicolumn{4}{|c|}{$\begin{array}{l}\text { Organismos imóveis } \\
\text { por réplica }\end{array}$} & \multirow[t]{2}{*}{$\begin{array}{l}\text { \% de } \\
\text { imóveis }\end{array}$} & \multirow[t]{2}{*}{$\mathrm{pH}_{\mathrm{i}}$} & \multirow[t]{2}{*}{$\mathrm{pH}_{\mathrm{f}}$} & \multirow[t]{2}{*}{$\begin{array}{l}\mathrm{OD}_{\mathrm{i}} \\
\left(\mathrm{mg} \mathrm{L}^{-1}\right)\end{array}$} & \multirow[t]{2}{*}{$\begin{array}{l}\mathrm{OD}_{\mathrm{f}} \\
\left(\mathrm{mg} \mathrm{L}^{-1}\right)\end{array}$} & \multirow[t]{2}{*}{$\begin{array}{l}\text { Cond }_{\cdot \mathrm{i}} \\
\left(\mu \mathrm{cm}^{-1}\right)\end{array}$} & \multirow[t]{2}{*}{$\begin{array}{l}\text { Cond.f }_{. f} \\
\left(\mu \mathrm{S} \mathrm{cm}^{-1}\right)\end{array}$} \\
\hline & 1 & 2 & 3 & 4 & & & & & & & \\
\hline Controle & 0 & 0 & 0 & 0 & 0 & 7,82 & 7,85 & 7,55 & 7,73 & 177,8 & 182,6 \\
\hline 6,25 & 0 & 0 & 0 & 0 & 0 & 7,75 & 7,70 & 7,92 & 7,76 & 168,7 & 164,7 \\
\hline 12,50 & 0 & 0 & 0 & 0 & 0 & 7,66 & 7,68 & 7,88 & 7,73 & 160,9 & 161,0 \\
\hline 25,00 & 0 & 0 & 0 & 0 & 0 & 7,51 & 7,53 & 7,89 & 7,73 & 139,8 & 141,2 \\
\hline 50,00 & 0 & 0 & 1 & 1 & 10 & 7,17 & 7,40 & 7,92 & 7,69 & 97,4 & 100,4 \\
\hline 75,00 & 5 & 5 & 5 & 5 & 100 & 5,88 & 6,16 & 7,90 & 7,50 & 56,1 & 62,1 \\
\hline 100,00 & 5 & 5 & 5 & 5 & 100 & 3,94 & 3,95 & 7,84 & 7,64 & 55,3 & 61,9 \\
\hline
\end{tabular}




\section{Ensaios com cloridrato de fluoxetina em concentrações de $10,0 \mathrm{mg} \mathrm{L}^{-1}(20,0 \mathrm{kGy})$}

Ensaio 1

\begin{tabular}{|c|c|c|c|c|c|c|c|c|c|c|c|}
\hline \multicolumn{9}{|c|}{ ENSAIO DE TOXICIDADE AGUDA - Daphnia similis } & \multicolumn{3}{|c|}{ Dose de radiação: 20,0 kGy } \\
\hline \multicolumn{5}{|l|}{ Início } & \multicolumn{4}{|l|}{ Término } & \multicolumn{3}{|c|}{ Água de diluição } \\
\hline $\begin{array}{l}\text { Data: } \\
07 / 05 / 2013\end{array}$ & \multicolumn{4}{|c|}{$\begin{array}{l}\text { Hora: } \\
16: 00\end{array}$} & \multicolumn{2}{|l|}{ Data: } & \multicolumn{2}{|l|}{$\begin{array}{l}\text { Hora: } \\
16: 00\end{array}$} & \multicolumn{2}{|c|}{$\begin{array}{l}\text { Dureza: } 45,0 \\
\mathrm{mg} \mathrm{CaCO}_{3} \mathrm{~L}^{-1}\end{array}$} & $\begin{array}{l}\text { Manancial: } \\
\text { Salto - SP }\end{array}$ \\
\hline \multicolumn{5}{|c|}{ Organismo - teste: Daphnia similis } & \multicolumn{4}{|c|}{ Amostra: Cloridrato de fluoxetina } & \multicolumn{3}{|c|}{ Operador: Vanessa } \\
\hline \multirow[t]{2}{*}{$\begin{array}{l}\text { Concentração } \\
\text { nominal (\%) }\end{array}$} & \multicolumn{4}{|c|}{$\begin{array}{l}\text { Organismos } \\
\text { imóveis por réplica }\end{array}$} & \multirow[t]{2}{*}{$\begin{array}{l}\text { \% de } \\
\text { imóveis }\end{array}$} & \multirow[t]{2}{*}{$\mathrm{pH}_{\mathrm{i}}$} & \multirow[t]{2}{*}{$\mathrm{pH}_{\mathrm{f}}$} & \multirow[t]{2}{*}{$\begin{array}{l}\mathrm{OD}_{\mathrm{i}} \\
\left(\mathrm{mg} \mathrm{L}^{-1}\right)\end{array}$} & \multirow[t]{2}{*}{$\begin{array}{l}\mathrm{OD}_{\mathrm{f}} \\
\left(\mathrm{mg} \mathrm{L}^{-1}\right)\end{array}$} & \multirow[t]{2}{*}{$\begin{array}{l}\text { Cond }_{\cdot \mathrm{i}} \\
\left(\mu \mathrm{Sm}^{-1}\right)\end{array}$} & \multirow[t]{2}{*}{$\begin{array}{l}\text { Cond }_{. f} \\
\left(\mu \mathrm{S} \mathrm{cm}^{-1}\right)\end{array}$} \\
\hline & 1 & 2 & 3 & 4 & & & & & & & \\
\hline Controle & 0 & 0 & 0 & 0 & 0 & 8,02 & 7,66 & 7,93 & 7,89 & 172,3 & 177,2 \\
\hline 6,25 & 0 & 0 & 0 & 0 & 0 & 7,74 & 7,60 & 7,96 & 7,85 & 160,6 & 157,9 \\
\hline 12,50 & 0 & 0 & 0 & 0 & 0 & 7,84 & 7,79 & 7,83 & 7,84 & 156,0 & 153,4 \\
\hline 25,00 & 0 & 0 & 0 & 0 & 0 & 7,82 & 7,81 & 7,81 & 7,84 & 136,1 & 134,6 \\
\hline 50,00 & 0 & 0 & 0 & 0 & 0 & 7,56 & 7,78 & 7,85 & 7,82 & 95,5 & 96,6 \\
\hline 75,00 & 2 & 3 & 4 & 2 & 55 & 6,93 & 7,20 & 7,90 & 7,76 & 53,7 & 59,5 \\
\hline 100,00 & 5 & 5 & 5 & 5 & 100 & 4,04 & 4,21 & 8,03 & 7,78 & 52,6 & 45,7 \\
\hline
\end{tabular}

Ensaio 2

\begin{tabular}{|c|c|c|c|c|c|c|c|c|c|c|c|}
\hline \multicolumn{9}{|c|}{ ENSAIO DE TOXICIDADE AGUDA - Daphnia similis } & \multirow{2}{*}{\multicolumn{3}{|c|}{$\begin{array}{l}\text { Dose de radiação: } 20,0 \text { kGy } \\
\text { Água de diluição }\end{array}$}} \\
\hline \multicolumn{5}{|l|}{ Início } & \multicolumn{4}{|l|}{ Término } & & & \\
\hline $\begin{array}{l}\text { Data: } \\
11 / 06 / 2013\end{array}$ & \multicolumn{4}{|c|}{$\begin{array}{l}\text { Hora: } \\
16: 15\end{array}$} & \multicolumn{2}{|c|}{$\begin{array}{l}\text { Data: } \\
13 / 06 / 2013\end{array}$} & \multicolumn{2}{|l|}{$\begin{array}{l}\text { Hora: } \\
16: 15\end{array}$} & \multicolumn{2}{|c|}{$\begin{array}{l}\text { Dureza: } 45,0 \\
\mathrm{mg} \mathrm{CaCO}_{3} \mathrm{~L}^{-1}\end{array}$} & $\begin{array}{l}\text { Manancial: } \\
\text { Salto - SP }\end{array}$ \\
\hline \multicolumn{5}{|c|}{ Organismo - teste: Daphnia similis } & \multicolumn{4}{|c|}{ Amostra: Cloridrato de fluoxetina } & \multicolumn{3}{|c|}{ Operador: Vanessa } \\
\hline \multirow[t]{2}{*}{$\begin{array}{l}\text { Concentração } \\
\text { nominal (\%) }\end{array}$} & \multicolumn{4}{|c|}{$\begin{array}{l}\text { Organismos imóveis } \\
\text { por réplica }\end{array}$} & \multirow[t]{2}{*}{$\begin{array}{l}\text { \% de } \\
\text { imóveis }\end{array}$} & \multirow[t]{2}{*}{$\mathrm{pH}_{\mathrm{i}}$} & \multirow[t]{2}{*}{$\mathrm{pH}_{\mathrm{f}}$} & \multirow[t]{2}{*}{$\begin{array}{l}\mathrm{OD}_{\mathrm{i}} \\
\left(\mathrm{mg} \mathrm{L}^{-1}\right)\end{array}$} & \multirow[t]{2}{*}{$\begin{array}{l}\mathrm{OD}_{\mathrm{f}} \\
\left(\mathrm{mg} \mathrm{L}^{-1}\right)\end{array}$} & \multirow[t]{2}{*}{$\begin{array}{l}\text { Cond }_{\cdot \mathrm{i}} \\
\left(\mu \mathrm{cm}^{-1}\right)\end{array}$} & \multirow[t]{2}{*}{$\begin{array}{l}\text { Cond }_{\cdot f} \\
\left(\mu \mathrm{S} \mathrm{cm}^{-1}\right)\end{array}$} \\
\hline & 1 & 2 & 3 & 4 & & & & & & & \\
\hline Controle & 0 & 0 & 0 & 0 & 0 & 7,90 & 7,90 & 7,68 & 7,91 & 173,0 & 176,9 \\
\hline 6,25 & 0 & 0 & 0 & 0 & 0 & 7,82 & 7,87 & 7,78 & 7,86 & 162,9 & 163,4 \\
\hline 12,50 & 0 & 0 & 0 & 0 & 0 & 7,83 & 7,88 & 7,72 & 7,83 & 153,4 & 153,7 \\
\hline 25,00 & 0 & 0 & 0 & 0 & 0 & 7,81 & 7,89 & 7,71 & 7,89 & 134,8 & 138,4 \\
\hline 50,00 & 0 & 0 & 0 & 0 & 0 & 7,51 & 7,62 & 7,72 & 7,89 & 95,0 & 97,2 \\
\hline 75,00 & 2 & 0 & 5 & 3 & 50 & 6,72 & 7,21 & 7,76 & 7,74 & 54,0 & 58,6 \\
\hline 100,00 & 5 & 5 & 5 & 5 & 100 & 4,19 & 4,65 & 7,80 & 7,86 & 40,5 & 33,0 \\
\hline
\end{tabular}

\section{Ensaio 3}

\begin{tabular}{|c|c|c|c|c|c|c|c|c|c|c|c|}
\hline \multicolumn{9}{|c|}{ ENSAIO DE TOXICIDADE AGUDA - Daphnia similis } & \multirow{2}{*}{\multicolumn{3}{|c|}{$\begin{array}{l}\text { Dose de radiação: } 20,0 \text { kGy } \\
\text { Água de diluição }\end{array}$}} \\
\hline \multicolumn{5}{|l|}{ Início } & \multicolumn{4}{|l|}{ Término } & & & \\
\hline $\begin{array}{l}\text { Data: } \\
29 / 10 / 2013\end{array}$ & \multicolumn{4}{|c|}{$\begin{array}{l}\text { Hora: } \\
16: 30 \\
\end{array}$} & \multicolumn{2}{|c|}{$\begin{array}{l}\text { Data: } \\
31 / 10 / 2013\end{array}$} & \multicolumn{2}{|l|}{$\begin{array}{l}\text { Hora: } \\
16: 30\end{array}$} & \multicolumn{2}{|c|}{$\begin{array}{l}\text { Dureza: } 45,0 \\
\mathrm{mg} \mathrm{CaCO}_{3} \mathrm{~L}^{-1}\end{array}$} & $\begin{array}{l}\text { Manancial: } \\
\text { Salto - SP }\end{array}$ \\
\hline \multicolumn{5}{|c|}{ Organismo - teste: Daphnia similis } & \multicolumn{4}{|c|}{ Amostra: Cloridrato de fluoxetina } & \multicolumn{3}{|c|}{ Operador: Vanessa } \\
\hline \multirow[t]{2}{*}{$\begin{array}{l}\text { Concentração } \\
\text { nominal }(\%)\end{array}$} & \multicolumn{4}{|c|}{$\begin{array}{l}\text { Organismos imóveis } \\
\text { por réplica }\end{array}$} & \multirow[t]{2}{*}{$\begin{array}{l}\text { \% de } \\
\text { imóveis }\end{array}$} & \multirow[t]{2}{*}{$\mathrm{pH}_{\mathrm{i}}$} & \multirow[t]{2}{*}{$\mathrm{pH}_{\mathrm{f}}$} & \multirow[t]{2}{*}{$\begin{array}{l}\mathrm{OD}_{\mathrm{i}} \\
\left(\mathrm{mg} \mathrm{L}^{-1}\right)\end{array}$} & \multirow[t]{2}{*}{$\begin{array}{l}\mathrm{OD}_{\mathrm{f}} \\
\left(\mathrm{mg} \mathrm{L}^{-1}\right)\end{array}$} & \multirow[t]{2}{*}{$\begin{array}{l}\text { Cond }_{\cdot \mathrm{i}} \\
\left(\mu \mathrm{cm}^{-1}\right)\end{array}$} & \multirow[t]{2}{*}{$\begin{array}{l}\text { Cond }_{\cdot f} \\
\left(\mu \mathrm{cm}^{-1}\right)\end{array}$} \\
\hline & 1 & 2 & 3 & 4 & & & & & & & \\
\hline Controle & 0 & 1 & 0 & 0 & 5 & 7,97 & 7,97 & 7,14 & 7,61 & 190,7 & 183,7 \\
\hline 6,25 & 0 & 0 & 0 & 0 & 0 & 7,88 & 7,99 & 7,04 & 7,54 & 173,5 & 171,8 \\
\hline 12,50 & 0 & 0 & 1 & 0 & 5 & 7,79 & 7,98 & 7,05 & 7,63 & 168,0 & 166,1 \\
\hline 25,00 & 0 & 0 & 0 & 0 & 0 & 7,47 & 7,83 & 7,03 & 7,65 & 144,9 & 145,2 \\
\hline 50,00 & 0 & 0 & 0 & 0 & 0 & 7,09 & 7,57 & 7,02 & 7,67 & 100,3 & 102,3 \\
\hline 75,00 & 3 & 4 & 3 & 4 & 70 & 6,31 & 7,50 & 7,04 & 7,63 & 56,4 & 62,5 \\
\hline 100,00 & 5 & 5 & 5 & 5 & 100 & 3,77 & 3,98 & 7,05 & 7,64 & 52,5 & 61,3 \\
\hline
\end{tabular}

Observações: CE50 ${ }_{48 \mathrm{~h}}$ : 68,09 $(63,40-73,13)$ 


\section{Ensaios com cloridrato de fluoxetina em concentrações de $10,0 \mathrm{mg} \mathrm{L}^{-1}$ com pH corrigido $(20,0 \mathrm{kGy})$}

Ensaio 4

\begin{tabular}{|c|c|c|c|c|c|c|c|c|c|c|c|}
\hline \multicolumn{9}{|c|}{ ENSAIO DE TOXICIDADE AGUDA - Daphnia similis } & \multirow{2}{*}{\multicolumn{3}{|c|}{$\begin{array}{l}\text { Dose de radiação: } 20,0 \mathrm{kGy} \\
\text { Água de diluição }\end{array}$}} \\
\hline \multicolumn{5}{|l|}{ Início } & \multicolumn{4}{|l|}{ Término } & & & \\
\hline $\begin{array}{l}\text { Data: } \\
05 / 12 / 2013\end{array}$ & \multicolumn{4}{|c|}{$\begin{array}{l}\text { Hora: } \\
16: 30\end{array}$} & \multicolumn{2}{|c|}{$\begin{array}{l}\text { Data: } \\
07 / 12 / 2013\end{array}$} & \multicolumn{2}{|l|}{$\begin{array}{l}\text { Hora: } \\
16: 30\end{array}$} & \multicolumn{2}{|c|}{$\begin{array}{l}\text { Dureza: } 45,0 \\
\mathrm{mg} \mathrm{CaCO}_{3} \mathrm{~L}^{-1}\end{array}$} & $\begin{array}{l}\text { Manancial: } \\
\text { Salto - SP }\end{array}$ \\
\hline \multicolumn{5}{|c|}{ Organismo - teste: Daphnia similis } & \multicolumn{4}{|c|}{ Amostra: Cloridrato de fluoxetina } & \multicolumn{3}{|c|}{ Operador: Vanessa } \\
\hline \multirow[t]{2}{*}{$\begin{array}{l}\text { Concentração } \\
\text { nominal (\%) }\end{array}$} & \multicolumn{4}{|c|}{$\begin{array}{l}\text { Organismos imóveis } \\
\text { por réplica }\end{array}$} & \multirow[t]{2}{*}{$\begin{array}{l}\text { \% de } \\
\text { imóveis }\end{array}$} & \multirow[t]{2}{*}{$\mathrm{pH}_{\mathrm{i}}$} & \multirow[t]{2}{*}{$\mathrm{pH}_{\mathrm{f}}$} & \multirow[t]{2}{*}{$\begin{array}{l}\mathrm{OD}_{\mathrm{i}} \\
\left(\mathrm{mg} \mathrm{L}^{-1}\right)\end{array}$} & \multirow[t]{2}{*}{$\begin{array}{l}\mathrm{OD}_{\mathrm{f}} \\
\left(\mathrm{mg} \mathrm{L}^{-1}\right)\end{array}$} & \multirow[t]{2}{*}{$\begin{array}{l}\text { Cond }_{. \mathrm{i}} \\
\left(\mu \mathrm{cm}^{-1}\right)\end{array}$} & \multirow[t]{2}{*}{$\begin{array}{l}\text { Cond.f }_{{ }_{f}} \\
\left(\mu \mathrm{cm}^{-1}\right)\end{array}$} \\
\hline & 1 & 2 & 3 & 4 & & & & & & & \\
\hline Controle & 0 & 0 & 0 & 0 & 0 & 8,07 & 8,02 & 7,18 & 7,43 & 198,0 & 197,1 \\
\hline 6,25 & 0 & 0 & 0 & 0 & 0 & 8,14 & 8,18 & 7,03 & 7,55 & 201,1 & 198,9 \\
\hline 12,50 & 0 & 0 & 0 & 0 & 0 & 8,14 & 8,21 & 7,02 & 7,51 & 208,3 & 211,5 \\
\hline 25,00 & 0 & 0 & 0 & 0 & 0 & 8,14 & 8,28 & 7,02 & 7,50 & 217,3 & 215,9 \\
\hline 50,00 & 0 & 0 & 0 & 0 & 0 & 8,13 & 8,30 & 7,03 & 7,49 & 239,0 & 238,0 \\
\hline 75,00 & 0 & 0 & 0 & 0 & 0 & 8,13 & 8,35 & 7,05 & 7,48 & 262,0 & 259,0 \\
\hline 100,00 & 1 & 2 & 0 & 0 & 15 & 7,87 & 8,40 & 7,08 & 7,48 & 305,0 & 283,0 \\
\hline
\end{tabular}

\section{Ensaio 5}

\begin{tabular}{|c|c|c|c|c|c|c|c|c|c|c|c|}
\hline \multicolumn{9}{|c|}{ ENSAIO DE TOXICIDADE AGUDA - Daphnia similis } & \multirow{2}{*}{\multicolumn{3}{|c|}{$\begin{array}{l}\text { Dose de radiação: } 20,0 \text { kGy } \\
\text { Água de diluição }\end{array}$}} \\
\hline \multicolumn{5}{|l|}{ Início } & \multicolumn{4}{|c|}{ Término } & & & \\
\hline $\begin{array}{l}\text { Data: } \\
12 / 02 / 2014\end{array}$ & \multicolumn{4}{|c|}{$\begin{array}{l}\text { Hora: } \\
16: 30\end{array}$} & \multicolumn{2}{|l|}{ Data: } & \multicolumn{2}{|l|}{$\begin{array}{l}\text { Hora: } \\
16: 30\end{array}$} & \multicolumn{2}{|c|}{$\begin{array}{l}\text { Dureza: } 45,0 \\
\mathrm{mg} \mathrm{CaCO}_{3} \mathrm{~L}^{-1}\end{array}$} & $\begin{array}{l}\text { Manancial: } \\
\text { Salto - SP }\end{array}$ \\
\hline \multicolumn{5}{|c|}{ Organismo - teste: Daphnia similis } & \multicolumn{4}{|c|}{ Amostra: Cloridrato de fluoxetina } & \multicolumn{3}{|c|}{ Operador: Vanessa } \\
\hline \multirow[t]{2}{*}{$\begin{array}{l}\text { Concentração } \\
\text { nominal (\%) }\end{array}$} & \multicolumn{4}{|c|}{$\begin{array}{l}\text { Organismos imóveis } \\
\text { por réplica }\end{array}$} & \multirow[t]{2}{*}{$\begin{array}{l}\text { \% de } \\
\text { imóveis }\end{array}$} & \multirow[t]{2}{*}{$\mathrm{pH}_{\mathrm{i}}$} & \multirow[t]{2}{*}{$\mathrm{pH}_{\mathrm{f}}$} & \multirow[t]{2}{*}{$\begin{array}{l}\mathrm{OD}_{\mathrm{i}} \\
\left(\mathrm{mg} \mathrm{L}^{-1}\right)\end{array}$} & \multirow[t]{2}{*}{$\begin{array}{l}\mathrm{OD}_{\mathrm{f}} \\
\left(\mathrm{mg} \mathrm{L}^{-1}\right)\end{array}$} & \multirow[t]{2}{*}{$\begin{array}{l}\text { Cond }_{\cdot \mathrm{i}} \\
\left(\mu \mathrm{cm}^{-1}\right)\end{array}$} & \multirow[t]{2}{*}{$\begin{array}{l}\text { Cond }_{. f} \\
\left(\mu \mathrm{cm}^{-1}\right)\end{array}$} \\
\hline & 1 & 2 & 3 & 4 & & & & & & & \\
\hline Controle & 0 & 0 & 0 & 0 & 0 & 7,91 & 7,86 & 6,68 & 7,10 & 193,8 & 204,1 \\
\hline 6,25 & 0 & 0 & 0 & 0 & 0 & 7,86 & 7,86 & 6,80 & 7,09 & 187,6 & 187,8 \\
\hline 12,50 & 0 & 0 & 0 & 0 & 0 & 7,84 & 7,85 & 6,83 & 7,10 & 170,3 & 175,8 \\
\hline 25,00 & 0 & 0 & 0 & 0 & 0 & 7,83 & 7,82 & 6,78 & 7,11 & 162,4 & 161,9 \\
\hline 50,00 & 0 & 0 & 0 & 0 & 0 & 7,78 & 7,81 & 6,77 & 7,12 & 131,6 & 131,9 \\
\hline 75,00 & 1 & 0 & 1 & 1 & 15 & 7,75 & 7,80 & 6,78 & 7,10 & 100,8 & 103,7 \\
\hline 100,00 & 2 & 1 & 2 & 3 & 40 & 7,70 & 7,70 & 6,92 & 7,10 & 69,9 & 76,1 \\
\hline
\end{tabular}




\section{Ensaios com cloridrato de fluoxetina em concentrações de $20,0 \mathrm{mg} \mathrm{L}^{-1}(20,0 \mathrm{kGy})$}

Ensaio 6

\begin{tabular}{|c|c|c|c|c|c|c|c|c|c|c|c|}
\hline \multicolumn{9}{|c|}{ ENSAIO DE TOXICIDADE AGUDA - Daphnia similis } & \multirow{2}{*}{\multicolumn{3}{|c|}{$\begin{array}{l}\text { Dose de radiação: } 20,0 \text { kGy } \\
\text { Água de dilução }\end{array}$}} \\
\hline \multicolumn{5}{|l|}{ Início } & \multicolumn{4}{|c|}{ Término } & & & \\
\hline $\begin{array}{l}\text { Data: } \\
19 / 03 / 2013\end{array}$ & \multicolumn{4}{|c|}{$\begin{array}{l}\text { Hora: } \\
16: 15\end{array}$} & \multicolumn{2}{|c|}{$\begin{array}{l}\text { Data: } \\
21 / 03 / 2013\end{array}$} & \multicolumn{2}{|l|}{$\begin{array}{l}\text { Hora: } \\
16: 15\end{array}$} & \multicolumn{2}{|c|}{$\begin{array}{l}\text { Dureza: } 45,0 \\
\mathrm{mg} \mathrm{CaCO}_{3} \mathrm{~L}^{-1}\end{array}$} & $\begin{array}{l}\text { Manancial: } \\
\text { Salto - SP }\end{array}$ \\
\hline \multicolumn{5}{|c|}{ Organismo - teste: Daphnia similis } & \multicolumn{4}{|c|}{ Amostra: Cloridrato de fluoxetina } & \multicolumn{3}{|c|}{ Operador: Vanessa } \\
\hline \multirow[t]{2}{*}{$\begin{array}{l}\text { Concentração } \\
\text { nominal }(\%)\end{array}$} & \multicolumn{4}{|c|}{$\begin{array}{l}\text { Organismos imóveis } \\
\text { por réplica }\end{array}$} & \multirow[t]{2}{*}{$\begin{array}{l}\text { \% de } \\
\text { imóveis }\end{array}$} & \multirow[t]{2}{*}{$\mathrm{pH}_{\mathrm{i}}$} & \multirow[t]{2}{*}{$\mathrm{pH}_{\mathrm{f}}$} & \multirow[t]{2}{*}{$\begin{array}{l}\mathrm{OD}_{\mathrm{i}} \\
\left(\mathrm{mg} \mathrm{L}^{-1}\right)\end{array}$} & \multirow[t]{2}{*}{$\begin{array}{l}\mathrm{OD}_{\mathrm{f}} \\
\left(\mathrm{mg} \mathrm{L}^{-1}\right)\end{array}$} & \multirow[t]{2}{*}{$\begin{array}{l}\text { Cond }_{. i} \\
\left(\mu \mathrm{S} \mathrm{cm}^{-1}\right)\end{array}$} & \multirow[t]{2}{*}{$\begin{array}{l}\text { Cond }_{\cdot f} \\
\left(\mu \mathrm{cm}^{-1}\right)\end{array}$} \\
\hline & 1 & 2 & 3 & 4 & & & & & & & \\
\hline Controle & 0 & 0 & 0 & 0 & 0 & 7,78 & 7,83 & 7,74 & 7,61 & 173,8 & 167,2 \\
\hline 6,25 & 0 & 1 & 0 & 0 & 5 & 7,54 & 7,85 & 7,67 & 7,61 & 155,3 & 161,0 \\
\hline 12,50 & 0 & 0 & 1 & 0 & 5 & 7,70 & 7,90 & 7,64 & 7,60 & 151,5 & 152,0 \\
\hline 25,00 & 0 & 0 & 0 & 1 & 5 & 7,52 & 7,89 & 7,64 & 7,56 & 131,4 & 133,1 \\
\hline 50,00 & 0 & 0 & 0 & 2 & 10 & 7,17 & 7,30 & 7,65 & 7,48 & 92,6 & 96,5 \\
\hline 75,00 & 5 & 5 & 5 & 5 & 100 & 5,00 & 6,24 & 7,69 & 7,34 & 59,0 & 60,4 \\
\hline 100,00 & 5 & 5 & 5 & 5 & 100 & 3,80 & 3,90 & 7,84 & 7,54 & 83,8 & 75,2 \\
\hline
\end{tabular}

\section{Ensaio 7}

\begin{tabular}{|c|c|c|c|c|c|c|c|c|c|c|c|}
\hline \multicolumn{9}{|c|}{ ENSAIO DE TOXICIDADE AGUDA - Daphnia similis } & \multirow{2}{*}{\multicolumn{3}{|c|}{$\begin{array}{l}\text { Dose de radiação: } 20,0 \text { kGy } \\
\text { Água de diluição }\end{array}$}} \\
\hline \multicolumn{5}{|l|}{ Início } & \multicolumn{4}{|c|}{ Término } & & & \\
\hline $\begin{array}{l}\text { Data: } \\
19 / 03 / 2013\end{array}$ & \multicolumn{4}{|c|}{$\begin{array}{l}\text { Hora: } \\
16: 15\end{array}$} & \multicolumn{2}{|c|}{$\begin{array}{l}\text { Data: } \\
21 / 03 / 2013\end{array}$} & \multicolumn{2}{|l|}{$\begin{array}{l}\text { Hora: } \\
16: 15\end{array}$} & \multicolumn{2}{|c|}{$\begin{array}{l}\text { Dureza: } 45,0 \\
\mathrm{mg} \mathrm{CaCO}_{3} \mathrm{~L}^{-1}\end{array}$} & $\begin{array}{l}\text { Manancial: } \\
\text { Salto - SP }\end{array}$ \\
\hline \multicolumn{5}{|c|}{ Organismo - teste: Daphnia similis } & \multicolumn{4}{|c|}{ Amostra: Cloridrato de fluoxetina } & \multicolumn{3}{|c|}{ Operador: Vanessa } \\
\hline \multirow[t]{2}{*}{$\begin{array}{l}\text { Concentração } \\
\text { nominal (\%) }\end{array}$} & \multicolumn{4}{|c|}{$\begin{array}{l}\text { Organismos imóveis } \\
\text { por réplica }\end{array}$} & \multirow[t]{2}{*}{$\begin{array}{l}\text { \% de } \\
\text { imóveis }\end{array}$} & \multirow[t]{2}{*}{$\mathrm{pH}_{\mathrm{i}}$} & \multirow[t]{2}{*}{$\mathrm{pH}_{\mathrm{f}}$} & \multirow[t]{2}{*}{$\begin{array}{l}\mathrm{OD}_{\mathrm{i}} \\
\left(\mathrm{mg} \mathrm{L}^{-1}\right)\end{array}$} & \multirow[t]{2}{*}{$\begin{array}{l}\mathrm{OD}_{\mathrm{f}} \\
\left(\mathrm{mg} \mathrm{L}^{-1}\right)\end{array}$} & \multirow[t]{2}{*}{$\begin{array}{l}\text { Cond }_{\cdot \mathrm{i}} \\
\left(\mu \mathrm{S} \mathrm{cm}^{-1}\right)\end{array}$} & \multirow[t]{2}{*}{$\begin{array}{l}\text { Cond.f }_{. f} \\
\left(\mu \mathrm{S} \mathrm{cm}^{-1}\right)\end{array}$} \\
\hline & 1 & 2 & 3 & 4 & & & & & & & \\
\hline Controle & 0 & 0 & 0 & 0 & 0 & 7,82 & 7,85 & 7,55 & 7,73 & 177,8 & 182,6 \\
\hline 6,25 & 0 & 0 & 0 & 0 & 0 & 7,63 & 7,82 & 7,76 & 7,76 & 169,0 & 171,7 \\
\hline 12,50 & 0 & 0 & 0 & 0 & 0 & 7,43 & 7,82 & 7,81 & 7,71 & 160,5 & 162,1 \\
\hline 25,00 & 0 & 0 & 0 & 0 & 0 & 7,05 & 7,75 & 7,86 & 7,69 & 139,1 & 140,8 \\
\hline 50,00 & 0 & 1 & 0 & 0 & 5 & 6,49 & 7,38 & 7,87 & 7,67 & 98,6 & 101,8 \\
\hline 75,00 & 5 & 5 & 5 & 5 & 100 & 4,59 & 6,04 & 7,94 & 7,49 & 93,1 & 93,7 \\
\hline 100,00 & 5 & 5 & 5 & 5 & 100 & 3,74 & 3,84 & 7,94 & 7,66 & 91,7 & 81,5 \\
\hline
\end{tabular}




\section{Ensaios com o esgoto bruto $(0,0 \mathrm{kGy})$}

\section{Ensaio 1}

\begin{tabular}{|c|c|c|c|c|c|c|c|c|c|c|c|}
\hline \multicolumn{9}{|c|}{ ENSAIO DE TOXICIDADE AGUDA - Daphnia similis } & \multirow{2}{*}{\multicolumn{3}{|c|}{$\begin{array}{l}\text { Dose de radiação: } 0,0 \text { kGy } \\
\text { Água de diluição }\end{array}$}} \\
\hline \multicolumn{5}{|l|}{ Início } & \multicolumn{4}{|l|}{ Término } & & & \\
\hline $\begin{array}{l}\text { Data: } \\
15 / 05 / 2013\end{array}$ & \multicolumn{4}{|c|}{$\begin{array}{l}\text { Hora: } \\
16: 00\end{array}$} & \multicolumn{2}{|c|}{$\begin{array}{l}\text { Data: } \\
17 / 05 / 2013\end{array}$} & \multicolumn{2}{|l|}{$\begin{array}{l}\text { Hora: } \\
16: 00\end{array}$} & \multicolumn{2}{|c|}{$\begin{array}{l}\text { Dureza: } 45,0 \\
\text { mg CaCO}_{3} \mathrm{~L}^{-1}\end{array}$} & $\begin{array}{l}\text { Manancial: } \\
\text { Salto - SP }\end{array}$ \\
\hline \multicolumn{5}{|c|}{ Organismo - teste: Daphnia similis } & \multicolumn{4}{|c|}{ Amostra: Esgoto bruto } & \multicolumn{3}{|c|}{ Operador: Vanessa } \\
\hline \multirow[t]{2}{*}{$\begin{array}{l}\text { Concentração } \\
\text { nominal (\%) }\end{array}$} & \multicolumn{4}{|c|}{$\begin{array}{l}\text { Organismos imóveis } \\
\text { por réplica }\end{array}$} & \multirow[t]{2}{*}{$\begin{array}{l}\text { \% de } \\
\text { imóveis }\end{array}$} & \multirow[t]{2}{*}{$\mathrm{pH}_{\mathrm{i}}$} & \multirow[t]{2}{*}{$\mathrm{pH}_{\mathrm{f}}$} & \multirow[t]{2}{*}{$\begin{array}{l}\mathrm{OD}_{\mathrm{i}} \\
\left(\mathrm{mg} \mathrm{L}^{-1}\right)\end{array}$} & \multirow[t]{2}{*}{$\begin{array}{l}\mathrm{OD}_{\mathrm{f}} \\
\left(\mathrm{mg} \mathrm{L}^{-1}\right)\end{array}$} & \multirow[t]{2}{*}{$\begin{array}{l}\text { Cond }_{. \mathrm{i}} \\
\left(\mu \mathrm{Sm}^{-1}\right)\end{array}$} & \multirow[t]{2}{*}{$\begin{array}{l}\text { Cond. }_{f_{f}} \\
\left(\mu \mathrm{cm}^{-1}\right)\end{array}$} \\
\hline & 1 & 2 & 3 & 4 & & & & & & & \\
\hline Controle & 0 & 0 & 0 & 0 & 0 & 7,94 & 7,87 & 7,56 & 7,05 & 180,7 & 184,3 \\
\hline 6,25 & 0 & 0 & 0 & 0 & 0 & 7,97 & 7,90 & 7,40 & 6,81 & 206,3 & 207,3 \\
\hline 12,50 & 0 & 0 & 1 & 1 & 10 & 7,95 & 7,77 & 7,39 & 6,09 & 240,0 & 234,0 \\
\hline 25,00 & 2 & 0 & 1 & 1 & 20 & 8,03 & 7,75 & 7,39 & 4,39 & 307,0 & 297,0 \\
\hline 50,00 & 2 & 2 & 0 & 0 & 20 & 8,04 & 7,95 & 7,49 & 2,23 & 436,0 & 414,0 \\
\hline 75,00 & 5 & 5 & 5 & 5 & 100 & 7,97 & 8,14 & 7,55 & 0,66 & 569,0 & 537,0 \\
\hline 100,00 & 5 & 5 & 5 & 5 & 100 & 7,91 & 8,26 & 7,46 & 0,58 & 694,0 & 650,0 \\
\hline
\end{tabular}

Ensaio 2

\begin{tabular}{|c|c|c|c|c|c|c|c|c|c|c|c|}
\hline \multicolumn{9}{|c|}{ ENSAIO DE TOXICIDADE AGUDA - Daphnia similis } & \multicolumn{3}{|c|}{ Dose de radiação: $0,0 \mathrm{kGy}$} \\
\hline \multicolumn{5}{|l|}{ Início } & \multicolumn{4}{|l|}{ Término } & \multicolumn{3}{|c|}{ Água de diluição } \\
\hline $\begin{array}{l}\text { Data: } \\
11 / 06 / 2013\end{array}$ & \multicolumn{4}{|c|}{$\begin{array}{l}\text { Hora: } \\
17: 00\end{array}$} & \multicolumn{2}{|c|}{$\begin{array}{l}\text { Data: } \\
13 / 06 / 2013\end{array}$} & \multicolumn{2}{|l|}{$\begin{array}{l}\text { Hora: } \\
17: 00\end{array}$} & \multicolumn{2}{|c|}{$\begin{array}{l}\text { Dureza: } 45,0 \\
\mathrm{mg} \mathrm{CaCO}_{3} \mathrm{~L}^{-1}\end{array}$} & $\begin{array}{l}\text { Manancial: } \\
\text { Salto - SP }\end{array}$ \\
\hline \multicolumn{5}{|c|}{ Organismo - teste: Daphnia similis } & \multicolumn{4}{|c|}{ Amostra: Esgoto bruto } & \multicolumn{3}{|c|}{ Operador: Vanessa } \\
\hline \multirow[t]{2}{*}{$\begin{array}{l}\text { Concentração } \\
\text { nominal (\%) }\end{array}$} & \multicolumn{4}{|c|}{$\begin{array}{l}\text { Organismos imóveis } \\
\text { por réplica }\end{array}$} & \multirow[t]{2}{*}{$\begin{array}{l}\% \text { de } \\
\text { imóveis }\end{array}$} & \multirow[t]{2}{*}{$\mathrm{pH}_{\mathrm{i}}$} & \multirow[t]{2}{*}{$\mathrm{pH}_{\mathrm{f}}$} & \multirow[t]{2}{*}{$\begin{array}{l}\mathrm{OD}_{\mathrm{i}} \\
\left(\mathrm{mg} \mathrm{L}^{-1}\right)\end{array}$} & \multirow[t]{2}{*}{$\begin{array}{l}\mathrm{OD}_{\mathrm{f}} \\
\left(\mathrm{mg} \mathrm{L}^{-1}\right)\end{array}$} & \multirow[t]{2}{*}{$\begin{array}{l}\text { Cond }_{\cdot \mathrm{i}} \\
\left(\mu \mathrm{cm}^{-1}\right)\end{array}$} & \multirow[t]{2}{*}{$\begin{array}{l}\text { Cond }_{. f} \\
\left(\mu \mathrm{Cm}^{-1}\right)\end{array}$} \\
\hline & 1 & 2 & 3 & 4 & & & & & & & \\
\hline Controle & 0 & 0 & 0 & 0 & 0 & 7,90 & 7,90 & 7,68 & 7,91 & 173,0 & 176,9 \\
\hline 6,25 & 0 & 0 & 0 & 0 & 0 & 7,98 & 7,79 & 7,69 & 6,76 & 219,0 & 204,7 \\
\hline 12,50 & 0 & 1 & 0 & 0 & 5 & 7,96 & 7,69 & 7,57 & 4,75 & 242,0 & 234,0 \\
\hline 25,00 & 1 & 1 & 3 & 1 & 20 & 7,97 & 7,74 & 7,57 & 4,14 & 299,0 & 286,0 \\
\hline 50,00 & 1 & 1 & 3 & 3 & 40 & 7,98 & 7,88 & 7,59 & 1,63 & 421,0 & 397,0 \\
\hline 75,00 & 5 & 5 & 1 & 3 & 70 & 7,99 & 7,97 & 7,63 & 0,63 & 541,0 & 507,0 \\
\hline 100,00 & 5 & 5 & 5 & 5 & 100 & 8,09 & 8,12 & 6,61 & 0,48 & 667,0 & 615,0 \\
\hline
\end{tabular}

Ensaio 3

\begin{tabular}{|c|c|c|c|c|c|c|c|c|c|c|c|}
\hline \multicolumn{9}{|c|}{ ENSAIO DE TOXICIDADE AGUDA - Daphnia similis } & \multirow{2}{*}{\multicolumn{3}{|c|}{$\begin{array}{l}\text { Dose de radiação: } 0,0 \mathrm{kGy} \\
\text { Água de diluição }\end{array}$}} \\
\hline \multicolumn{5}{|l|}{ Início } & \multicolumn{4}{|l|}{ Término } & & & \\
\hline $\begin{array}{l}\text { Data: } \\
05 / 12 / 2013\end{array}$ & \multicolumn{4}{|c|}{$\begin{array}{l}\text { Hora: } \\
16: 45 \\
\end{array}$} & \multicolumn{2}{|c|}{$\begin{array}{l}\text { Data: } \\
07 / 12 / 2013\end{array}$} & \multicolumn{2}{|l|}{$\begin{array}{l}\text { Hora: } \\
16: 45\end{array}$} & \multicolumn{2}{|c|}{$\begin{array}{l}\text { Dureza: } 45,0 \\
\mathrm{mg} \mathrm{CaCO}_{3} \mathrm{~L}^{-1}\end{array}$} & $\begin{array}{l}\text { Manancial: } \\
\text { Salto - SP }\end{array}$ \\
\hline \multicolumn{5}{|c|}{ Organismo - teste: Daphnia similis } & \multicolumn{4}{|c|}{ Amostra: Esgoto bruto } & \multicolumn{3}{|c|}{ Operador: Vanessa } \\
\hline \multirow[t]{2}{*}{$\begin{array}{l}\text { Concentração } \\
\text { nominal (\%) }\end{array}$} & \multicolumn{4}{|c|}{$\begin{array}{l}\text { Organismos imóveis } \\
\text { por réplica }\end{array}$} & \multirow[t]{2}{*}{$\begin{array}{l}\text { \% de } \\
\text { imóveis }\end{array}$} & \multirow[t]{2}{*}{$\mathrm{pH}_{\mathrm{i}}$} & \multirow[t]{2}{*}{$\mathrm{pH}_{\mathrm{f}}$} & \multirow[t]{2}{*}{$\begin{array}{l}\mathrm{OD}_{\mathrm{i}} \\
\left(\mathrm{mg} \mathrm{L}^{-1}\right)\end{array}$} & \multirow[t]{2}{*}{$\begin{array}{l}\mathrm{OD}_{\mathrm{f}} \\
\left(\mathrm{mg} \mathrm{L}^{-1}\right)\end{array}$} & \multirow[t]{2}{*}{$\begin{array}{l}\text { Cond. }_{{ }_{\mathrm{i}}} \\
\left(\mu \mathrm{S} \mathrm{cm}{ }^{-1}\right)\end{array}$} & \multirow[t]{2}{*}{$\begin{array}{l}\text { Cond.f }_{. f} \\
\left(\mu \mathrm{cm}^{-1}\right)\end{array}$} \\
\hline & 1 & 2 & 3 & 4 & & & & & & & \\
\hline Controle & 0 & 0 & 0 & 0 & 0 & 8,07 & 8,02 & 7,18 & 7,43 & 198,0 & 197,1 \\
\hline 6,25 & 0 & 0 & 0 & 0 & 0 & 7,85 & 7,93 & 7,07 & 6,30 & 233,0 & 239,0 \\
\hline 12,50 & 1 & 1 & 0 & 0 & 10 & 7,81 & 7,98 & 6,83 & 6,25 & 255,0 & 249,0 \\
\hline 25,00 & 1 & 1 & 1 & 1 & 20 & 7,78 & 7,98 & 6,30 & 5,58 & 316,0 & 306,0 \\
\hline 50,00 & 2 & 2 & 3 & 4 & 55 & 7,78 & 7,99 & 6,34 & 3,63 & 437,0 & 407,0 \\
\hline 75,00 & 4 & 4 & 4 & 3 & 75 & 7,84 & 8,04 & 6,28 & 1,09 & 557,0 & 519,0 \\
\hline 100,00 & 5 & 5 & 5 & 5 & 100 & 7,84 & 8,10 & 6,26 & 0,06 & 683,0 & 648,0 \\
\hline
\end{tabular}

Observações: CE50 $48 \mathrm{~h}$ : 40,10 $(32,55-49,39)$ 


\section{Ensaios com o esgoto bruto $(5,0 \mathrm{kGy})$}

Ensaio 1

\begin{tabular}{|c|c|c|c|c|c|c|c|c|c|c|c|}
\hline \multicolumn{9}{|c|}{ ENSAIO DE TOXICIDADE AGUDA - Daphnia similis } & \multirow{2}{*}{\multicolumn{3}{|c|}{$\begin{array}{l}\text { Dose de radiação: } 5,0 \text { kGy } \\
\text { Água de diluição }\end{array}$}} \\
\hline \multicolumn{5}{|l|}{ Início } & \multicolumn{4}{|l|}{ Término } & & & \\
\hline $\begin{array}{l}\text { Data: } \\
15 / 05 / 2013\end{array}$ & \multicolumn{4}{|c|}{$\begin{array}{l}\text { Hora: } \\
17: 00\end{array}$} & \multicolumn{2}{|c|}{$\begin{array}{l}\text { Data: } \\
17 / 05 / 2013\end{array}$} & \multicolumn{2}{|l|}{$\begin{array}{l}\text { Hora: } \\
17: 00\end{array}$} & \multicolumn{2}{|c|}{$\begin{array}{l}\text { Dureza: } 45,0 \\
\mathrm{mg} \mathrm{CaCO}_{3} \mathrm{~L}^{-1}\end{array}$} & $\begin{array}{l}\text { Manancial: } \\
\text { Salto - SP }\end{array}$ \\
\hline \multicolumn{5}{|c|}{ Organismo - teste: Daphnia similis } & \multicolumn{4}{|c|}{ Amostra: Esgoto bruto } & \multicolumn{3}{|c|}{ Operador: Vanessa } \\
\hline \multirow[t]{2}{*}{$\begin{array}{l}\text { Concentração } \\
\text { nominal (\%) }\end{array}$} & \multicolumn{4}{|c|}{$\begin{array}{l}\text { Organismos imóveis } \\
\text { por réplica }\end{array}$} & \multirow[t]{2}{*}{$\begin{array}{l}\text { \% de } \\
\text { imóveis }\end{array}$} & \multirow[t]{2}{*}{$\mathrm{pH}_{\mathrm{i}}$} & \multirow[t]{2}{*}{$\mathrm{pH}_{\mathrm{f}}$} & \multirow[t]{2}{*}{$\begin{array}{l}\mathrm{OD}_{\mathrm{i}} \\
\left(\mathrm{mg} \mathrm{L}^{-1}\right)\end{array}$} & \multirow[t]{2}{*}{$\begin{array}{l}\mathrm{OD}_{\mathrm{f}} \\
\left(\mathrm{mg} \mathrm{L}^{-1}\right)\end{array}$} & \multirow[t]{2}{*}{$\begin{array}{l}\text { Cond. }_{. i} \\
\left(\mu \mathrm{cm}^{-1}\right)\end{array}$} & \multirow[t]{2}{*}{$\begin{array}{l}\text { Cond.f }_{f} \\
\left(\mu \mathrm{S} \mathrm{cm}{ }^{-1}\right)\end{array}$} \\
\hline & 1 & 2 & 3 & 4 & & & & & & & \\
\hline Controle & 0 & 0 & 0 & 0 & 0 & 7,94 & 7,87 & 7,56 & 7,05 & 180,7 & 184,3 \\
\hline 6,25 & 0 & 0 & 0 & 0 & 0 & 7,99 & 7,66 & 7,36 & 7,02 & 208,8 & 204,9 \\
\hline 12,50 & 0 & 0 & 0 & 0 & 0 & 7,89 & 7,61 & 7,35 & 5,61 & 240,0 & 234,0 \\
\hline 25,00 & 0 & 0 & 0 & 0 & 0 & 7,97 & 7,69 & 7,35 & 3,66 & 302,0 & 293,0 \\
\hline 50,00 & 0 & 0 & 0 & 0 & 0 & 7,97 & 7,95 & 7,53 & 2,77 & 431,0 & 407,0 \\
\hline 75,00 & 1 & 0 & 0 & 0 & 5 & 8,02 & 8,07 & 7,58 & 1,66 & 558,0 & 526,0 \\
\hline 100,00 & 0 & 1 & 1 & 2 & 20 & 8,02 & 8,23 & 7,78 & 1,23 & 684,0 & 637,0 \\
\hline
\end{tabular}

Ensaio 2

\begin{tabular}{|c|c|c|c|c|c|c|c|c|c|c|c|}
\hline \multicolumn{9}{|c|}{ ENSAIO DE TOXICIDADE AGUDA - Daphnia similis } & \multirow{2}{*}{\multicolumn{3}{|c|}{$\begin{array}{l}\text { Dose de radiação: } 5,0 \mathrm{kGy} \\
\text { Água de diluição }\end{array}$}} \\
\hline \multicolumn{5}{|l|}{ Início } & \multicolumn{4}{|c|}{ Término } & & & \\
\hline $\begin{array}{l}\text { Data: } \\
20 / 06 / 2013\end{array}$ & \multicolumn{4}{|c|}{$\begin{array}{l}\text { Hora: } \\
16: 15\end{array}$} & \multicolumn{2}{|c|}{$\begin{array}{l}\text { Data: } \\
22 / 06 / 2013\end{array}$} & \multicolumn{2}{|l|}{$\begin{array}{l}\text { Hora: } \\
16: 15\end{array}$} & \multicolumn{2}{|c|}{$\begin{array}{l}\text { Dureza: } 45,0 \\
\mathrm{mg} \mathrm{CaCO}_{3} \mathrm{~L}^{-1}\end{array}$} & $\begin{array}{l}\text { Manancial: } \\
\text { Salto - SP }\end{array}$ \\
\hline \multicolumn{5}{|c|}{ Organismo - teste: Daphnia similis } & \multicolumn{4}{|c|}{ Amostra: Esgoto bruto } & \multicolumn{3}{|c|}{ Operador: Vanessa } \\
\hline \multirow[t]{2}{*}{$\begin{array}{l}\text { Concentração } \\
\text { nominal (\%) }\end{array}$} & \multicolumn{4}{|c|}{$\begin{array}{l}\text { Organismos imóveis } \\
\text { por réplica }\end{array}$} & \multirow[t]{2}{*}{$\begin{array}{l}\text { \% de } \\
\text { imóveis }\end{array}$} & \multirow[t]{2}{*}{$\mathrm{pH}_{\mathrm{i}}$} & \multirow[t]{2}{*}{$\mathrm{pH}_{\mathrm{f}}$} & \multirow[t]{2}{*}{$\begin{array}{l}\mathrm{OD}_{\mathrm{i}} \\
\left(\mathrm{mg} \mathrm{L}^{-1}\right)\end{array}$} & \multirow[t]{2}{*}{$\begin{array}{l}\mathrm{OD}_{\mathrm{f}} \\
\left(\mathrm{mg} \mathrm{L}^{-1}\right)\end{array}$} & \multirow[t]{2}{*}{$\begin{array}{l}\text { Cond }_{. i} \\
\left(\mu \mathrm{cm}^{-1}\right)\end{array}$} & \multirow[t]{2}{*}{$\begin{array}{l}\text { Cond. }_{. f} \\
\left(\mu \mathrm{cm}^{-1}\right)\end{array}$} \\
\hline & 1 & 2 & 3 & 4 & & & & & & & \\
\hline Controle & 0 & 0 & 0 & 0 & 0 & 7,82 & 7,91 & 7,90 & 7,57 & 173,2 & 191,0 \\
\hline 6,25 & 0 & 1 & 0 & 0 & 5 & 7,82 & 7,86 & 7,70 & 6,90 & 202,8 & 212,0 \\
\hline 12,50 & 1 & 0 & 0 & 0 & 5 & 7,84 & 7,76 & 7,75 & 6,05 & 241,0 & 236,0 \\
\hline 25,00 & 0 & 0 & 0 & 0 & 0 & 7,87 & 7,81 & 7,78 & 5,08 & 308,0 & 295,0 \\
\hline 50,00 & 1 & 0 & 0 & 0 & 5 & 7,89 & 7,90 & 7,86 & 3,47 & 440,0 & 410,0 \\
\hline 75,00 & 0 & 0 & 0 & 1 & 5 & 7,90 & 8,15 & 7,87 & 2,76 & 572,0 & 520,0 \\
\hline 100,00 & 2 & 3 & 2 & 0 & 35 & 7,85 & 8,30 & 8,04 & 2,32 & 706,0 & 635,0 \\
\hline
\end{tabular}

Ensaio 3

\begin{tabular}{|c|c|c|c|c|c|c|c|c|c|c|c|}
\hline \multicolumn{9}{|c|}{ ENSAIO DE TOXICIDADE AGUDA - Daphnia similis } & \multirow{2}{*}{\multicolumn{3}{|c|}{$\begin{array}{l}\text { Dose de radiação: } 5,0 \mathrm{kGy} \\
\text { Água de diluição }\end{array}$}} \\
\hline \multicolumn{5}{|l|}{ Início } & \multicolumn{4}{|l|}{ Término } & & & \\
\hline $\begin{array}{l}\text { Data: } \\
05 / 12 / 2013\end{array}$ & $\begin{array}{l}\text { Ho } \\
17:\end{array}$ & & & & $\begin{array}{l}\text { Data: } \\
07 / 12 / 201\end{array}$ & & $\begin{array}{l}\text { Hora: } \\
16: 00\end{array}$ & & \multicolumn{2}{|c|}{$\begin{array}{l}\text { Dureza: } 45,0 \\
\mathrm{mg} \mathrm{CaCO}_{3} \mathrm{~L}^{-1}\end{array}$} & $\begin{array}{l}\text { Manancial: } \\
\text { Salto - SP }\end{array}$ \\
\hline \multicolumn{5}{|c|}{ Organismo - teste: Daphnia similis } & \multicolumn{4}{|c|}{ Amostra: Esgoto bruto } & \multicolumn{3}{|c|}{ Operador: Vanessa } \\
\hline \multirow[t]{2}{*}{$\begin{array}{l}\text { Concentração } \\
\text { nominal (\%) }\end{array}$} & \multicolumn{4}{|c|}{$\begin{array}{l}\text { Organismos imóveis } \\
\text { por réplica }\end{array}$} & \multirow[t]{2}{*}{$\begin{array}{l}\% \text { de } \\
\text { imóveis }\end{array}$} & \multirow[t]{2}{*}{$\mathrm{pH}_{\mathrm{i}}$} & \multirow[t]{2}{*}{$\mathrm{pH}_{\mathrm{f}}$} & \multirow[t]{2}{*}{$\begin{array}{l}\mathrm{OD}_{\mathrm{i}} \\
\left(\mathrm{mg} \mathrm{L}^{-1}\right)\end{array}$} & \multirow[t]{2}{*}{$\begin{array}{l}\mathrm{OD}_{\mathrm{f}} \\
\left(\mathrm{mg} \mathrm{L}^{-1}\right)\end{array}$} & \multirow[t]{2}{*}{$\begin{array}{l}\text { Cond }_{\cdot \mathrm{i}} \\
\left(\mu \mathrm{cm}^{-1}\right)\end{array}$} & \multirow[t]{2}{*}{$\begin{array}{l}\text { Cond.f }_{\cdot f} \\
\left(\mu \mathrm{S} \mathrm{cm}^{-1}\right)\end{array}$} \\
\hline & 1 & 2 & 3 & 4 & & & & & & & \\
\hline Controle & 0 & 0 & 0 & 0 & 0 & 8,07 & 8,02 & 7,18 & 7,43 & 198,0 & 197,1 \\
\hline 6,25 & 0 & 0 & 0 & 0 & 0 & 8,10 & 8,01 & 7,00 & 6,33 & 236,0 & 228,0 \\
\hline 12,50 & 0 & 0 & 0 & 0 & 0 & 8,10 & 8,01 & 7,00 & 5,89 & 266,0 & 261,0 \\
\hline 25,00 & 0 & 0 & 0 & 0 & 0 & 8,11 & 8,01 & 6,99 & 4,21 & 328,0 & 320,0 \\
\hline 50,00 & 0 & 0 & 0 & 0 & 0 & 8,11 & 8,12 & 6,96 & 4,11 & 447,0 & 428,0 \\
\hline 75,00 & 0 & 0 & 0 & 1 & 5 & 8,11 & 8,13 & 6,87 & 3,39 & 568,0 & 539,0 \\
\hline 100,00 & 2 & 1 & 1 & 2 & 30 & 8,08 & 8,13 & 6,63 & 2,45 & 688,0 & 639,0 \\
\hline
\end{tabular}

Observações: CE50 48h: NT (Não tóxico) 


\section{Ensaios com o esgoto bruto (20,0 kGy)}

\section{Ensaio 1}

\begin{tabular}{|c|c|c|c|c|c|c|c|c|c|c|c|}
\hline \multicolumn{9}{|c|}{ ENSAIO DE TOXICIDADE AGUDA - Daphnia similis } & \multirow{2}{*}{\multicolumn{3}{|c|}{$\begin{array}{l}\text { Dose de radiação: } 20,0 \text { kGy } \\
\text { Água de diluição }\end{array}$}} \\
\hline \multicolumn{5}{|l|}{ Início } & \multicolumn{4}{|l|}{ Término } & & & \\
\hline $\begin{array}{l}\text { Data: } \\
11 / 06 / 2013\end{array}$ & \multicolumn{4}{|c|}{$\begin{array}{l}\text { Hora: } \\
16: 45\end{array}$} & \multicolumn{2}{|c|}{$\begin{array}{l}\text { Data: } \\
13 / 06 / 2013 \\
\end{array}$} & \multicolumn{2}{|l|}{$\begin{array}{l}\text { Hora: } \\
16: 45\end{array}$} & \multicolumn{2}{|c|}{$\begin{array}{l}\text { Dureza: } 45,0 \\
\mathrm{mg} \mathrm{CaCO}_{3} \mathrm{~L}^{-1}\end{array}$} & $\begin{array}{l}\text { Manancial: } \\
\text { Salto - SP }\end{array}$ \\
\hline \multicolumn{5}{|c|}{ Organismo - teste: Daphnia similis } & \multicolumn{4}{|c|}{ Amostra: Esgoto bruto } & \multicolumn{3}{|c|}{ Operador: Vanessa } \\
\hline \multirow[t]{2}{*}{$\begin{array}{l}\text { Concentração } \\
\text { nominal (\%) }\end{array}$} & \multicolumn{4}{|c|}{$\begin{array}{l}\text { Organismos imóveis } \\
\text { por réplica }\end{array}$} & \multirow[t]{2}{*}{$\begin{array}{l}\text { \% de } \\
\text { imóveis }\end{array}$} & \multirow[t]{2}{*}{$\mathrm{pH}_{\mathrm{i}}$} & \multirow[t]{2}{*}{$\mathrm{pH}_{\mathrm{f}}$} & \multirow[t]{2}{*}{$\begin{array}{l}\mathrm{OD}_{\mathrm{i}} \\
\left(\mathrm{mg} \mathrm{L}^{-1}\right)\end{array}$} & \multirow[t]{2}{*}{$\begin{array}{l}\mathrm{OD}_{\mathrm{f}} \\
\left(\mathrm{mg} \mathrm{L}^{-1}\right)\end{array}$} & \multirow[t]{2}{*}{$\begin{array}{l}\text { Cond. }_{. i} \\
\left(\mu \mathrm{cm}^{-1}\right)\end{array}$} & \multirow[t]{2}{*}{$\begin{array}{l}\text { Cond }_{f_{\mathrm{f}}} \\
\left(\mu \mathrm{Sm}^{-1}\right)\end{array}$} \\
\hline & 1 & 2 & 3 & 4 & & & & & & & \\
\hline Controle & 0 & 0 & 0 & 0 & 0 & 7,90 & 7,90 & 7,68 & 7,91 & 173,0 & 176,9 \\
\hline 6,25 & 0 & 0 & 0 & 0 & 0 & 7,90 & 7,94 & 7,73 & 5,97 & 201,2 & 221,0 \\
\hline 12,50 & 1 & 0 & 0 & 0 & 5 & 8,00 & 7,84 & 7,69 & 5,64 & 238,0 & 241,0 \\
\hline 25,00 & 0 & 0 & 0 & 0 & 0 & 8,04 & 7,92 & 7,68 & 3,89 & 299,0 & 298,0 \\
\hline 50,00 & 0 & 0 & 0 & 0 & 0 & 8,06 & 8,09 & 7,71 & 3,57 & 414,0 & 404,0 \\
\hline 75,00 & 0 & 0 & 0 & 0 & 0 & 8,07 & 8,12 & 7,72 & 2,62 & 535,0 & 513,0 \\
\hline 100,00 & 5 & 5 & 5 & 5 & 100 & 8,08 & 8,10 & 7,77 & 0,85 & 668,0 & 622,0 \\
\hline
\end{tabular}

Ensaio 2

\begin{tabular}{|c|c|c|c|c|c|c|c|c|c|c|c|}
\hline \multicolumn{9}{|c|}{ ENSAIO DE TOXICIDADE AGUDA - Daphnia similis } & \multirow{2}{*}{\multicolumn{3}{|c|}{$\begin{array}{l}\text { Dose de radiação: } 20,0 \mathrm{kGy} \\
\text { Água de diluição }\end{array}$}} \\
\hline \multicolumn{5}{|c|}{ 年 } & \multicolumn{4}{|c|}{ Término } & & & \\
\hline $\begin{array}{l}\text { Data: } \\
20 / 06 / 2013\end{array}$ & \multicolumn{4}{|c|}{$\begin{array}{l}\text { Hora: } \\
16: 30\end{array}$} & \multicolumn{2}{|c|}{$\begin{array}{l}\text { Data: } \\
22 / 06 / 2013\end{array}$} & \multicolumn{2}{|c|}{$\begin{array}{l}\text { Hora: } \\
16: 30\end{array}$} & \multicolumn{2}{|c|}{$\begin{array}{l}\text { Dureza: } 45,0 \\
\mathrm{mg} \mathrm{CaCO}_{3} \mathrm{~L}^{-1}\end{array}$} & $\begin{array}{l}\text { Manancial: } \\
\text { Salto - SP }\end{array}$ \\
\hline \multicolumn{5}{|c|}{ Organismo - teste: Daphnia similis } & \multicolumn{4}{|c|}{ Amostra: Esgoto bruto } & \multicolumn{3}{|c|}{ Operador: Vanessa } \\
\hline \multirow[t]{2}{*}{$\begin{array}{l}\text { Concentração } \\
\text { nominal (\%) }\end{array}$} & \multicolumn{4}{|c|}{$\begin{array}{l}\text { Organismos imóveis } \\
\text { por réplica }\end{array}$} & \multirow[t]{2}{*}{$\begin{array}{l}\text { \% de } \\
\text { imóveis }\end{array}$} & \multirow[t]{2}{*}{$\mathrm{pH}_{\mathrm{i}}$} & \multirow[t]{2}{*}{$\mathrm{pH}_{\mathrm{f}}$} & \multirow[t]{2}{*}{$\begin{array}{l}\mathrm{OD}_{\mathrm{i}} \\
\left(\mathrm{mg} \mathrm{L}^{-1}\right)\end{array}$} & \multirow[t]{2}{*}{$\begin{array}{l}\mathrm{OD}_{\mathrm{f}} \\
\left(\mathrm{mg} \mathrm{L}^{-1}\right)\end{array}$} & \multirow[t]{2}{*}{$\begin{array}{l}\text { Cond }_{. i} \\
\left(\mu \mathrm{cm}^{-1}\right)\end{array}$} & \multirow[t]{2}{*}{$\begin{array}{l}\text { Cond }_{. \mathrm{f}} \\
\left(\mu \mathrm{S} \mathrm{cm}{ }^{-1}\right)\end{array}$} \\
\hline & 1 & 2 & 3 & 4 & & & & & & & \\
\hline Controle & 0 & 0 & 0 & 0 & 0 & 7,82 & 7,91 & 7,90 & 7,57 & 173,2 & 191,0 \\
\hline 6,25 & 2 & 0 & 0 & 0 & 10 & 7,92 & 8,00 & 7,85 & 6,63 & 227,0 & 209,8 \\
\hline 12,50 & 2 & 0 & 2 & 1 & 25 & 7,89 & 8,02 & 7,73 & 5,35 & 239,0 & 234,0 \\
\hline 25,00 & 1 & 0 & 3 & 0 & 20 & 7,88 & 7,94 & 7,70 & 4,75 & 301,0 & 294,0 \\
\hline 50,00 & 1 & 1 & 0 & 0 & 10 & 7,86 & 8,00 & 7,67 & 4,72 & 426,0 & 405,0 \\
\hline 75,00 & 0 & 0 & 0 & 0 & 0 & 7,93 & 8,06 & 7,65 & 3,81 & 554,0 & 515,0 \\
\hline 100,00 & 5 & 5 & 5 & 5 & 100 & 7,86 & 8,11 & 7,24 & 2,16 & 695,0 & 632,0 \\
\hline
\end{tabular}

Ensaio 3

\begin{tabular}{|c|c|c|c|c|c|c|c|c|c|c|c|}
\hline \multicolumn{9}{|c|}{ ENSAIO DE TOXICIDADE AGUDA - Daphnia similis } & \multirow{2}{*}{\multicolumn{3}{|c|}{ Dose de radiação: 20,0 kGy }} \\
\hline \multicolumn{5}{|l|}{ Início } & \multicolumn{4}{|l|}{ Término } & & & \\
\hline $\begin{array}{l}\text { Data: } \\
05 / 12 / 2013\end{array}$ & \multicolumn{4}{|c|}{$\begin{array}{l}\text { Hora: } \\
17: 15\end{array}$} & \multicolumn{2}{|c|}{$\begin{array}{l}\text { Data: } \\
07 / 12 / 2013\end{array}$} & \multicolumn{2}{|l|}{$\begin{array}{l}\text { Hora: } \\
17: 15\end{array}$} & \multicolumn{2}{|c|}{$\begin{array}{l}\text { Dureza: } 45,0 \\
\mathrm{mg} \mathrm{CaCO}_{3} \mathrm{~L}^{-1}\end{array}$} & $\begin{array}{l}\text { Manancial: } \\
\text { Salto - SP }\end{array}$ \\
\hline \multicolumn{5}{|c|}{ Organismo - teste: Daphnia similis } & \multicolumn{4}{|c|}{ Amostra: Esgoto bruto } & \multicolumn{3}{|c|}{ Operador: Vanessa } \\
\hline \multirow[t]{2}{*}{$\begin{array}{l}\text { Concentração } \\
\text { nominal (\%) }\end{array}$} & \multicolumn{4}{|c|}{$\begin{array}{l}\text { Organismos imóveis } \\
\text { por réplica }\end{array}$} & \multirow[t]{2}{*}{$\begin{array}{l}\text { \% de } \\
\text { imóveis }\end{array}$} & \multirow[t]{2}{*}{$\mathrm{pH}_{\mathrm{i}}$} & \multirow[t]{2}{*}{$\mathrm{pH}_{\mathrm{f}}$} & \multirow[t]{2}{*}{$\begin{array}{l}\mathrm{OD}_{\mathrm{i}} \\
\left(\mathrm{mg} \mathrm{L}^{-1}\right)\end{array}$} & \multirow[t]{2}{*}{$\begin{array}{l}\mathrm{OD}_{\mathrm{f}} \\
\left(\mathrm{mg} \mathrm{L}^{-1}\right)\end{array}$} & \multirow[t]{2}{*}{$\begin{array}{l}\text { Cond }_{\cdot \mathrm{i}} \\
\left(\mu \mathrm{S} \mathrm{cm}^{-1}\right)\end{array}$} & \multirow[t]{2}{*}{$\begin{array}{l}\text { Cond }_{. f} \\
\left(\mu \mathrm{S} \mathrm{cm}^{-1}\right)\end{array}$} \\
\hline & 1 & 2 & 3 & 4 & & & & & & & \\
\hline Controle & 0 & 0 & 0 & 0 & 0 & 8,07 & 8,02 & 7,18 & 7,43 & 198,0 & 197,1 \\
\hline 6,25 & 0 & 0 & 0 & 0 & 0 & 8,14 & 8,09 & 7,00 & 6,60 & 234,0 & 227,0 \\
\hline 12,50 & 0 & 0 & 0 & 0 & 0 & 8,14 & 8,05 & 7,01 & 6,49 & 260,0 & 257,0 \\
\hline 25,00 & 0 & 0 & 0 & 0 & 0 & 8,11 & 8,05 & 7,02 & 5,75 & 317,0 & 313,0 \\
\hline 50,00 & 0 & 0 & 0 & 0 & 0 & 8,09 & 8,05 & 7,00 & 4.48 & 435,0 & 429,0 \\
\hline 75,00 & 0 & 0 & 0 & 0 & 0 & 8,07 & 8,23 & 6,99 & 3,71 & 556,0 & 532,0 \\
\hline 100,00 & 5 & 5 & 5 & 5 & 100 & 8,05 & 8,19 & 6,96 & 0,45 & 682,0 & 638,0 \\
\hline
\end{tabular}




\section{Ensaios com a mistura $(\mathrm{CF}+$ esgoto $)(0,0 \mathrm{kGy})$}

Ensaio 1

\begin{tabular}{|c|c|c|c|c|c|c|c|c|c|c|c|}
\hline \multicolumn{9}{|c|}{ ENSAIO DE TOXICIDADE AGUDA - Daphnia similis } & \multirow{2}{*}{\multicolumn{3}{|c|}{$\begin{array}{l}\text { Dose de radiação: } 0,0 \mathrm{kGy} \\
\text { Água de diluição }\end{array}$}} \\
\hline \multicolumn{5}{|c|}{ 2010 } & \multicolumn{4}{|c|}{ Término } & & & \\
\hline $\begin{array}{l}\text { Data: } \\
30 / 04 / 2013\end{array}$ & \multicolumn{4}{|c|}{$\begin{array}{l}\text { Hora: } \\
15: 30\end{array}$} & \multicolumn{2}{|c|}{$\begin{array}{l}\text { Data: } \\
02 / 05 / 2013\end{array}$} & \multicolumn{2}{|l|}{$\begin{array}{l}\text { Hora: } \\
15: 30\end{array}$} & \multicolumn{2}{|c|}{$\begin{array}{l}\text { Dureza: } 45,0 \\
\mathrm{mg} \mathrm{CaCO}_{3} \mathrm{~L}^{-1}\end{array}$} & $\begin{array}{l}\text { Manancial: } \\
\text { Salto - SP }\end{array}$ \\
\hline \multicolumn{5}{|c|}{ Organismo - teste: Daphnia similis } & \multicolumn{4}{|c|}{ Amostra: Mistura (CF + esgoto) } & \multicolumn{3}{|c|}{ Operador: Vanessa } \\
\hline \multirow[t]{2}{*}{$\begin{array}{l}\text { Concentração } \\
\text { nominal }(\%)\end{array}$} & \multicolumn{4}{|c|}{$\begin{array}{l}\text { Organismos imóveis } \\
\text { por réplica }\end{array}$} & \multirow[t]{2}{*}{$\begin{array}{l}\text { \% de } \\
\text { imóveis }\end{array}$} & \multirow[t]{2}{*}{$\mathrm{pH}_{\mathrm{i}}$} & \multirow[t]{2}{*}{$\mathrm{pH}_{\mathrm{f}}$} & \multirow[t]{2}{*}{$\begin{array}{l}\mathrm{OD}_{\mathrm{i}} \\
\left(\mathrm{mg} \mathrm{L}^{-1}\right)\end{array}$} & \multirow[t]{2}{*}{$\begin{array}{l}\mathrm{OD}_{\mathrm{f}} \\
\left(\mathrm{mg} \mathrm{L}^{-1}\right)\end{array}$} & \multirow[t]{2}{*}{$\begin{array}{l}\text { Cond }_{{ }_{\mathrm{i}}} \\
\left(\mu \mathrm{cm}^{-1}\right)\end{array}$} & \multirow[t]{2}{*}{$\begin{array}{l}\text { Cond }_{f} \\
\left(\mu \mathrm{cm}^{-1}\right)\end{array}$} \\
\hline & 1 & 2 & 3 & 4 & & & & & & & \\
\hline Controle & 0 & 0 & 0 & 0 & 0 & 7,71 & 7,83 & 7,53 & 7,55 & 178,5 & 176,1 \\
\hline 6,25 & 1 & 0 & 0 & 0 & 5 & 7,99 & 7,79 & 7,47 & 6,87 & 196,0 & 196,6 \\
\hline 12,50 & 1 & 1 & 2 & 0 & 20 & 7,98 & 7,74 & 7,50 & 6,14 & 225,0 & 222,0 \\
\hline 25,00 & 5 & 4 & 2 & 3 & 70 & 7,95 & 7,84 & 7,55 & 5,32 & 276,0 & 264,0 \\
\hline 50,00 & 5 & 5 & 5 & 5 & 100 & 7,93 & 7,88 & 7,64 & 3,03 & 375,0 & 352,0 \\
\hline 75,00 & 5 & 5 & 5 & 5 & 100 & 7,90 & 8,08 & 7,71 & 1,62 & 474,0 & 441,0 \\
\hline 100,00 & 5 & 5 & 5 & 5 & 100 & 7,77 & 8,19 & 7,90 & 0,49 & 585,0 & 532,0 \\
\hline
\end{tabular}

Ensaio 2

\begin{tabular}{|c|c|c|c|c|c|c|c|c|c|c|c|}
\hline \multicolumn{9}{|c|}{ ENSAIO DE TOXICIDADE AGUDA - Daphnia similis } & \multirow{2}{*}{\multicolumn{3}{|c|}{$\begin{array}{l}\text { Dose de radiação: } 0,0 \mathrm{kGy} \\
\text { Água de diluição }\end{array}$}} \\
\hline \multicolumn{5}{|c|}{ 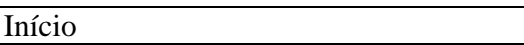 } & \multicolumn{4}{|c|}{ Término } & & & \\
\hline $\begin{array}{l}\text { Data: } \\
25 / 06 / 2013\end{array}$ & \multicolumn{4}{|c|}{$\begin{array}{l}\text { Hora: } \\
16: 00\end{array}$} & \multicolumn{2}{|c|}{$\begin{array}{l}\text { Data: } \\
27 / 06 / 2013\end{array}$} & \multicolumn{2}{|l|}{$\begin{array}{l}\text { Hora: } \\
16: 00\end{array}$} & \multicolumn{2}{|c|}{$\begin{array}{l}\text { Dureza: } 45,0 \\
\mathrm{mg} \mathrm{CaCO}_{3} \mathrm{~L}^{-1}\end{array}$} & $\begin{array}{l}\text { Manancial: } \\
\text { Salto - SP }\end{array}$ \\
\hline \multicolumn{5}{|c|}{ Organismo - teste: Daphnia similis } & \multicolumn{4}{|c|}{ Amostra: Mistura (CF + esgoto) } & \multicolumn{3}{|c|}{ Operador: Vanessa } \\
\hline \multirow[t]{2}{*}{$\begin{array}{l}\text { Concentração } \\
\text { nominal (\%) }\end{array}$} & \multicolumn{4}{|c|}{$\begin{array}{l}\text { Organismos imóveis } \\
\text { por réplica }\end{array}$} & \multirow[t]{2}{*}{$\begin{array}{l}\text { \% de } \\
\text { imóveis }\end{array}$} & \multirow[t]{2}{*}{$\mathrm{pH}_{\mathrm{i}}$} & \multirow[t]{2}{*}{$\mathrm{pH}_{\mathrm{f}}$} & \multirow[t]{2}{*}{$\begin{array}{l}\mathrm{OD}_{\mathrm{i}} \\
\left(\mathrm{mg} \mathrm{L}^{-1}\right)\end{array}$} & \multirow[t]{2}{*}{$\begin{array}{l}\mathrm{OD}_{\mathrm{f}} \\
\left(\mathrm{mg} \mathrm{L}^{-1}\right)\end{array}$} & \multirow[t]{2}{*}{$\begin{array}{l}\text { Cond. }_{. i} \\
\left(\mu \mathrm{cm}^{-1}\right)\end{array}$} & \multirow[t]{2}{*}{$\begin{array}{l}\text { Cond }_{. \mathrm{f}} \\
\left(\mu \mathrm{S} \mathrm{cm}^{-1}\right)\end{array}$} \\
\hline & 1 & 2 & 3 & 4 & & & & & & & \\
\hline Controle & 0 & 0 & 0 & 0 & 0 & 7,97 & 8,01 & 8,00 & 7,80 & 175,5 & 189,5 \\
\hline 6,25 & 0 & 1 & 0 & 1 & 10 & 8,03 & 7,79 & 7,89 & 7,07 & 203,4 & 195,0 \\
\hline 12,50 & 2 & 2 & 1 & 1 & 30 & 8,00 & 7,77 & 7,83 & 6,04 & 226,0 & 218,0 \\
\hline 25,00 & 3 & 1 & 4 & 1 & 45 & 7,95 & 7,80 & 7,65 & 4,37 & 275,0 & 264,0 \\
\hline 50,00 & 5 & 5 & 5 & 5 & 100 & 7,90 & 7,92 & 7,28 & 1,62 & 376,0 & 353,0 \\
\hline 75,00 & 5 & 5 & 5 & 5 & 100 & 7,89 & 8,07 & 7,04 & 0,80 & 478,0 & 448,0 \\
\hline 100,00 & 5 & 5 & 5 & 5 & 100 & 7,83 & 8,17 & 6,63 & 0,86 & 581,0 & 535,0 \\
\hline
\end{tabular}

Ensaio 3

\begin{tabular}{|c|c|c|c|c|c|c|c|c|c|c|c|}
\hline \multicolumn{9}{|c|}{ ENSAIO DE TOXICIDADE AGUDA - Daphnia similis } & \multirow{2}{*}{\multicolumn{3}{|c|}{$\begin{array}{l}\text { Dose de radiação: } 0,0 \mathrm{kGy} \\
\text { Água de diluição }\end{array}$}} \\
\hline \multicolumn{5}{|l|}{ Início } & \multicolumn{4}{|l|}{ Término } & & & \\
\hline $\begin{array}{l}\text { Data: } \\
04 / 12 / 2013\end{array}$ & \multicolumn{4}{|c|}{$\begin{array}{l}\text { Hora: } \\
16: 00 \\
\end{array}$} & \multicolumn{2}{|c|}{$\begin{array}{l}\text { Data: } \\
06 / 12 / 2013\end{array}$} & \multicolumn{2}{|l|}{$\begin{array}{l}\text { Hora: } \\
16: 00\end{array}$} & \multicolumn{2}{|c|}{$\begin{array}{l}\text { Dureza: } 45,0 \\
\mathrm{mg} \mathrm{CaCO}_{3} \mathrm{~L}^{-1}\end{array}$} & $\begin{array}{l}\text { Manancial: } \\
\text { Salto - SP }\end{array}$ \\
\hline \multicolumn{5}{|c|}{ Organismo - teste: Daphnia similis } & \multicolumn{4}{|c|}{ Amostra: Mistura (CF + esgoto) } & \multicolumn{3}{|c|}{ Operador: Vanessa } \\
\hline \multirow[t]{2}{*}{$\begin{array}{l}\text { Concentração } \\
\text { nominal (\%) }\end{array}$} & \multicolumn{4}{|c|}{$\begin{array}{l}\text { Organismos imóveis } \\
\text { por réplica }\end{array}$} & \multirow[t]{2}{*}{$\begin{array}{l}\text { \% de } \\
\text { imóveis }\end{array}$} & \multirow[t]{2}{*}{$\mathrm{pH}_{\mathrm{i}}$} & \multirow[t]{2}{*}{$\mathrm{pH}_{\mathrm{f}}$} & \multirow[t]{2}{*}{$\begin{array}{l}\mathrm{OD}_{\mathrm{i}} \\
\left(\mathrm{mg} \mathrm{L}^{-1}\right)\end{array}$} & \multirow[t]{2}{*}{$\begin{array}{l}\mathrm{OD}_{\mathrm{f}} \\
\left(\mathrm{mg} \mathrm{L}^{-1}\right)\end{array}$} & \multirow[t]{2}{*}{$\begin{array}{l}\text { Cond }_{. i} \\
\left(\mu \mathrm{cm}^{-1}\right)\end{array}$} & \multirow[t]{2}{*}{$\begin{array}{l}\text { Cond.f }_{. f} \\
\left(\mu \mathrm{cm}^{-1}\right)\end{array}$} \\
\hline & 1 & 2 & 3 & 4 & & & & & & & \\
\hline Controle & 0 & 0 & 0 & 0 & 0 & 8,08 & 8,05 & 7,28 & 7,20 & 209,4 & 206,4 \\
\hline 6,25 & 0 & 1 & 0 & 0 & 5 & 7,95 & 7,93 & 7,28 & 6,77 & 218,7 & 215,0 \\
\hline 12,50 & 2 & 3 & 3 & 3 & 55 & 7,95 & 7,92 & 7,21 & 5,98 & 242,0 & 240,0 \\
\hline 25,00 & 4 & 3 & 3 & 3 & 65 & 7,94 & 7,90 & 7,21 & 4,40 & 290,0 & 284,0 \\
\hline 50,00 & 5 & 4 & 5 & 5 & 95 & 7,94 & 7,90 & 7,14 & 3,97 & 383,0 & 375,0 \\
\hline 75,00 & 5 & 5 & 5 & 5 & 100 & 7,90 & 7,88 & 7,03 & 2,76 & 479,0 & 475,0 \\
\hline 100,00 & 5 & 5 & 5 & 5 & 100 & 7,87 & 7,86 & 6,48 & 0,30 & 580,0 & 570,0 \\
\hline
\end{tabular}

Observações: CE50 $48 \mathrm{~h}: 15,15(11,88-19,33)$ 


\section{Ensaios com a mistura $(\mathrm{CF}+$ esgoto $)(5,0 \mathrm{kGy})$}

Ensaio 1

\begin{tabular}{|c|c|c|c|c|c|c|c|c|c|c|c|}
\hline \multicolumn{9}{|c|}{ ENSAIO DE TOXICIDADE AGUDA - Daphnia similis } & \multirow{2}{*}{\multicolumn{3}{|c|}{$\begin{array}{l}\text { Dose de radiação: } 5,0 \mathrm{kGy} \\
\text { Água de diluição }\end{array}$}} \\
\hline \multicolumn{5}{|c|}{ 2010 } & \multicolumn{4}{|c|}{ Término } & & & \\
\hline $\begin{array}{l}\text { Data: } \\
30 / 04 / 2013\end{array}$ & \multicolumn{4}{|c|}{$\begin{array}{l}\text { Hora: } \\
15: 45\end{array}$} & \multicolumn{2}{|c|}{$\begin{array}{l}\text { Data: } \\
02 / 05 / 2013\end{array}$} & \multicolumn{2}{|l|}{$\begin{array}{l}\text { Hora: } \\
15: 45\end{array}$} & \multicolumn{2}{|c|}{$\begin{array}{l}\text { Dureza: } 45,0 \\
\mathrm{mg} \mathrm{CaCO}_{3} \mathrm{~L}^{-1}\end{array}$} & $\begin{array}{l}\text { Manancial: } \\
\text { Salto - SP }\end{array}$ \\
\hline \multicolumn{5}{|c|}{ Organismo - teste: Daphnia similis } & \multicolumn{4}{|c|}{ Amostra: Mistura (CF + esgoto) } & \multicolumn{3}{|c|}{ Operador: Vanessa } \\
\hline \multirow[t]{2}{*}{$\begin{array}{l}\text { Concentração } \\
\text { nominal (\%) }\end{array}$} & \multicolumn{4}{|c|}{$\begin{array}{l}\text { Organismos imóveis } \\
\text { por réplica }\end{array}$} & \multirow[t]{2}{*}{$\begin{array}{l}\text { \% de } \\
\text { imóveis }\end{array}$} & \multirow[t]{2}{*}{$\mathrm{pH}_{\mathrm{i}}$} & \multirow[t]{2}{*}{$\mathrm{pH}_{\mathrm{f}}$} & \multirow[t]{2}{*}{$\begin{array}{l}\mathrm{OD}_{\mathrm{i}} \\
\left(\mathrm{mg} \mathrm{L}^{-1}\right)\end{array}$} & \multirow[t]{2}{*}{$\begin{array}{l}\mathrm{OD}_{\mathrm{f}} \\
\left(\mathrm{mg} \mathrm{L}^{-1}\right)\end{array}$} & \multirow[t]{2}{*}{$\begin{array}{l}\text { Cond }_{\cdot \mathrm{i}} \\
\left(\mu \mathrm{S} \mathrm{cm}^{-1}\right)\end{array}$} & \multirow[t]{2}{*}{$\begin{array}{l}\text { Cond }_{. f} \\
\left(\mu \mathrm{cm}^{-1}\right)\end{array}$} \\
\hline & 1 & 2 & 3 & 4 & & & & & & & \\
\hline Controle & 0 & 0 & 0 & 0 & 0 & 7,71 & 7,83 & 7,53 & 7,55 & 178,5 & 176,1 \\
\hline 6,25 & 0 & 0 & 0 & 0 & 0 & 7,98 & 7,91 & 7,55 & 6,21 & 210,8 & 201,4 \\
\hline 12,50 & 0 & 0 & 1 & 0 & 5 & 8,00 & 7,83 & 7,47 & 5,51 & 223,0 & 222,0 \\
\hline 25,00 & 0 & 0 & 0 & 0 & 0 & 7,98 & 7,79 & 7,46 & 4,01 & 273,0 & 270,0 \\
\hline 50,00 & 0 & 0 & 0 & 0 & 0 & 7,99 & 7,87 & 7,48 & 2,75 & 372,0 & 360,0 \\
\hline 75,00 & 0 & 0 & 0 & 1 & 5 & 7,99 & 7,99 & 7,50 & 2,58 & 470,0 & 448,0 \\
\hline 100,00 & 4 & 3 & 1 & 4 & 60 & 7,92 & 8,07 & 7,63 & 2,34 & 575,0 & 535,0 \\
\hline
\end{tabular}

Ensaio 2

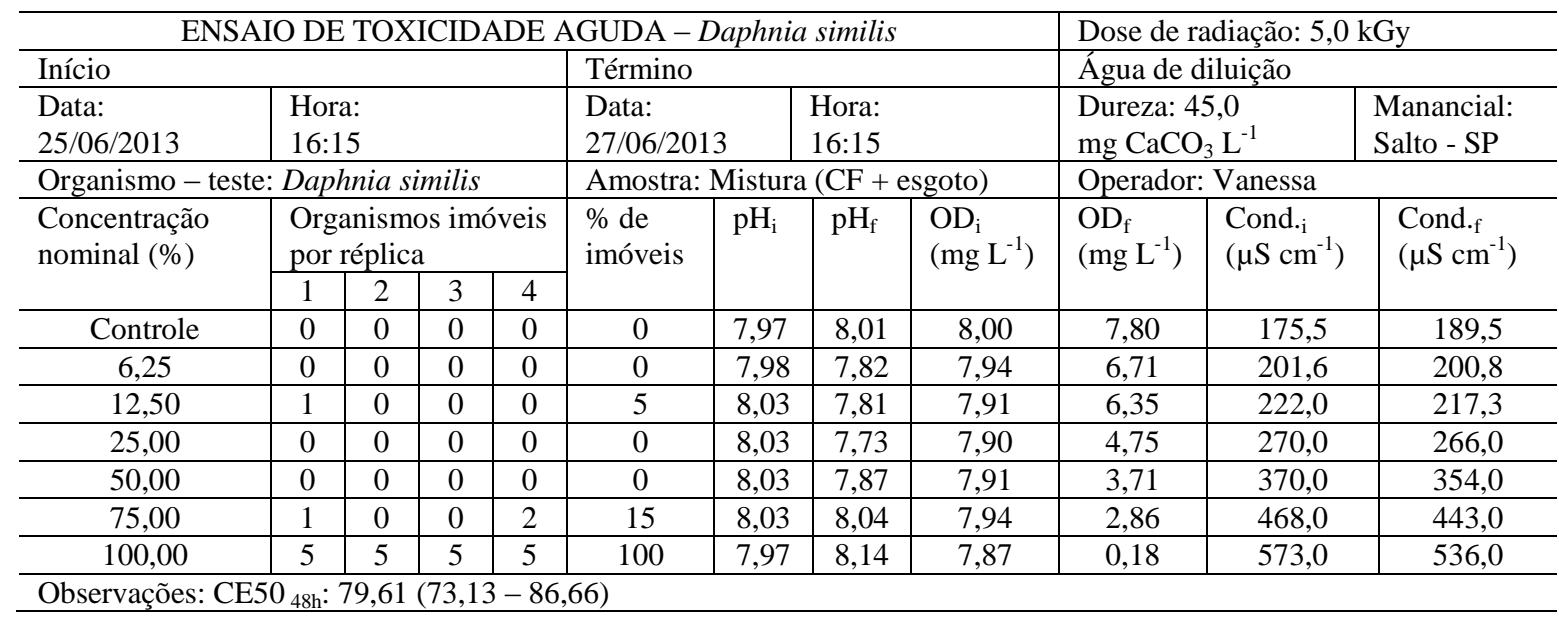

Ensaio 3

\begin{tabular}{|c|c|c|c|c|c|c|c|c|c|c|c|}
\hline \multicolumn{9}{|c|}{ ENSAIO DE TOXICIDADE AGUDA - Daphnia similis } & \multirow{2}{*}{\multicolumn{3}{|c|}{$\begin{array}{l}\text { Dose de radiação: } 5,0 \text { kGy } \\
\text { Água de diluição }\end{array}$}} \\
\hline \multicolumn{5}{|l|}{ Início } & \multicolumn{4}{|l|}{ Término } & & & \\
\hline $\begin{array}{l}\text { Data: } \\
04 / 12 / 2013\end{array}$ & $\begin{array}{l}\text { Ho } \\
16:\end{array}$ & & & & $\begin{array}{l}\text { Data: } \\
06 / 12 / 201\end{array}$ & & $\begin{array}{l}\text { Hora: } \\
16: 15\end{array}$ & & \multicolumn{2}{|c|}{$\begin{array}{l}\text { Dureza: } 45,0 \\
\mathrm{mg} \mathrm{CaCO}_{3} \mathrm{~L}^{-1}\end{array}$} & $\begin{array}{l}\text { Manancial: } \\
\text { Salto - SP }\end{array}$ \\
\hline \multicolumn{5}{|c|}{ Organismo - teste: Daphnia similis } & \multicolumn{4}{|c|}{ Amostra: Mistura (CF + esgoto) } & \multicolumn{3}{|c|}{ Operador: Vanessa } \\
\hline \multirow[t]{2}{*}{$\begin{array}{l}\text { Concentração } \\
\text { nominal (\%) }\end{array}$} & \multicolumn{4}{|c|}{$\begin{array}{l}\text { Organismos imóveis } \\
\text { por réplica }\end{array}$} & \multirow[t]{2}{*}{$\begin{array}{l}\% \text { de } \\
\text { imóveis }\end{array}$} & \multirow[t]{2}{*}{$\mathrm{pH}_{\mathrm{i}}$} & \multirow[t]{2}{*}{$\mathrm{pH}_{\mathrm{f}}$} & \multirow[t]{2}{*}{$\begin{array}{l}\mathrm{OD}_{\mathrm{i}} \\
\left(\mathrm{mg} \mathrm{L}^{-1}\right)\end{array}$} & \multirow[t]{2}{*}{$\begin{array}{l}\mathrm{OD}_{\mathrm{f}} \\
\left(\mathrm{mg} \mathrm{L}^{-1}\right)\end{array}$} & \multirow[t]{2}{*}{$\begin{array}{l}\text { Cond }_{\cdot \mathrm{i}} \\
\left(\mu \mathrm{cm}^{-1}\right)\end{array}$} & \multirow[t]{2}{*}{$\begin{array}{l}\text { Cond }_{. f} \\
\left(\mu \mathrm{S} \mathrm{cm}^{-1}\right)\end{array}$} \\
\hline & 1 & 2 & 3 & 4 & & & & & & & \\
\hline Controle & 0 & 0 & 0 & 0 & 0 & 8,08 & 8,05 & 7,28 & 7,20 & 218,7 & 206,4 \\
\hline 6,25 & 0 & 0 & 0 & 0 & 0 & 7,99 & 7,99 & 7,19 & 6,98 & 225,0 & 223,0 \\
\hline 12,50 & 0 & 0 & 0 & 0 & 0 & 8,02 & 7,99 & 7,18 & 6,24 & 239,0 & 232,0 \\
\hline 25,00 & 1 & 1 & 0 & 0 & 10 & 8,00 & 7,98 & 7,18 & 4,97 & 288,0 & 285,0 \\
\hline 50,00 & 0 & 1 & 0 & 1 & 10 & 8,01 & 7,98 & 7,07 & 3,99 & 377,0 & 372,0 \\
\hline 75,00 & 0 & 0 & 1 & 1 & 10 & 8,01 & 7,95 & 6,91 & 2,90 & 473,0 & 470,0 \\
\hline 100,00 & 2 & 5 & 3 & 1 & 55 & 7,98 & 7,90 & 6,16 & 0,42 & 571,0 & 562,0 \\
\hline
\end{tabular}

Observações: CE50 48h: 96,85 $(85,32-109,95)$ 


\section{Ensaios com a mistura (CF + esgoto) $(20,0 \mathrm{kGy})$}

Ensaio 1

\begin{tabular}{|c|c|c|c|c|c|c|c|c|c|c|c|}
\hline \multicolumn{9}{|c|}{ ENSAIO DE TOXICIDADE AGUDA - Daphnia similis } & \multirow{2}{*}{\multicolumn{3}{|c|}{$\begin{array}{l}\text { Dose de radiação: } 20,0 \mathrm{kGy} \\
\text { Água de diluição }\end{array}$}} \\
\hline \multicolumn{5}{|c|}{ 2010 } & \multicolumn{4}{|c|}{ Término } & & & \\
\hline $\begin{array}{l}\text { Data: } \\
04 / 06 / 2013\end{array}$ & $\begin{array}{ll}\mathrm{Hol} \\
16:\end{array}$ & & & & $\begin{array}{l}\text { Data: } \\
06 / 06 / 201\end{array}$ & & $\begin{array}{l}\text { Hora: } \\
16: 00\end{array}$ & & \multicolumn{2}{|c|}{$\begin{array}{l}\text { Dureza: } 45,0 \\
m g \mathrm{CaCO}_{3} \mathrm{~L}^{-1}\end{array}$} & $\begin{array}{l}\text { Manancial: } \\
\text { Salto - SP }\end{array}$ \\
\hline \multicolumn{5}{|c|}{ Organismo - teste: Daphnia similis } & \multicolumn{4}{|c|}{ Amostra: Mistura (CF + esgoto) } & \multicolumn{3}{|c|}{ Operador: Vanessa } \\
\hline \multirow[t]{2}{*}{$\begin{array}{l}\text { Concentração } \\
\text { nominal (\%) }\end{array}$} & \multicolumn{4}{|c|}{$\begin{array}{l}\text { Organismos imóveis } \\
\text { por réplica }\end{array}$} & \multirow[t]{2}{*}{$\begin{array}{l}\text { \% de } \\
\text { imóveis }\end{array}$} & \multirow[t]{2}{*}{$\mathrm{pH}_{\mathrm{i}}$} & \multirow[t]{2}{*}{$\mathrm{pH}_{\mathrm{f}}$} & \multirow[t]{2}{*}{$\begin{array}{l}\mathrm{OD}_{\mathrm{i}} \\
\left(\mathrm{mg} \mathrm{L}^{-1}\right)\end{array}$} & \multirow[t]{2}{*}{$\begin{array}{l}\mathrm{OD}_{\mathrm{f}} \\
\left(\mathrm{mg} \mathrm{L}^{-1}\right)\end{array}$} & \multirow[t]{2}{*}{$\begin{array}{l}\text { Cond }_{\cdot \mathrm{i}} \\
\left(\mu \mathrm{S} \mathrm{cm}^{-1}\right)\end{array}$} & \multirow[t]{2}{*}{$\begin{array}{l}\text { Cond. }_{f_{f}} \\
\left(\mu \mathrm{cm}^{-1}\right)\end{array}$} \\
\hline & 1 & 2 & 3 & 4 & & & & & & & \\
\hline Controle & 0 & 0 & 0 & 0 & 0 & 7,94 & 7,82 & 7,69 & 7,94 & 174,0 & 177,7 \\
\hline 6,25 & 0 & 0 & 0 & 0 & 0 & 7,85 & 7,76 & 7,89 & 7,39 & 192,1 & 191,8 \\
\hline 12,50 & 0 & 0 & 0 & 0 & 0 & 7,93 & 7,72 & 7,81 & 6,69 & 219,0 & 218,2 \\
\hline 25,00 & 0 & 0 & 0 & 0 & 0 & 7,93 & 7,71 & 7,78 & 6,15 & 264,0 & 262,0 \\
\hline 50,00 & 0 & 0 & 0 & 0 & 0 & 7,93 & 7,74 & 7,74 & 4,71 & 355,0 & 344,0 \\
\hline 75,00 & 5 & 3 & 4 & 3 & 75 & 7,92 & 7,81 & 7,78 & 3,97 & 454,0 & 438,0 \\
\hline 100,00 & 5 & 5 & 5 & 5 & 100 & 7,83 & 7,83 & 8,18 & 2,28 & 558,0 & 559,0 \\
\hline
\end{tabular}

Ensaio 2

\begin{tabular}{|c|c|c|c|c|c|c|c|c|c|c|c|}
\hline \multicolumn{9}{|c|}{ ENSAIO DE TOXICIDADE AGUDA - Daphnia similis } & \multirow{2}{*}{\multicolumn{3}{|c|}{$\begin{array}{l}\text { Dose de radiação: } 20,0 \mathrm{kGy} \\
\text { Água de diluição }\end{array}$}} \\
\hline \multicolumn{5}{|c|}{ 年 } & \multicolumn{4}{|c|}{ Término } & & & \\
\hline $\begin{array}{l}\text { Data: } \\
25 / 06 / 2013\end{array}$ & $\begin{array}{l}\text { Hol } \\
16:\end{array}$ & & & & $\begin{array}{l}\text { Data: } \\
27 / 06 / 201\end{array}$ & & $\begin{array}{l}\text { Hora: } \\
16: 30\end{array}$ & & \multicolumn{2}{|c|}{ Dureza: 45,0} & $\begin{array}{l}\text { Manancial: } \\
\text { Salto - SP }\end{array}$ \\
\hline \multicolumn{5}{|c|}{ Organismo - teste: Daphnia similis } & \multicolumn{4}{|c|}{ Amostra: Mistura (CF + esgoto) } & \multicolumn{3}{|c|}{ Operador: Vanessa } \\
\hline \multirow[t]{2}{*}{$\begin{array}{l}\text { Concentração } \\
\text { nominal (\%) }\end{array}$} & \multicolumn{4}{|c|}{$\begin{array}{l}\text { Organismos imóveis } \\
\text { por réplica }\end{array}$} & \multirow[t]{2}{*}{$\begin{array}{l}\text { \% de } \\
\text { imóveis }\end{array}$} & \multirow[t]{2}{*}{$\mathrm{pH}_{\mathrm{i}}$} & \multirow[t]{2}{*}{$\mathrm{pH}_{\mathrm{f}}$} & \multirow[t]{2}{*}{$\begin{array}{l}\mathrm{OD}_{\mathrm{i}} \\
\left(\mathrm{mg} \mathrm{L}^{-1}\right)\end{array}$} & \multirow[t]{2}{*}{$\begin{array}{l}\mathrm{OD}_{\mathrm{f}} \\
\left(\mathrm{mg} \mathrm{L}^{-1}\right)\end{array}$} & \multirow[t]{2}{*}{$\begin{array}{l}\text { Cond }_{. i} \\
\left(\mu \mathrm{cm}^{-1}\right)\end{array}$} & \multirow[t]{2}{*}{$\begin{array}{l}\text { Cond }_{. \mathrm{f}} \\
\left(\mu \mathrm{S} \mathrm{cm}^{-1}\right)\end{array}$} \\
\hline & 1 & 2 & 3 & 4 & & & & & & & \\
\hline Controle & 0 & 0 & 0 & 0 & 0 & 7,97 & 8,01 & 8,00 & 6,80 & 175,5 & 189,5 \\
\hline 6,25 & 0 & 0 & 0 & 0 & 0 & 7,98 & 7,85 & 7,73 & 5,79 & 210,9 & 205,2 \\
\hline 12,50 & 0 & 0 & 2 & 0 & 10 & 7,97 & 7,71 & 7,66 & 6,08 & 221,0 & 217,0 \\
\hline 25,00 & 0 & 0 & 0 & 0 & 0 & 7,94 & 7,70 & 7,75 & 5,55 & 265,0 & 261,0 \\
\hline 50,00 & 0 & 0 & 0 & 4 & 20 & 7,89 & 7,80 & 7,56 & 4,75 & 361,0 & 345,0 \\
\hline 75,00 & 5 & 5 & 5 & 5 & 100 & 7,88 & 7,86 & 7,53 & 3,13 & 459,0 & 440,0 \\
\hline 100,00 & 5 & 5 & 5 & 5 & 100 & 7,83 & 7,95 & 6,70 & 1,56 & 566,0 & 537,0 \\
\hline
\end{tabular}

Ensaio 3

\begin{tabular}{|c|c|c|c|c|c|c|c|c|c|c|c|}
\hline \multicolumn{9}{|c|}{ ENSAIO DE TOXICIDADE AGUDA - Daphnia similis } & \multirow{2}{*}{\multicolumn{3}{|c|}{$\begin{array}{l}\text { Dose de radiação: } 20,0 \mathrm{kGy} \\
\text { Água de diluição }\end{array}$}} \\
\hline \multicolumn{5}{|l|}{ Início } & \multicolumn{4}{|l|}{ Término } & & & \\
\hline $\begin{array}{l}\text { Data: } \\
05 / 12 / 2013\end{array}$ & \multicolumn{4}{|c|}{$\begin{array}{l}\text { Hora: } \\
17: 30 \\
\end{array}$} & \multicolumn{2}{|c|}{$\begin{array}{l}\text { Data: } \\
07 / 12 / 2013\end{array}$} & \multicolumn{2}{|l|}{$\begin{array}{l}\text { Hora: } \\
17: 30\end{array}$} & \multicolumn{2}{|c|}{$\begin{array}{l}\text { Dureza: } 45,0 \\
\mathrm{mg} \mathrm{CaCO}_{3} \mathrm{~L}^{-1}\end{array}$} & $\begin{array}{l}\text { Manancial: } \\
\text { Salto - SP }\end{array}$ \\
\hline \multicolumn{5}{|c|}{ Organismo - teste: Daphnia similis } & \multicolumn{4}{|c|}{ Amostra: Mistura (CF + esgoto) } & \multicolumn{3}{|c|}{ Operador: Vanessa } \\
\hline \multirow[t]{2}{*}{$\begin{array}{l}\text { Concentração } \\
\text { nominal (\%) }\end{array}$} & \multicolumn{4}{|c|}{$\begin{array}{l}\text { Organismos imóveis } \\
\text { por réplica }\end{array}$} & \multirow[t]{2}{*}{$\begin{array}{l}\text { \% de } \\
\text { imóveis }\end{array}$} & \multirow[t]{2}{*}{$\mathrm{pH}_{\mathrm{i}}$} & \multirow[t]{2}{*}{$\mathrm{pH}_{\mathrm{f}}$} & \multirow[t]{2}{*}{$\begin{array}{l}\mathrm{OD}_{\mathrm{i}} \\
\left(\mathrm{mg} \mathrm{L}^{-1}\right)\end{array}$} & \multirow[t]{2}{*}{$\begin{array}{l}\mathrm{OD}_{\mathrm{f}} \\
\left(\mathrm{mg} \mathrm{L}^{-1}\right)\end{array}$} & \multirow[t]{2}{*}{$\begin{array}{l}\text { Cond }_{. \mathrm{i}} \\
\left(\mu \mathrm{S} \mathrm{cm}^{-1}\right)\end{array}$} & \multirow[t]{2}{*}{$\begin{array}{l}\text { Cond.f }_{. f} \\
\left(\mu \mathrm{cm}^{-1}\right)\end{array}$} \\
\hline & 1 & 2 & 3 & 4 & & & & & & & \\
\hline Controle & 0 & 0 & 0 & 0 & 0 & 8,07 & 8,02 & 7,18 & 7,43 & 198,0 & 197,1 \\
\hline 6,25 & 0 & 0 & 0 & 0 & 0 & 8,05 & 8,00 & 7,87 & 7,19 & 233,0 & 223,0 \\
\hline 12,50 & 0 & 0 & 0 & 0 & 0 & 8,03 & 7,99 & 7,43 & 6,81 & 240,0 & 237,0 \\
\hline 25,00 & 0 & 0 & 0 & 0 & 0 & 7,95 & 7,97 & 6,60 & 6,32 & 280,0 & 277,0 \\
\hline 50,00 & 0 & 0 & 0 & 0 & 0 & 7,84 & 7,96 & 6,59 & 5,14 & 362,0 & 357,0 \\
\hline 75,00 & 3 & 2 & 2 & 2 & 45 & 7,81 & 7,96 & 6,59 & 3,97 & 452,0 & 439,0 \\
\hline 100,00 & 5 & 5 & 5 & 5 & 100 & 7,79 & 7,96 & 6,28 & 2.46 & 546,0 & 527,0 \\
\hline
\end{tabular}

Observações: CE50 $48 \mathrm{~h}: 74,10(68,60-80,04)$ 
APÊNDICE B: Fichas controle para os ensaios de toxicidade aguda com Vibrio fischeri

\section{Amostras de cloridrato de fluoxetina $(0,0 \mathrm{kGy})$}

\begin{tabular}{|c|c|c|c|c|c|c|c|c|}
\hline \multicolumn{9}{|c|}{ ENSAIO DE TOXICIDADE AGUDA - Vibrio fischeri - $1^{\circ}$ Ensaio } \\
\hline \multicolumn{2}{|c|}{ Data do ensaio: $23 / 11 / 2012$} & \multicolumn{7}{|c|}{ Amostra: Cloridrato de fluoxetina $(0,0 \mathrm{kGy})$} \\
\hline \multirow{2}{*}{$\begin{array}{c}\text { Bioluminescência } \\
\text { emitida pela } \\
\text { bactéria }\end{array}$} & \multirow[t]{2}{*}{ Controle } & \multicolumn{4}{|c|}{ Concentração (\%) } & $\mathrm{pH}$ & OD & Cond. \\
\hline & & 10,23 & 20,47 & 40,95 & 81,90 & \multirow{3}{*}{5,52} & \multirow{3}{*}{7,45} & \multirow{3}{*}{12,9} \\
\hline $\mathrm{I}_{0}$ & 94 & 107 & 120 & 123 & 99 & & & \\
\hline $\mathrm{I}_{15}$ & 112 & 98 & 94 & 57 & 01 & & & \\
\hline \multicolumn{9}{|c|}{ CE50 $_{15 \mathrm{~min}}=21,30(5,28-84,92)$} \\
\hline
\end{tabular}

\begin{tabular}{|c|c|c|c|c|c|c|c|c|}
\hline \multicolumn{9}{|c|}{ ENSAIO DE TOXICIDADE AGUDA - Vibrio fischeri - $2^{\circ}$ Ensaio } \\
\hline \multicolumn{2}{|c|}{ Data do ensaio: 08/02/2013 } & \multicolumn{7}{|c|}{ Amostra: Cloridrato de fluoxetina $(0,0 \mathrm{kGy})$} \\
\hline \multirow{2}{*}{$\begin{array}{c}\text { Bioluminescência } \\
\text { emitida pela } \\
\text { bactéria }\end{array}$} & \multirow[t]{2}{*}{ Controle } & \multicolumn{4}{|c|}{ Concentração (\%) } & $\mathrm{pH}$ & $\mathrm{OD}$ & Cond. \\
\hline & & 10,23 & 20,47 & 40,95 & 81,90 & \multirow{3}{*}{6,06} & \multirow{3}{*}{7,55} & \multirow{3}{*}{6,09} \\
\hline $\mathrm{I}_{0}$ & 103 & 99 & 102 & 100 & 104 & & & \\
\hline $\mathrm{I}_{15}$ & 105 & 86 & 77 & 41 & 01 & & & \\
\hline \multicolumn{9}{|c|}{$\mathrm{CE} 0_{15 \min }=23,96(6,53-87,88)$} \\
\hline
\end{tabular}

\begin{tabular}{|c|c|c|c|c|c|c|c|c|}
\hline \multicolumn{9}{|c|}{ ENSAIO DE TOXICIDADE AGUDA - Vibrio fischeri - $3^{\circ}$ Ensaio } \\
\hline \multicolumn{2}{|c|}{ Data do ensaio: $26 / 04 / 2013$} & \multicolumn{7}{|c|}{ Amostra: Cloridrato de fluoxetina $(0,0 \mathrm{kGy})$} \\
\hline \multirow{2}{*}{$\begin{array}{c}\text { Bioluminescência } \\
\text { emitida pela } \\
\text { bactéria }\end{array}$} & \multirow[t]{2}{*}{ Controle } & \multicolumn{4}{|c|}{ Concentração (\%) } & $\mathrm{pH}$ & OD & Cond. \\
\hline & & 10,23 & 20,47 & 40,95 & 81,90 & \multirow{3}{*}{5,96} & \multirow{3}{*}{7,75} & \multirow{3}{*}{4,93} \\
\hline $\mathrm{I}_{0}$ & 89 & 94 & 96 & 92 & 96 & & & \\
\hline $\mathrm{I}_{15}$ & 90 & 76 & 67 & 30 & 02 & & & \\
\hline \multicolumn{9}{|c|}{ CE50 $_{15 \min }=22,71(9,21-55,99)$} \\
\hline
\end{tabular}

\begin{tabular}{|c|c|c|c|c|c|c|c|c|}
\hline \multicolumn{9}{|c|}{ ENSAIO DE TOXICIDADE AGUDA - Vibrio fischeri - $4^{\circ}$ Ensaio } \\
\hline \multicolumn{2}{|c|}{ Data do ensaio: $31 / 10 / 2013$} & \multicolumn{7}{|c|}{ Amostra: Cloridrato de fluoxetina $(0,0 \mathrm{kGy})$} \\
\hline \multirow{2}{*}{$\begin{array}{l}\text { Bioluminescência } \\
\text { emitida pela } \\
\text { bactéria }\end{array}$} & \multirow[t]{2}{*}{ Controle } & \multicolumn{4}{|c|}{ Concentração (\%) } & $\mathrm{pH}$ & OD & Cond. \\
\hline & & 10,23 & 20,47 & 40,95 & 81,90 & \multirow{3}{*}{6,04} & \multirow{3}{*}{7,95} & \multirow{3}{*}{11,4} \\
\hline $\mathrm{I}_{0}$ & 107 & 103 & 106 & 103 & 96 & & & \\
\hline $\mathrm{I}_{15}$ & 134 & 107 & 97 & 67 & 01 & & & \\
\hline \multicolumn{9}{|c|}{ CE50 $_{15 \min }=24,08(4,79-121,16)$} \\
\hline
\end{tabular}

\begin{tabular}{|c|c|c|c|c|c|c|c|c|}
\hline \multicolumn{9}{|c|}{ ENSAIO DE TOXICIDADE AGUDA - Vibrio fischeri $-5^{\circ}$ Ensaio } \\
\hline \multicolumn{2}{|c|}{ Data do ensaio: 04/02/2014 } & \multicolumn{7}{|c|}{ Amostra: Cloridrato de fluoxetina $(0,0 \mathrm{kGy})$} \\
\hline \multirow{2}{*}{$\begin{array}{l}\text { Bioluminescência } \\
\text { emitida pela } \\
\text { bactéria }\end{array}$} & \multirow[t]{2}{*}{ Controle } & \multicolumn{4}{|c|}{ Concentração $(\%)$} & $\mathrm{pH}$ & OD & Cond. \\
\hline & & 10,23 & 20,47 & 40,95 & 81,90 & \multirow{3}{*}{7,39} & \multirow{3}{*}{7,25} & \multirow{3}{*}{22,4} \\
\hline $\mathrm{I}_{0}$ & 97 & 113 & 104 & 110 & 116 & & & \\
\hline $\mathrm{I}_{15}$ & 121 & 119 & 98 & 74 & 01 & & & \\
\hline \multicolumn{9}{|c|}{ CE50 $_{15 \min }=24,55(4,40-136,96)$} \\
\hline
\end{tabular}


Amostras de cloridrato de fluoxetina (0,5 kGy)

\begin{tabular}{|c|c|c|c|c|c|c|c|c|}
\hline \multicolumn{9}{|c|}{ ENSAIO DE TOXICIDADE AGUDA - Vibrio fischeri - $5^{\circ}$ Ensaio } \\
\hline \multicolumn{2}{|c|}{ Data do ensaio: $23 / 11 / 2012$} & \multicolumn{7}{|c|}{ Amostra: Cloridrato de fluoxetina $(0,5 \mathrm{kGy})$} \\
\hline \multirow{2}{*}{$\begin{array}{c}\text { Bioluminescência } \\
\text { emitida pela } \\
\text { bactéria }\end{array}$} & \multirow[t]{2}{*}{ Controle } & \multicolumn{4}{|c|}{ Concentração (\%) } & $\mathrm{pH}$ & OD & Cond. \\
\hline & & 10,23 & 20,47 & 40,95 & 81,90 & \multirow{3}{*}{7,30} & \multirow{3}{*}{7,18} & \multirow{3}{*}{24,1} \\
\hline $\mathrm{I}_{0}$ & 81 & 101 & 90 & 99 & 100 & & & \\
\hline $\mathrm{I}_{15}$ & 96 & 104 & 91 & 69 & 01 & & & \\
\hline \multicolumn{9}{|c|}{ CE50 $_{15 \min }=27,22(4,47-165,83)$} \\
\hline
\end{tabular}

Amostras de cloridrato de fluoxetina (5,0 kGy)

\begin{tabular}{|c|c|c|c|c|c|c|c|c|}
\hline \multicolumn{9}{|c|}{ ENSAIO DE TOXICIDADE AGUDA - Vibrio fischeri - $1^{\circ}$ Ensaio } \\
\hline \multicolumn{2}{|c|}{ Data do ensaio: $23 / 11 / 2012$} & \multicolumn{7}{|c|}{ Amostra: Cloridrato de fluoxetina $(5,0 \mathrm{kGy})$} \\
\hline \multirow{2}{*}{$\begin{array}{c}\text { Bioluminescência } \\
\text { emitida pela } \\
\text { bactéria }\end{array}$} & \multirow[t]{2}{*}{ Controle } & \multicolumn{4}{|c|}{ Concentração (\%) } & $\mathrm{pH}$ & OD & Cond. \\
\hline & & 10,23 & 20,47 & 40,95 & 81,90 & \multirow{3}{*}{4,43} & \multirow{3}{*}{7,43} & \multirow{3}{*}{23,7} \\
\hline $\mathrm{I}_{0}$ & 99 & 139 & 136 & 134 & 127 & & & \\
\hline $\mathrm{I}_{15}$ & 113 & 139 & 120 & 79 & 03 & & & \\
\hline \multicolumn{9}{|c|}{ CE50 $_{15 \min }=27,35(8,33-89,72)$} \\
\hline
\end{tabular}

\begin{tabular}{|c|c|c|c|c|c|c|c|c|}
\hline \multicolumn{9}{|c|}{ ENSAIO DE TOXICIDADE AGUDA - Vibrio fischeri - $2^{\circ}$ Ensaio } \\
\hline \multicolumn{2}{|c|}{ Data do ensaio: 08/02/2013 } & \multicolumn{7}{|c|}{ Amostra: Cloridrato de fluoxetina $(5,0 \mathrm{kGy})$} \\
\hline \multirow{2}{*}{$\begin{array}{c}\text { Bioluminescência } \\
\text { emitida pela } \\
\text { bactéria }\end{array}$} & \multirow[t]{2}{*}{ Controle } & \multicolumn{4}{|c|}{ Concentração (\%) } & $\mathrm{pH}$ & OD & Cond. \\
\hline & & 10,23 & 20,47 & 40,95 & 81,90 & \multirow{3}{*}{4,34} & \multirow{3}{*}{7,44} & \multirow{3}{*}{24,2} \\
\hline $\mathrm{I}_{0}$ & 106 & 101 & 101 & 96 & 86 & & & \\
\hline $\mathrm{I}_{15}$ & 127 & 112 & 96 & 55 & 02 & & & \\
\hline \multicolumn{9}{|c|}{$\mathrm{CE} 50_{15 \min }=28,60(10,52-77,76$} \\
\hline
\end{tabular}

ENSAIO DE TOXICIDADE AGUDA - Vibrio fischeri - $3^{\circ}$ Ensaio

\begin{tabular}{|c|c|c|c|c|c|c|c|c|}
\hline \multicolumn{2}{|c|}{ Data do ensaio: $26 / 04 / 2013$} & \multicolumn{7}{|c|}{ Amostra: Cloridrato de fluoxetina $(5,0 \mathrm{kGy})$} \\
\hline \multirow{2}{*}{$\begin{array}{c}\text { Bioluminescência } \\
\text { emitida pela } \\
\text { bactéria }\end{array}$} & \multirow[t]{2}{*}{ Controle } & \multicolumn{4}{|c|}{ Concentração (\%) } & $\mathrm{pH}$ & OD & 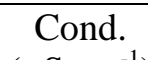 \\
\hline & & 10,23 & 20,47 & 40,95 & 81,90 & \multirow{3}{*}{4,36} & \multirow{3}{*}{7,37} & \multirow{3}{*}{27,9} \\
\hline $\mathrm{I}_{0}$ & 108 & 105 & 102 & 98 & 105 & & & \\
\hline$I_{15}$ & 129 & 110 & 91 & 42 & 03 & & & \\
\hline
\end{tabular}

\begin{tabular}{|c|c|c|c|c|c|c|c|c|}
\hline \multicolumn{9}{|c|}{ ENSAIO DE TOXICIDADE AGUDA - Vibrio fischeri - $4^{\circ}$ Ensaio } \\
\hline \multicolumn{2}{|c|}{ Data do ensaio: $31 / 10 / 2013$} & \multicolumn{7}{|c|}{ Amostra: Cloridrato de fluoxetina (5,0 kGy) } \\
\hline \multirow{2}{*}{$\begin{array}{c}\text { Bioluminescência } \\
\text { emitida pela } \\
\text { bactéria }\end{array}$} & \multirow[t]{2}{*}{ Controle } & \multicolumn{4}{|c|}{ Concentração (\%) } & $\mathrm{pH}$ & $\mathrm{OD}$ & Cond. \\
\hline & & 10,23 & 20,47 & 40,95 & 81,90 & \multirow{3}{*}{4,57} & \multirow{3}{*}{7,51} & \multirow{3}{*}{20,1} \\
\hline $\mathrm{I}_{0}$ & 75 & 89 & 86 & 87 & 91 & & & \\
\hline $\mathrm{I}_{15}$ & 97 & 106 & 98 & 73 & 01 & & & \\
\hline \multicolumn{9}{|c|}{ CE50 $_{15 \min }=29,63(4,87-180,36)$} \\
\hline
\end{tabular}




\begin{tabular}{|c|c|c|c|c|c|c|c|c|}
\hline \multicolumn{9}{|c|}{ ENSAIO DE TOXICIDADE AGUDA - Vibrio fischeri - $5^{\circ}$ Ensaio } \\
\hline \multicolumn{2}{|c|}{ Data do ensaio: $04 / 02 / 2014$} & \multicolumn{7}{|c|}{ Amostra: Cloridrato de fluoxetina (5,0 kGy) } \\
\hline \multirow{2}{*}{$\begin{array}{c}\text { Bioluminescência } \\
\text { emitida pela } \\
\text { bactéria }\end{array}$} & \multirow[t]{2}{*}{ Controle } & \multicolumn{4}{|c|}{ Concentração (\%) } & $\mathrm{pH}$ & OD & Cond. \\
\hline & & 10,23 & 20,47 & 40,95 & 81,90 & \multirow{3}{*}{7,32} & \multirow{3}{*}{7,18} & \multirow{3}{*}{28,7} \\
\hline$\overline{I_{0}}$ & 84 & 88 & 78 & 85 & 95 & & & \\
\hline $\mathrm{I}_{15}$ & 116 & 102 & 94 & 74 & 01 & & & \\
\hline \multicolumn{9}{|c|}{ CE50 } \\
\hline
\end{tabular}

\section{Amostras de cloridrato de fluoxetina (7,5 kGy)}

\begin{tabular}{|c|c|c|c|c|c|c|c|c|}
\hline \multicolumn{9}{|c|}{ ENSAIO DE TOXICIDADE AGUDA - Vibrio fischeri - $1^{\circ}$ Ensaio } \\
\hline \multicolumn{2}{|c|}{ Data do ensaio: $23 / 11 / 2012$} & \multicolumn{7}{|c|}{ Amostra: Cloridrato de fluoxetina (7,5 kGy) } \\
\hline \multirow{2}{*}{$\begin{array}{c}\text { Bioluminescência } \\
\text { emitida pela } \\
\text { bactéria }\end{array}$} & \multirow[t]{2}{*}{ Controle } & \multicolumn{4}{|c|}{ Concentração (\%) } & $\mathrm{pH}$ & $\mathrm{OD}$ & Cond. \\
\hline & & 10,23 & 20,47 & 40,95 & 81,90 & \multirow{3}{*}{4,31} & \multirow{3}{*}{7,35} & \multirow{3}{*}{27,5} \\
\hline $\mathrm{I}_{0}$ & 96 & 72 & 79 & 86 & 84 & & & \\
\hline $\mathrm{I}_{15}$ & 105 & 75 & 65 & 26 & 01 & & & \\
\hline \multicolumn{9}{|c|}{$\mathrm{CE} 0_{15 \min }=26,29(14,11-48,99)$} \\
\hline
\end{tabular}

\begin{tabular}{|c|c|c|c|c|c|c|c|c|}
\hline \multicolumn{9}{|c|}{ ENSAIO DE TOXICIDADE AGUDA - Vibrio fischeri - $2^{\circ}$ Ensaio } \\
\hline \multicolumn{2}{|c|}{ Data do ensaio: 08/02/2013 } & \multicolumn{7}{|c|}{ Amostra: Cloridrato de fluoxetina (7,5 kGy) } \\
\hline \multirow{2}{*}{$\begin{array}{c}\text { Bioluminescência } \\
\text { emitida pela } \\
\text { bactéria }\end{array}$} & \multirow[t]{2}{*}{ Controle } & \multicolumn{4}{|c|}{ Concentração (\%) } & $\mathrm{pH}$ & OD & Cond. \\
\hline & & 10,23 & 20,47 & 40,95 & 81,90 & \multirow{3}{*}{4,23} & \multirow{3}{*}{7,46} & \multirow{3}{*}{25,4} \\
\hline $\mathrm{I}_{0}$ & 108 & 96 & 95 & 113 & 115 & & & \\
\hline $\mathrm{I}_{15}$ & 112 & 90 & 69 & 51 & 02 & & & \\
\hline \multicolumn{9}{|c|}{ CE50 $_{15 \min }=26,00(9,79-69,06)$} \\
\hline
\end{tabular}

\begin{tabular}{|c|c|c|c|c|c|c|c|c|}
\hline \multicolumn{9}{|c|}{ ENSAIO DE TOXICIDADE AGUDA - Vibrio fischeri - $3^{\circ}$ Ensaio } \\
\hline \multicolumn{2}{|c|}{ Data do ensaio: $26 / 04 / 2013$} & \multicolumn{7}{|c|}{ Amostra: Cloridrato de fluoxetina (7,5 kGy) } \\
\hline \multirow{2}{*}{$\begin{array}{c}\text { Bioluminescência } \\
\text { emitida pela } \\
\text { bactéria }\end{array}$} & \multirow[t]{2}{*}{ Controle } & \multicolumn{4}{|c|}{ Concentração (\%) } & $\mathrm{pH}$ & OD & Cond. \\
\hline & & 10,23 & 20,47 & 40,95 & 81,90 & \multirow{3}{*}{4,23} & \multirow{3}{*}{7,37} & \multirow{3}{*}{27,5} \\
\hline $\mathrm{I}_{0}$ & 97 & 100 & 94 & 99 & 95 & & & \\
\hline $\mathrm{I}_{15}$ & 91 & 84 & 71 & 34 & 01 & & & \\
\hline \multicolumn{9}{|c|}{$\mathrm{CE}_{0}{ }_{15 \mathrm{~min}}=25,78(8,26-80,45$} \\
\hline
\end{tabular}

\begin{tabular}{|c|c|c|c|c|c|c|c|c|}
\hline \multicolumn{9}{|c|}{ ENSAIO DE TOXICIDADE AGUDA - Vibrio fischeri - $4^{\circ}$ Ensaio } \\
\hline \multicolumn{2}{|c|}{ Data do ensaio: $31 / 10 / 2013$} & \multicolumn{7}{|c|}{ Amostra: Cloridrato de fluoxetina $(7,5 \mathrm{kGy})$} \\
\hline \multirow{2}{*}{$\begin{array}{c}\text { Bioluminescência } \\
\text { emitida pela } \\
\text { bactéria }\end{array}$} & \multirow[t]{2}{*}{ Controle } & \multicolumn{4}{|c|}{ Concentração $(\%)$} & $\mathrm{pH}$ & OD & Cond. \\
\hline & & 10,23 & 20,47 & 40,95 & 81,90 & \multirow{3}{*}{4,20} & \multirow{3}{*}{7,45} & \multirow{3}{*}{24,2} \\
\hline $\mathrm{I}_{0}$ & 97 & 100 & 94 & 99 & 95 & & & \\
\hline $\mathrm{I}_{15}$ & 91 & 84 & 71 & 34 & 01 & & & \\
\hline \multicolumn{9}{|c|}{ CE50 $_{15 \min }=26,71(4,05-176,13)$} \\
\hline
\end{tabular}




\begin{tabular}{|c|c|c|c|c|c|c|c|c|}
\hline \multicolumn{9}{|c|}{ ENSAIO DE TOXICIDADE AGUDA - Vibrio fischeri - $5^{\circ}$ Ensaio } \\
\hline \multicolumn{2}{|c|}{ Data do ensaio: 04/02/2014 } & \multicolumn{7}{|c|}{ Amostra: Cloridrato de fluoxetina (7,5 kGy) } \\
\hline \multirow{2}{*}{$\begin{array}{c}\text { Bioluminescência } \\
\text { emitida pela } \\
\text { bactéria }\end{array}$} & \multirow[t]{2}{*}{ Controle } & \multicolumn{4}{|c|}{ Concentração (\%) } & $\mathrm{pH}$ & OD & Cond. \\
\hline & & 10,23 & 20,47 & 40,95 & 81,90 & \multirow{3}{*}{7,34} & \multirow{3}{*}{7,08} & \multirow{3}{*}{28,9} \\
\hline $\mathrm{I}_{0}$ & 95 & 96 & 90 & 101 & 102 & & & \\
\hline $\mathrm{I}_{15}$ & 119 & 108 & 99 & 79 & 01 & & & \\
\hline \multicolumn{9}{|c|}{$\mathrm{CE} 0_{15 \min }=28,54(4,41-184,77)$} \\
\hline
\end{tabular}

\section{Amostras de cloridrato de fluoxetina (15,0 kGy)}

\begin{tabular}{|c|c|c|c|c|c|c|c|c|}
\hline \multicolumn{9}{|c|}{ ENSAIO DE TOXICIDADE AGUDA - Vibrio fischeri - $2^{\circ}$ Ensaio } \\
\hline \multicolumn{2}{|c|}{ Data do ensaio: $08 / 02 / 2013$} & \multicolumn{7}{|c|}{ Amostra: Cloridrato de fluoxetina $(15,0 \mathrm{kGy})$} \\
\hline \multirow{2}{*}{$\begin{array}{c}\text { Bioluminescência } \\
\text { emitida pela } \\
\text { bactéria }\end{array}$} & \multirow[t]{2}{*}{ Controle } & \multicolumn{4}{|c|}{ Concentração (\%) } & $\mathrm{pH}$ & OD & Cond. \\
\hline & & 10,23 & 20,47 & 40,95 & 81,90 & \multirow{3}{*}{4,11} & \multirow{3}{*}{7,43} & \multirow{3}{*}{25,6} \\
\hline$I_{0}$ & 99 & 90 & 82 & 97 & 96 & & & \\
\hline $\mathrm{I}_{15}$ & 93 & 79 & 56 & 37 & 01 & & & \\
\hline \multicolumn{9}{|c|}{$\mathrm{CE}_{0}{ }_{15 \min }=26,35(9,81-70,79$} \\
\hline
\end{tabular}

\begin{tabular}{|c|c|c|c|c|c|c|c|c|}
\hline \multicolumn{9}{|c|}{ ENSAIO DE TOXICIDADE AGUDA - Vibrio fischeri - $3^{\circ}$ Ensaio } \\
\hline \multicolumn{2}{|c|}{ Data do ensaio: $26 / 04 / 2013$} & \multicolumn{7}{|c|}{ Amostra: Cloridrato de fluoxetina $(15,0 \mathrm{kGy})$} \\
\hline \multirow{2}{*}{$\begin{array}{c}\text { Bioluminescência } \\
\text { emitida pela } \\
\text { bactéria }\end{array}$} & \multirow[t]{2}{*}{ Controle } & \multicolumn{4}{|c|}{ Concentração (\%) } & $\mathrm{pH}$ & OD & Cond. \\
\hline & & 10,23 & 20,47 & 40,95 & 81,90 & \multirow{3}{*}{3,95} & \multirow{3}{*}{7,32} & \multirow{3}{*}{28,0} \\
\hline $\mathrm{I}_{0}$ & 94 & 93 & 96 & 89 & 95 & & & \\
\hline $\mathrm{I}_{15}$ & 89 & 78 & 66 & 25 & 01 & & & \\
\hline \multicolumn{9}{|c|}{$\mathrm{CE} 0_{15 \min }=23,98(9,59-59,99)$} \\
\hline
\end{tabular}

\begin{tabular}{|c|c|c|c|c|c|c|c|c|}
\hline \multicolumn{9}{|c|}{ ENSAIO DE TOXICIDADE AGUDA - Vibrio fischeri - $4^{\circ}$ Ensaio } \\
\hline \multicolumn{2}{|c|}{ Data do ensaio: $31 / 10 / 2013$} & \multicolumn{7}{|c|}{ Amostra: Cloridrato de fluoxetina ( $15,0 \mathrm{kGy})$} \\
\hline \multirow{2}{*}{$\begin{array}{c}\text { Bioluminescência } \\
\text { emitida pela } \\
\text { bactéria }\end{array}$} & \multirow[t]{2}{*}{ Controle } & \multicolumn{4}{|c|}{ Concentração (\%) } & $\mathrm{pH}$ & $\mathrm{OD}$ & Cond. \\
\hline & & 10,23 & 20,47 & 40,95 & 81,90 & \multirow{3}{*}{4,06} & \multirow{3}{*}{7,43} & \multirow{3}{*}{27,0} \\
\hline $\mathrm{I}_{0}$ & 88 & 93 & 95 & 95 & 95 & & & \\
\hline $\mathrm{I}_{15}$ & 111 & 100 & 96 & 79 & 01 & & & \\
\hline \multicolumn{9}{|c|}{$\mathrm{CE}^{2} 0_{15 \min }=26,65(3,90-182,09)$} \\
\hline
\end{tabular}

\begin{tabular}{|c|c|c|c|c|c|c|c|c|}
\hline \multicolumn{9}{|c|}{ ENSAIO DE TOXICIDADE AGUDA - Vibrio fischeri $-5^{\circ}$ Ensaio } \\
\hline \multicolumn{2}{|c|}{ Data do ensaio: 04/02/2014 } & \multicolumn{7}{|c|}{ Amostra: Cloridrato de fluoxetina $(15,0 \mathrm{kGy})$} \\
\hline \multirow{2}{*}{$\begin{array}{c}\text { Bioluminescência } \\
\text { emitida pela } \\
\text { bactéria }\end{array}$} & \multirow[t]{2}{*}{ Controle } & \multicolumn{4}{|c|}{ Concentração (\%) } & $\mathrm{pH}$ & OD & Cond. \\
\hline & & 10,23 & 20,47 & 40,95 & 81,90 & \multirow{3}{*}{7,32} & \multirow{3}{*}{7,06} & \multirow{3}{*}{29,1} \\
\hline $\mathrm{I}_{0}$ & 96 & 92 & 90 & 99 & 116 & & & \\
\hline $\mathrm{I}_{15}$ & 119 & 111 & 98 & 79 & 01 & & & \\
\hline \multicolumn{9}{|c|}{ CE50 $_{15 \min }=31,27(6,60-148,17)$} \\
\hline
\end{tabular}


Amostras de cloridrato de fluoxetina (20,0 kGy)

\begin{tabular}{|c|c|c|c|c|c|c|c|c|}
\hline \multicolumn{9}{|c|}{ ENSAIO DE TOXICIDADE AGUDA - Vibrio fischeri - $2^{\circ}$ Ensaio } \\
\hline \multicolumn{2}{|c|}{ Data do ensaio: 08/02/2013 } & \multicolumn{7}{|c|}{ Amostra: Cloridrato de fluoxetina $(20,0 \mathrm{kGy})$} \\
\hline \multirow{2}{*}{$\begin{array}{c}\text { Bioluminescência } \\
\text { emitida pela } \\
\text { bactéria }\end{array}$} & \multirow[t]{2}{*}{ Controle } & \multicolumn{4}{|c|}{ Concentração (\%) } & $\mathrm{pH}$ & OD & Cond. \\
\hline & & 10,23 & 20,47 & 40,95 & 81,90 & \multirow{3}{*}{3,78} & \multirow{3}{*}{7,43} & \multirow{3}{*}{27,0} \\
\hline $\mathrm{I}_{0}$ & 87 & 94 & 95 & 99 & 95 & & & \\
\hline $\mathrm{I}_{15}$ & 89 & 88 & 68 & 42 & 02 & & & \\
\hline \multicolumn{9}{|c|}{ CE50 $_{15 \min }=26,57(11,70-60,32)$} \\
\hline
\end{tabular}

\begin{tabular}{|c|c|c|c|c|c|c|c|c|}
\hline \multicolumn{9}{|c|}{ ENSAIO DE TOXICIDADE AGUDA - Vibrio fischeri - $3^{\circ}$ Ensaio } \\
\hline \multicolumn{2}{|c|}{ Data do ensaio: $26 / 04 / 2013$} & \multicolumn{7}{|c|}{ Amostra: Cloridrato de fluoxetina $(20,0 \mathrm{kGy})$} \\
\hline \multirow{2}{*}{$\begin{array}{c}\text { Bioluminescência } \\
\text { emitida pela } \\
\text { bactéria }\end{array}$} & \multirow[t]{2}{*}{ Controle } & \multicolumn{4}{|c|}{ Concentração (\%) } & $\mathrm{pH}$ & OD & Cond. \\
\hline & & 10,23 & 20,47 & 40,95 & 81,90 & \multirow{3}{*}{3,75} & \multirow{3}{*}{7,46} & \multirow{3}{*}{32,9} \\
\hline $\mathrm{I}_{0}$ & 97 & 99 & 96 & 98 & 94 & & & \\
\hline $\mathrm{I}_{15}$ & 106 & 87 & 70 & 45 & 02 & & & \\
\hline \multicolumn{9}{|c|}{$\mathrm{CE}^{2} 0_{15 \min }=23,29(7,90-68,64)$} \\
\hline
\end{tabular}

\begin{tabular}{|c|c|c|c|c|c|c|c|c|}
\hline \multicolumn{9}{|c|}{ ENSAIO DE TOXICIDADE AGUDA - Vibrio fischeri - $4^{\circ}$ Ensaio } \\
\hline \multicolumn{2}{|c|}{ Data do ensaio: $31 / 10 / 2013$} & \multicolumn{7}{|c|}{ Amostra: Cloridrato de fluoxetina (20,0 kGy) } \\
\hline \multirow{2}{*}{$\begin{array}{c}\text { Bioluminescência } \\
\text { emitida pela } \\
\text { bactéria }\end{array}$} & \multirow[t]{2}{*}{ Controle } & \multicolumn{4}{|c|}{ Concentração (\%) } & $\mathrm{pH}$ & OD & Cond. \\
\hline & & 10,23 & 20,47 & 40,95 & 81,90 & \multirow{3}{*}{3,72} & \multirow{3}{*}{7,35} & \multirow{3}{*}{27,6} \\
\hline $\mathrm{I}_{0}$ & 93 & 98 & 108 & 93 & 92 & & & \\
\hline $\mathrm{I}_{15}$ & 127 & 111 & 103 & 81 & 01 & & & \\
\hline & & E50 1 & $=2$ & $8(3,8$ & 158 , & & & \\
\hline
\end{tabular}

\begin{tabular}{|c|c|c|c|c|c|c|c|c|}
\hline \multicolumn{9}{|c|}{ ENSAIO DE TOXICIDADE AGUDA - Vibrio fischeri - $5^{\circ}$ Ensaio } \\
\hline \multicolumn{2}{|c|}{ Data do ensaio: 04/02/2014 } & \multicolumn{7}{|c|}{ Amostra: Cloridrato de fluoxetina $(20,0 \mathrm{kGy})$} \\
\hline \multirow{2}{*}{$\begin{array}{c}\text { Bioluminescência } \\
\text { emitida pela } \\
\text { bactéria }\end{array}$} & \multirow[t]{2}{*}{ Controle } & \multicolumn{4}{|c|}{ Concentração $(\%)$} & $\mathrm{pH}$ & OD & Cond. \\
\hline & & 10,23 & 20,47 & 40,95 & 81,90 & \multirow{3}{*}{7,33} & \multirow{3}{*}{7,06} & \multirow{3}{*}{35,2} \\
\hline $\mathrm{I}_{0}$ & 91 & 93 & 97 & 107 & 97 & & & \\
\hline $\mathrm{I}_{15}$ & 134 & 137 & 124 & 107 & 01 & & & \\
\hline \multicolumn{9}{|c|}{ CE50 $_{15 \text { min }}=33,58(8,39-134,34)$} \\
\hline
\end{tabular}

\section{Amostras de esgoto bruto (0,0 kGy)}

\begin{tabular}{|c|c|c|c|c|c|c|c|c|}
\hline \multicolumn{9}{|c|}{ ENSAIO DE TOXICIDADE AGUDA - Vibrio fischeri - $1^{\circ}$ Ensaio } \\
\hline \multicolumn{2}{|c|}{ Data do ensaio: $23 / 11 / 2012$} & \multicolumn{7}{|c|}{ Amostra: Esgoto bruto $(0,0 \mathrm{kGy})$} \\
\hline \multirow{2}{*}{$\begin{array}{l}\text { Bioluminescência } \\
\text { emitida pela } \\
\text { bactéria }\end{array}$} & \multirow[t]{2}{*}{ Controle } & \multicolumn{4}{|c|}{ Concentração (\%) } & $\mathrm{pH}$ & OD & Cond. \\
\hline & & 10,23 & 20,47 & 40,95 & 81,90 & \multirow{3}{*}{7,60} & \multirow{3}{*}{0,43} & \multirow{3}{*}{663} \\
\hline $\mathrm{I}_{0}$ & 97 & 97 & 89 & 91 & 100 & & & \\
\hline $\mathrm{I}_{15}$ & 99 & 63 & 43 & 19 & 01 & & & \\
\hline \multicolumn{9}{|c|}{ CE50 $_{15 \text { min }}=16,36(6,36-42,05)$} \\
\hline
\end{tabular}




\begin{tabular}{|c|c|c|c|c|c|c|c|c|}
\hline \multicolumn{9}{|c|}{ ENSAIO DE TOXICIDADE AGUDA - Vibrio fischeri - $2^{\circ}$ Ensaio } \\
\hline \multicolumn{2}{|c|}{ Data do ensaio: 08/02/2013 } & \multicolumn{7}{|c|}{ Amostra: Esgoto bruto $(0,0 \mathrm{kGy})$} \\
\hline \multirow{2}{*}{$\begin{array}{c}\text { Bioluminescência } \\
\text { emitida pela } \\
\text { bactéria }\end{array}$} & \multirow[t]{2}{*}{ Controle } & \multicolumn{4}{|c|}{ Concentração (\%) } & $\mathrm{pH}$ & OD & Cond. \\
\hline & & 10,23 & 20,47 & 40,95 & 81,90 & \multirow{3}{*}{7,55} & \multirow{3}{*}{1,33} & \multirow{3}{*}{537} \\
\hline $\mathrm{I}_{0}$ & 109 & 107 & 107 & 104 & 101 & & & \\
\hline $\mathrm{I}_{15}$ & 114 & 78 & 59 & 25 & 02 & & & \\
\hline \multicolumn{9}{|c|}{$\mathrm{CE} 0_{15 \min }=18,15(8,79-37,47)$} \\
\hline
\end{tabular}

\begin{tabular}{|c|c|c|c|c|c|c|c|c|}
\hline \multicolumn{9}{|c|}{ ENSAIO DE TOXICIDADE AGUDA - Vibrio fischeri - $3^{\circ}$ Ensaio } \\
\hline \multicolumn{2}{|c|}{ Data do ensaio: $26 / 04 / 2013$} & \multicolumn{7}{|c|}{ Amostra: Esgoto bruto $(0,0 \mathrm{kGy})$} \\
\hline \multirow{2}{*}{$\begin{array}{c}\text { Bioluminescência } \\
\text { emitida pela } \\
\text { bactéria }\end{array}$} & \multirow[t]{2}{*}{ Controle } & \multicolumn{4}{|c|}{ Concentração (\%) } & $\mathrm{pH}$ & OD & Cond. \\
\hline & & 10,23 & 20,47 & 40,95 & 81,90 & \multirow{3}{*}{7,63} & \multirow{3}{*}{1,54} & \multirow{3}{*}{707} \\
\hline$\overline{\mathrm{I}_{0}}$ & 98 & 98 & 96 & 93 & 94 & & & \\
\hline $\mathrm{I}_{15}$ & 101 & 62 & 43 & 19 & 01 & & & \\
\hline \multicolumn{9}{|c|}{ CE50 $_{15 \min }=15,64(6,35-38,47)$} \\
\hline
\end{tabular}

\section{Amostras de esgoto bruto (5,0 kGy)}

\begin{tabular}{|c|c|c|c|c|c|c|c|c|}
\hline \multicolumn{9}{|c|}{ ENSAIO DE TOXICIDADE AGUDA - Vibrio fischeri - $1^{\circ}$ Ensaio } \\
\hline \multicolumn{2}{|c|}{ Data do ensaio: $23 / 11 / 2012$} & \multicolumn{7}{|c|}{ Amostra: Esgoto bruto (5,0 kGy) } \\
\hline \multirow{2}{*}{$\begin{array}{c}\text { Bioluminescência } \\
\text { emitida pela } \\
\text { bactéria }\end{array}$} & \multirow[t]{2}{*}{ Controle } & \multicolumn{4}{|c|}{ Concentração (\%) } & $\mathrm{pH}$ & $\mathrm{OD}$ & Cond. \\
\hline & & 10,23 & 20,47 & 40,95 & 81,90 & \multirow{3}{*}{7,73} & \multirow{3}{*}{4,16} & \multirow{3}{*}{660} \\
\hline $\mathrm{I}_{0}$ & 98 & 111 & 88 & 98 & 95 & & & \\
\hline $\mathrm{I}_{15}$ & 98 & 82 & 58 & 32 & 01 & & & \\
\hline \multicolumn{9}{|c|}{ CE50 $_{15 \min }=20,58(5,97-70,93)$} \\
\hline
\end{tabular}

\begin{tabular}{|c|c|c|c|c|c|c|c|c|}
\hline \multicolumn{9}{|c|}{ ENSAIO DE TOXICIDADE AGUDA - Vibrio fischeri $-2^{\circ}$ Ensaio } \\
\hline \multicolumn{2}{|c|}{ Data do ensaio: 08/02/2013 } & \multicolumn{7}{|c|}{ Amostra: Esgoto bruto (5,0 kGy) } \\
\hline \multirow{2}{*}{$\begin{array}{c}\text { Bioluminescência } \\
\text { emitida pela } \\
\text { bactéria }\end{array}$} & \multirow[t]{2}{*}{ Controle } & \multicolumn{4}{|c|}{ Concentração (\%) } & $\mathrm{pH}$ & OD & Cond. \\
\hline & & 10,23 & 20,47 & 40,95 & 81,90 & \multirow{3}{*}{7,66} & \multirow{3}{*}{5,36} & \multirow{3}{*}{550} \\
\hline $\mathrm{I}_{0}$ & 108 & 113 & 111 & 109 & 110 & & & \\
\hline $\mathrm{I}_{15}$ & 125 & 98 & 80 & 53 & 02 & & & \\
\hline \multicolumn{9}{|c|}{ CE50 $_{15 \min }=21,43(6,32-72,62)$} \\
\hline
\end{tabular}

\begin{tabular}{|c|c|c|c|c|c|c|c|c|}
\hline \multicolumn{9}{|c|}{ ENSAIO DE TOXICIDADE AGUDA - Vibrio fischeri - $3^{\circ}$ Ensaio } \\
\hline \multicolumn{2}{|c|}{ Data do ensaio: $26 / 04 / 2012$} & \multicolumn{7}{|c|}{ Amostra: Esgoto bruto (5,0 kGy) } \\
\hline \multirow{2}{*}{$\begin{array}{c}\text { Bioluminescência } \\
\text { emitida pela } \\
\text { bactéria }\end{array}$} & \multirow[t]{2}{*}{ Controle } & \multicolumn{4}{|c|}{ Concentração (\%) } & $\mathrm{pH}$ & OD & Cond. \\
\hline & & 10,23 & 20,47 & 40,95 & 81,90 & \multirow{3}{*}{7,73} & \multirow{3}{*}{4,08} & \multirow{3}{*}{727} \\
\hline $\mathrm{I}_{0}$ & 94 & 93 & 92 & 94 & 95 & & & \\
\hline $\mathrm{I}_{15}$ & 93 & 69 & 56 & 28 & 01 & & & \\
\hline \multicolumn{9}{|c|}{ CE50 $_{15 \min }=20,14(6,60-61,47)$} \\
\hline
\end{tabular}




\section{Amostras de esgoto bruto (7,5 kGy)}

\begin{tabular}{|c|c|c|c|c|c|c|c|c|}
\hline \multicolumn{9}{|c|}{ ENSAIO DE TOXICIDADE AGUDA - Vibrio fischeri - $1^{\circ}$ Ensaio } \\
\hline \multicolumn{2}{|c|}{ Data do ensaio: $23 / 11 / 2012$} & \multicolumn{7}{|c|}{ Amostra: Esgoto bruto (7,5 kGy) } \\
\hline \multirow{2}{*}{$\begin{array}{c}\text { Bioluminescência } \\
\text { emitida pela } \\
\text { bactéria }\end{array}$} & \multirow[t]{2}{*}{ Controle } & \multicolumn{4}{|c|}{ Concentração (\%) } & $\mathrm{pH}$ & & - \\
\hline & & 10,23 & 20,47 & 40,95 & 81,90 & \multirow{3}{*}{7,71} & \multirow{3}{*}{3,98} & \multirow{3}{*}{663} \\
\hline $\mathrm{I}_{0}$ & 98 & 104 & 94 & 94 & 101 & & & \\
\hline $\mathrm{I}_{15}$ & 106 & 88 & 64 & 33 & 01 & & & \\
\hline \multicolumn{9}{|c|}{$\mathrm{CE}^{2} 0_{15 \min }=20,88(6,39-68,22)$} \\
\hline
\end{tabular}

\begin{tabular}{|c|c|c|c|c|c|c|c|c|}
\hline \multicolumn{9}{|c|}{ ENSAIO DE TOXICIDADE AGUDA - Vibrio fischeri - $2^{\circ}$ Ensaio } \\
\hline \multicolumn{2}{|c|}{ Data do ensaio: $08 / 02 / 2013$} & \multicolumn{7}{|c|}{ Amostra: Esgoto bruto (7,5 kGy) } \\
\hline \multirow{2}{*}{$\begin{array}{c}\text { Bioluminescência } \\
\text { emitida pela } \\
\text { bactéria }\end{array}$} & \multirow[t]{2}{*}{ Controle } & \multicolumn{4}{|c|}{ Concentração (\%) } & $\mathrm{pH}$ & OD & Cond. \\
\hline & & 10,23 & 20,47 & 40,95 & 81,90 & \multirow{3}{*}{7,62} & \multirow{3}{*}{5,84} & \multirow{3}{*}{550} \\
\hline $\mathrm{I}_{0}$ & 108 & 98 & 103 & 108 & 111 & & & \\
\hline $\mathrm{I}_{15}$ & 123 & 78 & 71 & 47 & 02 & & & \\
\hline \multicolumn{9}{|c|}{$\mathrm{CE} 0_{15 \min }=20,07(6,05-66,53)$} \\
\hline
\end{tabular}

\begin{tabular}{|c|c|c|c|c|c|c|c|c|}
\hline \multicolumn{9}{|c|}{ ENSAIO DE TOXICIDADE AGUDA - Vibrio fischeri - $3^{\circ}$ Ensaio } \\
\hline \multicolumn{2}{|c|}{ Data do ensaio: $26 / 04 / 2013$} & \multicolumn{7}{|c|}{ Amostra: Esgoto bruto (7,5 kGy) } \\
\hline \multirow{2}{*}{$\begin{array}{c}\text { Bioluminescência } \\
\text { emitida pela } \\
\text { bactéria }\end{array}$} & \multirow[t]{2}{*}{ Controle } & \multicolumn{4}{|c|}{ Concentração $(\%)$} & $\mathrm{pH}$ & OD & Cond. \\
\hline & & 10,23 & 20,47 & 40,95 & 81,90 & \multirow{3}{*}{7,82} & \multirow{3}{*}{4,96} & \multirow{3}{*}{722} \\
\hline $\mathrm{I}_{0}$ & 94 & 92 & 92 & 92 & 90 & & & \\
\hline $\mathrm{I}_{15}$ & 89 & 63 & 53 & 25 & 01 & & & \\
\hline \multicolumn{9}{|c|}{ CE50 $_{15 \min }=19,60(6,63-57,92)$} \\
\hline
\end{tabular}

\section{Amostras de esgoto bruto (15,0 kGy)}

\begin{tabular}{|c|c|c|c|c|c|c|c|c|}
\hline \multicolumn{9}{|c|}{ ENSAIO DE TOXICIDADE AGUDA - Vibrio fischeri - $2^{\circ}$ Ensaio } \\
\hline \multicolumn{2}{|c|}{ Data do ensaio: 08/02/2013 } & \multicolumn{7}{|c|}{ Amostra: Esgoto bruto $(15,0 \mathrm{kGy})$} \\
\hline \multirow{2}{*}{$\begin{array}{c}\text { Bioluminescência } \\
\text { emitida pela } \\
\text { bactéria }\end{array}$} & \multirow[t]{2}{*}{ Controle } & \multicolumn{4}{|c|}{ Concentração (\%) } & $\mathrm{pH}$ & OD & Cond. \\
\hline & & 10,23 & 20,47 & 40,95 & 81,90 & \multirow{3}{*}{7,64} & \multirow{3}{*}{6,53} & \multirow{3}{*}{549} \\
\hline $\mathrm{I}_{0}$ & 84 & 80 & 88 & 88 & 87 & & & \\
\hline $\mathrm{I}_{15}$ & 78 & 61 & 54 & 28 & 01 & & & \\
\hline \multicolumn{9}{|c|}{$\mathrm{CE}^{2} 0_{15 \min }=22,35(7,73-64,58)$} \\
\hline
\end{tabular}

\begin{tabular}{|c|c|c|c|c|c|c|c|c|}
\hline \multicolumn{9}{|c|}{ ENSAIO DE TOXICIDADE AGUDA - Vibrio fischeri - $3^{\circ}$ Ensaio } \\
\hline \multicolumn{2}{|c|}{ Data do ensaio: $26 / 04 / 2013$} & \multicolumn{7}{|c|}{ Amostra: Esgoto bruto $(15,0 \mathrm{kGy})$} \\
\hline \multirow{2}{*}{$\begin{array}{c}\text { Bioluminescência } \\
\text { emitida pela } \\
\text { bactéria }\end{array}$} & \multirow[t]{2}{*}{ Controle } & \multicolumn{4}{|c|}{ Concentração (\%) } & $\mathrm{pH}$ & OD & Cond. \\
\hline & & 10,23 & 20,47 & 40,95 & 81,90 & \multirow{3}{*}{7,81} & \multirow{3}{*}{4,96} & \multirow{3}{*}{722} \\
\hline $\mathrm{I}_{0}$ & 88 & 88 & 85 & 86 & 83 & & & \\
\hline $\mathrm{I}_{15}$ & 81 & 61 & 49 & 24 & 01 & & & \\
\hline \multicolumn{9}{|c|}{$\mathrm{CE} 0_{15 \min }=20,48(7,19-58,32)$} \\
\hline
\end{tabular}


Amostras de esgoto bruto (20,0 kGy)

\begin{tabular}{|c|c|c|c|c|c|c|c|c|}
\hline \multicolumn{9}{|c|}{ ENSAIO DE TOXICIDADE AGUDA - Vibrio fischeri - $2^{\circ}$ Ensaio } \\
\hline \multicolumn{2}{|c|}{ Data do ensaio: 08/02/2013 } & \multicolumn{7}{|c|}{ Amostra: Esgoto bruto $(20,0 \mathrm{kGy})$} \\
\hline \multirow{2}{*}{$\begin{array}{c}\text { Bioluminescência } \\
\text { emitida pela } \\
\text { bactéria }\end{array}$} & \multirow[t]{2}{*}{ Controle } & \multicolumn{4}{|c|}{ Concentração (\%) } & $\mathrm{pH}$ & OD & Cond. \\
\hline & & 10,23 & 20,47 & 40,95 & 81,90 & \multirow{3}{*}{7,56} & \multirow{3}{*}{6,76} & \multirow{3}{*}{553} \\
\hline $\mathrm{I}_{0}$ & 91 & 90 & 92 & 94 & 90 & & & \\
\hline $\mathrm{I}_{15}$ & 86 & 68 & 57 & 30 & 01 & & & \\
\hline \multicolumn{9}{|c|}{$\mathrm{CE}^{2} 0_{15 \min }=21,78(7,19-65,93)$} \\
\hline
\end{tabular}

\begin{tabular}{|c|c|c|c|c|c|c|c|c|}
\hline \multicolumn{9}{|c|}{ ENSAIO DE TOXICIDADE AGUDA - Vibrio fischeri - $3^{\circ}$ Ensaio } \\
\hline \multicolumn{2}{|c|}{ Data do ensaio: $26 / 04 / 2013$} & \multicolumn{7}{|c|}{ Amostra: Esgoto bruto $(20,0 \mathrm{kGy})$} \\
\hline \multirow{2}{*}{$\begin{array}{c}\text { Bioluminescência } \\
\text { emitida pela } \\
\text { bactéria }\end{array}$} & \multirow[t]{2}{*}{ Controle } & \multicolumn{4}{|c|}{ Concentração (\%) } & $\mathrm{pH}$ & OD & Cond. \\
\hline & & 10,23 & 20,47 & 40,95 & 81,90 & \multirow{3}{*}{7,74} & \multirow{3}{*}{5,72} & \multirow{3}{*}{723} \\
\hline $\mathrm{I}_{0}$ & 97 & 93 & 95 & 86 & 98 & & & \\
\hline $\mathrm{I}_{15}$ & 101 & 74 & 58 & 29 & 01 & & & \\
\hline \multicolumn{9}{|c|}{$\mathrm{CE}_{0}{ }_{15 \min }=20,21(6,38-63,93)$} \\
\hline
\end{tabular}

\section{Amostras da mistura (CF + esgoto $)(0,0$ kGy $)$}

\begin{tabular}{|c|c|c|c|c|c|c|c|c|}
\hline \multicolumn{9}{|c|}{ ENSAIO DE TOXICIDADE AGUDA - Vibrio fischeri - $1^{\circ}$ Ensaio } \\
\hline \multicolumn{2}{|c|}{ Data do ensaio: $23 / 11 / 2012$} & \multicolumn{7}{|c|}{ Amostra: Mistura (CF + esgoto) $(0,0 \mathrm{kGy})$} \\
\hline \multirow{2}{*}{$\begin{array}{c}\text { Bioluminescência } \\
\text { emitida pela } \\
\text { bactéria }\end{array}$} & \multirow[t]{2}{*}{ Controle } & \multicolumn{4}{|c|}{ Concentração (\%) } & $\mathrm{pH}$ & OD & Cond. \\
\hline & & 10,23 & 20,47 & 40,95 & 81,90 & \multirow{3}{*}{7,66} & \multirow{3}{*}{0,28} & \multirow{3}{*}{497} \\
\hline $\mathrm{I}_{0}$ & 97 & 100 & 95 & 97 & 111 & & & \\
\hline $\mathrm{I}_{15}$ & 94 & 63 & 40 & 17 & 01 & & & \\
\hline \multicolumn{9}{|c|}{ CE50 $_{15 \min }=16,05(6,92-37,22)$} \\
\hline
\end{tabular}

ENSAIO DE TOXICIDADE AGUDA - Vibrio fischeri - $2^{\mathbf{0}}$ Ensaio

\begin{tabular}{|c|c|c|c|c|c|c|c|c|}
\hline \multicolumn{2}{|c|}{ Data do ensaio: 08/02/2013 } & \multicolumn{7}{|c|}{ Amostra: Mistura (CF + esgoto $)(0,0 \mathrm{kGy})$} \\
\hline \multirow{2}{*}{$\begin{array}{c}\text { Bioluminescência } \\
\text { emitida pela } \\
\text { bactéria }\end{array}$} & \multirow[t]{2}{*}{ Controle } & \multicolumn{4}{|c|}{ Concentração (\%) } & $\mathrm{pH}$ & OD & \\
\hline & & 10,23 & 20,47 & 40,95 & 81,90 & \multirow{3}{*}{7,74} & \multirow{3}{*}{0,25} & \multirow{3}{*}{487} \\
\hline $\mathrm{I}_{0}$ & 98 & 94 & 101 & 101 & 98 & & & \\
\hline $\mathrm{I}_{15}$ & 101 & 68 & 56 & 26 & 02 & & & \\
\hline
\end{tabular}

\begin{tabular}{|c|c|c|c|c|c|c|c|c|}
\hline \multicolumn{9}{|c|}{ ENSAIO DE TOXICIDADE AGUDA - Vibrio fischeri - $3^{\circ}$ Ensaio } \\
\hline \multicolumn{2}{|c|}{ Data do ensaio: $26 / 04 / 2013$} & \multicolumn{7}{|c|}{ Amostra: Mistura (CF + esgoto) $(0,0 \mathrm{kGy})$} \\
\hline \multirow{2}{*}{$\begin{array}{c}\text { Bioluminescência } \\
\text { emitida pela } \\
\text { bactéria }\end{array}$} & \multirow[t]{2}{*}{ Controle } & \multicolumn{4}{|c|}{ Concentração (\%) } & $\mathrm{pH}$ & OD & Cond. \\
\hline & & 10,23 & 20,47 & 40,95 & 81,90 & \multirow{3}{*}{7,56} & \multirow{3}{*}{0,96} & \multirow{3}{*}{648} \\
\hline $\mathrm{I}_{0}$ & 94 & 90 & 93 & 92 & 95 & & & \\
\hline $\mathrm{I}_{15}$ & 94 & 54 & 37 & 15 & 01 & & & \\
\hline \multicolumn{9}{|c|}{$\mathrm{CE}_{0}{ }_{15 \min }=14,85(6,90-31,94$} \\
\hline
\end{tabular}




\section{Amostras da mistura (CF + esgoto) $(5,0$ kGy)}

\begin{tabular}{|c|c|c|c|c|c|c|c|c|}
\hline \multicolumn{9}{|c|}{ ENSAIO DE TOXICIDADE AGUDA - Vibrio fischeri - $1^{\circ}$ Ensaio } \\
\hline \multicolumn{2}{|c|}{ Data do ensaio: $23 / 11 / 2012$} & \multicolumn{7}{|c|}{ Amostra: Mistura (CF + esgoto) $(5,0 \mathrm{kGy})$} \\
\hline \multirow{2}{*}{$\begin{array}{c}\text { Bioluminescência } \\
\text { emitida pela } \\
\text { bactéria }\end{array}$} & \multirow[t]{2}{*}{ Controle } & \multicolumn{4}{|c|}{ Concentração (\%) } & $\mathrm{pH}$ & OD & Cond. \\
\hline & & 10,23 & 20,47 & 40,95 & 81,90 & \multirow{3}{*}{7,57} & \multirow{3}{*}{4,83} & \multirow{3}{*}{514} \\
\hline $\mathrm{I}_{0}$ & 97 & 71 & 86 & 96 & 73 & & & \\
\hline $\mathrm{I}_{15}$ & 103 & 62 & 60 & 27 & 01 & & & \\
\hline \multicolumn{9}{|c|}{$\mathrm{CE}^{2} 0_{15 \min }=21,75(9,10-50,03)$} \\
\hline
\end{tabular}

\begin{tabular}{|c|c|c|c|c|c|c|c|c|}
\hline \multicolumn{9}{|c|}{ ENSAIO DE TOXICIDADE AGUDA - Vibrio fischeri - $2^{\circ}$ Ensaio } \\
\hline \multicolumn{2}{|c|}{ Data do ensaio: $08 / 02 / 2013$} & \multicolumn{7}{|c|}{ Amostra: Mistura (CF + esgoto) (5,0 kGy) } \\
\hline \multirow{2}{*}{$\begin{array}{c}\text { Bioluminescência } \\
\text { emitida pela } \\
\text { bactéria }\end{array}$} & \multirow[t]{2}{*}{ Controle } & \multicolumn{4}{|c|}{ Concentração (\%) } & $\mathrm{pH}$ & OD & Cond. \\
\hline & & 10,23 & 20,47 & 40,95 & 81,90 & \multirow{3}{*}{7,65} & \multirow{3}{*}{5,26} & \multirow{3}{*}{498} \\
\hline $\mathrm{I}_{0}$ & 100 & 101 & 84 & 83 & 74 & & & \\
\hline $\mathrm{I}_{15}$ & 120 & 89 & 61 & 41 & 02 & & & \\
\hline \multicolumn{9}{|c|}{ CE50 $_{15 \min }=21,29(7,30-62,09)$} \\
\hline
\end{tabular}

\begin{tabular}{|c|c|c|c|c|c|c|c|c|}
\hline \multicolumn{9}{|c|}{ ENSAIO DE TOXICIDADE AGUDA - Vibrio fischeri - $3^{\circ}$ Ensaio } \\
\hline \multicolumn{2}{|c|}{ Data do ensaio: $26 / 04 / 2012$} & \multicolumn{7}{|c|}{ Amostra: Mistura (CF + esgoto) $(5,0 \mathrm{kGy})$} \\
\hline \multirow{2}{*}{$\begin{array}{c}\text { Bioluminescência } \\
\text { emitida pela } \\
\text { bactéria }\end{array}$} & \multirow[t]{2}{*}{ Controle } & \multicolumn{4}{|c|}{ Concentração $(\%)$} & $\mathrm{pH}$ & $\mathrm{OD}$ & Cond. \\
\hline & & 10,23 & 20,47 & 40,95 & 81,90 & \multirow{3}{*}{7,75} & \multirow{3}{*}{4,08} & \multirow{3}{*}{661} \\
\hline $\mathrm{I}_{0}$ & 94 & 93 & 93 & 92 & 92 & & & \\
\hline $\mathrm{I}_{15}$ & 83 & 63 & 49 & 22 & 01 & & & \\
\hline \multicolumn{9}{|c|}{$\mathrm{CE} 50_{15 \min }=20,14(7,83-51,82)$} \\
\hline
\end{tabular}

\section{Amostras da mistura (CF + esgoto) $(7,5$ kGy)}

\begin{tabular}{|c|c|c|c|c|c|c|c|c|}
\hline \multicolumn{9}{|c|}{ ENSAIO DE TOXICIDADE AGUDA - Vibrio fischeri - $1^{\circ}$ Ensaio } \\
\hline \multicolumn{2}{|c|}{ Data do ensaio: $23 / 11 / 2012$} & \multicolumn{7}{|c|}{ Amostra: Mistura (CF + esgoto) (7,5 kGy) } \\
\hline \multirow{2}{*}{$\begin{array}{c}\text { Bioluminescência } \\
\text { emitida pela } \\
\text { bactéria }\end{array}$} & \multirow[t]{2}{*}{ Controle } & \multicolumn{4}{|c|}{ Concentração (\%) } & $\mathrm{pH}$ & OD & Cond. \\
\hline & & 10,23 & 20,47 & 40,95 & 81,90 & \multirow{3}{*}{7,55} & \multirow{3}{*}{4,71} & \multirow{3}{*}{515} \\
\hline $\mathrm{I}_{0}$ & 91 & 90 & 87 & 77 & 96 & & & \\
\hline $\mathrm{I}_{15}$ & 98 & 70 & 57 & 28 & 01 & & & \\
\hline \multicolumn{9}{|c|}{$\mathrm{CE} 0_{15 \min }=19,82(5,58-70,36)$} \\
\hline
\end{tabular}

\begin{tabular}{|c|c|c|c|c|c|c|c|c|}
\hline \multicolumn{9}{|c|}{ ENSAIO DE TOXICIDADE AGUDA - Vibrio fischeri - $2^{\circ}$ Ensaio } \\
\hline \multicolumn{2}{|c|}{ Data do ensaio: 08/02/2013 } & \multicolumn{7}{|c|}{ Amostra: Mistura (CF + esgoto) $(7,5 \mathrm{kGy})$} \\
\hline \multirow{2}{*}{$\begin{array}{c}\text { Bioluminescência } \\
\text { emitida pela } \\
\text { bactéria }\end{array}$} & \multirow[t]{2}{*}{ Controle } & \multicolumn{4}{|c|}{ Concentração (\%) } & $\mathrm{pH}$ & $\mathrm{OD}$ & Cond. \\
\hline & & 10,23 & 20,47 & 40,95 & 81,90 & \multirow{3}{*}{7,56} & \multirow{3}{*}{5,38} & \multirow{3}{*}{498} \\
\hline $\mathrm{I}_{0}$ & 117 & 113 & 116 & 113 & 115 & & & \\
\hline $\mathrm{I}_{15}$ & 113 & 90 & 76 & 48 & 02 & & & \\
\hline \multicolumn{9}{|c|}{$\mathrm{CE}_{0}{ }_{15 \min }=23,90(7,78-73,42$} \\
\hline
\end{tabular}




\begin{tabular}{|c|c|c|c|c|c|c|c|c|}
\hline \multicolumn{9}{|c|}{ ENSAIO DE TOXICIDADE AGUDA - Vibrio fischeri - $3^{\circ}$ Ensaio } \\
\hline \multicolumn{2}{|c|}{ Data do ensaio: $26 / 04 / 2013$} & \multicolumn{7}{|c|}{ Amostra: Mistura (CF + esgoto) $(7,5 \mathrm{kGy})$} \\
\hline \multirow{2}{*}{$\begin{array}{c}\text { Bioluminescência } \\
\text { emitida pela } \\
\text { bactéria }\end{array}$} & \multirow[t]{2}{*}{ Controle } & \multicolumn{4}{|c|}{ Concentração (\%) } & $\mathrm{pH}$ & OD & Cond. \\
\hline & & 10,23 & 20,47 & 40,95 & 81,90 & \multirow{3}{*}{7,77} & \multirow{3}{*}{4,76} & \multirow{3}{*}{660} \\
\hline$\overline{I_{0}}$ & 95 & 101 & 95 & 99 & 97 & & & \\
\hline $\mathrm{I}_{15}$ & 100 & 75 & 60 & 34 & 01 & & & \\
\hline \multicolumn{9}{|c|}{$\mathrm{CE}^{2} 0_{15 \min }=19,40(5,53-68,08)$} \\
\hline
\end{tabular}

\section{Amostras da mistura (CF + esgoto) $(15,0 \mathrm{kGy})$}

\begin{tabular}{|c|c|c|c|c|c|c|c|c|}
\hline \multicolumn{9}{|c|}{ ENSAIO DE TOXICIDADE AGUDA - Vibrio fischeri - $2^{\circ}$ Ensaio } \\
\hline \multicolumn{2}{|c|}{ Data do ensaio: 08/02/2013 } & \multicolumn{7}{|c|}{ Amostra: Mistura (CF + esgoto) $(15,0 \mathrm{kGy})$} \\
\hline \multirow{2}{*}{$\begin{array}{c}\text { Bioluminescência } \\
\text { emitida pela } \\
\text { bactéria }\end{array}$} & \multirow[t]{2}{*}{ Controle } & \multicolumn{4}{|c|}{ Concentração (\%) } & $\mathrm{pH}$ & OD & Cond. \\
\hline & & 10,23 & 20,47 & 40,95 & 81,90 & \multirow{3}{*}{7,53} & \multirow{3}{*}{5,89} & \multirow{3}{*}{498} \\
\hline $\mathrm{I}_{0}$ & 97 & 96 & 98 & 96 & 94 & & & \\
\hline $\mathrm{I}_{15}$ & 93 & 73 & 62 & 32 & 01 & & & \\
\hline \multicolumn{9}{|c|}{ CE50 $_{15 \min }=21,72(6,76-69,74)$} \\
\hline
\end{tabular}

\begin{tabular}{|c|c|c|c|c|c|c|c|c|}
\hline \multicolumn{9}{|c|}{ ENSAIO DE TOXICIDADE AGUDA - Vibrio fischeri - $3^{\circ}$ Ensaio } \\
\hline \multicolumn{2}{|c|}{ Data do ensaio: $26 / 04 / 2013$} & \multicolumn{7}{|c|}{ Amostra: Mistura (CF + esgoto) $(15,0 \mathrm{kGy})$} \\
\hline \multirow{2}{*}{$\begin{array}{c}\text { Bioluminescência } \\
\text { emitida pela } \\
\text { bactéria }\end{array}$} & \multirow[t]{2}{*}{ Controle } & \multicolumn{4}{|c|}{ Concentração (\%) } & $\mathrm{pH}$ & OD & Cond. \\
\hline & & 10,23 & 20,47 & 40,95 & 81,90 & \multirow{3}{*}{7,81} & \multirow{3}{*}{5,23} & \multirow{3}{*}{655} \\
\hline $\mathrm{I}_{0}$ & 88 & 98 & 97 & 94 & 94 & & & \\
\hline $\mathrm{I}_{15}$ & 93 & 72 & 57 & 31 & 01 & & & \\
\hline \multicolumn{9}{|c|}{$\mathrm{CE} 0_{15 \min }=18,74(5,69-61,69)$} \\
\hline
\end{tabular}

\section{Amostras da mistura (CF + esgoto) $(20,0 \mathrm{kGy})$}

\begin{tabular}{|c|c|c|c|c|c|c|c|c|}
\hline \multicolumn{9}{|c|}{ ENSAIO DE TOXICIDADE AGUDA - Vibrio fischeri - $2^{\circ}$ Ensaio } \\
\hline \multicolumn{2}{|c|}{ Data do ensaio: 08/02/2013 } & \multicolumn{7}{|c|}{ Amostra: Mistura (CF + esgoto) (20,0 kGy) } \\
\hline \multirow{2}{*}{$\begin{array}{c}\text { Bioluminescência } \\
\text { emitida pela } \\
\text { bactéria }\end{array}$} & \multirow[t]{2}{*}{ Controle } & \multicolumn{4}{|c|}{ Concentração (\%) } & $\mathrm{pH}$ & OD & Cond. \\
\hline & & 10,23 & 20,47 & 40,95 & 81,90 & \multirow{3}{*}{7,56} & \multirow{3}{*}{6,67} & \multirow{3}{*}{502} \\
\hline $\mathrm{I}_{0}$ & 87 & 94 & 95 & 99 & 95 & & & \\
\hline $\mathrm{I}_{15}$ & 90 & 78 & 59 & 37 & 01 & & & \\
\hline \multicolumn{9}{|c|}{ CE50 $_{15 \min }=21,32(8,95-50,77)$} \\
\hline
\end{tabular}

\begin{tabular}{|c|c|c|c|c|c|c|c|c|}
\hline \multicolumn{9}{|c|}{ ENSAIO DE TOXICIDADE AGUDA - Vibrio fischeri $-3^{\circ}$ Ensaio } \\
\hline \multicolumn{2}{|c|}{ Data do ensaio: $26 / 04 / 2013$} & \multicolumn{7}{|c|}{ Amostra: Mistura (CF + esgoto) $(20,0 \mathrm{kGy})$} \\
\hline \multirow{2}{*}{$\begin{array}{c}\text { Bioluminescência } \\
\text { emitida pela } \\
\text { bactéria }\end{array}$} & \multirow[t]{2}{*}{ Controle } & \multicolumn{4}{|c|}{ Concentração $(\%)$} & $\mathrm{pH}$ & OD & Cond. \\
\hline & & 10,23 & 20,47 & 40,95 & 81,90 & \multirow{3}{*}{7,68} & \multirow{3}{*}{5,77} & \multirow{3}{*}{645} \\
\hline $\mathrm{I}_{0}$ & 105 & 94 & 94 & 92 & 94 & & & \\
\hline $\mathrm{I}_{15}$ & 100 & 68 & 56 & 27 & 01 & & & \\
\hline
\end{tabular}




\section{APÊNDICE C: Fichas - controle ensaios de toxicidade crônica com Ceriodaphnia dubia.}

\section{Ensaio 1 - Amostra de cloridrato de fluoxetina $(0,0 \mathrm{kGy})$}

\begin{tabular}{|c|c|c|c|c|c|c|c|c|c|c|c|c|c|c|}
\hline \multicolumn{15}{|c|}{ Ensaio de toxicidade crônica } \\
\hline \multicolumn{5}{|c|}{ Início } & \multicolumn{7}{|c|}{ Término } & \multicolumn{3}{|c|}{ Água de diluição } \\
\hline \multicolumn{2}{|l|}{$\begin{array}{l}\text { Data: } \\
\text { 17/10/2012 }\end{array}$} & \multicolumn{3}{|c|}{ Hora: } & \multicolumn{3}{|c|}{$\begin{array}{l}\text { Data: } \\
\text { 24/10/2012 }\end{array}$} & \multicolumn{4}{|c|}{$\begin{array}{l}\text { Hora: } \\
17: 00 \\
\end{array}$} & $\begin{array}{l}\text { pH: } \\
7,87\end{array}$ & \multicolumn{2}{|c|}{$\begin{array}{l}\text { Dureza: } 45,0 \\
\mathrm{mg} \mathrm{CaCO}_{3} \mathrm{~L}^{-1}\end{array}$} \\
\hline \multicolumn{5}{|c|}{$\begin{array}{l}\text { Organismo - teste: } \\
\text { Ceriodaphnia dubia }\end{array}$} & \multicolumn{7}{|c|}{$\begin{array}{l}\text { Amostra: Cloridrato de fluoxetina } \\
(0,0 \mathrm{kGy})\end{array}$} & \multicolumn{3}{|c|}{ Operador: Vanessa } \\
\hline \multirow{2}{*}{$\begin{array}{l}\text { Conc. } \\
(\%):\end{array}$} & \multirow{2}{*}{$\begin{array}{l}\text { Dia da } \\
\text { leitura: }\end{array}$} & \multicolumn{10}{|c|}{ Réplicas } & \multirow{2}{*}{\multicolumn{2}{|c|}{$\begin{array}{c}\text { Total de } \\
\text { jovens } \\
\text { vivas }\end{array}$}} & \multirow{2}{*}{$\begin{array}{l}\text { Total de } \\
\text { adultas } \\
\text { vivas: }\end{array}$} \\
\hline & & 1 & 2 & 3 & 4 & 5 & 6 & 7 & 8 & 9 & 10 & & & \\
\hline \multirow{4}{*}{ Controle } & $1^{\circ}$ & 0 & 0 & 0 & 0 & + & 0 & 0 & 0 & 0 & 0 & \multirow{4}{*}{\multicolumn{2}{|c|}{136}} & \multirow{4}{*}{9} \\
\hline & $2^{\circ}$ & 13 & 13 & 11 & 13 & + & 11 & 11 & 12 & 14 & 12 & & & \\
\hline & $3^{\circ}$ & 4 & 6 & 2 & 3 & + & 4 & 3 & 3 & 1 & 0 & & & \\
\hline & $4^{\circ}$ & & & & & & & & & & & & & \\
\hline \multirow{4}{*}{0,63} & $1^{\circ}$ & 0 & 0 & 0 & + & 0 & 0 & 0 & 0 & 0 & 0 & \multirow{4}{*}{\multicolumn{2}{|c|}{136}} & \multirow{4}{*}{9} \\
\hline & $2^{\circ}$ & 3 & 10 & 12 & + & 2 & 4 & 13 & 12 & 12 & 4 & & & \\
\hline & $3^{\circ}$ & 10 & 2 & 4 & + & 11 & 13 & 6 & 4 & 5 & 9 & & & \\
\hline & $4^{\circ}$ & & & & & & & & & & & & & \\
\hline \multirow{4}{*}{1,25} & $1^{\circ}$ & 0 & 0 & 0 & 0 & 0 & 0 & 0 & 0 & 0 & 0 & \multirow{4}{*}{\multicolumn{2}{|c|}{103}} & \\
\hline & $2^{\circ}$ & 3 & 13 & 8 & 6 & 0 & 0 & 10 & 4 & 8 & 4 & & & 9 \\
\hline & $3^{\circ}$ & 14 & 4 & 6 & 0 & 8 & + & 0 & 0 & 0 & 15 & & & \\
\hline & $4^{\circ}$ & & & & & & & & & & & & & \\
\hline & $1^{\circ}$ & 0 & 0 & + & + & 0 & 0 & 0 & 0 & + & 0 & & & \\
\hline 2,50 & $2^{\circ}$ & 11 & 3 & + & + & 7 & 4 & 3 & 9 & + & 8 & 7 & & 7 \\
\hline & $3^{\circ}$ & 4 & 13 & + & + & 0 & 0 & 8 & 0 & + & 0 & & & \\
\hline & $4^{\circ}$ & & & & & & & & & & & & & \\
\hline & $1^{\circ}$ & 0 & 0 & 0 & 0 & + & 0 & 0 & 0 & 0 & 0 & & & \\
\hline 5,00 & $2^{\circ}$ & 8 & 7 & 0 & 6 & + & 0 & + & 2 & 4 & 5 & 3 & & 8 \\
\hline & $3^{\circ}$ & 0 & 0 & 2 & 0 & + & 3 & + & 0 & 0 & 0 & & & \\
\hline & $4^{\circ}$ & & & & & & & & & & & & & \\
\hline & $1^{\circ}$ & 0 & 0 & 0 & 0 & 0 & 0 & 0 & 0 & 0 & 0 & & & \\
\hline 10,00 & $2^{\circ}$ & 1 & 0 & 1 & 1 & 2 & 1 & + & 2 & 2 & + & 1 & & 8 \\
\hline & $3^{\circ}$ & 0 & 1 & 0 & 0 & 0 & 0 & + & 0 & 0 & + & & & \\
\hline & $4^{\circ}$ & & & & & & & & & & & & & \\
\hline $\begin{array}{c}\text { Conc. } \\
(\%)\end{array}$ & $\mathrm{pH}$ & & & $\mathrm{pH}_{\mathrm{f}}$ & & & $(\mathrm{mg}$ & & & $(\mathrm{mg}$ & & $\begin{array}{l}\text { Co } \\
(\mu \mathrm{S}\end{array}$ & & $\begin{array}{c}\text { Cond }_{. \mathrm{f}} \\
\left(\mu \mathrm{S} \mathrm{cm}^{-1}\right)\end{array}$ \\
\hline Controle & 7,8 & & & 7,84 & & & 7,63 & & & 6,77 & & 19 & & 202,3 \\
\hline 0,625 & 7,8 & & & 7,93 & & & 7,63 & & & 7,2 & & 18 & & 183,3 \\
\hline 10,00 & 7,9 & & & 7,92 & & & 7,50 & & & 7,4 & & 17 & & 189,3 \\
\hline
\end{tabular}


Ensaio 1 - Amostra de cloridrato de fluoxetina (5,0 kGy)

\begin{tabular}{|c|c|c|c|c|c|c|c|c|c|c|c|c|c|c|}
\hline \multicolumn{15}{|c|}{ Ensaio de toxicidade crônica } \\
\hline \multicolumn{5}{|c|}{ Início } & \multicolumn{7}{|c|}{ Término } & \multicolumn{3}{|c|}{ Água de diluição } \\
\hline \multicolumn{2}{|l|}{$\begin{array}{l}\text { Data: } \\
\text { 17/10/2012 }\end{array}$} & \multicolumn{3}{|c|}{ Hora: } & \multicolumn{3}{|c|}{$\begin{array}{l}\text { Data: } \\
\text { 24/10/2012 }\end{array}$} & \multicolumn{4}{|c|}{$\begin{array}{l}\text { Hora: } \\
\text { 16:00 }\end{array}$} & $\begin{array}{l}\text { pH: } \\
7,87\end{array}$ & \multicolumn{2}{|c|}{$\begin{array}{l}\text { Dureza: } 45,0 \\
\mathrm{mg} \mathrm{CaCO}_{3} \mathrm{~L}^{-1}\end{array}$} \\
\hline \multicolumn{5}{|c|}{$\begin{array}{l}\text { Organismo - teste: } \\
\text { Ceriodaphnia dubia }\end{array}$} & \multicolumn{7}{|c|}{$\begin{array}{l}\text { Amostra: Cloridrato de fluoxetina } \\
(5,0 \mathrm{kGy})\end{array}$} & \multicolumn{3}{|c|}{ Operador: Vanessa } \\
\hline \multirow{2}{*}{$\begin{array}{l}\text { Conc. } \\
(\%) \text { : }\end{array}$} & \multirow{2}{*}{$\begin{array}{l}\text { Dia da } \\
\text { leitura: }\end{array}$} & \multicolumn{10}{|c|}{ Réplicas } & \multirow{2}{*}{\multicolumn{2}{|c|}{$\begin{array}{c}\text { Total de } \\
\text { jovens } \\
\text { vivas }\end{array}$}} & \multirow{2}{*}{$\begin{array}{c}\text { Total de } \\
\text { adultas } \\
\text { vivas: }\end{array}$} \\
\hline & & 1 & 2 & 3 & 4 & 5 & 6 & 7 & 8 & 9 & 10 & & & \\
\hline \multirow{4}{*}{ Controle } & $1^{\circ}$ & 0 & 0 & 0 & 0 & + & 0 & 0 & 0 & 0 & 0 & \multirow{4}{*}{\multicolumn{2}{|c|}{136}} & \multirow{4}{*}{9} \\
\hline & $2^{\circ}$ & 13 & 13 & 11 & 13 & + & 11 & 11 & 12 & 14 & 12 & & & \\
\hline & $3^{\circ}$ & 4 & 6 & 2 & 3 & + & 4 & 3 & 3 & 1 & 0 & & & \\
\hline & $4^{\circ}$ & & & & & & & & & & & & & \\
\hline \multirow{4}{*}{1,25} & $1^{\circ}$ & 0 & 0 & 0 & 0 & 0 & 0 & 0 & 0 & 0 & 0 & \multirow{4}{*}{\multicolumn{2}{|c|}{137}} & \multirow{4}{*}{10} \\
\hline & $2^{\circ}$ & 3 & 13 & 3 & 15 & 9 & 12 & 13 & 10 & 11 & 5 & & & \\
\hline & $3^{\circ}$ & 10 & 2 & 11 & 1 & 1 & 2 & 3 & 4 & 0 & 9 & & & \\
\hline & $4^{\circ}$ & & & & & & & & & & & & & \\
\hline \multirow{4}{*}{2,50} & $1^{\circ}$ & 0 & 0 & 0 & 0 & 0 & 0 & 0 & 0 & + & 0 & \multirow{4}{*}{\multicolumn{2}{|c|}{119}} & \\
\hline & $2^{\circ}$ & 14 & 13 & 2 & 3 & 11 & 6 & 3 & 5 & + & 5 & & & 9 \\
\hline & $3^{\circ}$ & 2 & 1 & 6 & 10 & 2 & 7 & 12 & 11 & + & 6 & & & \\
\hline & $4^{\circ}$ & & & & & & & & & & & & & \\
\hline & $1^{\circ}$ & 0 & 0 & 0 & 0 & + & 0 & 0 & 0 & 0 & 0 & & & \\
\hline 5,00 & $2^{\circ}$ & 4 & 11 & 2 & 12 & + & 4 & 11 & 5 & 2 & 13 & 1 & & 9 \\
\hline & $3^{\circ}$ & 11 & 2 & 3 & 1 & + & 0 & 4 & 6 & 11 & 2 & & & \\
\hline & $4^{\circ}$ & & & & & & & & & & & & & \\
\hline & $1^{\circ}$ & 0 & 0 & 0 & 0 & 0 & 0 & 0 & 0 & + & 0 & & & \\
\hline 10,00 & $2^{\circ}$ & 14 & 6 & 14 & 14 & 11 & 11 & 9 & 13 & + & 4 & 1 & & 9 \\
\hline & $3^{\circ}$ & 3 & 9 & 5 & 3 & 6 & 3 & 11 & 4 & + & 10 & & & \\
\hline & $4^{\circ}$ & & & & & & & & & & & & & \\
\hline & $1^{\mathrm{o}}$ & 0 & + & 0 & 0 & + & 0 & 0 & 0 & 0 & 0 & & & \\
\hline 20,00 & $2^{\circ}$ & 13 & + & 3 & 15 & + & 9 & 8 & 8 & 11 & 10 & 1 & & 8 \\
\hline & $3^{\circ}$ & 4 & + & 11 & 3 & + & 3 & 0 & 4 & 3 & 10 & & & \\
\hline & $4^{\circ}$ & & & & & & & & & & & & & \\
\hline $\begin{array}{c}\text { Conc. } \\
(\%)\end{array}$ & $\mathrm{pH}$ & & & $\mathrm{pH}_{\mathrm{f}}$ & & & ( $\mathrm{mg}$ & & & $\mathrm{f}(\mathrm{mg}$ & & $\begin{array}{l}\text { Co } \\
(\mu \mathrm{S}\end{array}$ & & $\begin{array}{l}\text { Cond }_{. f} \\
\left(\mu \mathrm{S} \mathrm{cm}^{-1}\right)\end{array}$ \\
\hline Controle & 7,8 & & & 7,84 & & & 7,63 & & & $6,7^{\prime}$ & & 19 & & 202,3 \\
\hline 1,25 & 7,9 & & & 7,76 & & & 7,55 & & & 6,8 & & 18 & & 193,9 \\
\hline 20,00 & 7,8 & & & 7,80 & & & 7,46 & & & 6,7 & & 17 & & 185,8 \\
\hline
\end{tabular}


Ensaio 2 - Amostra de cloridrato de fluoxetina (0,0 kGy)

\begin{tabular}{|c|c|c|c|c|c|c|c|c|c|c|c|c|c|c|}
\hline \multicolumn{15}{|c|}{ Ensaio de toxicidade crônica } \\
\hline \multicolumn{5}{|c|}{ Início } & \multicolumn{7}{|c|}{ Término } & \multicolumn{3}{|c|}{ Água de diluição } \\
\hline \multicolumn{2}{|l|}{$\begin{array}{l}\text { Data: } \\
05 / 06 / 2013\end{array}$} & \multicolumn{3}{|c|}{ Hora: } & \multicolumn{3}{|c|}{$\begin{array}{l}\text { Data: } \\
12 / 06 / 2013\end{array}$} & \multicolumn{4}{|c|}{$\begin{array}{l}\text { Hora: } \\
\text { 16:00 }\end{array}$} & $\begin{array}{l}\mathrm{pH}: \\
7,82\end{array}$ & \multicolumn{2}{|c|}{$\begin{array}{l}\text { Dureza: } 45,0 \\
\mathrm{mg} \mathrm{CaCO}_{3} \mathrm{~L}^{-1}\end{array}$} \\
\hline \multicolumn{5}{|c|}{$\begin{array}{l}\text { Organismo - teste: } \\
\text { Ceriodaphnia dubia }\end{array}$} & \multicolumn{7}{|c|}{$\begin{array}{l}\text { Amostra: Cloridrato de fluoxetina } \\
(5,0 \mathrm{kGy})\end{array}$} & \multicolumn{3}{|c|}{ Operador: Vanessa } \\
\hline \multirow{2}{*}{$\begin{array}{l}\text { Conc. } \\
(\%) \text { : }\end{array}$} & \multirow{2}{*}{$\begin{array}{l}\text { Dia da } \\
\text { leitura: }\end{array}$} & \multicolumn{10}{|c|}{ Réplicas } & \multirow{2}{*}{\multicolumn{2}{|c|}{$\begin{array}{c}\text { Total de } \\
\text { jovens } \\
\text { vivas }\end{array}$}} & \multirow{2}{*}{$\begin{array}{c}\text { Total de } \\
\text { adultas } \\
\text { vivas: }\end{array}$} \\
\hline & & 1 & 2 & 3 & 4 & 5 & 6 & 7 & 8 & 9 & 10 & & & \\
\hline \multirow{4}{*}{ Controle } & $1^{\circ}$ & 0 & 0 & 0 & 0 & 0 & 0 & 0 & 0 & 0 & 0 & \multirow{4}{*}{\multicolumn{2}{|c|}{135}} & \multirow{4}{*}{9} \\
\hline & $2^{\circ}$ & 4 & 4 & 7 & 5 & 3 & 4 & 5 & 4 & + & 5 & & & \\
\hline & $3^{\circ}$ & 13 & 11 & 16 & 10 & 10 & 11 & 9 & 7 & + & 7 & & & \\
\hline & $4^{\circ}$ & & & & & & & & & & & & & \\
\hline \multirow{4}{*}{0,16} & $1^{\circ}$ & 0 & 0 & 0 & 0 & 0 & 0 & 0 & 0 & 0 & 0 & \multirow{4}{*}{\multicolumn{2}{|c|}{179}} & \multirow{4}{*}{10} \\
\hline & $2^{\circ}$ & 5 & 4 & 4 & 7 & 5 & 1 & 5 & 3 & 4 & 6 & & & \\
\hline & $3^{\circ}$ & 13 & 16 & 9 & 14 & 14 & 13 & 15 & 11 & 14 & 16 & & & \\
\hline & $4^{\circ}$ & & & & & & & & & & & & & \\
\hline \multirow{4}{*}{0,31} & $1^{\circ}$ & 0 & 0 & 0 & 0 & 0 & 0 & + & 0 & 0 & 0 & \multirow{4}{*}{\multicolumn{2}{|c|}{187}} & \\
\hline & $2^{\circ}$ & 4 & 4 & 4 & 5 & 4 & 5 & + & 3 & 5 & 3 & & & 9 \\
\hline & $3^{\circ}$ & 13 & 16 & 18 & 16 & 14 & 16 & + & 27 & 16 & 14 & & & \\
\hline & $4^{\circ}$ & & & & & & & & & & & & & \\
\hline & $1^{\circ}$ & 0 & 0 & 0 & 0 & 0 & 0 & 0 & 0 & 0 & 0 & & & \\
\hline 0,63 & $2^{\circ}$ & 4 & 3 & 2 & 3 & 2 & 3 & 2 & 10 & 11 & 4 & 18 & & 10 \\
\hline & $3^{\circ}$ & 10 & 8 & 20 & 13 & 12 & 14 & 16 & 11 & 13 & 19 & & & \\
\hline & $4^{\circ}$ & & & & & & & & & & & & & \\
\hline & $1^{\circ}$ & 0 & 0 & 0 & 0 & 0 & 0 & + & 0 & 0 & + & & & \\
\hline 1,25 & $2^{\circ}$ & 3 & 0 & 0 & 2 & 2 & 2 & + & 2 & 2 & + & 8 & & 8 \\
\hline & $3^{\circ}$ & 13 & 6 & 9 & 16 & 3 & 9 & + & 12 & 8 & + & & & \\
\hline & $4^{\circ}$ & & & & & & & & & & & & & \\
\hline & $1^{\mathrm{o}}$ & 0 & 0 & + & 0 & 0 & 0 & 0 & 0 & 0 & 0 & & & \\
\hline 2,50 & $2^{\circ}$ & 0 & 0 & + & 0 & 0 & 1 & 0 & 0 & 0 & 0 & 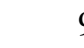 & & 9 \\
\hline & $3^{\circ}$ & 1 & 1 & + & 1 & 1 & 0 & 1 & 1 & 1 & 1 & & & \\
\hline & $4^{\circ}$ & & & & & & & & & & & & & \\
\hline $\begin{array}{c}\text { Conc. } \\
(\%)\end{array}$ & $\mathrm{pH}$ & & & $\mathrm{pH}_{\mathrm{f}}$ & & & $(\mathrm{mg}$ & & & $\mathrm{f}(\mathrm{mg}$ & & $\begin{array}{r}\mathrm{Co} \\
(\mu \mathrm{S}\end{array}$ & & $\begin{array}{l}\text { Cond }_{. \mathrm{f}} \\
\left(\mu \mathrm{S} \mathrm{cm}^{-1}\right)\end{array}$ \\
\hline Controle & 7,8 & & & 7,89 & & & 7,94 & & & 7,2 & & 17 & & 212,6 \\
\hline 1,25 & 7,8 & & & 8,15 & & & 7,63 & & & $7,4 c$ & & 18 & & 204,3 \\
\hline 20 & 7,8 & & & 8,06 & & & 7,54 & & & 7,3 & & 17 & & 194,4 \\
\hline
\end{tabular}


Ensaio 2 - Amostra de cloridrato de fluoxetina $(5,0 \mathrm{kGy})$

\begin{tabular}{|c|c|c|c|c|c|c|c|c|c|c|c|c|c|c|}
\hline \multicolumn{15}{|c|}{ Ensaio de toxicidade crônica } \\
\hline \multicolumn{5}{|c|}{ Início } & \multicolumn{7}{|c|}{ Término } & \multicolumn{3}{|c|}{ Água de diluição } \\
\hline \multicolumn{2}{|l|}{$\begin{array}{l}\text { Data: } \\
12 / 06 / 2013\end{array}$} & \multicolumn{3}{|c|}{$\begin{array}{l}\text { Hora: } \\
16: 00\end{array}$} & \multicolumn{3}{|c|}{$\begin{array}{l}\text { Data: } \\
19 / 06 / 2013\end{array}$} & \multicolumn{4}{|c|}{$\begin{array}{l}\text { Hora: } \\
\text { 16:00 }\end{array}$} & $\begin{array}{l}\text { pH: } \\
7,77\end{array}$ & \multicolumn{2}{|c|}{$\begin{array}{l}\text { Dureza: } 45,0 \\
\mathrm{mg} \mathrm{CaCO}_{3} \mathrm{~L}^{-1}\end{array}$} \\
\hline \multicolumn{5}{|c|}{$\begin{array}{l}\text { Organismo - teste: } \\
\text { Ceriodaphnia dubia }\end{array}$} & \multicolumn{7}{|c|}{$\begin{array}{l}\text { Amostra: Cloridrato de fluoxetina } \\
(5,0 \mathrm{kGy})\end{array}$} & \multicolumn{3}{|c|}{ Operador: Vanessa } \\
\hline \multirow{2}{*}{$\begin{array}{l}\text { Conc. } \\
(\%) \text { : }\end{array}$} & \multirow{2}{*}{$\begin{array}{l}\text { Dia da } \\
\text { leitura: }\end{array}$} & \multicolumn{10}{|c|}{ Réplicas } & \multirow{2}{*}{\multicolumn{2}{|c|}{$\begin{array}{c}\text { Total de } \\
\text { jovens } \\
\text { vivas }\end{array}$}} & \multirow{2}{*}{$\begin{array}{c}\text { Total de } \\
\text { adultas } \\
\text { vivas: }\end{array}$} \\
\hline & & 1 & 2 & 3 & 4 & 5 & 6 & 7 & 8 & 9 & 10 & & & \\
\hline \multirow{4}{*}{ Controle } & $1^{\circ}$ & 0 & 0 & 0 & 0 & 0 & 0 & 0 & 0 & 0 & 0 & \multirow{4}{*}{\multicolumn{2}{|c|}{208}} & \multirow{4}{*}{10} \\
\hline & $2^{\circ}$ & 11 & 13 & 9 & 11 & 9 & 9 & 8 & 11 & 11 & 13 & & & \\
\hline & $3^{\circ}$ & 11 & 7 & 22 & 10 & 5 & 13 & 13 & 9 & 6 & 7 & & & \\
\hline & $4^{\circ}$ & & & & & & & & & & & & & \\
\hline \multirow{4}{*}{6,25} & $1^{\circ}$ & 0 & 0 & 0 & 0 & 0 & 0 & 0 & 0 & 0 & 0 & \multirow{4}{*}{\multicolumn{2}{|c|}{201}} & \multirow{4}{*}{10} \\
\hline & $2^{\circ}$ & 10 & 8 & 12 & 9 & 9 & 7 & 11 & 10 & 1 & 5 & & & \\
\hline & $3^{\circ}$ & 11 & 11 & 7 & 17 & 8 & 21 & 11 & 8 & 4 & 21 & & & \\
\hline & $4^{\circ}$ & & & & & & & & & & & & & \\
\hline \multirow{4}{*}{12,5} & $1^{\circ}$ & 0 & 0 & 0 & 0 & 0 & 0 & 0 & 0 & 0 & 0 & \multirow{4}{*}{\multicolumn{2}{|c|}{201}} & \\
\hline & $2^{\circ}$ & 11 & 10 & 13 & 8 & 3 & 5 & 13 & 10 & 15 & + & & & 9 \\
\hline & $3^{\circ}$ & 9 & 10 & 16 & 23 & 12 & 9 & 12 & 10 & 12 & + & & & \\
\hline & $4^{\circ}$ & & & & & & & & & & & & & \\
\hline & $1^{\circ}$ & 0 & 0 & 0 & 0 & 0 & 0 & 0 & 0 & 0 & 0 & & & \\
\hline 25 & $2^{\circ}$ & 8 & 9 & 7 & 9 & 7 & 9 & 11 & 10 & 9 & 11 & 22 & & 10 \\
\hline & $3^{\circ}$ & 16 & 8 & 10 & 6 & 27 & 26 & 11 & 9 & 8 & 9 & & & \\
\hline & $4^{\circ}$ & & & & & & & & & & & & & \\
\hline & $1^{\circ}$ & 0 & 0 & 0 & 0 & 0 & 0 & 0 & 0 & 0 & 0 & & & \\
\hline 50 & $2^{\circ}$ & 3 & 10 & 10 & 16 & 15 & 16 & 12 & 19 & 8 & 8 & 19 & & 10 \\
\hline & $3^{\circ}$ & 1 & 5 & 12 & 9 & 7 & 7 & 8 & 12 & 12 & 9 & & & \\
\hline & $4^{\circ}$ & & & & & & & & & & & & & \\
\hline & $1^{\circ}$ & + & + & + & + & + & + & + & + & + & + & & & \\
\hline 100 & $2^{\circ}$ & & & & & & & & & & & ( & & 0 \\
\hline & $3^{\circ}$ & & & & & & & & & & & & & \\
\hline & $4^{\circ}$ & & & & & & & & & & & & & \\
\hline $\begin{array}{c}\text { Conc. } \\
(\%)\end{array}$ & $\mathrm{pl}$ & & & $\mathrm{pH}_{\mathrm{f}}$ & & & (mg & & & $\mathrm{f}(\mathrm{mg}$ & & $\begin{array}{r}\mathrm{Co} \\
(\mu \mathrm{S}\end{array}$ & & $\begin{array}{l}\text { Cond }_{. \mathrm{f}} \\
\left(\mu \mathrm{S} \mathrm{cm}^{-1}\right)\end{array}$ \\
\hline Controle & 7, & & & 7,90 & & & 7,59 & & & 7,48 & & 17 & & 182,2 \\
\hline 1,25 & 7 & & & 8,01 & & & 7,53 & & & 7,45 & & 16 & & 178,1 \\
\hline 20 & 4 , & & & 7,70 & & & 7,74 & & & 7,7 & & 51 & & 107,8 \\
\hline
\end{tabular}




\section{REFERÊNCIAS BIBLIOGRÁFICAS}

ABDOU, L.A.W.; HAKEIM, O.A.; MAHMOUD, M.S.; EL-NAGGAR, A.M. Comparative study between the efficiency of electron beam and gamma irradiation for treatment of dye solutions. Chemical Engineering Journal , v.168, p.752-758, 2011.

ALMEIDA, G.A. \& WEBER, R.R. Fármacos na Represa Billings. Revista Saúde e Ambiente, v.6, n.2, p.7-13, 2005.

ANDREOZZI R.; CAPRIO V.; INSOLA A.; MAROTTA R. Advanced oxidation processes (AOP) for water purification and recovery. Catalysis Today, v.53, p.51-59, 1999.

ARDITSOGLOU, A. \& VOUTSA, D. Occurrence and partitioning of endocrine disrupting compounds in the marine environment of Thermaikos Gulf, Northern Aegean Sea, Greece. Marine Pollution Bulletin, v.64, p.2443-2452, 2012.

ASSOCIAÇÃO BRASILEIRA DE NORMAS TÉCNICAS. Ecotoxicologia aquática Determinação do efeito inibitório de amostras de água sobre a emissão de luz de Vibrio fischeri (Ensaio de bactéria luminescente) Parte 3: Método utilizando bactérias liofilizadas. Rio de Janeiro: ABNT, 2012. (NBR 15411-3).

ASSOCIAÇÃO BRASILEIRA DE NORMAS TÉCNICAS. Ecotoxicologia Aquática Toxicidade aguda - Método de ensaio com Dapnhia spp (Crustacea, Cladocera). Rio de Janeiro: ABNT, 2009. (NBR 12713).

ASSOCIAÇÃO BRASILEIRA DE NORMAS TÉCNICAS. Ecotoxicologia Aquática Toxicidade crônica - Método de Ensaio com Ceriodaphnia spp (Crustacea, Cladocera). Rio de Janeiro: ABNT, 2010. (NBR 13373).

BENDZ, D.; PAXÉUS, N.A.; GINN, T.R.; LOGE, F.J. Occurrence and fate of pharmaceutically active compounds in the environment, a case study: Höje River in Sweden. Journal of Hazardous Materials, v.122, n.3, p.195-204, 2005.

BERTOLETTI, E.; BURATINI, S. V.; PROSPÉRI, V. A.; ARAÚJO, R. P. A.; WERNER, L. I. Selection of Relevant Effect Levels for Using Bioequivalence Hypothesis Testing. Journal of the Brazilian Society of Ecotoxicology, v.2, n.2, p.139-145, 2007.

BILA D.M. \& DEZOTTI, M. Fármacos no meio ambiente. Química Nova, v.26, n.4, p.523-530, 2003.

BILA D.M. \& DEZOTTI, M. Desreguladores endócrinos no meio ambiente: efeitos e consequências. Química Nova, v.30, n.3, p.651-666, 2007.

BORRELY, S.I. Tratamento de esgoto sanitário com o uso de acelerador de elétrons. 1995. Dissertação (Mestrado) - Instituto de Pesquisas Energéticas e Nucleares Universidade de São Paulo, São Paulo.

BORRELY, S.I. Redução da toxicidade aguda de efluentes industriais e domésticos tratados por irradiação com feixes de elétrons, avaliada com as espécies Vibrio 
fischeri, Daphnia similis e Poecilia reticulata. 2001. Tese (Doutorado) - Instituto de Pesquisas Energéticas e Nucleares - Universidade de São Paulo, São Paulo.

BORRELY, S.I.; CAMINADA, S.M.L.; PONEZI, A.N.; SANTOS, D.R; OGIHARA SILVA, V.H. Contaminação das águas por resíduos de medicamentos: ênfase ao cloridrato de fluoxetina. O mundo da saúde, v.36, n.4, p.556-563, 2012.

BOUND, J.P.; KATERINA, K.; VOULVOULIS, N. Household disposal of pharmaceuticals and perception of risk to the environment. Environmental Toxicology \& Pharmacology, v. 21, n.3, p.301-307, 2006.

BOUND, J.P. \& VOULVOULIS, N. Pharmaceuticals in the aquatic environment - a comparison of risk assessment strategies. Chemosphere, v.56, p.1143-1155, 2004.

BROOKS, B.W.; CHAMBLISS, C.K.; STANLEY, J.K.; RAMIREZ, A.; BANKS, K.E.; JOHNSON, R.D.; LEWIS, R.J. Determination of select antidepressants in fish from an effluent dominated stream. Environmental Toxicology and Chemistry, v.24, p.464469, 2005.

BROOKS, B.W; TURNER, P.K.; STANLEY, J.K.; WESTON, J.J.; GLIDEWELL, E.A.; FORAN, C.M.; SLATTERY, M.; POINT, T.W.; HUGGETT, D.B. Waterborne and sediment toxicity of fluoxetine to select organisms. Chemosphere, v.52, p.135-140, 2003.

BURATINI, S.V. A utilização do cloreto de potássio como substância de referência no controle da sensibilidade das culturas de Daphnia similis. Resumos VII ECOTOX, Vitória, ES, 2002.

CAMINADA, S.M.L. Estudo da biodegradação do Hidrocloridrato de Fluoxetina, empregando ensaios de respirometria e toxicidade. 2008. Dissertação (Mestrado). Universidade Estadual de Campinas, Campinas.

CARBALLA, M.; OMIL, F.; LEMA, J.M.; LLOMPART, M.; GARCÍA-JARES, C.; RODRÍGUEZ, I.; GÓMEZ, M.; TERNES, T. Behavior of pharmaceuticals, cosmetics and hormones in a sewage treatment plant. Water Research, v.38, n.12, p.2918-2926, 2004.

CASAS, A.L. Tratamento de efluentes industriais utilizando a radiação ionizante de acelerador industrial de elétrons e por adsorção com carvão ativado. Estudo comparativo. 2004. Dissertação (Mestrado) - Instituto de Pesquisas Energéticas e Nucleares - Universidade de São Paulo, São Paulo.

CERON, L.P. Contaminação de água por descarte de fármacos. Revista Tratamento de Água \& Efluentes, v.1, n.1, p.14-19, 2011.

CETESB (Companhia de Tecnologia de Saneamento Ambiental). Carbono Orgânico Dissolvido (COD) e Carbono Orgânico Total (COT). Disponível em: < http://www.cetesb.sp.gov.br/userfiles/file/agua/aguas-superficiais/aguasinteriores/variaveis/aguas/variaveis_quimicas/carbono_organico_dissolvido_e_carbon o_organico_total.pdf >. Acesso em 20/01/2014. 
CETESB (Companhia de Tecnologia de Saneamento Ambiental). Determinação da dureza total em águas - método titulometrico do EDTA: método de ensaio (Norma Técnica L5.124). 1992.

CETESB (Companhia de Tecnologia de Saneamento Ambiental). Teste de toxicidade com a bactéria luminescente Vibrio fischeri: método de ensaio. (Norma Técnica L5.227). 2001.

COMISSION OF THE EUROPEAN COMMUNITIES (CEC). Technical Guidance Document in Support of Commission Directive 93/67/EEC on Risk Assessment for New Notified Substances and Commission Regulation (EC) $n^{\circ} 1488 / 94$ on Risk Assessment for Existing Substances. Part II: Environmental Risk Assessment. Office for Official Publications of the European Communities, Luxembourg. 1996.

COSTA, C.R.; OLIVI, P.; BOTTA, C.M.R.; ESPINDOLA, E.L.G. A toxicidade em ambientes aquáticos: discussão e métodos de avaliação. Química Nova, n.31, v.7, p. 1820-1830, 2008.

DEBlONDE, T., COSSU-LEGUILlE, C., HARTEMANN, P. Emerging pollutants in wastewater: A review of the literature. International Journal of Hygiene and Environmental Health, v.214, p.442-448. 2011.

DE-LANGE, H.J.; NOORDOVEN, W.; MURK, A.J.; LÜRLING, M.; PEETERS, E.T.H.M. Behavioural responses of Gammarus pulex (Crustacea, Amphipoda)to low concentrations of pharmaceuticals. Aquatic Toxicology, v.78, n.3, p.209-216, 2006.

DIRETIVA (92/18/CEE) de 20 de março de 1992, modifica o anexo da diretiva 81/852/CEE relativa à aproximação das legislações dos Estados membros respeitantes para análise, normas e protocolos farmacológicas e clínicas relacionados a testes de medicamentos veterinários. Conselho das Comunidades Europeias. Jornal Oficial da Comunidade Europeia.

DIRETIVA (2004/27/CE) de 31 de março de 2004, que altera a diretiva 2001/83/CE que estabelece um código comunitário relativo aos medicamentos para uso humano. Conselho das Comunidades Europeias. Jornal Oficial da Comunidade Europeia.

DUARTE, C.L. Aplicação do Processo Avançado de Oxidação por feixe de elétrons na degradação de compostos orgânicos presentes em efluentes industriais. 1999. Tese (doutorado) - Instituto de Pesquisas Energéticas e Nucleares - Universidade de São Paulo, São Paulo.

DUARTE, C.L.; SAMPA, M.H.O.; RELA, P.R.; OIKAWA, H.; CHERBAKIAN, E.H.; SENA, H.C.; ABE, H.; SCIANI, V. Application of electron beam irradiation combined to conventional treatment to treat industrial effluents. Radiation Physics and Chemistry, v.57, n. 3-6, p.513-518, 2000.

EL-DAWY, M.A.; MABROUK, M.M.; EL-BARBARY, F.A. Liquid chromatographic determination of fluoxetine. Journal of Pharmaceutical and Biomedical Analysis, v.30, p.561-571, 2002. 
ELI LILLY \& COMPANY. Prozac. Disponível em: < https://www.lilly.com.br/Inserts/Patients/Bula_Prozac_Pac_CDS22NOV10_v5.0_15J UN11.pdf >. Acesso em: 27/02/2013.

FENT, K.; WESTON, A.A.; CAMINADA, D. Ecotoxicology of human pharmaceuticals. Aquatic Toxicology, v.76, n.2, p.122-159, 2006.

FERNANDES, A.; BRAGA, A.; RUIZ, A. R. Fluoxetina, monografia. Disponível em: <http://www.ff.up.pt/toxicologia/monografias/ano0708/g52_fluoxetina/FLUOXET INA/pag2.htm>. UNIVERSIDADE DO PORTO. Acesso em: 20 de out. de 2009.

FREGONEZI-NERY, M. M.; BARACAT, M. M.; CASAGRANDE, R.; MACHADO, H. T.; MIGLIORANZA, B.; GIANOTTO, E.A.S. Validação de métodos para determinação de fluoxetina em cápsulas. Química Nova, v.31, n.7, p.1665-1669, 2008.

GELBHAR BERTHOLDI, K., BUENO, F. \& BERGOLD, A.M. Doseamento da fluoxetina por CLAE em diferentes formulações. Acta Farmaceutica Bonaerense, v.20, n.3, p.209-214, 2001.

GETOFF, N. Radiation-induced degradation of water pollutants - State of the art. Radiation Physics and Chemistry, v.47, n.4, p.581-593, 1996.

GHISELE, G. Avaliação da qualidade das águas destinadas ao abastecimento público na região de Campinas: ocorrência e determinação dos interferentes endócrinos (IE) e produtos farmacêuticos e de higiene pessoal (PFHP). 2006. Tese (Doutorado) Universidade Estadual de Campinas, Campinas.

GIL, E.S.\& MATHIAS, R.O. Classificação e riscos associados aos resíduos químico farmacêuticos. Revista Eletrônica de Farmácia, v.2, n.2, p.87-93, 2005.

GONZALEZ, C.; GREENWOOD, R.; QUEVAUVILLER, P. Rapid chemical and biological techniques for water monitoring. $1^{\text {a }}$ Ed. Wiley, 2009.

GONZALEZ-REY, M. \& BEBIANNO, M.J. Does selective serotonin reuptake inhibitor (SSRI) fluoxetine affects mussel Mytilus galloprovincialis? Environmental Pollution, v.173, p.200-209 2013.

GUO, Z.; ZHOU, F.; ZHAO, Y.; ZHANG, C.; LIU, F.; BAO, C.; LIN, M. Gamma irradiation-induced sulfadiazine degradation and its removal mechanisms. Chemical Engineering Journal, v.191, p.256-262, 2012.

HALLING-SORENSEN, B.; NORS-NIELSEN, S.; LANZKY, P.F.; INGERSLEV, F.; HOLTEN-LUTZHOFT, H.C.; JORGENSEN, S.E. Occurrence, fate and effects of pharmaceutical substances in the environment - A review. Chemosphere, v.36, n.2, p. 357-393, 1998.

HAMILTON, M.A.; RUSSO, R.C.; THURSTON, R.V. Trimmed Spearman-Karber method for estimating median lethal concentrations in toxicity bioassays. Environmental Science \& Technology, v.11, n.7, p.714-719, 1977.

HARVEY, B.G. Introduction to Nuclear Physics and Chemistry. Englewwod Cliffs, N.J.: Prentice-Hall, 1969. 
HENRY, T.B.; KWON, J-W.; ARMBRUST, K.L.; BLACK, M.C. Acute and chronic toxicity of five selective serotonin reuptake inhibitors in Ceriodaphnia dubia. Environmental Toxicology and Chemistry, v.23, n.9, p.2229-2233, 2004.

HIGA, M.C. Aplicação de ensaios de toxicidade na avaliação da eficiência da radiação ionizante e da adsorção em zeólitas para o tratamento de efluentes coloridos. 2008. Dissertação (Mestrado) - Instituto de Pesquisas Energéticas e Nucleares Universidade de São Paulo, São Paulo.

HOLLER, F.J.; SKOOG, D.A.; CROUCH, S.R. Princípios de análise instrumental. Ed.

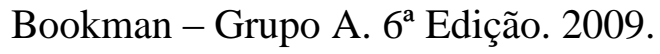

HOMLOK, R.; TAKÁCS, E.; WOJNÁROVITS, L. Elimination of diclofenac from water using irradiation technology. Chemosphere, v.85, p.603-608, 2011.

IAEA. Radiation treatment of polluted water and wastewater. 2008. Disponível em: <http://www-pub.iaea.org/mtcd/publications/pdf/te_1598_web.pdf>. Acesso em: 09/08/2013.

IMS Health. Top 15 Global Therapeutic Classes. Disponível em: < http://www.imshealth.com/deployedfiles/imshealth/Global/Content/StaticFile/Top_Lin e_Data/Global_Top_15_Therapy_Classes.pdf >. Acesso em: 02/04/2013.

IUPAC. Nomenclature for chromatography. Pure \& Applied Chemistry, 65(4), pp. 819$872,1993$.

KARCI, A.; ARSLAN-ALATON, I.; OLMEZ-HANCI, T.; BEKBŌLET, M. Transformation of 2,4-dichlorophenol by $\mathrm{H}_{2} \mathrm{O}_{2} / \mathrm{UV}-\mathrm{C}$, Fenton and photo-Fenton processes: Oxidation products and toxicity evolution. Journal of Photochemistry and Photobiology A: Chemistry, v.230, p.65-73, 2012.

KENKEL, J. Analytical Chemistry for Technicians. Third Edition. CRC Press LLC. 2003.

KIMURA, K.; AMY, G.; DREWES, J.; HEBERER, T.; KIM, T.; WATANABE, Y. Rejection of organic micropollutants (disinfection by-products, endocrine disrupting compounds, and pharmaceutically active compounds) by NF/RO membranes. Journal of Membrane Science, v.227, n.1-2, p.113-121, 2003.

KNIE, J.L.W. \& LOPES, E.W.B. Testes Ecotoxicológicos: métodos, técnicas e aplicações. Florianópolis: FATMA / GTZ. 289p., 2004.

KOLPIN, D.W.; FURLONG, E.T.; MEYER, M.T.; THURMAN, E.M.; ZAUGG, S.D.; BARBER, L.B.; BUXTON, H.T. Pharmaceuticals, hormones, and other organic wastewater contaminants in US streams, 1999-2000: a national reconnaissance. Environmental Science \& Technology, v.36, n.6, p.1202-1211. 2002.

KWON, J.W. \& ARMBRUST, K.L. Laboratory persistence and fate of fluoxetine in aquatic environments. Environmental Toxicology and Chemistry, v.25, n.10, p.25612568, 2006. 
LAZZARA, R.; BLÁZQUEZ, M.; PORTE, C.; BARATA, C. Low environmental levels of fluoxetine induce spawning and changes in endogenous estradiol levels in the zebra mussel Dreissena polymorpha, Aquatic toxicology, v.106-107, p.123-130, 2012.

LEAL, A. A. X.; HENRIQUES, C. A.; LUNA, A. S. Validação e estimativa da incerteza do método de determinação de fósforo por espectrofotometria UV-VIS. Revista Analytica, n.32, p.28-34, 2008.

LEITE, G. S.; AFONSO, R.J.C.F.; AQUINO,S.F. Caracterização de contaminantes presentes em sistemas de tratamento de esgotos, por cromatografia líquida acoplada à espectrometria de massas tandem em alta resolução. Química nova, v.33, n.3, p.734738, 2010.

MACHADO, K.S.; CASALI, M.P.; OLIVEIRA, D.M.; ISIQUE,W.D.; LEITE, M. A.; MINILLO, A. Bioensaios de toxicidade aguda com fármacos: diclofenaco de sódio e paracetamol. In: 80 Jornada Científica e Tecnológica da UFSCar - Congresso de Meio Ambiente AUGM (Associação das Universidades de Montevidéu) II Congresso de Iniciação em Desenvolvimento Tecnológico e Inovação, 2009, São Carlos. Desenvolvimento ambiental e inovação tecnológica, 2009.

MAGAlHÃES, D.P. \& FERRÃO FILHO, A.S. A ecotoxicologia como ferramenta no biomonitoramento de ecossistemas aquáticos. Oecologia Brasiliensis, v.12, n.3, p. 355-381, 2008.

MEDLEY, Laboratórios dobram faturamento com as lucrativas pílulas da "felicidade". Disponível em: < http://www.medley.com.br/portal/src/noticias_det.asp?id=209 > . Acesso em 02/04/2013.

MELO, S.A.S.; TROVÓ, A.G.; BAUTITZ, I.R.; NOGUEIRA, R.F.P.. Degradação de fármacos residuais por processo oxidativos avançados. Química Nova, v.32, n.1, p.188-197, 2009.

MERCK. Cloridrato de fluoxetina. Disponível em: < http://www2.merck.com.br/pdf/bulas/genericos/fluoxetina.pdf>. Acesso em: 27/02/2013.

METCALFE, C.D.; MIAO X-S.; KOENIG, B.G.; STRUGER, J. Distribution of acidic and neutral drugs in surface waters near sewage treatment plants in the lower great lakes, Canada. Environmental Toxicology and Chemistry, v.22, n.12, p.2881-2889, 2003.

MORAES, M.C.F. de. Estudos dos efeitos da radiação ionizante na toxicidade aguda de efluentes que apresentam surfactantes aniônicos. 2004. Dissertação (Mestrado) Instituto de Pesquisas Energéticas e Nucleares, Universidade de São Paulo, São Paulo.

OAKS, J.L.; GILBERT, M.; VIRANI, M.Z.; WATSON, R.T.; METEYER, C.U.; RIDEOUT, B.A.; SHIVAPRASAD, H.L.; AHMED, S.; CHAUDHRY, M.J.I.; ARSHAD, M.; MAHMOOD, S.; ALI, A.; KHAN, A. A. Diclofenac residues as the cause of vulture population declines in Pakistan. Nature, v.427, p.630-633, 2004.

ONU. “World Water Development Report”. Disponível em: < http://www.unesco.org/new/en/natural- 
sciences/environment/water/wwap/wwdr/wwdr4-2012/>. Acessado em: 09/08/2013 (2012).

PATERSON G. \& METCALFE C.D. Uptake and depuration of the anti-depressant fluoxetine by the Japanese medaka (Oryzias latipes). Chemosphere, v.74, p.125-130 2008.

PAUL, J.; RAWAT, K.P.; SARMA, K.S.S.; SABHARWAL, S. Decoloration and degradation of Reactive Red-120 dye by electron beam irradiation in aqueous solution. Applied Radiation and Isotopes, v.69, p.982-987, 2011.

PENG, X.; YU, Y.; TANG, C.; TAN, J.; HUANG, Q.; WANG, Z. Occurrence of steroid estrogens, endocrine disrupting phenols, and acid pharmaceutical residues in urban riverine water of the Pearl River Delta, South China. Science of the Total Environment, v.397, n.1-3, p.158-166, 2008.

PINHEIRO, A.S. Avaliação da toxicidade e genotoxicidade dos corantes azo reativos Remazol Preto $B$ e Remazol Alaranjado $3 R$ e da eficácia da radiação com feixe de elétrons na redução da cor e efeitos tóxicos. 2011. Tese (Doutorado) - Instituto de Pesquisas Energéticas e Nucleares - Universidade de São Paulo, São Paulo.

PNAS. Proceedings of the National Academy of Sciences of the United States of America. Vibrio fischeri. Disponível em: http://www.pnas.org/content/102/8/2673/F2.expansion.html >. Acesso em: 07/09/2013.

PRADO, J.N.; PISSATO, S.; MORAIS, E.C.; FOPPA, T.; MURAKAMI, F.S.; SILVA, M.A.S. Validação de metodologia analítica por cromatografia líquida de alta eficiência para doseamento de cápsulas de fluoxetina. Acta Farmaceutica Bonaerense, v.25, n.3, p.436-440, 2006.

RAGGI, M.A.;BUGAMELLI, F.; CASAMENTI, G.; MANDRIOLI, R.; RONCHI, D.; VOLTERRA V. Analytical methods for the quality control of Prozac ${ }^{\circledR}$ capsules. Journal of Pharmaceutical and Biomedical Analysis, v.18, p.699-706, 1998.

RAIMUNDO, C.C.M. Ocorrência de interferentes endócrinos e produtos farmacêuticos nas águas superficiais da bacia do rio Atibaia. 2007. Dissertação (Mestrado). Universidade Estadual de Campinas, Campinas.

RAND, G. M. Fundamental of Aquatic Toxicology: Effects, Environmental Fate and Risk Assessment. 2a Ed. Taylor \& Francis, 1995.

REDSHAW, C.H.; COOKE, M.P.; TALBOT, H.M.; MCGRATH S. \& ROWLAND, S.J. Low biodegradability of fluoxetine $\mathrm{HCl}$, diazepam and their human metabolites in sewage sludge-amended soil. Journal of Soils and Sediments, v.8, p.217-230, 2008.

REIS FILHO, R.W.; LUVIZOTTO-SANTOS, R.;VIEIRA, E.M. Poluentes Emergentes como desreguladores endócrinos. Journal of the Brazilian Society of Ecotoxicology, v.2, n.3, p.283-288, 2007. 
RIBANI, M.; BOTTOLI, C.B.G.; COLLINS, C.H.; JARDIM, I.C.S.F.; MELO, L.F.C. Validação em métodos cromatográficos e eletroforéticos. Química Nova, v.27, n.5, p.771-780, 2004.

RICACHENEVSKY, C.; LACERDA, F. V.; OLIVEIRA, L. C.; OLIVEIRA, H. P. M.; MAGINI, M.R.R. Dosagem experimental de cloridrato de fluoxetina utilizando espectroscopia de fluorescência. XI Encontro Latino Americano de Iniciação Científica e VII Encontro Latino Americano de Pós - Graduação - Universidade do Vale do Paraíba, 2007.

RIZZO, L. Bioassays as a tool for evaluating advanced oxidation processes in water and wastewater treatment. Water Research, v.45, p.4311-4340, 2011.

ROCHA, R.S.; BEATI, A.A.G.F; OLIVEIRA, J.G.; LANZA, M.R.V. Avaliação da degradação do diclofenaco sódico utilizando $\mathrm{H}_{2} \mathrm{O}_{2}$ / Fenton em reator eletroquímico. Química Nova, 32(2):354-358, 2009.

RODRIGUES, C.R.B. Aspectos legais e ambientais do descarte de resíduos de fármacos. 2009. Dissertação (Mestrado) - Universidade Tecnológica Federal do Paraná, Ponta Grossa.

ROMANELLI, M.F. Avaliação da toxicidade aguda e crônica dos surfactantes DSS e LAS submetidos à irradiação com feixes de elétrons. 2004. Dissertação (Mestrado) Instituto de Pesquisas Energéticas e Nucleares, Universidade de São Paulo, São Paulo.

ROMANELLI, M.F.; MORAES, M.C.F.; VILLAVICENCIO, A.L.C.H.; BORRELY, S.I. Evaluation of toxicity reduction of sodium dodecyl sulfate submitted to electron beam radiation, Radiation Physics and Chemistry, v.71, p.409-411, 2004.

ROMANELLI, M.F.; SILVA,G.P.; BORRELY,S.I. Redução da toxicidade do surfactante LAS tratado com o feixe de elétrons. Journal of the Brazilian Society of Ecotoxicology, v.1, p.103-107, 2006.

SANTOKE, H.; SONG, W.; COOPER, W.J.; PEAKE, B.M. Advanced oxidation treatment and photochemical fate of selected antidepressant pharmaceuticals in solutions of Suwannee River humic acid. Journal of Hazardous Materials, v.217-218, p.382-390, 2012.

SANTOS, D.R.A. Avaliação ecotoxicológica do fármaco cloridrato de fluoxetina e do surfactante dodecil sulfato de sódio quando submetidos a tratamento por radiação ionizante. 2012. Dissertação (Mestrado) - Instituto de Pesquisas Energéticas e Nucleares - Universidade de São Paulo, São Paulo.

SANTOS, L.H.M.L.M.; ARAÚJO, A.N.; FACHINI, A.; PENA, A.; DELERUE-MATOS, C. e MONTENEGRO, M.C.B.S.M., Ecotoxicological aspects related to the presence of pharmaceuticals in the aquatic environment. Journal of Hazardous Materials, v.175, p.45-95, 2010.

SCAPIN, M.A. Estudos de remoção de elementos inorgânicos e degradação de compostos orgânicos por radiação gama em óleos lubrificantes usados. 2008. Tese 
(Doutorado). Instituto de Pesquisas Energéticas e Nucleares - Universidade de São Paulo, São Paulo.

SHIMADZU, Cromatógrafo Líquido Ultra Rápido. Disponível em: < http://www.shimadzu.com.br/analitica/produtos/hplc/uflc01.shtml >. Acesso em: 05/12/2013.

SILVA, C.G.A. \& COLLINS, C.H. Aplicações de cromatografia líquida de alta eficiência para o estudo de poluentes orgânicos emergentes. Química Nova, v.34, n.4, p.665676, 2011.

SNYDER, L.R.; KIRKLAND, J.J.; DOLAN, J.W. Introduction to Modern Liquid Chromatography, Third Edition A John Wiley \& Sons Inc., chapter 4, pp. 147-197, 2010.

SOARES, P.J. R. Fluoxetina. Psychiatry on line Brasil, v.10, n.12, 2005. Disponível em: < http://www.polbr.med.br/ano05/artigo1205b.php>. Acesso em: 27/02/2013.

SOARES, W.Â.A. Estudo da distribuição de metais em água, sedimento e organismos aquáticos de rios e reservatórios pertencentes à rede de monitoramento da qualidade dos sedimentos do Estado de São Paulo, Brasil. 2012. Dissertação (Mestrado) Instituto de Pesquisas Energéticas e Nucleares, Universidade de São Paulo, São Paulo.

SODRÉ, F.F.; LOCATELLI, M.A.F.; JARDIM, W.F. Occurrence of emerging contaminants in Brazilian drinking waters: a sewage-to-tap issue. Water Air Soil Pollution, 206, pp. 57-67, 2010.

SOUZA, J.P. Toxicidade aguda e risco ambiental do diflubenzuron para Daphnia magna, Poecilia reticulata e Lemna minor na ausência e presença de sedimento. 2008. Dissertação (Mestrado) - Programa de Pós- graduação em Aquicultura, da Universidade Estadual Paulista "Júlio de Mesquita Filho", Jaboticabal.

SUCHARA, E.A. Desenvolvimento de metodologias analíticas para determinação de fármacos em fluidos biológicos e amostras ambientais por cromatografia líquida $e$ gasosa. 2007. Tese (Doutorado) - Universidade Federal de Santa Catarina, Florianópolis.

TAMBOSI, J. L. Remoção de fármacos e avaliação de seus produtos de degradação através de tecnologias avançadas de tratamento. 2008. Tese (Doutorado) - Pósgraduação em Engenharia Química do Centro Tecnológico da Universidade Federal de Santa Catarina, Santa Catarina.

TERNES, T.A.; STUMPF, M.; MUELLER, J.; HABERER, K.; WILKEN, R.D.; SERVOS, M. Behavior and occurrence of estrogens in municipal sewage treatment plants - I. Investigations in Germany, Canada and Brazil. Science of the Total Environment, v.225, n.1-2, p.81-90, 1999.

TERNES, T. A.; STÜBER, J.; HERRMANN, N.; McDOWELL, D.; RIED, A.; KAMPMANN, M.; TEISER, B. Ozonation: a tool for removal of pharmaceuticals, contrast media and musk fragrances from wasterwater?, Water Research, v.37, p.1976-1982, 2003. 
TRUHAUT, R. Ecotoxicology: objectives, principles and perspectives. Ecotoxicology and Environmental Safety, v.1, p.151-173, 1977.

UFPR, Universidade Federal do Paraná (Departamento de Estatística). Estatística II. 2009. Disponível em: < http://www.est.ufpr.br/ce003/material/apostilace003.pdf >. Acesso em: $10 / 02 / 2014$.

USEPA. Taxonomy of Ceriodaphnia (Crustacea: Cladocera) in U.S. Environmental Protection Agency cultures. D.B. Berner. U. S. Environmental Protection Agency, Environmental Monitoring and Support Laboratory, Cincinnati, OH. EPA/600/486/032, 1986.

UW EYE RESEARCH INSTITUTE. Vibrio fischeri. Disponível em: < http://labs.medmicro.wisc.edu/mcfall-ngai/media/news_fall09.html >. Acesso em: 09/09/2013.

WEINBERGER II, J.; KLAPER, R. Environmental concentrations of the selective serotonin reuptake inhibitor fluoxetine impact specific behaviors involved in reproduction, feeding and predator avoidance in the fish Pimephales promelas (fathead minnow). Aquatic Toxicology, Article in Press.

ZAGATtO, P. A. \& BERTOLETTI, E. (org.). Ecotoxicologia Aquática: Princípios e Aplicações. Ed. Rima: São Carlos, 2006.

ZHAO, Y.H.; JI, G.D.; CRONIN, M.T.D.; DEARDEN, J.C. QSAR study of the toxicity of benzoic acids to Vibrio fischeri, Daphnia magna and carp. The Science of the Total Environment, v.216, p.205-215, 1998. 